\title{
TREATMENT TANK CORROSION STUDIES FOR THE ENHANCED CHEMICAL CLEANING PROCESS
}

\author{
B. J. Wiersma
}

\author{
Savannah River National Laboratory \\ Materials Science and Technology Directorate
}

August 2011

Savannah River National Laboratory

Savannah River Nuclear Solutions

Aiken, SC 29808

Prepared for the U.S. Department of Energy Under

Contract Number DE-AC09-08SR22470

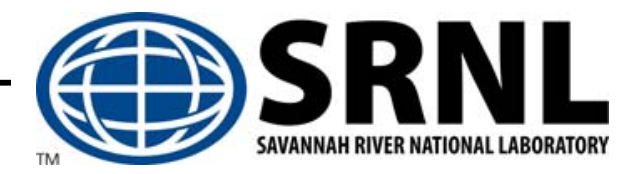




\section{DISCLAIMER}

This work was prepared under an agreement with and funded by the U.S. Government. Neither the U. S. Government or its employees, nor any of its contractors, subcontractors or their employees, makes any express or implied:

1. warranty or assumes any legal liability for the accuracy, completeness, or for the use or results of such use of any information, product, or process disclosed; or

2. representation that such use or results of such use would not infringe privately owned rights; or

3. endorsement or recommendation of any specifically identified commercial product, process, or service.

Any views and opinions of authors expressed in this work do not necessarily state or reflect those of the United States Government, or its contractors, or subcontractors.

Printed in the United States of America

Prepared for

U.S. Department of Energy 
Revision 1

DOCUMENT: $\quad$ SRNL-STI-2010-00535, Rev. 1

TITLE: TREATMENT TANK CORROSION STUDIES FOR THE ENHANCED CHEMICAL CLEANING PROCESS

\section{APPROVALS:}

Date:

B. J. Wiersma, Author

Materials Performance and Corrosion Technology, Materials Science and Technology

Date:

B. L. Garcia-Diaz, Technical Reviewer

Materials Performance and Corrosion Technology, Materials Science and Technology

Date:

K. E. Zeigler, Manager

Materials Performance and Corrosion Technology, Materials Science and Technology

Date:

F. M. Pennebaker

E\&CPT Research Programs

Date:

C. J. Martino

E\&CPT Research Programs

Date:

E. T. Ketusky, Technical Reviewer

Closure Project Engineering, Savannah River Remediation

Date:

P. E. Carroll

Chemical Cleaning Engineering, Savannah River Remediation

Date:

R. H. Spires

Waste Removal and Tank Closure, Savannah River Remediation 


\section{Table of Contents}

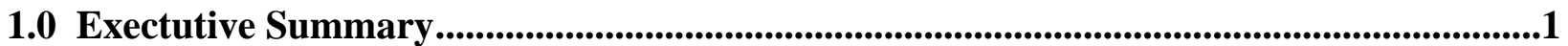

2.0 Background

2.1 Corrosion Testing for the Enhanced Chemical Cleaning Treatment Tank

2.2 Review of Corrosion Mechanisms of Carbon Steel in Chemical Cleaning Environments

3.0 Experimental

3.1 Materials

3.2 Solutions

3.3 Test Activites and Procedures.

3.3.1 Electrochemical Tests .

3.3.2 Coupon Tests.

4.0 Results and Discussion

4.1 Electrochemical Tests

4.1.1 Open Circuit Potential

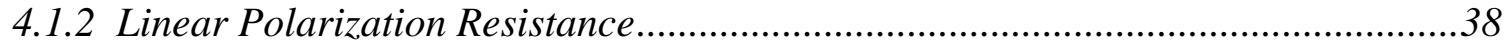

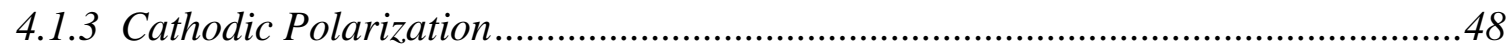

4.1.4 Anodic and Cyclic Potentiodynamic Polarization.................................................53

4.2 Coupon Tests

4.2.1 Solution Analyses

4.2.2 Surface Analyses....

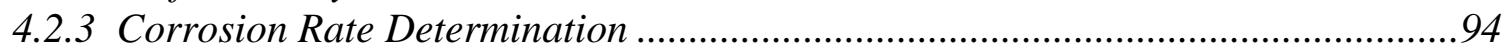

5.0 Summary and Conclusions ........................................................................................107

6.0 Records and Quality Assurance 


\section{LIST OF FIGURES}

Figure 1. Pourbaix diagram for water 4

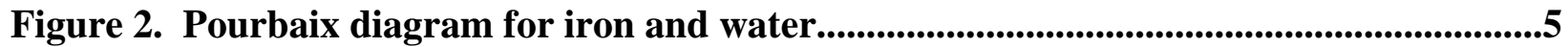

Figure 3. Iron-Oxalic Acid-Water Pourbaix Diagram..............................................................6

Figure 4. Distribution of oxalic acid species.............................................6

Figure 5. Coupon test in 1 wt. $\%$ oxalic acid with no agitation at (a) $45^{\circ} \mathrm{C}$ and (b) $75^{\circ} \mathrm{C} \ldots . .8$

Figure 6. PAR cell utilized for electrochemical tests.....................................13

Figure 7. Pourbaix Diagram for water................................................15

Figure 8. Example of Linear Polarization Resistance curve measured during tests........17

Figure 9. Examples of Cathodic Polarization curve measured during tests.................18

Figure 10. Plot of schematic CPP data showing characteristic potentials and currents....20

Figure 11. Vessel for Coupon Tests.......................................................22

Figure 12. Effect of test simulant on the OCP for agitated solutions that contain 1 wt.\%

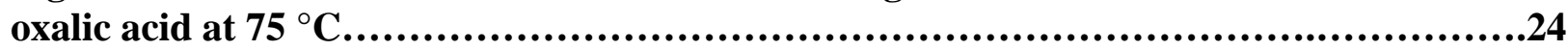

Figure 13. Effect of test simulant on the OCP for agitated solutions that contain 2.5 wt. $\%$

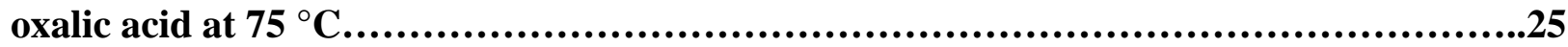

Figure 14. Effect of test simulant on the OCP for agitated solutions that contain 1 wt.\%

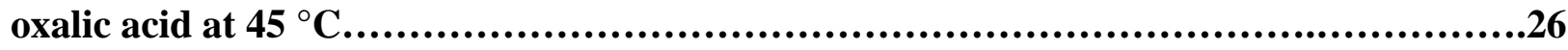

Figure 15. Effect of test simulant on the OCP for agitated solutions that contain 2.5 wt. $\%$

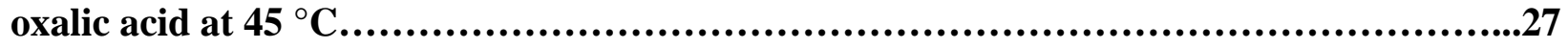

Figure 16. OCP transients for 1 wt. \% oxalic acid in an agitated solution at 45 and $75{ }^{\circ} \mathrm{C} . .28$ Figure 17. OCP transients for 1 wt.\% oxalic acid in a non-agitated solution at 45 and $75{ }^{\circ} \mathrm{C}$

Figure 18. OCP transients for 2.5 wt. $\%$ oxalic acid in an agitated and non-agitated solutions

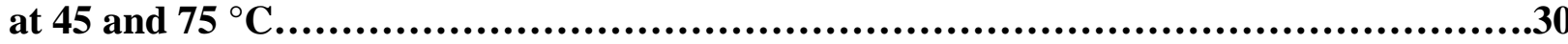

Figure 19. OCP transients for HM sludge simulant/1 wt. \% oxalic acid mixtures............31 Figure 20. OCP transients for HM sludge simulant/2.5 wt.\% oxalic acid mixtures.........32 Figure 21. OCP transients for PUREX sludge simulant/1 wt.\% oxalic acid mixtures.......33 Figure 22. OCP transients for PUREX sludge simulant/ 2.5 wt. \% oxalic acid mixtures....34 Figure 23. OCP transients for HM-PUREX sludge simulant/1 wt. \% oxalic acid mixtures................................................................................36 Figure 24. OCP transients for HM sludge simulant/1 wt. \% oxalic acid mixtures in aerated and de-aerated conditions.

Figure 25. OCP transients for PUREX sludge simulant/1 wt. \% oxalic acid mixtures in aerated and de-aerated conditions...................................................37 Figure 26. OCP transients for HM-PUREX sludge simulant/1 wt.\% oxalic acid mixtures in aerated and de-aerated conditions.....................................................38 Figure 27. LPR scan for $\mathrm{HM} / 2.5$ wt. \% oxalic acid at $50^{\circ} \mathrm{C}$ with the $\mathrm{OCP}$ at $-0.405 \mathrm{~V}$ vs. Ag/AgCl.................................................................................39

Figure 28. LPR scan for HM/2.5 wt.\% OA with OCP at -0.085 V vs. Ag/AgCl ..............39 Figure 29. Corrosion rates in simulant/ 1 wt. \% oxalic acid mixtures measured by the LPR technique...............................................................................40 Figure 30. Corrosion rates in simulant/ 2.5 wt. \% oxalic acid mixtures measured by the LPR technique. 


\section{List of Figures (continued)}

Figure 31. Corrosion rates in simulant/oxalic acid mixtures compared with pure oxalic acid in agitated solutions measured by the LPR technique.

Figure 32. Corrosion rates in simulant/oxalic acid mixtures compared to pure oxalic acid in non-agitated solutions.

Figure 33. Corrosion rates in HM and PUREX sludge simulant/oxalic acid (1 wt.\% and 2.5 wt.\%) mixtures compared with Tank 5F sludge simulant in 8 wt.\% oxalic acid............ 44 Figure 34. Corrosion rates in simulant/ oxalic acid mixtures as a function of agitation at 45 ${ }^{\circ} \mathrm{C}$ or $50{ }^{\circ} \mathrm{C}$

Figure 35. Corrosion rates in simulant/oxalic acid mixtures as a function of agitation at 75

${ }^{\circ}$ C.............................................................................................45

Figure 36. Corrosion rates in agitated simulant/ 1 wt.\% oxalic acid mixtures as a function of temperature. .46

Figure 37. Corrosion rates in agitated simulant/oxalic acid mixtures as a function of temperature.

Figure 38. Corrosion rates in agitated simulant/ 1 wt. \% oxalic acid mixtures aerated and de-

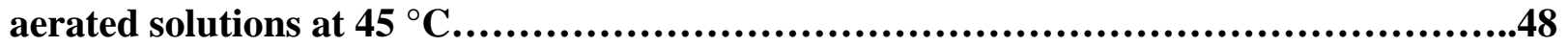
Figure 39. Cathodic polarization curves for the simulants with 1 wt. $\%$ oxalic acid at $75{ }^{\circ} \mathrm{C}$ with agitation............................................................................51 Figure 40. Cathodic polarization curves for the simulants with $2.5 \mathrm{wt} \% \%$ oxalic acid at $75^{\circ} \mathrm{C}$ with agitation..................................................................................51 Figure 41. Cathodic polarization curves for $\mathrm{HM} / 2.5$ wt. \% oxalic acid at $50{ }^{\circ} \mathrm{C}$ with and without agitation. .52 Figure 42. Cathodic polarization curves for $\mathrm{HM} / 2.5$ wt. $\%$ oxalic acid at $50{ }^{\circ} \mathrm{C}$ and $75{ }^{\circ} \mathrm{C}$ without agitation.....................................................................53 Figure 43. CPP scan in agitated, 1 wt. $\%$ oxalic acid at $75^{\circ} \mathrm{C} \ldots \ldots \ldots \ldots \ldots \ldots . . \ldots \ldots . . . . . . . . .54$ Figure 44. CPP scan in agitated, 2.5 wt.\% oxalic acid at $75{ }^{\circ} \mathrm{C} \ldots \ldots \ldots \ldots \ldots \ldots \ldots \ldots \ldots \ldots . . . . . .54$ Figure 45. CPP scan in agitated, PUREX/1 wt. \% oxalic acid mixture at $75{ }^{\circ} \mathrm{C} . . . . . . . . . .55$ Figure 46. CPP scan in agitated, PUREX/2.5 wt.\% oxalic acid mixture at $75{ }^{\circ} \mathrm{C} . . . . . . . .56$ Figure 47. CPP scan in agitated, PUREX/2.5 wt. \% oxalic acid mixture at $50{ }^{\circ} \mathrm{C} . . . . . . . .56$ Figure 48. CPP scan in agitated, HM/1 wt. \% oxalic acid mixture at $75^{\circ} \mathrm{C} \ldots \ldots . . . . . . . . .57$ Figure 49. CPP scan in agitated, HM/2.5 wt.\% oxalic acid mixture at $75^{\circ} \mathrm{C} \ldots . . . . . . . . . .58$ Figure 50. CPP scan in HM/2.5 wt. \% oxalic acid mixture at $75{ }^{\circ} \mathrm{C} . \ldots \ldots \ldots \ldots \ldots . . . \ldots . . . . .58$ Figure 51. Photograph of electrochemical samples after testing in agitated, HM/1 wt. \%

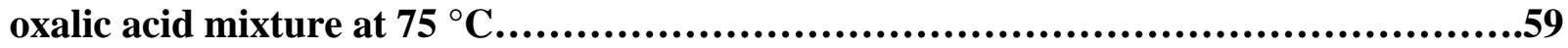
Figure 52. CPP scan in agitated, HM-PUREX/1 wt. \% oxalic acid mixture at $75{ }^{\circ} \mathrm{C} . . . . .60$ Figure 53. Anodic polarization scans for the different simulants with 1 wt.\% oxalic acid at $75^{\circ} \mathrm{C}$ with agitation.

Figure 54. Anodic polarization scans for the different simulants with 2.5 wt. $\%$ oxalic acid at $75{ }^{\circ} \mathrm{C}$ with agitation..................................................................62

Figure 55. Anodic polarization scans for the PUREX/1wt. \% oxalic acid mixture.........63 Figure 56. XRD results for electrochemical sample exposed to the PUREX/1 wt.\% oxalic acid mixture........................................................................64

Figure 57. Anodic polarization scans for the PUREX/2.5 wt.\% oxalic acid mixture......65 Figure 58. Anodic polarization scans for the HM/1wt.\% oxalic acid mixture.............66 


\section{List of Figures (continued)}

Figure 59. Anodic polarization scans for the HM/2.5wt. \% oxalic acid mixture.

Figure 60. Anodic polarization scans for the HM-PUREX/1wt.\% oxalic

acid mixture..... . .68

Figure 61. Anodic polarization scans for the PUREX/1wt.\% oxalic acid mixture under aerated and de-aerated conditions.

Figure 62. Solution Color for (a) PUREX/1 wt.\% oxalic acid at $45^{\circ} \mathrm{C}$ and (b) PUREX/2.5 wt. \% oxalic acid at $50{ }^{\circ} \mathrm{C}$

Figure 63. pH transient during Coupon Tests in the PUREX/1 wt.\% oxalic acid mixture at

$75^{\circ} \mathrm{C}$.

Figure 64. pH transient during Coupon Tests in the PUREX/1 wt.\% oxalic acid mixture at

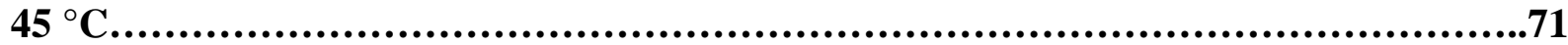

Figure 65. pH transient during Coupon Tests in the HM/1 wt.\% oxalic acid mixture at 75 ${ }^{\circ} \mathrm{C}$.

Figure 66. pH transient during Coupon Tests in the HM/1 wt.\% oxalic acid mixture at $45^{\circ} \mathrm{C}$ .72

Figure 67. pH transient during Coupon Tests in the HM-PUREX/1 wt. \% oxalic acid mixture at $75^{\circ} \mathrm{C}$ .73

Figure 68. pH transient during Coupon Tests in the HM-PUREX/1 wt. \% oxalic acid mixture at $45^{\circ} \mathrm{C}$ .73

Figure 69. Volume of acid added during coupon tests in the PUREX/1 wt.\% oxalic acid mixture. 74

Figure 70. Volume of acid added during coupon tests in the HM/1 wt.\% oxalic acid mixture. . .75

Figure 71. Volume of acid added during coupon tests in the HM-PUREX/1 wt.\% oxalic acid mixture.................................................................................75 Figure 72. Photographs from coupons tested in a) PUREX/1 wt. \% oxalic acid, b) HM/1 wt .\% oxalic acid, c) HM-PUREX/1 wt. \% oxalic acid, and d) 1 wt. \% oxalic acid at 75 ${ }^{\circ} \mathrm{C}$.

Figure 73. Photographs from coupons tested in a) PUREX/2.5 wt. \% oxalic acid, b) HM/2.5

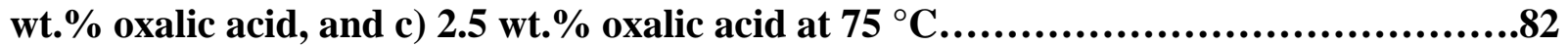
Figure 74. Photographs from coupons tested in a) PUREX/1 wt.\% oxalic acid, b) HM/1 wt.\% oxalic acid, c) HM-PUREX/1 wt. \% oxalic acid, and d) 1 wt. $\%$ oxalic acid at $45{ }^{\circ} \mathrm{C} . . . . . .83$ Figure 75. Photographs from coupons tested in a) PUREX/2.5 wt. \% oxalic acid, b) HM/2.5

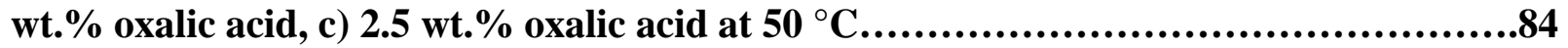
Figure 76. XRD analysis of coupon exposed to 1 wt. $\%$ oxalic acid at $75{ }^{\circ} \mathrm{C}$ under stagnant conditions.

Figure 77. XRD analysis of coupon exposed to $2.5 \mathrm{wt} \% \%$ oxalic acid at $75{ }^{\circ} \mathrm{C}$ under stagnant conditions...................................................................................85

Figure 78. XRD analysis of coupon exposed to the $\mathrm{HM} / 1$ wt. $\%$ oxalic acid mixture at $75^{\circ}$ under agitated conditions. .86 Figure 79. XRD analysis of coupon exposed to the HM/2.5 wt.\% oxalic acid mixture at $75^{\circ}$ under agitated conditions.

Figure 80. XRD analysis of coupon exposed to the HM/2.5 wt. \% oxalic acid mixture at $75^{\circ}$ under stagnant conditions. 


\section{List of Figures (continued)}

Figure 81. XRD analysis of coupon exposed to the HM-PUREX/1 wt.\% oxalic acid mixture at $75{ }^{\circ} \mathrm{C}$ under agitated conditions.

Figure 82. XRD analysis of coupon exposed to the PUREX/1 wt. \% oxalic acid mixture at 75

${ }^{\circ} \mathrm{C}$ under agitated conditions.

Figure 83. XRD analysis of coupon exposed to the PUREX/2.5 wt.\% oxalic acid mixture at $75^{\circ} \mathrm{C}$ under agitated conditions.

Figure 84. Cleaned Coupon showing general corrosion (a) oxalic acid, (b) HMPUREX.

Figure 85. Cleaned Coupon showing pitting corrosion in (a) HM/2.5 wt.\% \%xalic acid at 75

${ }^{\circ} \mathrm{C}$ with no agitation, (b) HM-PUREX/2.5 wt. $\%$ oxalic acid at $75{ }^{\circ} \mathrm{C}$ with agitation.........90

Figure 86. SEM micrograph showing the hemi-spherical and oblong shaped pits. This coupon was tested in $\mathrm{HM} / 2.5$ wt. \% oxalic acid at $75^{\circ} \mathrm{C}$ with no agitation.

Figure 87. SEM micrograph showing the mercury particles dispersed with in the corrosion product in side a pit. This coupon was tested in $\mathrm{HM} / 2.5 \mathrm{wt} \%$ oxalic acid at $75{ }^{\circ} \mathrm{C}$ with no agitation.......................................................................................92

Figure 88. SEM micrograph showing "striped” pattern on the surface. This coupon was tested in $\mathrm{HM} / 2.5 \mathrm{wt}$. \% oxalic acid at $75{ }^{\circ} \mathrm{C}$ with agitation. .93

Figure 89. SEM micrograph showing mercury (Spot 10) and silver (Spot 11) particles dispersed within the dark striped areas. This coupon was tested in HM/2.5 wt.\% oxalic acid at $75{ }^{\circ} \mathrm{C}$ with agitation. .93

Figure 90. Corrosion rates determined from coupon tests in the sludge simulants with 1 wt. \% oxalic acid. .95

Figure 91. Comparison between LPR and coupon test corrosion rate estimates for the sludge simulants in 1 wt.\% oxalic acid. .96

Figure 92. Corrosion rates determined from coupon tests in the sludge simulants with 2.5 wt. \% oxalic acid

Figure 93. Comparison between LPR and coupon test corrosion rate estimates for the sludge simulants in 2.5 wt. $\%$ oxalic acid.

Figure 94. Corrosion rate in sludge simulants compared with 1 wt. \% oxalic acid...........98 Figure 95. Corrosion rates in sludge simulants compared with 2.5 wt.\% oxalic acid in nonagitated solutions. . .99

Figure 96. Corrosion rates in sludge simulants compared with 2.5 wt. \% oxalic acid in agitated solutions. 100

Figure 97. Corrosion rates in sludge simulants compared with 8 wt. \% OA with sludge simulant at $50{ }^{\circ} \mathrm{C}$ (Note recent tests in $1 \mathrm{wt} . \%$ oxalic acid were at $45{ }^{\circ} \mathrm{C}$ ). The solutions were non-agitated.

Figure 98. The effect of agitation on the corrosion rates in the sludge simulants with 1 wt. $\%$ oxalic acid at $45^{\circ} \mathrm{C}$.

Figure 99. The effect of agitation on the corrosion rates in the sludge simulants with 1 wt. $\%$ oxalic acid at $75{ }^{\circ} \mathrm{C}$ .102

Figure 100. The effect of agitation on the corrosion rates in the sludge simulants with 2.5 wt. \% oxalic acid at $50{ }^{\circ} \mathrm{C}$.

Figure 101. The effect of agitation on the corrosion rates in the sludge simulants with 2.5 wt. \% oxalic acid at $75{ }^{\circ} \mathrm{C}$ 


\section{List of Figures (continued)}

Figure 102. The effect of temperature on the corrosion rates in the sludge simulants with 1 wt. \% oxalic acid with agitation.

Figure 103. The effect of temperature on the corrosion rates in the sludge simulant with 1 wt. $\%$ oxalic acid with no agitation.

Figure 104. The effect of temperature on the corrosion rates in the sludge simulants with 2.5 wt. $\%$ oxalic acid with agitation..........................................................106 Figure 105. The effect of temperature on the corrosion rates in the sludge simulant with 2.5 wt. \% oxalic acid with no agitation.

\section{LIST OF TABLES}

Table 1. Chemical Composition (Wt \%) of A285 Grade C, Carbon Steel.................11

Table 2. Mechanical Properties of A285 Grade C, Carbon Steel...........................11

Table 3. Matrix for Electrochemical Testing for 1 wt.\% Oxalic Acid......................14

Table 4. Matrix for Electrochemical Testing for 2.5 wt.\% Oxalic Acid....................14

Table 5. Calculated hydrogen evolution potential $\left(E_{H_{2}}\right)$ values for the sludge dissolution tests.......................................................................................16

Table 6. Matrix for Immersion Testing for 1 wt.\% Oxalic Acid...............................21

Table 7. Matrix for Immersion Testing for 2.5 wt. \% Oxalic Acid.........................22

Table 8. Kinetic data obtained from cathodic polarization tests........................49

Table 9. Final solution analyses for the coupon tests in the PUREX/1 wt.\% oxalic acid mixture..................................................................................77

Table 10. Final solution analyses for the coupon tests in the PUREX/2.5 wt.\% oxalic acid mixture....................................................................................77

Table 11. Final solution analyses for the coupon tests in the HM/1 wt.\% oxalic acid mixture...................................................................................77

Table 12. Final solution analyses for the coupon tests in the HM/2.5 wt.\% oxalic acid mixture....................................................................................78

Table 13. Final solution analyses for the coupon tests in the 2.5 wt. \% oxalic acid.........78 


\section{Acronyms}

AOP - Advanced Oxidation Process

ASTM - American Society for Testing and Materials

CPP - Cyclic Potentiodynamic Polarization

ECC - Enhanced Chemical Cleaning

EDS - Energy Dispersive Spectroscopy

HLW - High Level Waste

HM - Modified PUREX process

LPR - Linear Polarization Resistance

OCP - Open Circuit Potential

PAR - Princeton Applied Research

SEM - Scanning Electron Microscope

SRNL - Savannah River National Laboratory

SRR - Savannah River Remediation

SRS - Savannah River Site

UNS - Unified Numbering System

XRD - X-ray Diffraction 


\section{TREATMENT TANK CORROSION STUDIES FOR THE ENHANCED CHEMICAL CLEANING PROCESS}

\subsection{Executive Summary}

Radioactive waste is stored in high level waste tanks on the Savannah River Site (SRS). Savannah River Remediation (SRR) is aggressively seeking to close the non-compliant Type I and II waste tanks. The removal of sludge (i.e., metal oxide) heels from the tank is the final stage in the waste removal process. The Enhanced Chemical Cleaning (ECC) process is being developed and investigated by SRR to aid in Savannah River Site (SRS) High-Level Waste (HLW) as an option for sludge heel removal.

Corrosion rate data for carbon steel exposed to the ECC treatment tank environment was obtained to evaluate the degree of corrosion that occurs. These tests were also designed to determine the effect of various environmental variables such as temperature, agitation and sludge slurry type on the corrosion behavior of carbon steel. Coupon tests were performed to estimate the corrosion rate during the ECC process, as well as determine any susceptibility to localized corrosion. Electrochemical studies were performed to develop a better understanding of the corrosion mechanism. The tests were performed in 1 wt.\% and 2.5 wt. \% oxalic acid with HM and PUREX sludge simulants.

The following results and conclusions were made based on this testing:

1. In 1 wt.\% oxalic acid with a sludge simulant, carbon steel corroded at a rate of less than 25 mpy within the temperature and agitation levels of the test. No susceptibility to localized corrosion was observed.

2. In 2.5 wt. $\%$ oxalic acid with a sludge simulant, the carbon steel corrosion rates ranged between 15 and $88 \mathrm{mpy}$. The most severe corrosion was observed at 75 ${ }^{\circ} \mathrm{C}$ in the $\mathrm{HM} / 2.5$ wt.\% oxalic acid simulant. Pitting and general corrosion increased with the agitation level at this condition. No pitting and lower general corrosion rates were observed with the PUREX/2.5 wt.\% oxalic acid simulant. The electrochemical and coupon tests both indicated that carbon steel is more susceptible to localized corrosion in the HM/oxalic acid environment than in the PUREX/oxalic acid environment.

3. The corrosion rates for PUREX/8 wt.\% oxalic acid were greater than or equal to those observed for the PUREX/2.5 wt.\% oxalic acid. No localized corrosion was observed in the tests with the $8 \mathrm{wt} . \%$ oxalic acid. Testing with HM/8 wt.\% oxalic acid simulant was not performed. Thus, a comparison with the results with 2.5 wt.\% oxalic acid, where the corrosion rate was 88 mpy and localized corrosion was observed at $75^{\circ} \mathrm{C}$, cannot be made.

4. The corrosion rates in 1 and $2.5 \mathrm{wt} . \%$ oxalic acid solutions were temperature dependent:

a. At $50^{\circ} \mathrm{C}$, the corrosion rates ranged between 90 to 140 mpy over the 30 day test period. The corrosion rates were higher under stagnant conditions. 
b. At $75^{\circ} \mathrm{C}$, the initial corrosion rates were as high as $300 \mathrm{mpy}$ during the first day of exposure. The corrosion rates increased with agitation. However, once the passive ferrous oxalate film formed, the corrosion rate decreased dramatically to less than 20 mpy over the 30 day test period. This rate was independent of agitation.

5. Electrochemical testing indicated that for oxalic acid/sludge simulant mixtures the cathodic reaction has transport controlled reaction kinetics. The literature suggests that the dissolution of the sludge produces a di-oxalatoferrate ion that is reduced at the cathodic sites. The cathodic reaction does not appear to involve hydrogen evolution. On the other hand, electrochemical tests demonstrated that the cathodic reaction for corrosion of carbon steel in pure oxalic acid involves hydrogen evolution.

6. Agitation of the oxalic acid/sludge simulant mixtures typically resulted in a higher corrosion rates for both acid concentrations. The transport of the ferrous ion away from the metal surface results in a less protective ferrous oxalate film.

7. A mercury containing species along with aluminum, silicon and iron oxides was observed on the interior of the pits formed in the HM/2.5 wt.\% oxalic acid simulant at $75{ }^{\circ} \mathrm{C}$. The pitting rates in the agitated and non-agitated solution were $2 \mathrm{mils} /$ day and $1 \mathrm{mil} /$ day, respectively. A mechanism by which the mercury interacts with the aluminum and silicon oxides in this simulant to accelerate corrosion was proposed.

\subsection{Background}

\subsection{Corrosion Testing for the Enhanced Chemical Cleaning Treatment Tank}

The Enhanced Chemical Cleaning (ECC) process is being developed and investigated by Savannah River Remediation (SRR) to aid in Savannah River Site (SRS) High-Level Waste (HLW) tank closure. After bulk waste removal, the ECC process can be used to dissolve and remove much of the remaining sludge heel from Type I and II HLW tanks. The ECC process is similar to the previous chemical cleaning technology [1] in that oxalic acid is used for both, but the ECC process differs from the previous technology in the following ways: 1) The sludge heel will be washed with water rather than supernate; 2) dilute oxalic acid (i.e., 1 or $2 \mathrm{wt} \%$ ) is used in place of concentrated oxalic acid ( 8 wt $\%$ ); and 3) most of the resultant oxalate is decomposed by an Advanced Oxidation Process (AOP). Reducing the amount of oxalic acid used for dissolution of sludge and the subsequent oxidative destruction of oxalic acid will lead to a reduction of downstream impacts.

Technology gaps to implement the ECC process in the field have been identified. One such gap is the corrosion of the treatment tank (i.e., using an approximately 1 or $2 \mathrm{wt} \%$ oxalic acid solution to maintain a $\mathrm{pH}$ of less than 2.0). Corrosion rate data for carbon steel exposed to the chemical cleaning environment were needed to evaluate the degree of degradation that could occur in the treatment tank during this process. To date, most of the corrosion testing has been conducted using $4 \mathrm{wt} \%$ and $8 \mathrm{wt} \%$ oxalic acid [2]. Since the level of corrosion is expected to be a function of the oxalic acid concentration, 
the treatment tank corrosion rate for 1 and $2 \mathrm{wt} . \%$ oxalic acid need to be determined [3]. An upper limit of $2.5 \mathrm{wt} . \%$ oxalic acid was selected for the $2 \mathrm{wt} . \%$ tests.

The corrosion data included a combination of electrochemical and coupon immersion testing to determine the general corrosion rate, as well as susceptibility to localized corrosion. The electrochemical studies were typically performed to gain a better understanding of the corrosion mechanism.

The coupon immersion tests were performed under environmental conditions that were as representative of the actual process as possible. This includes the critical variable of time, which is not considered in the electrochemical tests. The coupons were examined for weight loss and any evidence of localized corrosion. The corrosion rates obtained from these tests will be utilized for estimates for the actual process.

\subsection{Review of Corrosion Mechanisms of Carbon Steel in Chemical Cleaning Environments}

The objective of the chemical cleaning process is to dissolve the metal oxides present in the sludge, while at the same time minimizing the corrosion of the tank wall. Given that the iron oxides present initially on the steel surface can mitigate corrosion, these goals would appear to be contradictory. That is, the oxalic acid could dissolve the protective oxide film on the steel surface as well as the iron oxides in the sludge, which would leave it vulnerable to more aggressive attack. Thus a review of the corrosion mechanism of carbon steel in oxalic acid was performed. Similar reviews of the dissolution of metal oxides in oxalic acid $[4,5]$ have been performed, but are outside the scope of this task.

Corrosion is a process that involves electrochemical as well as chemical reactions. The electrochemical reactions differ from the chemical reactions in that for corrosion an exchange of electrons occurs at the interface between the metal and the solution. In order to maintain a balance of charge, two reactions must occur at the metal surface. The metal dissolution reaction, or anodic reaction, results in the generation of electrons, while the cathodic reaction results in consumption of electrons. An example of these two reactions are given by equations 1 and 2, where iron is being oxidized to ferrous ions while hydrogen ions are being reduced such that hydrogen gas is evolved.

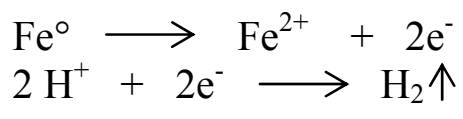

The $\mathrm{pH}$ and oxidizing power of a given environment determines whether a species is thermodynamically stable in a given environment as shown by Pourbaix diagrams (see Figures 1 and 2) [6-8]. These potential (E)-pH diagrams present a map of the regions of stability of a metal and its corrosion products in an aqueous environment. The diagrams also identify conditions under which 1) the metal is stable and will not corrode, 2) soluble reaction products are formed and corrosion will occur, and 3 ) insoluble reaction products are formed and passivity will occur. The Pourbaix diagram assists in the determination of regions where the corrosion reaction is possible in a given aqueous environment. 
In dealing the stability of metal in aqueous solutions, the thermodynamic stability of water is essential to an understanding of the possible corrosion reactions. Figure 1 shows the E-pH diagram for water with no metal involved. Line (a) represents the equilibrium reaction for hydrogen ions to evolve hydrogen gas (see Equation 2). At any potential and $\mathrm{pH}$ below this line the hydrogen ion in water will react with electrons to evolve hydrogen gas. Line (b) represents the equilibrium of oxygen evolution. For an acidic solution, the oxygen reduction reaction can be given by Equation 3:

$\mathrm{O}_{2}+4 \mathrm{H}^{+}+4 \mathrm{e}^{-} \longrightarrow 2 \mathrm{H}_{2} \mathrm{O}$

At any potential and $\mathrm{pH}$ above this line water is oxidized to evolve oxygen gas and hydrogen ions (the reverse of Equation (3)). For potential and $\mathrm{pH}$ conditions between lines (a) and (b), water is thermodynamically stable and no gas evolves.

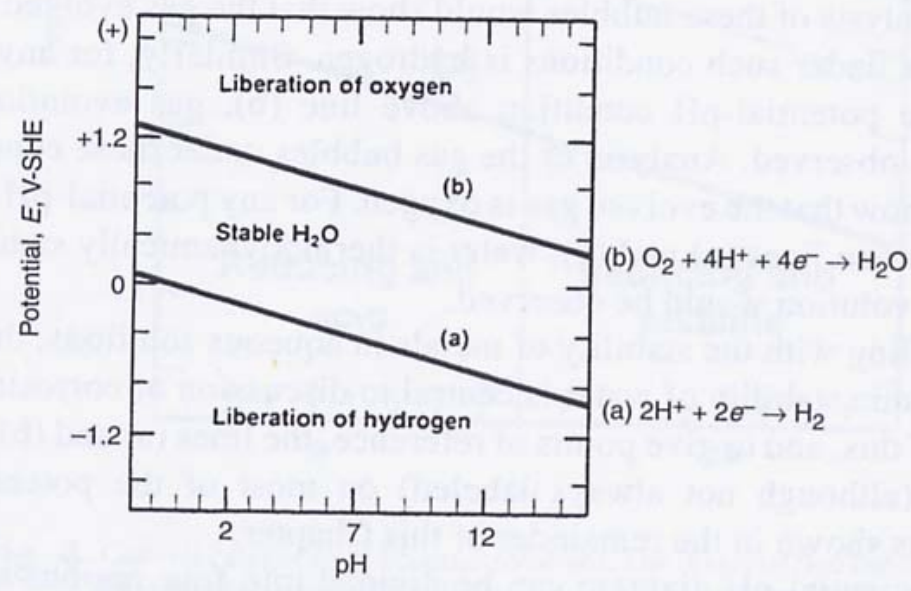

Figure 1. Pourbaix diagram for water [6].

Figure 2 shows the Pourbaix diagram for iron in an aqueous environment. The diagram shows the regions of stability for iron, the ferrous ion $\left(\mathrm{Fe}^{2+}\right)$, the ferric ion $\left(\mathrm{Fe}^{3+}\right)$, and the oxides that make up the corrosion products. The double lines separate species related to redox equilibria for iron and/or its oxidized species or corrosion product. The double line representing the corrosion of iron to ferrous ion (Equation 1) is highlighted, as is the dashed line (f), which represents the hydrogen evolution reaction (Equation 2). Therefore from the diagram it may be concluded that hydrogen evolution is accompanied by the oxidation of iron to ferrous species. 


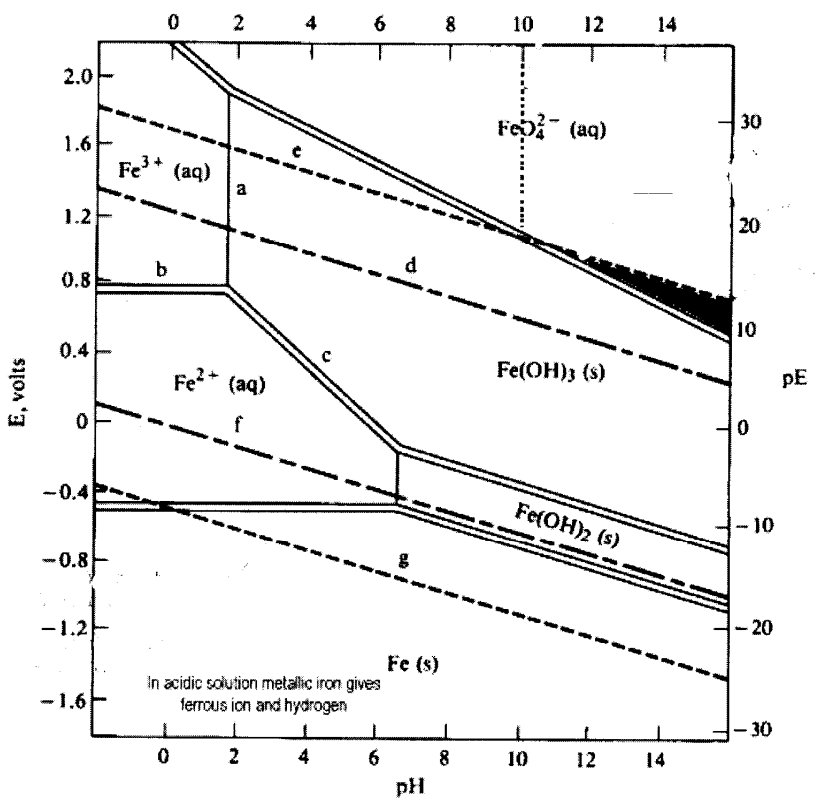

Figure 2. Pourbaix diagram for iron and water [8].

One of the weaknesses of the standard Pourbaix diagram is that it does not account for the presence of other ionic species in solution. Advances and extensions of the diagrams have been made to include other ionic species. The diagram for iron-oxalic acid-water is shown in Figure 3 [9]. Two features have been added to the iron-water diagram shown in Figure 2. The first feature describes the dissociation of the oxalic acid into the hydrooxalate $\left(\mathrm{HC}_{2} \mathrm{O}_{4}{ }^{-}\right)$and oxalate species (see solid red lines on diagram). The distribution of species for oxalic acid is shown in Figure 4 [9]. At a $\mathrm{pH}<1.25$ oxalic acid is the primary species, while at a $\mathrm{pH}$ between 1.25 and 4, the hydro-oxalate species is predominant. For $\mathrm{pH}$ greater than 4, the oxalate species is most stable species. The second feature is the region of stability for the ferrous oxalate species indicated by the cross-hatched area. This area is defined by the following electrochemical reactions.

$\mathrm{Fe}^{\circ}+\mathrm{H}_{2} \mathrm{C}_{2} \mathrm{O}_{4} \longrightarrow \mathrm{HCC}_{2} \mathrm{O}_{4}+2 \mathrm{H}^{+}+2 \mathrm{e}^{-}$
$\mathrm{Fe}^{\circ}+\mathrm{HC}_{2} \mathrm{O}_{4}^{-} \longrightarrow \mathrm{FeC}_{2} \mathrm{O}_{4}+\mathrm{H}^{+}+2 \mathrm{e}^{-}$
$\mathrm{Fe}^{\circ}+\mathrm{C}_{2} \mathrm{O}_{4}{ }^{\circ} \longrightarrow \mathrm{FeC}_{2} \mathrm{O}_{4}+2 \mathrm{e}^{-}$

A $0.11 \mathrm{M}$ oxalic acid solution $(\sim 1 \mathrm{wt} . \%)$ has a $\mathrm{pH}$ of approximately 1.2 . In this case the solution would be approximately $80 \%$ undissociated oxalic acid and $20 \%$ hydro-oxalate. Thus Equation (4) and/or (5) may be occurring at the metal surface to form the ferrous oxalate film. These equations may also be working in parallel with the iron dissolution reaction, Equation (1) [10]. 


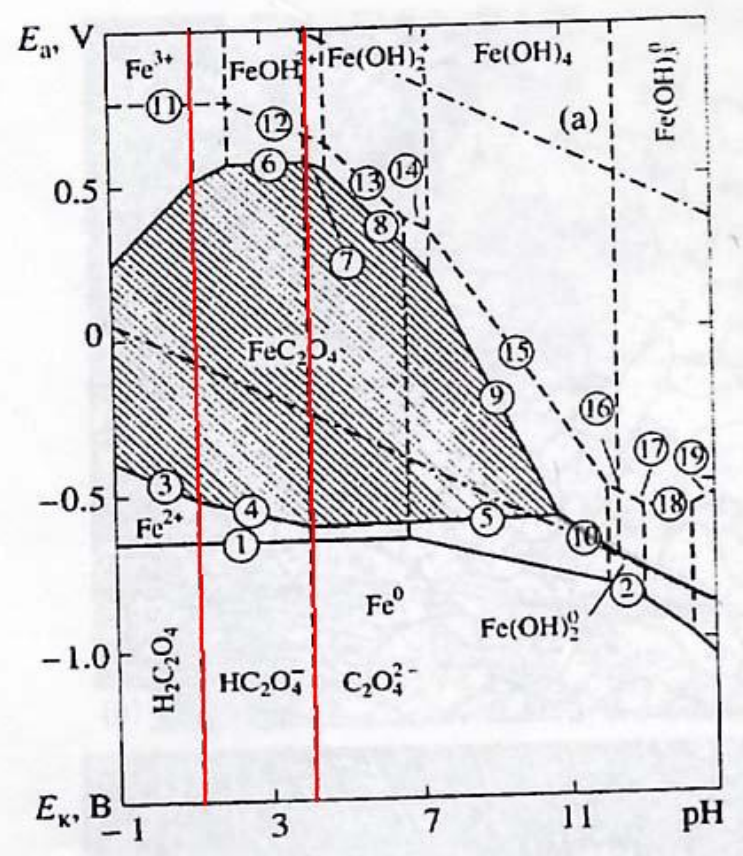

Figure 3. Iron-Oxalic Acid-Water Pourbaix Diagram [10].

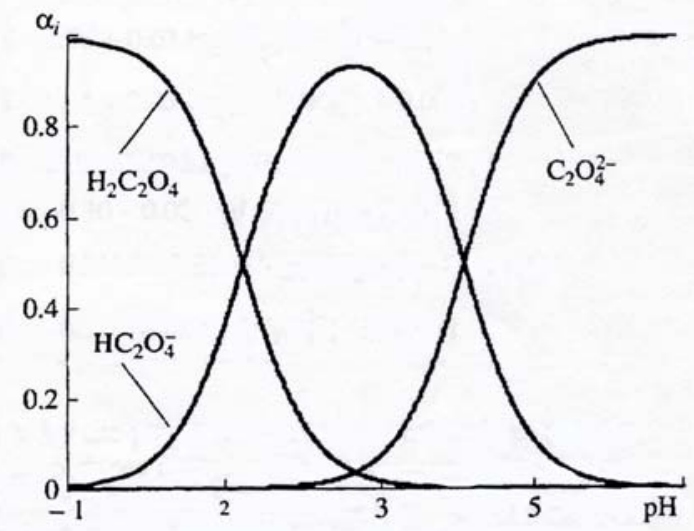

Figure 4. Distribution of oxalic acid species [9].

Earlier references inferred from the test results that the anodic reaction was simply iron being corroded to form ferrous ion [11-17]. It was theorized that passivation occurred as a result of deposition of ferrous oxalate near the metal surface that had become supersaturated with ferrous ions. However, the more recent electrochemical tests $[9,10]$ indicate that the hydro-oxalate species also participates in the corrosion reaction, as shown in Equation (5) in addition to the iron being oxidized to ferrous ion reaction.

Equation (7) is the sum of reactions (1) and (5).

$2 \mathrm{Fe}^{\circ}+\mathrm{HC}_{2} \mathrm{O}_{4}^{-} \longrightarrow \mathrm{FeC}_{2} \mathrm{O}_{4}(\mathrm{~s})+\mathrm{Fe}^{2+}+\mathrm{H}^{+}+4 \mathrm{e}^{-}$ 
It should be noted that the ferrous ions formed by this reaction could also result in the deposition of ferrous oxalate at the surface. This ferrous oxalate serves to passivate the surface and mitigate corrosion.

The protective properties of the ferrous oxalate layer can depend on its structure and porosity. These characteristics depend on the rate at which the film crystallized on the surface. Therefore, if passivation occurred at a high rate of ferrous ion formation (e.g., higher temperatures) a tightly adherent film would form and show strong inhibition characteristics. Other factors that might prevent the formation of the layer may include:

- agitation of the solution, which decreases the concentration of ferrous ions at the metal surface by transporting the ions to the bulk of the solution;

- oxidation of ferrous to ferric ion by oxidizing agents that increase the anodic electrochemical potential (e.g., mercury, nitrate, permanganate, etc.);

- introduction of anions that form soluble salts with ferrous ions (e.g., chloride, sulfate, etc.)

One or all of these factors could play a role during enhanced chemical cleaning.

For pure oxalic acid, the cathodic reaction that occurs is either hydrogen evolution:

$2 \mathrm{H}^{+}+2 \mathrm{e}^{-} \longrightarrow \mathrm{H}_{2}(\mathrm{~g})$

and/or, oxygen reduction:

$\mathrm{O}_{2}+4 \mathrm{H}^{+}+4 \mathrm{e}^{-} \longrightarrow 2 \mathrm{H}_{2} \mathrm{O}$

Hydrogen evolution is favored at de-aerated, stagnant, high temperature conditions [18]. Oxygen evolution on the other hand is more favored in the lower temperature and agitated conditions where oxygen solubility is greater.

Two competing processes determine the corrosion rate of steel in oxalic acid: a) the rate of the cathodic reaction, and $b$ ) the rate at which ferrous oxalate, the passivating species, forms. The competition between these two processes is illustrated by the following observation. Coupon tests were conducted in stagnant, 1 wt. $\%$ oxalic acid, at $45{ }^{\circ} \mathrm{C}$ and $75^{\circ} \mathrm{C}$ for two weeks. The corrosion rate for the test at $45^{\circ} \mathrm{C}$ was $90 \mathrm{mpy}$, while for the $75^{\circ} \mathrm{C}$ test the corrosion rate was approximately $22 \mathrm{mpy}$. Photographs of the coupons in solution showed a loosely adherent ferrous oxalate film for the $45^{\circ} \mathrm{C}$ exposure (see Figure 5). In fact, some of the ferrous oxalate had spalled off of the surface. On the other hand the same figure shows that a tightly adherent ferrous oxalate film in the $75^{\circ} \mathrm{C}$ test with no evidence of spallation. Initially these results were counter-intuitive given that corrosion rates generally increase with temperature.

These results may be interpreted as follows. If the steel is exposed to oxalic acid at high temperatures (e.g., $75^{\circ} \mathrm{C}$ ), hydrogen evolution is the likely cathodic reaction due to the 


\section{Revision 1}

limited solubility of oxygen at that temperature. In a stagnant environment, the cathodic reaction rate is relatively high due to the temperature; the high initial corrosion rate is expected to deplete the $\mathrm{H}^{+}$ion content near the surface. As a result, the rate of the cathodic reaction is controlled by the transport of $\mathrm{H}^{+}$ions to the surface of the electrode (i.e., not enough $\mathrm{H}^{+}$present to supply the current for the anodic reaction).

Simultaneously, the initial high rate of iron dissolution would result in a significant buildup in the ferrous ion concentration at the metal surface. Since there is no agitation to disperse the ferrous ions, precipitation of a tightly adherent ferrous oxalate film occurs rapidly. The result is a lower corrosion rate.

The situation in an agitated solution is much different. In this case, convection maintains the concentration of $\mathrm{H}^{+}$ion near the surface at a higher concentration such that the electrode kinetics control the corrosion rate. The cathodic reaction rate will remain at levels such that hydrogen evolution disrupts the formation of the ferrous oxalate film. In addition the build-up of ferrous ion at the metal surface is not as significant as it is in the stagnant solution. Therefore, less precipitate would form immediately adjacent to the metal surface. The result would be a loosely adherent ferrous oxalate film and higher corrosion rates than the stagnant condition.

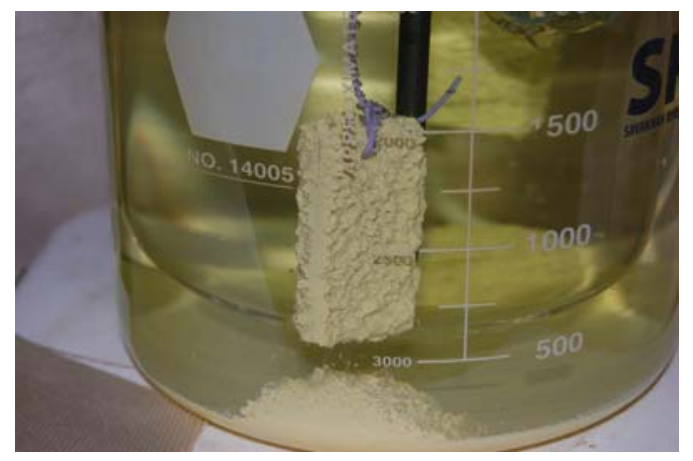

(a)

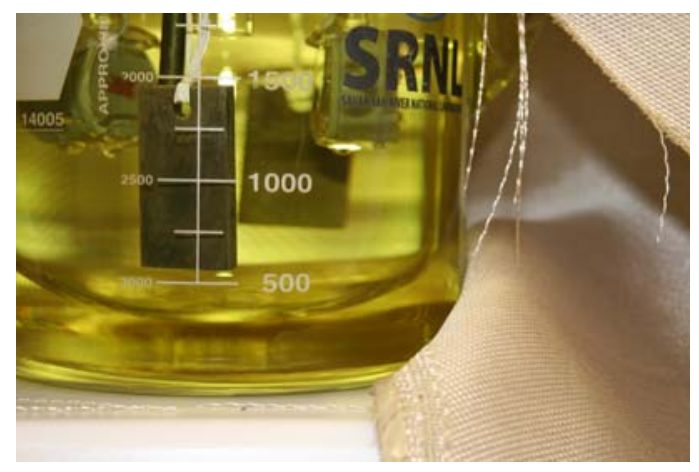

(b)

Figure 5. Coupon test in 1 wt. \% oxalic acid with no agitation at (a) $45^{\circ} \mathrm{C}$ and (b) 75 ${ }^{\circ} \mathbf{C}$. 
At lower temperatures (e.g., $\left.50^{\circ} \mathrm{C}\right)$, the effect of agitation is significantly different. The evidence suggests that hydrogen evolution is still the primary cathodic reaction [19], although oxygen solubility is greater and may have a small role in determining the corrosion rate as well. For the case of the stagnant environment, the lower temperature results in a slower cathodic reaction rate compared with the previous example. As a result the $\mathrm{H}^{+}$ion concentration, although the ion reacts at the surface, will not deplete as rapidly as it did at the higher temperature (i.e, there will not be a significant concentration gradient between the bulk solution and the surface) and therefore the corrosion rate will be controlled primarily by the kinetics of the electrode reaction at the surface rather than the transport of $\mathrm{H}^{+}$ions to the metal surface. Contrary to the results for the higher temperature, stagnant condition, hydrogen evolution would likely disrupt the formation of the ferrous oxalate film. The result would be a loosely adherent ferrous oxalate film and a higher corrosion rate. In the agitated environment, the $\mathrm{H}^{+}$ion concentration at the surface will again be maintained by convection. Thus, as in the case of the stagnant low temperature condition the electrode kinetics at the surface would determine the corrosion rate. The result again would be a loosely adherent ferrous oxalate film and a higher corrosion rate. It is difficult to predict which condition, agitated or stagnant, would result in a higher corrosion rate as other variables (e.g., surface oxide films, the steel microstructure and composition) have a greater impact when the electrode surface kinetics are controlling.

The environmental conditions are different for the chemical cleaning process than for the pure oxalic acid conditions. Corrosion of steel and dissolution of iron oxides result in a build-up of not only ferrous ions, but ferric oxalate complexes as well in the acidic environment. During the chemical cleaning process, the concentration of ferric species increases due to dissolution of iron oxides such as hematite, magnetite, and iron oxide corrosion products such as goethite or lepidocrocite. These oxides reside in the sludge solids and in a layer of mill scale or corrosion product on the tank wall. Ferric ions may also evolve as ferrous species react with oxygen present in the solution. Ferric oxalate complexes are relatively stable and remain soluble in oxalic acid.

It is postulated that the anodic reaction remains essentially the same as described above in equation 7 for the chemical cleaning process. In the presence of ferric oxalate complexes however, the following cathodic reaction may also occur:

$$
\mathrm{Fe}^{3+}+\mathrm{e}^{-} \longrightarrow \mathrm{Fe}^{2+}
$$

The free ferric ion concentration in oxalate media however, is essentially nil at a $\mathrm{pH}$ of 2 [4] as the ferric ion is readily complexed with the oxalate to form a di-oxolatoferrate $\left(\mathrm{Fe}\left(\mathrm{C}_{2} \mathrm{O}_{4}\right)_{2}{ }^{-}\right)$ion at a $\mathrm{pH}$ of approximately 2. This species may be reduced at cathodic sites. This reaction is also a function of the oxalate concentration as well [20]. For example, if the concentration is less than $0.1 \mathrm{M}$ oxalate the reaction proceeds as:

$$
\mathrm{Fe}\left(\mathrm{C}_{2} \mathrm{O}_{4}\right)_{2}^{-}+2 \mathrm{H}^{+}+\mathrm{e}^{-} \longrightarrow \mathrm{Fe}^{2+}+2 \mathrm{HC}_{2} \mathrm{O}_{4}^{-}
$$


while at concentrations greater than $0.1 \mathrm{M}$ oxalate the reaction proceeds as:

$\mathrm{Fe}\left(\mathrm{C}_{2} \mathrm{O}_{4}\right)_{2}^{-}+\mathrm{H}^{+}+\mathrm{e}^{-} \longrightarrow \mathrm{FeC}_{2} \mathrm{O}_{4}+\mathrm{HC}_{2} \mathrm{O}_{4}^{-}$

The initial molar concentration of $1 \mathrm{wt} . \%$ oxalic acid is approximately $0.11 \mathrm{M}$. Once dissolution of the iron oxides begins, the oxalate concentration would be expected to decrease and hence equation 9 would likely be operable.

At $\mathrm{pH}$ levels between 1 and 1.5 with oxalic acid concentrations of approximately 2.5 wt.\% so that in addition to the di-oxalatoferrate complex another iron (III) oxalate complex, the tri-oxalatoferrate species, $\mathrm{Fe}\left(\mathrm{C}_{2} \mathrm{O}_{4}\right)_{3}{ }^{3-}[20,21]$, is present in significant quantities. This species has been show to be reduced according to the following reaction:

$\mathrm{Fe}\left(\mathrm{C}_{2} \mathrm{O}_{4}\right)_{3}{ }^{3-}+\mathrm{e}^{-} \longrightarrow \mathrm{Fe}\left(\mathrm{C}_{2} \mathrm{O}_{4}\right)_{3}{ }^{4-}$

Note that in this case ferrous oxalate is not formed as it is for the reaction involving the di-oxalatoferrate complex. Thus, one might suspect that less ferrous oxalate would be present to maintain a passive layer at this condition.

At $\mathrm{pH}$ levels of approximately 1 with oxalic acid concentrations of $8 \mathrm{wt} . \%$, the primary species present would be the tri-oxalatoferrate species. The corrosion rate would be controlled by the rate at which reaction (11) occurs. Ferrous oxalate would not form by a cathodic electrochemical reaction however, the production of ferrous oxalate by the anodic reaction (4) would likely still continue.

Ferric ions increase the corrosion of steel in direct proportion to their concentration in the acid [15]. The result is that the rate of formation of the protective ferrous oxalate coating increases due to increasing the rate of dissolution at the anodic sites and the resultant increase in the amount of ferrous ion available at the surface. Once the passive oxalate layer has formed, the corrosion rate is depressed relative to that in oxalic acid.

The presence of the ferrous species in solution increases the oxidation reduction potential of the solution $[15,16]$, which impacts which cathodic reactions are thermodynamically possible. That is, the potential moves in the region of the Pourbaix diagram where water is thermodynamically stable and hydrogen evolution is less likely. These potential shifts were also observed in previous testing in $8 \mathrm{wt} . \%$ oxalic acid that contained sludge [18].

In addition to this thermodynamic evidence, polarization curves also indicated that the mechanism involved another species besides hydrogen. As the $\mathrm{E}_{\text {corr }}$ became more positive due to presence of the ferrous and ferric species, the cathodic polarization curves indicated that transport of the cathodic species was the rate determining step (i.e., reactions in agitated solutions occur at a higher rate than stagnant solutions).

The testing in this program was performed to confirm that these observations in the more concentrated oxalic acid apply to the more dilute solution as well. 


\subsection{Experimental}

\subsection{Test Materials}

The material tested was ASTM A285, Grade C carbon steel (UNS K02200). This material has similar chemical and physical properties as the Type I and II waste storage tanks that will be the focus of the initial chemical cleaning operations. Two different heats of steel were utilized (see Table 1). Heat 1 was utilized for the electrochemical tests for the test in $1 \mathrm{wt} . \%$ oxalic acid, and Heat 2 was utilized for the coupon tests in 1 wt.\% oxalic acid and the electrochemical and coupon tests in $2.5 \mathrm{wt} \%$ oxalic acid. The chemical compositions and the mechanical properties (see Table 2) of the as-received coupons were vendor certified. Given that the carbon content of these heats is the same, similar corrosion rates and mechanistic behavior is expected [22].

Table 1. Chemical Composition (Wt \%) of A285 Grade C, Carbon Steel

\begin{tabular}{|c|c|c|c|c|c|c|c|c|c|}
\hline Heat & $\mathbf{C}$ & $\mathbf{M n}$ & $\mathbf{P}$ & $\mathbf{S}$ & $\mathbf{C u}$ & $\mathbf{N i}$ & $\mathbf{C r}$ & $\mathbf{S i}$ & $\mathbf{F e}$ \\
\hline 1 & 0.18 & 0.43 & 0.009 & 0.026 & - & - & - & 0.07 & balance \\
\hline 2 & 0.18 & 0.75 & 0.011 & 0.008 & 0.03 & 0.03 & 0.06 & - & balance \\
\hline
\end{tabular}

Table 2. Mechanical Properties of A285 Grade C, Carbon Steel

\begin{tabular}{|c|c|c|c|}
\hline Heat & $\begin{array}{c}\text { Yield Strength } \\
\text { (ksi) }\end{array}$ & $\begin{array}{c}\text { Tensile Strength } \\
\text { (ksi) }\end{array}$ & \% Elongation \\
\hline 1 & 42 & 62 & $28(8$ inch $)$ \\
\hline 2 & 48 & 67 & $31(2 \mathrm{inch})$ \\
\hline
\end{tabular}

\subsection{Solutions}

Three sludge slurry simulants were prepared during effort 1 of task plan SRNL-RP-200901038, Rev. 1 [23]. The simulants that were prepared were:

1. PUREX sludge simulant consistent with sludge in F-Area Tanks 1-8.

2. HM sludge simulant consistent with sludge in H-Area Tanks 9-16.

3. PUREX/HM blend sludge simulant with a composition based on an equal weighted blend of both types of sludge.

Corrosion tests were performed in all three sludge simulants with $1 \mathrm{wt} . \%$ oxalic acid, while only the PUREX and HM were tested with the $2.5 \mathrm{wt} . \%$ oxalic acid. The PUREX simulant compositional basis was developed from information on Tank $8 \mathrm{~F}$ sludge to provide a link with prior ECC simulant testing [23]. The prior simulant did not include any hazardous materials and also did not include several components such as the 
lanthanides. The new PUREX sludge simulant used the same basis as the previous simulant modified by results from an analysis of a sample of Tank 8F. The PUREX sludge simulant included $\mathrm{Ag}, \mathrm{Ba}, \mathrm{Cd}, \mathrm{Cr}, \mathrm{Hg}$ and $\mathrm{Pb}$. The $\mathrm{HM}$ sludge simulant was based on a Tank $12 \mathrm{H}$ sample that was collected prior to transfer to Tank $51 \mathrm{H}$ for aluminum dissolution. This sludge simulant also contained the RCRA listed (i.e., hazardous) metals. The PUREX/HM Blend sludge simulant was based on an equally weighted blend composition.

Formulation of the sludge simulants was based on precipitation reactions that were used previously to generate sludge simulants. A portion of the major sludge species (Fe and Al) was added as oxide forms to produce a simulant with the appropriate acid dissolution characteristics. The sludge generation sequence was established to prevent undesirable reactions from producing inconsistent sludge compositions and to minimize potential safety issues during the application of the sludge recipe to bulk manufacture of the simulant.

The following general procedure was utilized to prepare approximately 3 liters of the oxalic acid/sludge simulant mixture that was used for the testing. The $\mathrm{pH}$ of the final mixture was approximately 2 .

1. Prepare 1 wt. $\%$ or 2.5 wt. $\%$ oxalic acid solution.

1. Agitate the sludge slurry simulant until the sludge solids are completely suspended.

2. Decant $500 \mathrm{ml}$ of the sludge slurry into a beaker and allow the solids to settle.

3. Remove approximately $250 \mathrm{ml}$ of liquid above the solids. The decant leaves approximately $250 \mathrm{ml}$ of solids and interstitial liquid.

4. Add $500 \mathrm{ml}$ of the $1 \mathrm{wt} . \%$ oxalic acid to the sludge slurry.

5. Agitate the solution for approximately 15 minutes and then measure the $\mathrm{pH}$.

6. Repeat steps 5 and 6 until the $\mathrm{pH}$ is stable at approximately 2.

As mentioned above, typically this procedure produced about 3 liters of the sludge simulant/oxalic acid mixture.

\subsection{Experimental Procedures}

\subsubsection{Electrochemical Tests}

The electrochemical studies were performed utilizing either a Gamry ${ }^{\mathrm{TM}}$ or Princeton Applied Research ${ }^{\mathrm{TM}}$ (PAR) potentiostat. The tests were performed in a PAR test cell similar to the one shown in Figure 6. The oxalic acid/sludge simulant having a $\mathrm{pH}$ of 2 or less was prepared prior to the test and placed in the PAR test cell. The test temperature was maintained by a hot plate that had a temperature controller. Evaporation of the solution during the test was minimized with the use of a condenser. The carbon steel working electrode was either a $5 \mathrm{~cm}^{2}$ cylinder or a $1.5 \mathrm{~cm}^{2}$ rectangle that was anchored in a cold mount. The counter electrode was either a graphite rod or a stainless 


\section{Revision 1}

steel mesh. A saturated silver-silver chloride $(\mathrm{Ag} / \mathrm{AgCl})$ electrode was utilized as the reference electrode.

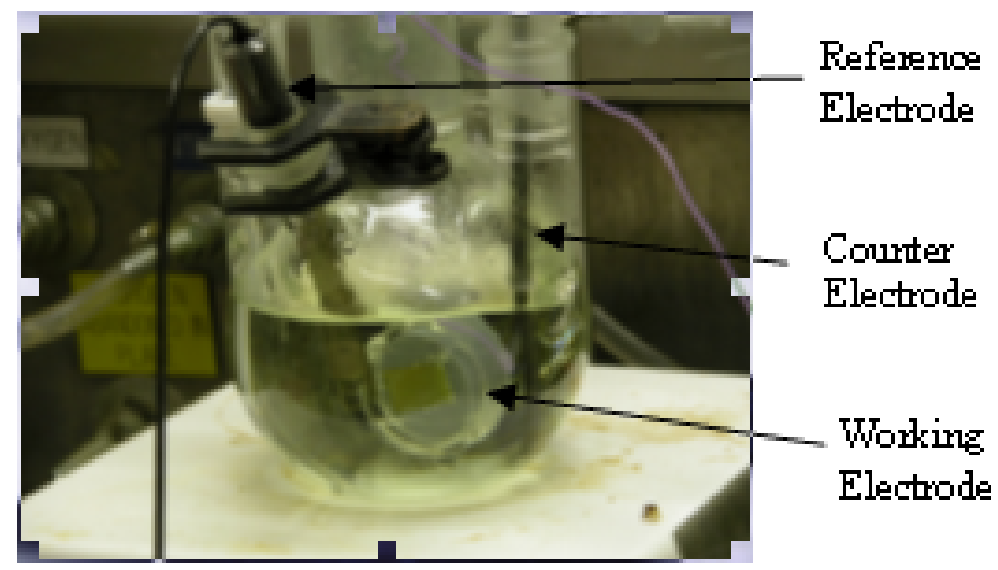

Figure 6. PAR cell utilized for electrochemical tests.

The electrochemical tests performed include: 1) Open circuit potential (OCP) measurement, 2) Linear polarization resistance (LPR) measurements, 3) Cathodic polarization, and 4) Cyclic potentiodynamic polarization (CPP). The matrix for the electrochemical tests with 1 wt.\% oxalic acid is shown in Table 3. This testing incorporated control cases in addition to the parameters that were investigated with the coupon tests. For example, oxalic acid $(1 \mathrm{wt} . \%)$ by itself under de-aerated conditions at the low temperatures was investigated. This provided necessary mechanistic information to support the results of the coupon tests. A similar test matrix was developed for the tests in $2.5 \mathrm{wt} . \%$ oxalic acid (see Table 4 ).

The initial test performed monitored the OCP for 1 to 4 hours. The OCP reflects a measure of the electrochemical activity at the metal surface, i.e. whether it is actively corroding or becoming passive. The test also provides information on the relative stability of the passive film, and whether hydrogen evolution is thermodynamically possible. The effects of material (e.g., surface condition of coupon) and environmental variables (e.g., temperature, mixing, etc.) on these measurements were also investigated.

The propensity for hydrogen evolution may be visualized with the Pourbaix diagram for water, which is is shown in Figure 7. The two diagonal lines, identified as (a) and (b), define the region of stability for water as a function of potential and $\mathrm{pH}$. For potential and $\mathrm{pH}$ conditions between lines (a) and (b) water is thermodynamically stable. For any value of potential above line (b) water is thermodynamically unstable and oxygen is liberated, while at any conditions of potential and $\mathrm{pH}$ below line (a) water is thermodynamically unstable and hydrogen gas is generated. Therefore, from the measured potential and the $\mathrm{pH}$ values, it can be determined if it is thermodynamically 
Revision 1

possible for the corrosion reaction to generate hydrogen. If the measured OCP value from the test is below line (a), hydrogen evolution is possible.

Table 3. Matrix for Electrochemical Testing for 1 wt. \% Oxalic Acid

\begin{tabular}{|c|c|c|c|c|}
\hline Test & Simulant & $\begin{array}{c}\text { Temperature } \\
\left({ }^{\circ} \mathrm{C}\right)\end{array}$ & Agitation $(\mathrm{Y} / \mathrm{N})$ & Aerated $(\mathrm{Y} / \mathrm{N})$ \\
\hline 1 & Oxalic Acid & 45 & $\mathrm{Y}$ & $\mathrm{Y}$ \\
\hline 2 & Oxalic Acid & 45 & $\mathrm{~N}$ & $\mathrm{Y}$ \\
\hline 3 & Oxalic Acid & 75 & $\mathrm{Y}$ & $\mathrm{Y}$ \\
\hline 4 & Oxalic Acid & 75 & $\mathrm{~N}$ & $\mathrm{Y}$ \\
\hline 5 & PUREX & 45 & $\mathrm{Y}$ & $\mathrm{Y}$ \\
\hline 6 & PUREX & 45 & $Y$ & $\mathrm{~N}$ \\
\hline 7 & PUREX & 45 & $\mathrm{~N}$ & $\mathrm{Y}$ \\
\hline 8 & PUREX & 45 & $\mathrm{~N}$ & $\mathrm{~N}$ \\
\hline 9 & PUREX & 75 & $\mathrm{Y}$ & $Y$ \\
\hline 10 & PUREX & 75 & $\mathrm{~N}$ & $\mathrm{Y}$ \\
\hline 11 & HM & 45 & $\mathrm{Y}$ & $\mathrm{Y}$ \\
\hline 12 & $\mathrm{HM}$ & 45 & $\mathrm{Y}$ & $\mathrm{N}$ \\
\hline 13 & $\mathrm{HM}$ & 45 & $\mathrm{~N}$ & $\mathrm{Y}$ \\
\hline 14 & $\mathrm{HM}$ & 45 & $\mathrm{~N}$ & $\mathrm{~N}$ \\
\hline 15 & HM & 75 & $\mathrm{Y}$ & $\mathrm{Y}$ \\
\hline 16 & HM & 75 & $\mathrm{~N}$ & $\mathrm{Y}$ \\
\hline 17 & HM-PUREX & 45 & $\mathrm{Y}$ & $\mathrm{Y}$ \\
\hline 18 & HM-PUREX & 45 & $\mathrm{Y}$ & $\mathrm{N}$ \\
\hline 19 & HM-PUREX & 45 & $\mathrm{~N}$ & $\mathrm{Y}$ \\
\hline 20 & HM-PUREX & 45 & $\mathrm{~N}$ & $\mathrm{~N}$ \\
\hline 21 & HM-PUREX & 75 & $\mathrm{Y}$ & $\mathrm{Y}$ \\
\hline 22 & HM-PUREX & 75 & $\mathrm{~N}$ & $\mathrm{Y}$ \\
\hline
\end{tabular}

Table 4. Matrix for Electrochemical Testing for 2.5 wt. \% Oxalic Acid

\begin{tabular}{|c|c|c|c|}
\hline Test & Simulant & $\begin{array}{c}\text { Temperature } \\
\left({ }^{\circ} \mathrm{C}\right)\end{array}$ & Agitation (Y/N) \\
\hline 1 & 2.5 wt.\% Oxalic Acid & 50 & $\mathrm{Y}$ \\
\hline 2 & $2.5 \mathrm{wt.} \%$ Oxalic Acid & 50 & $\mathrm{~N}$ \\
\hline 3 & $2.5 \mathrm{wt.} \%$ Oxalic Acid & 75 & $\mathrm{Y}$ \\
\hline 4 & $2.5 \mathrm{wt} \%$ Oxalic Acid & 75 & $\mathrm{Y}$ \\
\hline 5 & PUREX and $2.5 \mathrm{wt.} \%$ oxalic acid & 50 & $\mathrm{~N}$ \\
\hline 6 & PUREX and $2.5 \mathrm{wt.} \%$ oxalic acid & 50 & $\mathrm{Y}$ \\
\hline 7 & PUREX and $2.5 \mathrm{wt} \%$ oxalic acid & 75 & $\mathrm{~N}$ \\
\hline 8 & PUREX and $2.5 \mathrm{wt} \%$ oxalic acid & 75 & \\
\hline
\end{tabular}


Revision 1

\begin{tabular}{|c|c|c|c|}
\hline 9 & HM and $2.5 \mathrm{wt} . \%$ oxalic acid & 50 & $\mathrm{Y}$ \\
\hline 10 & HM and $2.5 \mathrm{wt.} \%$ oxalic acid & 50 & $\mathrm{~N}$ \\
\hline 11 & HM and $2.5 \mathrm{wt} \%$ oxalic acid & 75 & $\mathrm{Y}$ \\
\hline 12 & HM and $2.5 \mathrm{wt} \%$ oxalic acid & 75 & $\mathrm{~N}$ \\
\hline
\end{tabular}

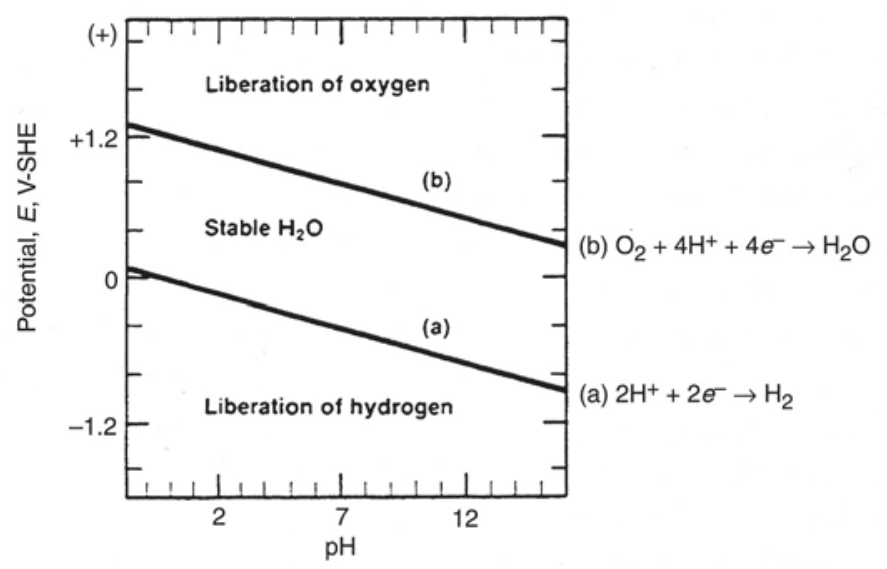

Figure 7. Pourbaix Diagram for water [6].

The equation for line (a) is derived from the Nernst Equation [6]:

$$
\mathrm{E}=\mathrm{E}^{\circ}-2.303 \frac{R T}{F} * \mathrm{pH}
$$

where $\mathrm{E}^{\circ}$ is the standard potential for hydrogen $\left(\mathrm{E}^{\circ}=0.0 \mathrm{~V}\right), \mathrm{R}$ is the ideal gas constant, $8.314 \mathrm{~J} /$ mole- $\mathrm{K}$, $\mathrm{T}$ is the temperature in $\mathrm{K}$, and $\mathrm{F}$ is the Faraday constant, $96,500 \mathrm{~J} / \mathrm{V}$. Thus, given the $\mathrm{pH}$ and temperature of the test, the potential below which hydrogen evolution would occur may be calculated. For tests with the $1 \mathrm{wt} . \%$ oxalic acid with a sludge simulant, the $\mathrm{pH}$ of the solution was approximately 2 , while for the pure oxalic acid tests, the $\mathrm{pH}$ was approximately 1.1. Table 5 shows the calculated potential, utilizing equation 11 , as a function of temperature. The potential utilized in the Nernst equation is with reference to the normal hydrogen electrode (NHE). Experimental measurements during these tests were made using a saturated $\mathrm{Ag} / \mathrm{AgCl}$ reference electrode. To convert the potentials that are referenced to the hydrogen potential to one with reference to the $\mathrm{Ag} / \mathrm{AgCl}$, subtract $197 \mathrm{mV}$. These potentials are also shown in Table 5. The OCP values measured during the tests were compared to these values to determine if hydrogen evolution is thermodynamically possible. The potentials shown in the table also indicate that if hydrogen is the controlling cathodic reaction, and it is determined by the kinetics of the surface at the metal, an increase in temperature should result in a decrease in the measured potential. 
Table 5. Calculated hydrogen evolution potential $\left(E_{\mathrm{H} 2}\right)$ values for the sludge dissolution tests.

\begin{tabular}{|c|c|c|c|}
\hline Simulant & $\begin{array}{c}\text { Temperature } \\
\left({ }^{\circ} \mathrm{C}\right)\end{array}$ & $\mathrm{E}_{\mathrm{H} 2}$ (V vs. NHE) & $\mathrm{E}_{\mathrm{H} 2}(\mathrm{mV}$ vs. Ag/AgCl) \\
\hline $\begin{array}{c}1 \mathrm{wt} \% \text { oxalic } \\
\text { acid }\end{array}$ & 45 & -0.070 & -0.267 \\
\hline $\begin{array}{c}1 \mathrm{wt} \% \text { oxalic } \\
\text { acid }\end{array}$ & 75 & -0.076 & -0.273 \\
\hline $\begin{array}{c}1 \mathrm{wt} \% \text { oxalic } \\
\text { acid w/sludge }\end{array}$ & 45 & -0.127 & -0.324 \\
\hline $\begin{array}{c}1 \mathrm{wt} \% \text { oxalic } \\
\text { acid w/sludge }\end{array}$ & 75 & -0.139 & -0.336 \\
\hline
\end{tabular}

The linear polarization test was performed next. The LPR technique provides a nondestructive, instantaneous estimate of the uniform or general corrosion rate. An ASTM standard practice was utilized to conduct the test [24]. The technique is based on the observation that when the potential at the metal surface is polarized anodically or cathodically within $15 \mathrm{mV}$ of the OCP, the measured current density at the metal surface increases linearly with potential. The slope of this line is defined as the polarization resistance $\left(R_{p}\right)$. Stern and Geary modified the fundamental equation for electrochemical reaction kinetics [25], and demonstrated that the relationship between the corrosion current density ( $\mathrm{i}_{\text {corr }}$ ) and $\mathrm{R}_{\mathrm{p}}$ at the OCP is:

$$
\mathrm{i}_{\mathrm{corr}}=\frac{\beta_{a} \beta_{c}}{2.3\left(\beta_{a}+\beta_{c}\right) R_{p}}
$$

where $\beta_{\mathrm{a}}$ and $\beta_{\mathrm{c}}$ are the anodic and cathodic Tafel slopes, respectively. The Tafel slope is determined experimentally as will be discussed in the subsequent section on the cathodic polarization tests. If the Tafel slopes are unknown, frequently the assumed value for $\beta_{\mathrm{a}}$ and $\beta_{\mathrm{c}}$ is $0.120 \mathrm{~V} /$ decade. Unless the actual slopes are quite different than 0.120 $\mathrm{V} /$ decade, the error in the value of $\mathrm{i}_{\text {corr }}$ is not significant. Both software packages for the potentiostats utilized the $0.120 \mathrm{~V} /$ decade assumption to calculate $\mathrm{i}_{\text {corr }}$. This assumption and its impact on the corrosion rate calculations was investigated during the cathodic polarization studies discussed in the next section. The corrosion current is related to the corrosion rate $(\mathrm{CR})$ by the following equation:

$$
\mathrm{CR}=0.13 * \frac{i_{\text {corr }} E_{w}}{\rho}
$$


where $E_{w}$ is the equivalent weight of iron (27.9 g/equivalent), and $\rho$ is the density of iron $\left(7.86 \mathrm{~g} / \mathrm{cm}^{3}\right)$. The corrosion rate is reported in mils $(0.001$ inches $)$ per year.

The potential scan rate is a critical variable for the LPR technique [26]. A test performed at too high of a scan rate causes a high capacitive current that results in hysteresis in the plot of the potential and the current. As a result, the polarization resistance may be under-estimated and the corrosion rate, which is inversely proportional to the polarization resistance, may be over-estimated. On the other hand faster scan rates are desirable since the time at which the specimen is polarized from its equilibrium potential is minimized. A scan rate of $0.167 \mathrm{mV} / \mathrm{s}$ was selected for these tests. Figure 8 shows an LPR curve generated from one of the tests.

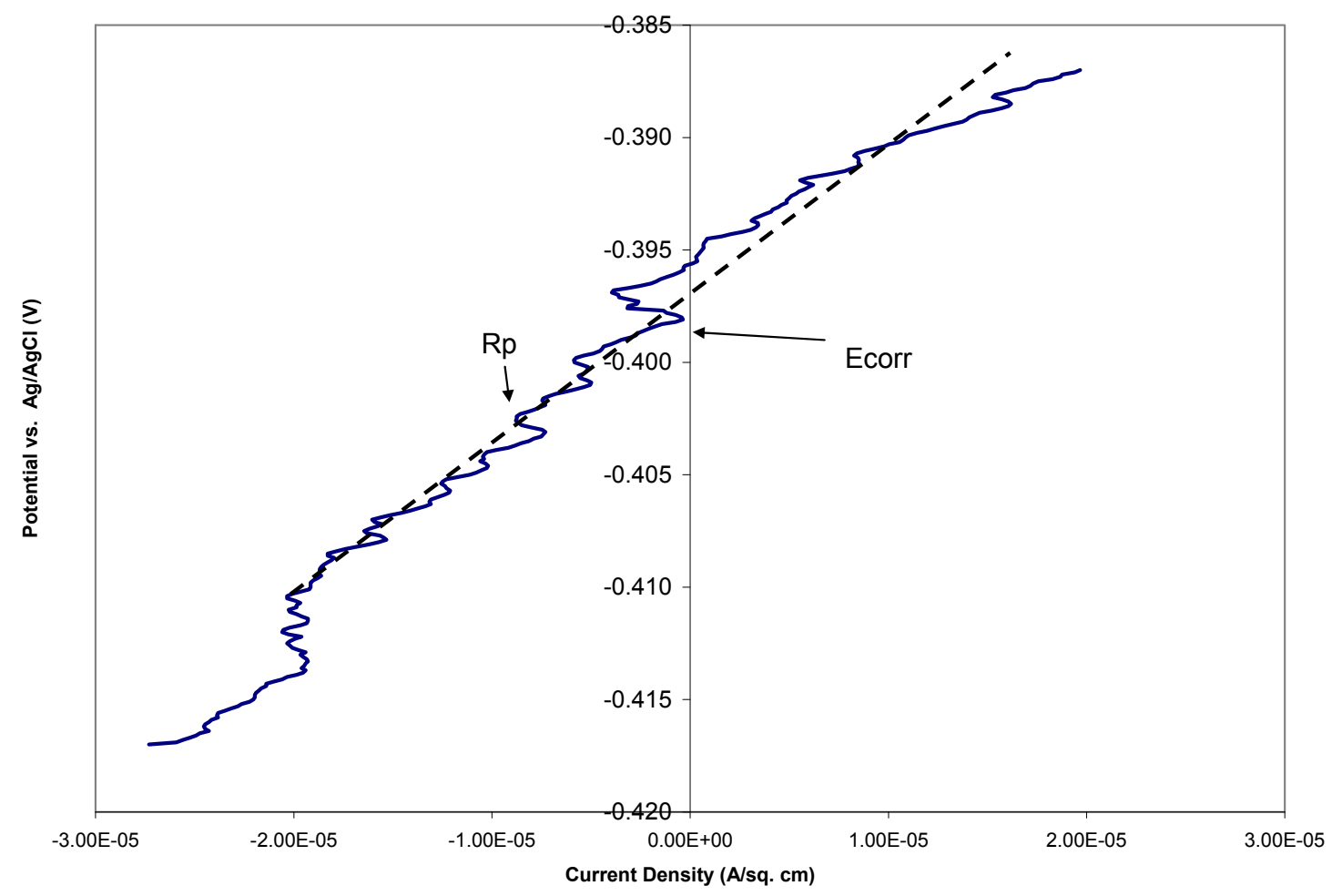

Figure 8. Example of Linear Polarization Resistance curve measured during tests.

Cathodic potentiodynamic polarization studies were performed next. These tests were utilized to investigate the kinetics of the rate cathodic electrochemical reaction. Based on these studies, it can be determined if hydrogen is indeed being evolved. The cathodic polarization test sequentially scans the potential of the working electrode toward more negative potentials with respect to OCP in a controlled manner. Although there is no standard practice for this test, it has long been utilized to probe the kinetics of not only the cathodic reaction but the corrosion rate as well [27]. At potentials relatively close to the OCP, the relationship between the potential and the current is given by the Tafel expression [28] 


$$
\eta=\beta \log \left(\mathrm{i} / \mathrm{i}_{0}\right)
$$

where $\eta$ is the overvoltage, defined as $\mathrm{E}-\mathrm{OCP}$, in volts; $\beta$ is the slope of the line on the potential-log current density plot, also known as the cathodic Tafel slope in volts/decade of current; $i$ is the measured current density at the applied potential $\mathrm{E}$ in $\mathrm{A} / \mathrm{sq} . \mathrm{cm}$; and $\mathrm{i}_{\mathrm{o}}$ is the exchange current density, in $\mathrm{A} / \mathrm{cm}^{2}$, and represents the current density equivalent to the equal forward and reverse reactions at the electrode at equilibrium.

Figures 9 show plots of $\eta$ vs. $\log$ current density for various test conditions. Figure 9 additionally illustrates how $\beta$ and $i_{o}$ are determined. The Tafel equation is obeyed within the region of applied current density, $i$, below the limiting current density $\left(i_{L}\right)$ for concentration polarization, and above the exchange current density. The cathodic Tafel slope is typically determined by finding the linear portion of the curve at current densities between $2 \times 10^{-5}$ and $1 \times 10^{-3} \mathrm{~A} / \mathrm{sq}$. cm [28]. In the case of the $1 \mathrm{wt} . \%$ and $2.5 \mathrm{wt} . \%$ oxalic acid the slope at $1 \times 10^{-3} \mathrm{~A} / \mathrm{sq}$. $\mathrm{cm}$. However, for the HM and PUREX solutions, the current density is less than $1 \times 10^{-3} \mathrm{~A} / \mathrm{sq}$. cm and thus, the linear portion of the lines were fitted to determine $\beta$. The exchange current density was determined by extrapolating the Tafel slope line until it intersects $\eta=0$ (see figure 9).

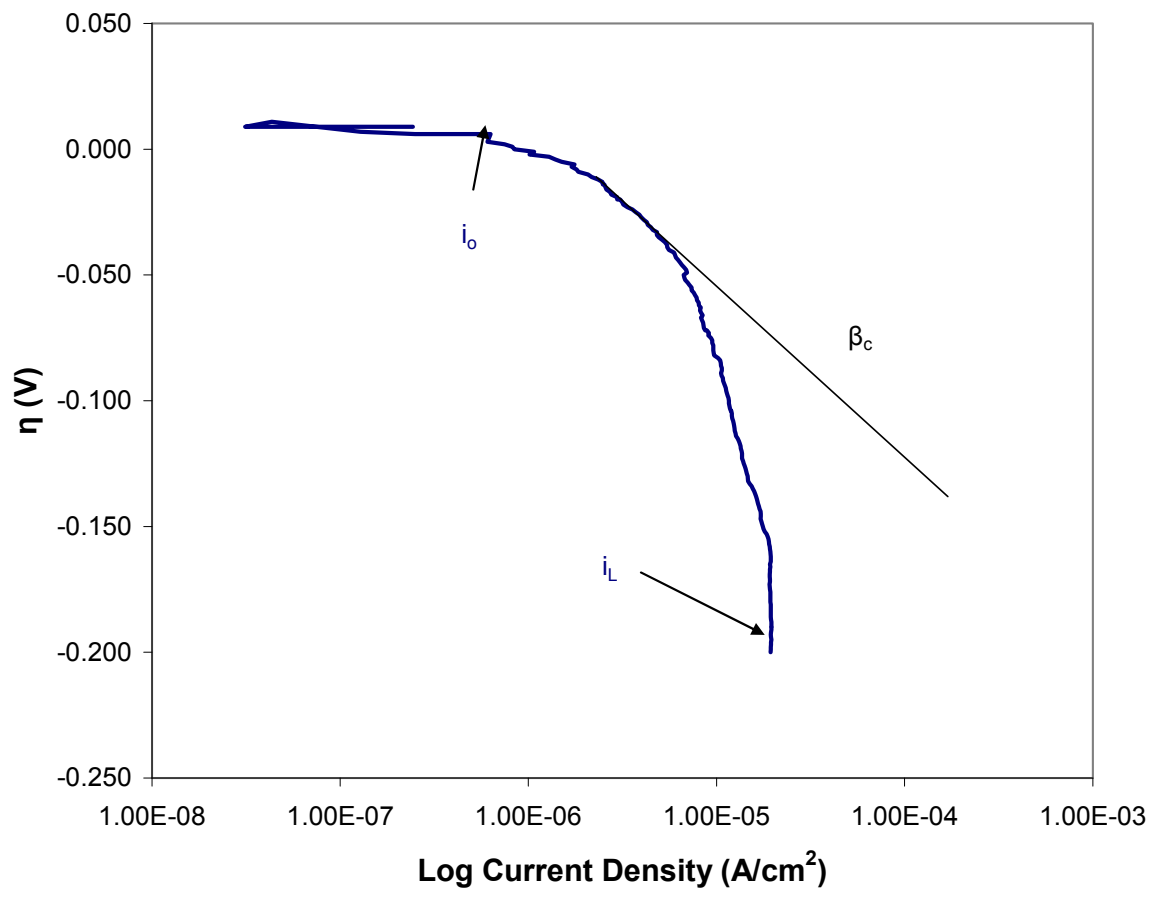

Figure 9. Example of Cathodic Polarization curve. 
The dominant term controlling the corrosion rate in many metals exposed to nonoxidizing acids, such as oxalic acid, is hydrogen overvoltage at cathodic areas of the metal. Hydrogen overvoltage is the difference of potential between a cathode at which hydrogen is being evolved, and a hydrogen electrode at equilibrium in the same solution. To determine if hydrogen is the cathodic reaction the following relationship is utilized:

$$
\alpha=2.3 \mathrm{R} \mathrm{T} /(\beta \mathrm{F})
$$

where $\alpha$ is the transfer coefficient, $\mathrm{R}$ is the universal gas constant equal to $1.99 \mathrm{cal} / \mathrm{mole}$ $\mathrm{K}, \mathrm{T}$ is the temperature in $\mathrm{K}$, and $\mathrm{F}$ is the Faraday constant equal to $23,061 \mathrm{cal} / \mathrm{V}$ equivalent. For iron and steel, $\alpha$ is typically between 0.4 and 0.6 if the hydrogen reaction is occurring.

Cyclic potentiodynamic polarization (CPP) was the final electrochemical test that was performed. CPP is utilized to investigate the susceptibility of a material to localized corrosion in a given environment. As a result, the protective or inhibitive capabilities of the oxalate film can be determined. A sample is exposed to the solution of interest and allowed to reach equilibrium. This test is initiated at a potential $50 \mathrm{mV}$ less than the OCP. A sequentially increasing potential is then applied to the sample. The current response to the change in potential is measured to establish a current-potential relationship. An example of this relationship is shown in Figure 10.

Various current responses that occur during the forward scan have been shown to be indicative of localized corrosion susceptibility. In particular, the breakdown potential, $\mathrm{E}_{\mathrm{b}}$, is the potential where the current increases rapidly with a small change in potential. This change has been correlated with a reduction in the passive nature of the material. The passive to active transition region shown in Figure 32 is the region in which the material is susceptible to localized corrosion. The smaller the difference between values of OCP and $\mathrm{E}_{\mathrm{b}}$, the more susceptible the material is to localized corrosion in that environment. The passive current density, $\mathrm{I}_{\mathrm{p}}$, is also indicative of the protective nature of the oxide film, or in this case the oxalate film. Lower passive current densities are indicative of a more stable protective film.

Data from the reverse scan as well as the forward scan are utilized for this purpose. The additional parameters that were evaluated included the repassivation potential, $\mathrm{E}_{\mathrm{rp}}$ and the observation of positive or negative hysteresis on the reverse scan. The following guidelines were also utilized to examine the CPP scans [29]:

- The differences of $E_{b}$ and $E_{r p}$ with OCP are a measure of the susceptibility of a material to localized attack in a given environment. When comparing a materials behavior in different environments, a larger difference indicates greater resistance to localized corrosion.

- If $\mathrm{E}_{\mathrm{rp}}$ is more negative than OCP, or if $\mathrm{E}_{\mathrm{rp}}$ is less than $200 \mathrm{mV}$ more positive than OCP, the material is susceptible to crevice corrosion in the environment. This guideline makes allowances for variability in the measurement of these potentials. 
- If the current density of the reverse scan is greater than that for the forward scan, localized corrosion is likely. This behavior is known as positive hysteresis.

- If the current density of the reverse scan is less than that for the forward scan, passive behavior is expected. This behavior is known as negative hysteresis.

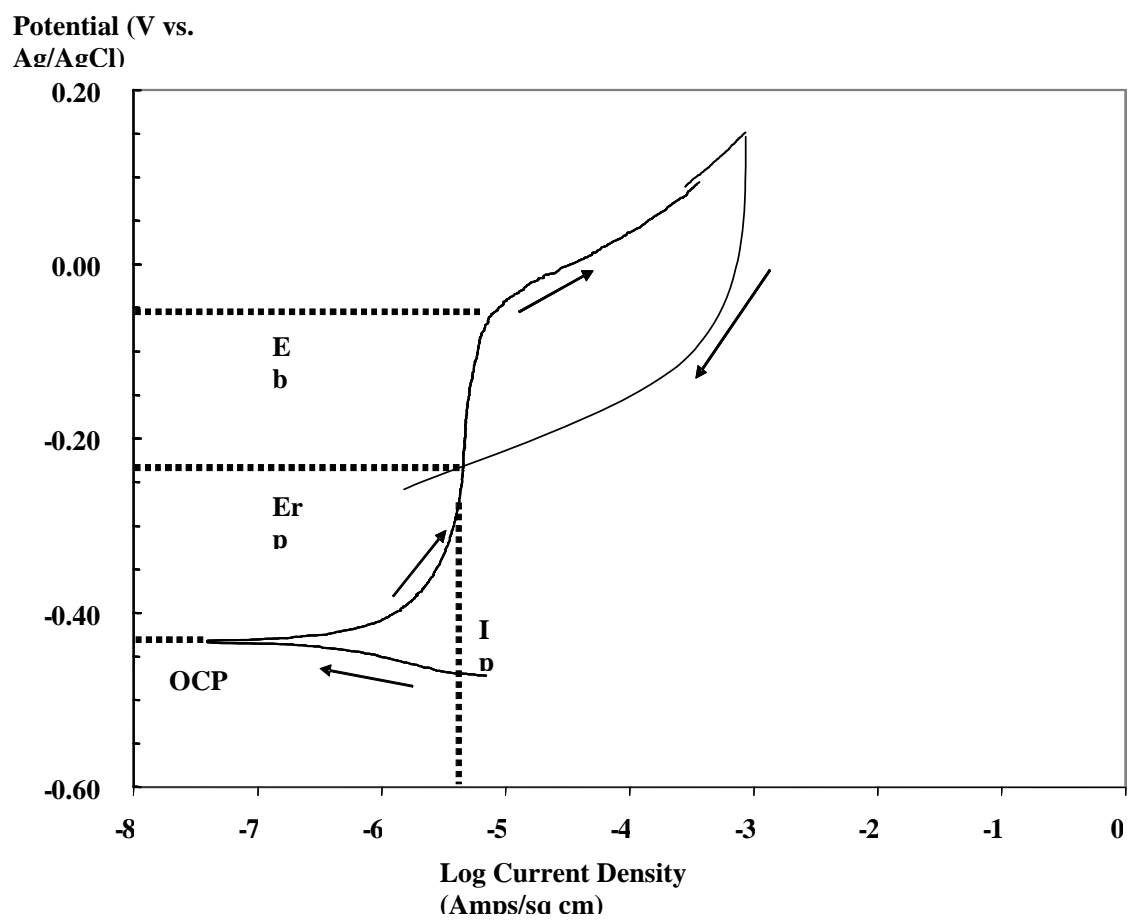

Figure 10. Plot of schematic CPP data showing characteristic potentials and currents.

\subsubsection{Coupon Immersion Tests}

The coupon immersion testing was conducted in a vessel with the coupon surface area to acid volume ratio representative of the ECC process (see Figure 11). The ratio utilized was comparable to a 5,000 gallon heel of sludge solids with 110,000 gallons of oxalic acid in a Type I or II waste tank. The matrix for the immersion tests in $1 \mathrm{wt} \%$ oxalic acid and $2.5 \mathrm{wt} . \%$ oxalic acid is shown in Table 6 and Table 7, respectively. Testing was performed using carbon steel coupons exposed to sludge simulant treated with either 1 $\mathrm{wt} \%$ or $2.5 \mathrm{wt} \%$ oxalic acid under both non-agitated (or minimal) and continuous vigorous mixing conditions. The coupons were weighed on an M\&TE calibrated balance to the nearest $0.0001 \mathrm{~g}$ prior to testing. The coupon dimensions were also measured to the nearest 0.001 inches with an M\&TE calibrated micrometer.

The solutions were maintained at a nominal $\mathrm{pH} 2$ or less through periodic refreshment with oxalic acid during the testing if necessary. The $\mathrm{pH}$ was checked daily on normal working days and acid refreshment was performed as needed. Two $\mathrm{pH}$ standards $(\mathrm{pH}$ 
1.68 and $\mathrm{pH} 4.1$ ) were utilized to calibrate the $\mathrm{pH}$ probe prior to performing the measurements. For $\mathrm{pH}$ levels less than 1.68, $\mathrm{pH}$ paper was utilized instead of the probe. The test duration was 28 or 30 days and test temperatures were 45 and $75{ }^{\circ} \mathrm{C}$ for the tests in $1 \mathrm{wt} . \%$ oxalic acid and 50 and $75^{\circ} \mathrm{C}$ for the tests in $2.5 \mathrm{wt} . \%$ oxalic acid.

At the completion of the test, the coupons were removed from the test vessel for visual examination. During this examination, the form of corrosion on each coupon was identified (e.g., general) and differences in the corrosion products were noted. Photographs were taken to document these results. ASTM standard practices were followed to determine the general corrosion rate [30]. The corrosion products were removed from the sample by a two step process. First, loose corrosion products were removed using a wire brush. The coupons were then immersed in Clarke's solution (i.e., an inhibited $\mathrm{HCl}$ acid solution) to remove the final corrosion products. After removal of the corrosion products, the coupons were weighed on an M\&TE calibrated balance to determine the resultant weight loss.

Solid samples were collected from the coupon surface and submitted for x-ray diffraction (XRD) analysis for identification. Scanning electron microscopy (SEM) and energy dispersive spectroscopy (EDS) were also utilized to examine the coupons. A sample of the remaining liquid in the test vessel was also submitted for post-test characterization. Ion chromatography (IC) was performed to identify the concentrations of anions, while inductively coupled plasma emission spectroscopy (ICP-ES) was performed to identify the concentrations of the elements in the final solution.

Table 6. Matrix for Immersion Testing for 1 wt. \% Oxalic Acid

\begin{tabular}{|c|c|c|c|}
\hline Test & Temperature $\left({ }^{\circ} \mathrm{C}\right)$ & Simulant & Agitiation (Yes/No) \\
\hline 1 & 45 & PUREX & Yes \\
\hline 2 & 45 & HM & Yes \\
\hline 3 & 45 & HM-PUREX & Yes \\
\hline 4 & 45 & PUREX & No \\
\hline 5 & 45 & HM & No \\
\hline 6 & 45 & HM-PUREX & Yes \\
\hline 7 & 75 & PUREX & Yes \\
\hline 8 & 75 & HM & Yes \\
\hline 9 & 75 & HM-PUREX & No \\
\hline 10 & 75 & PUREX & No \\
\hline 11 & 75 & HM-PUREX & \\
\hline 12 & 75 & &
\end{tabular}


Table 7. Matrix for Immersion Testing for 2.5 wt. \% Oxalic Acid

\begin{tabular}{|c|c|c|c|}
\hline Test & Temperature $\left({ }^{\circ} \mathrm{C}\right)$ & Simulant & Agitation (Y/N) \\
\hline 1 & 50 & $\begin{array}{c}\text { PUREX and } 2.5 \text { wt. } \% \\
\text { oxalic acid }\end{array}$ & $\mathrm{Y}$ \\
\hline 2 & 50 & $\begin{array}{c}\text { HM and } 2.5 \text { wt.\% oxalic } \\
\text { acid }\end{array}$ & $\mathrm{Y}$ \\
\hline 3 & 50 & 2.5 wt.\% oxalic acid & $\mathrm{N}$ \\
\hline 4 & 50 & $\begin{array}{c}\text { PUREX and } 2.5 \text { wt. } \% \\
\text { oxalic acid }\end{array}$ & $\mathrm{N}$ \\
\hline 5 & 50 & $\begin{array}{c}\text { HM and } 2.5 \text { wt.\% oxalic } \\
\text { acid }\end{array}$ & $\mathrm{N}$ \\
\hline 6 & 50 & 2.5 wt.\% oxalic acid & $\mathrm{Y}$ \\
\hline 7 & 75 & $\begin{array}{c}\text { PUREX and } 2.5 \text { wt. } \% \\
\text { oxalic acid }\end{array}$ & $\mathrm{Y}$ \\
\hline 8 & 75 & $\begin{array}{c}\text { HM and } 2.5 \text { wt.\% oxalic } \\
\text { acid }\end{array}$ & $\mathrm{Y}$ \\
\hline 9 & 75 & 2.5 wt.\% oxalic acid & $\mathrm{N}$ \\
\hline 10 & 75 & $\begin{array}{c}\text { PUREX and } 2.5 \text { wt. } \% \\
\text { oxalic acid }\end{array}$ & $\mathrm{N}$ \\
\hline 11 & 75 & $\begin{array}{c}\text { HM and } 2.5 \text { wt.\% oxalic } \\
\text { acid }\end{array}$ & $\mathrm{N}$ \\
\hline 12 & 75 & 2.5 wt.\% oxalic acid & \\
\hline
\end{tabular}




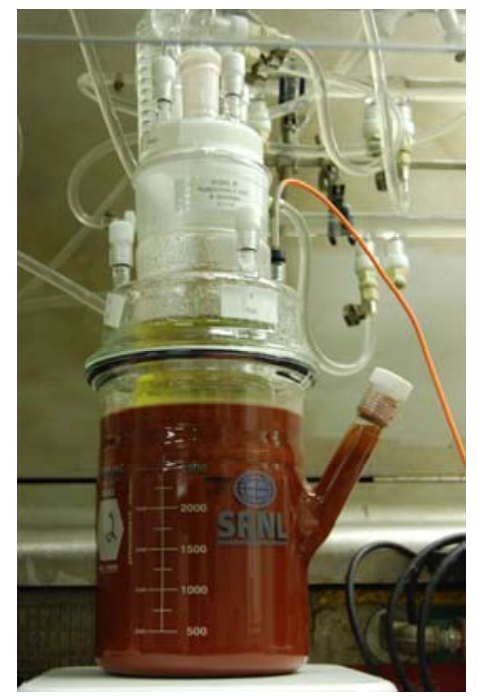

Figure 11. Vessel for Coupon Tests

\subsection{Results and Discussion}

\subsection{Electrochemical Tests}

\subsubsection{Open Circuit Potential (OCP) Monitoring}

The change in the OCP due to the presence of dissolved sludge species in the oxalic acid was examined initially. Figure 12 shows the two hour OCP transient for each sludge simulant type and compares it with $1 \mathrm{wt} . \%$ oxalic acid (OA) and the calculated hydrogen evolution potential. Each test was performed at $75{ }^{\circ} \mathrm{C}$ under agitated conditions. The figure shows that hydrogen evolution is possible in the OA solution, while the presence of the sludge simulants in the OA have shifted the potential toward more positive values in the other three solutions. The most noticeable effect occurred for the HM simulant. Initially the potential at the steel surface was at a potential where hydrogen evolution was possible. However, after about 10 minutes the potential shifted dramatically in the positive direction to a potential where hydrogen evolution is not possible. This shift may be due to a dissolved oxidizing species which achieved a critical concentration in the solution at this time. The shift may also reflect the time it takes to build-up an adherent oxide on the surface. A careful examination of the OCP during the initial measurements shows a gradual increase in the potential indicating the development of the oxalate film. One of the mechanisms that could impede the development of the film is the presence of species that are soluble with the ferrous ion. If the HM simulant has a lower concentration of these species, the development of the film may occur at a faster rate.

Similar shifts have been observed in PUREX wastes as well $[1,18]$. However, the shifts were observed after longer exposure times, perhaps indicating that a different chemistry with slower kinetics. On the other hand the PUREX and HM-PUREX simulants may 
have contained a greater quantity of a species that is soluble with the ferrous ion and thereby mitigated the development of an adherent oxalate film.

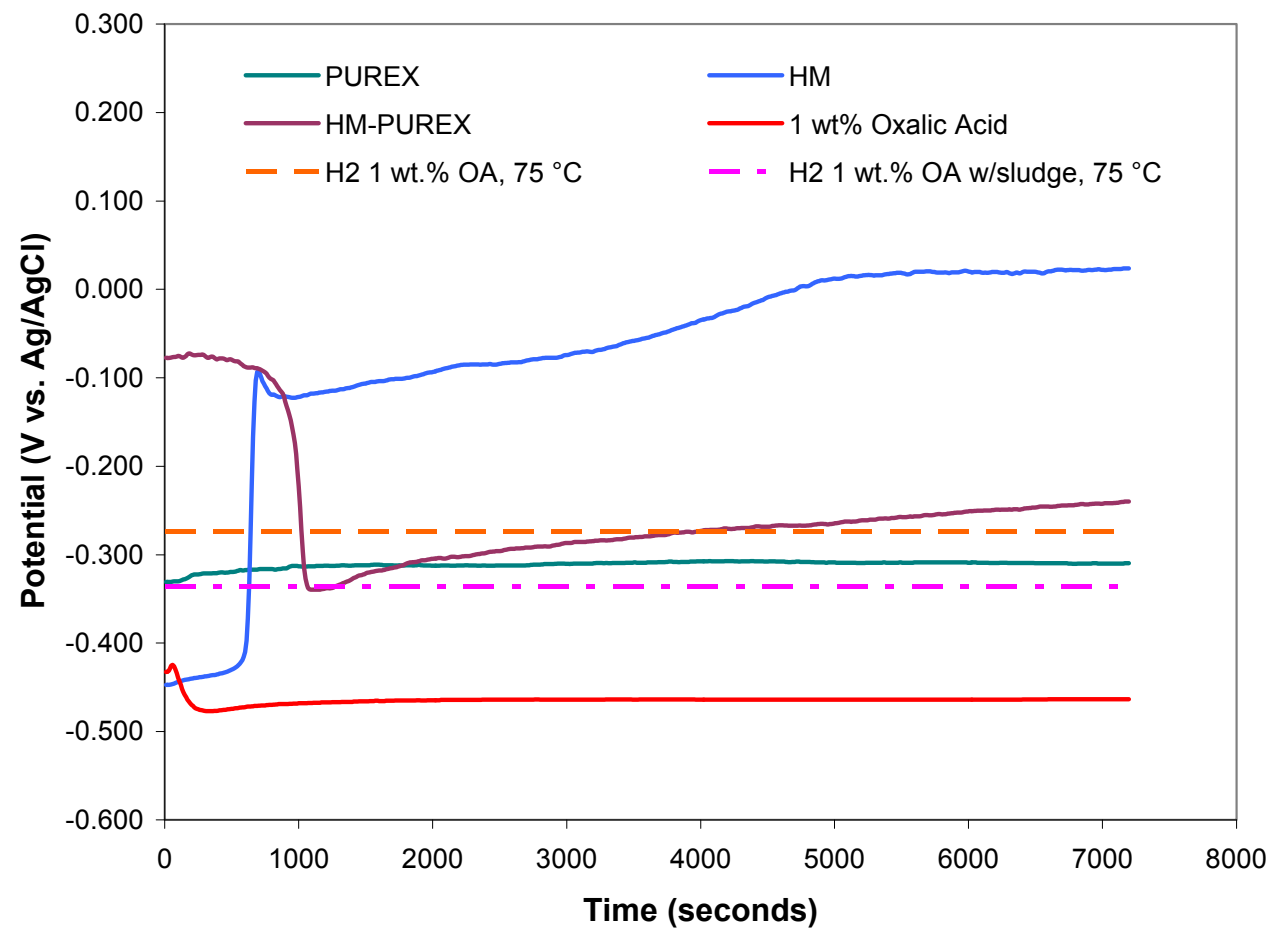

Figure 12. Effect of test simulant on the OCP for agitated solutions that contain 1 wt. \% oxalic acid at $75{ }^{\circ} \mathrm{C}$.

Figure 13 shows a comparison between the OCP transients for HM and PUREX sludge simulants with $2.5 \mathrm{wt} \% \mathrm{OA}$ and that for pure $2.5 \mathrm{wt} . \% \mathrm{OA}$. These tests were performed under agitated conditions at a temperature of $75^{\circ} \mathrm{C}$. As with the $1 \mathrm{wt} \% \% \mathrm{OA}$, the OCP for the $2.5 \mathrm{wt} . \%$ OA after an initial transient remained constant at a value well below the hydrogen equilibrium potential. The initial peak in this transient was also observed for the $8 \mathrm{wt} . \% \mathrm{OA}$, only in that case the maximum potential was approximately $-0.100 \mathrm{~V}$ vs. $\mathrm{Ag} / \mathrm{AgCl}$ before it decayed to a level of approximately $-0.400 \mathrm{~V}$ vs. $\mathrm{Ag} / \mathrm{AgCl}$ [18]. This early transient is possibly associated with the formation of the passive ferrous oxalate film. For both sludge simulants with $2.5 \mathrm{wt} . \%$ OA a dramatic shift in the OCP was observed 10-35 minutes after the start of the test. A similar shift was observed for HM simulant with $1 \mathrm{wt} . \%$ OA, but not for the case of the PUREX simulant. The noticeable difference between the two sludge simulants is that the OCP for the HM remains at a more positive potential, while the OCP for PUREX decays to a constant value after one hour that is approximately the same as that for the $1 \mathrm{wt} . \% \mathrm{OA}$. These potential shifts are again thought to be associated with the dissolution of an oxidizing species and/or the development of the passive film. In all cases, the OCP remains at more positive values 
likely due to the presence of electroactive dissolved species that drive the cathodic reactions.

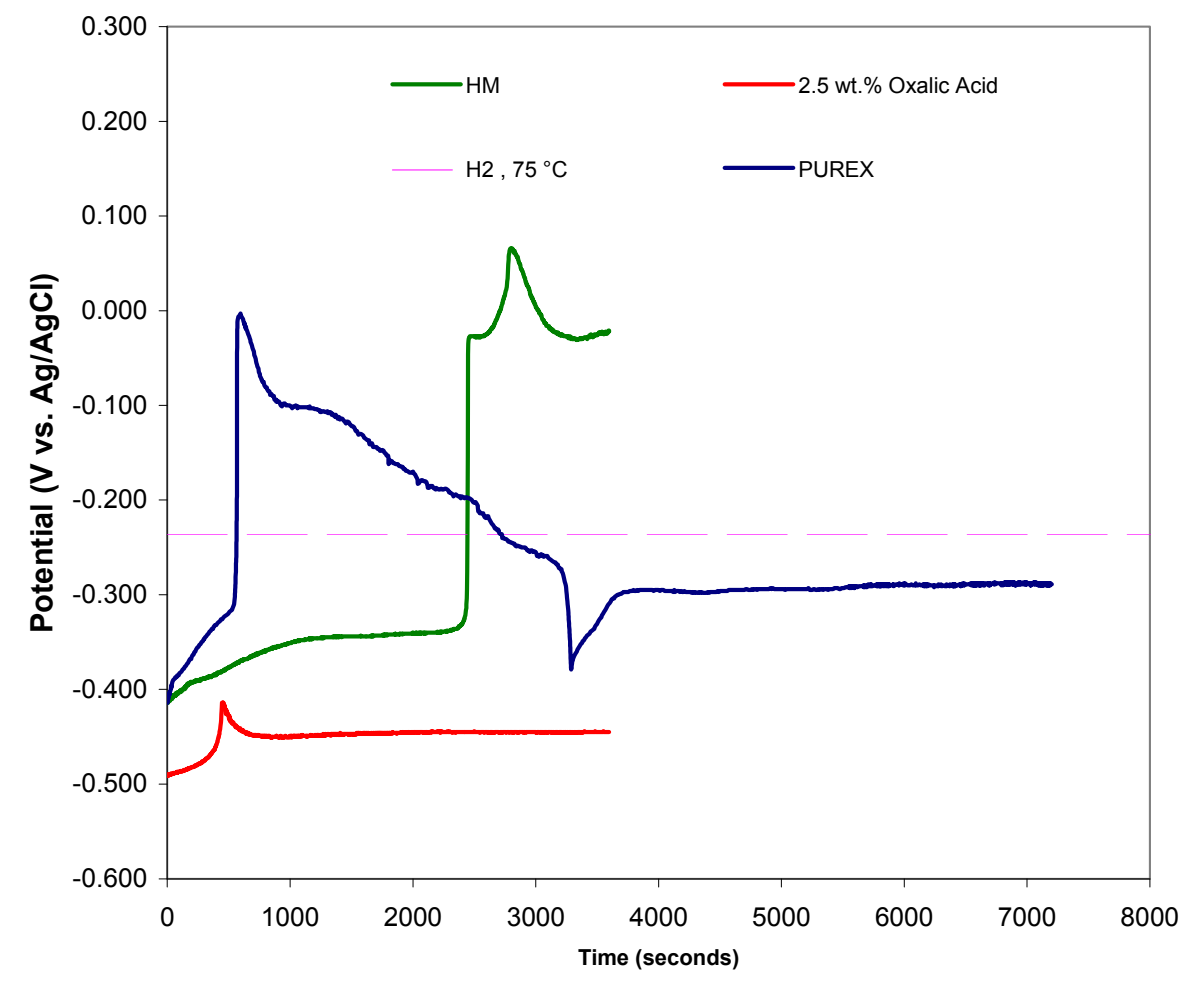

Figure 13. Effect of test simulant on the OCP for agitated solutions that contain 2.5 wt.\% oxalic acid at $75{ }^{\circ} \mathrm{C}$.

The increase in the OCP was less noticeable for the sludge simulants with $1 \mathrm{wt} . \% \mathrm{OA}$ at $45{ }^{\circ} \mathrm{C}$ (see Figure14) than at the higher temperatures. In fact, the potential for all but the $\mathrm{HM}$ waste remained in the regime where hydrogen evolution is possible. The potential shift in the HM simulant was observed again, although it occurred after a longer exposure time and the potential is at a lower value. This observation coupled with the relative instability of the potential relative to that observed at the higher temperature may indicate that the oxalate film that has formed is less adherent than that which develops at the higher temperatures. Additionally, the potential shift may be due to the presence of a dissolved oxidizing species in the HM simulant; the kinetics of the dissolution, or mass transport of the electroactive species, appears to be temperature dependent. The potentials for the PUREX and the HM-PUREX simulants are similar to that for the 1 wt.\% oxalic acid. Either the solutions do not contain sufficient amount of the dissolved oxidizing species, or other species are present that mitigate the build-up of the passive oxalate film. It is not known whether a potential shift would have occurred after longer exposure times in these simulants. 


\section{Revision 1}

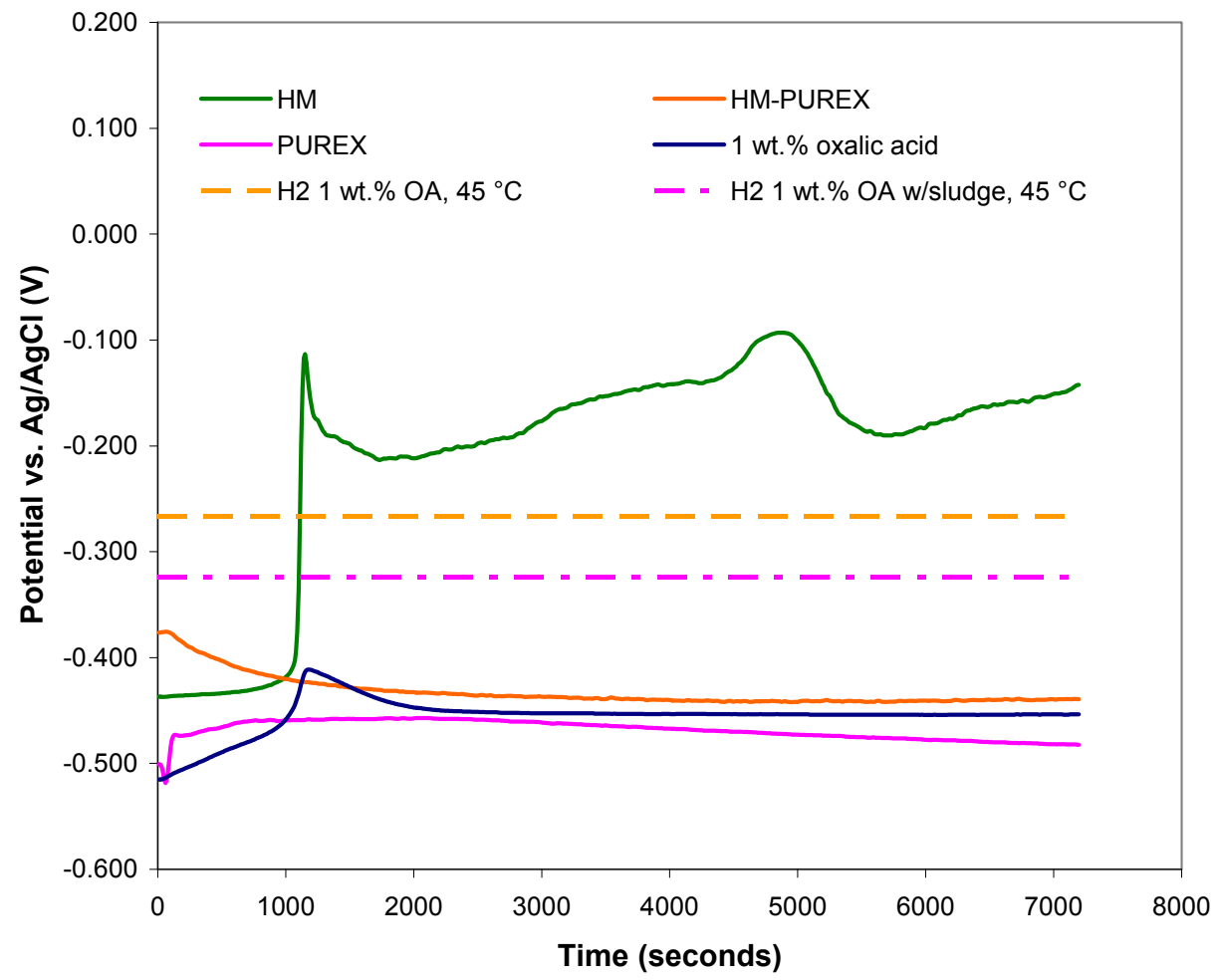

Figure 14. Effect of test simulant on the OCP for agitated solutions that contain 1 wt. \% oxalic acid at $45^{\circ} \mathrm{C}$.

The same shift in the OCP was observed for the sludge simulants with the $2.5 \mathrm{wt} . \% \mathrm{OA}$ (see Figure 15) for tests conducted at $50{ }^{\circ} \mathrm{C}$ with agitation. In contrast to the $1 \mathrm{wt} . \% \mathrm{OA}$ tests, however, the OCP for both HM and PUREX shift dramatically and remain above the hydrogen equilibrium potential at approximately $-0.050 \mathrm{~V}$ vs. $\mathrm{Ag} / \mathrm{AgCl}$. This result suggests that a sufficient quantity of the electroactive dissolved species is present in the solution to drive the cathodic reactions for both the HM and PUREX. 


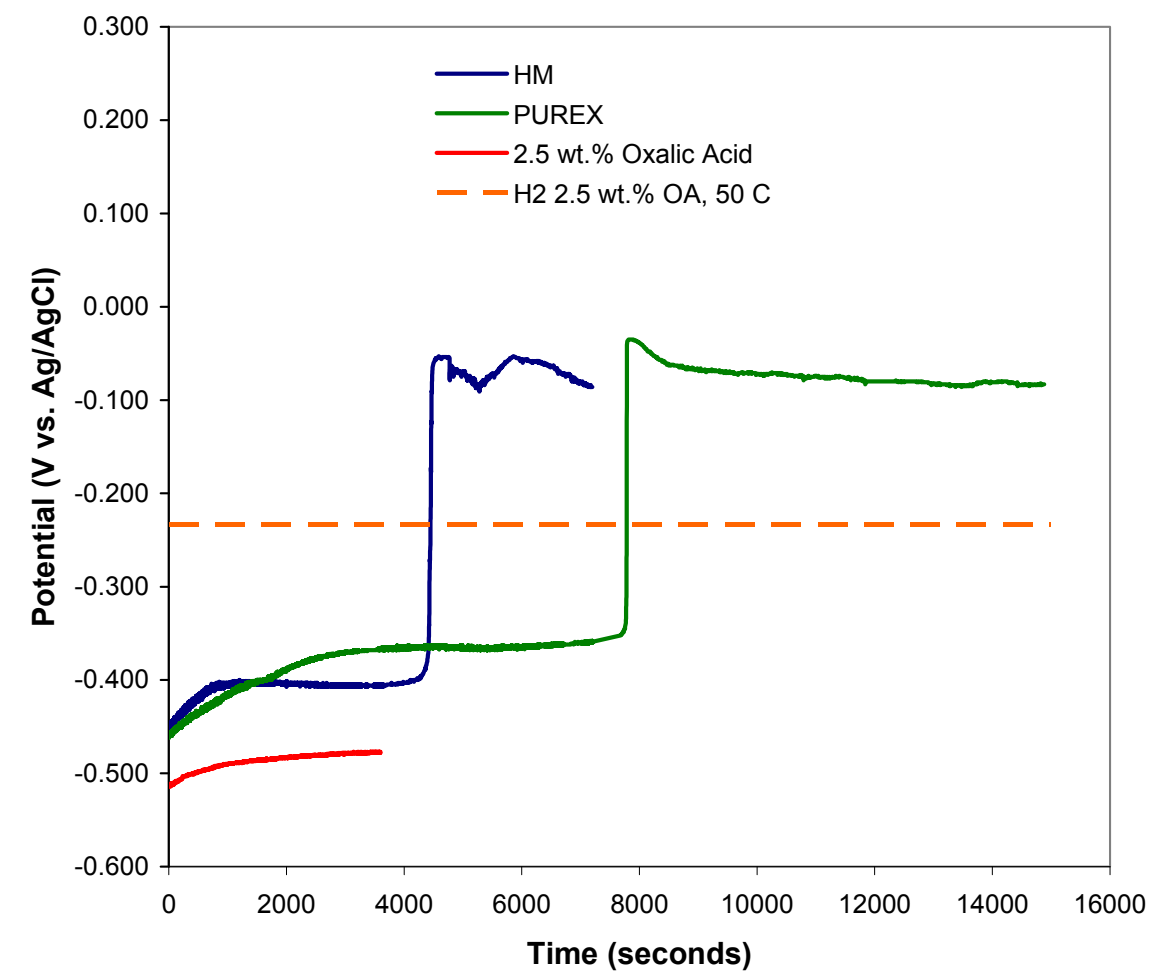

Figure 15. Effect of test simulant on the OCP for agitated solutions that contain 2.5 wt. \% oxalic acid at $45^{\circ} \mathrm{C}$.

It is clear from these OCP results that the presence of a sludge simulant in the oxalic acid has a significant impact on the corrosion behavior within the first two hours of exposure. The effect of temperature, agitation, and aeration on the potential in oxalic acid and each simulant were examined next.

Figure 16 shows the effect of temperature on the OCP for carbon steel in an agitated 1 wt.\% oxalic acid solution. The potential measured at $75^{\circ} \mathrm{C}$ was slightly lower than that measured at $45^{\circ} \mathrm{C}$. Hydrogen evolution is possible at both temperatures. In both cases, the OCP shifts in the noble direction for a short time before returning to a constant stable value. This shift is likely associated with the formation of the ferrous oxalate film on the surface. The shift occurs earlier for the $75^{\circ} \mathrm{C}$ test than the $45^{\circ} \mathrm{C}$ test, which suggests that passivation is occurring more rapidly at the higher temperature. Once the film forms, the OCP returns to a steady state value where the iron dissolution reaction, either reaction (4) or (5), is supported by the cathodic hydrogen evolution reaction. The steady state OCP for the $75^{\circ} \mathrm{C}$ test is more active than the $45^{\circ} \mathrm{C}$ test, which indicates that the corrosion rate is likely higher at this temperature. 


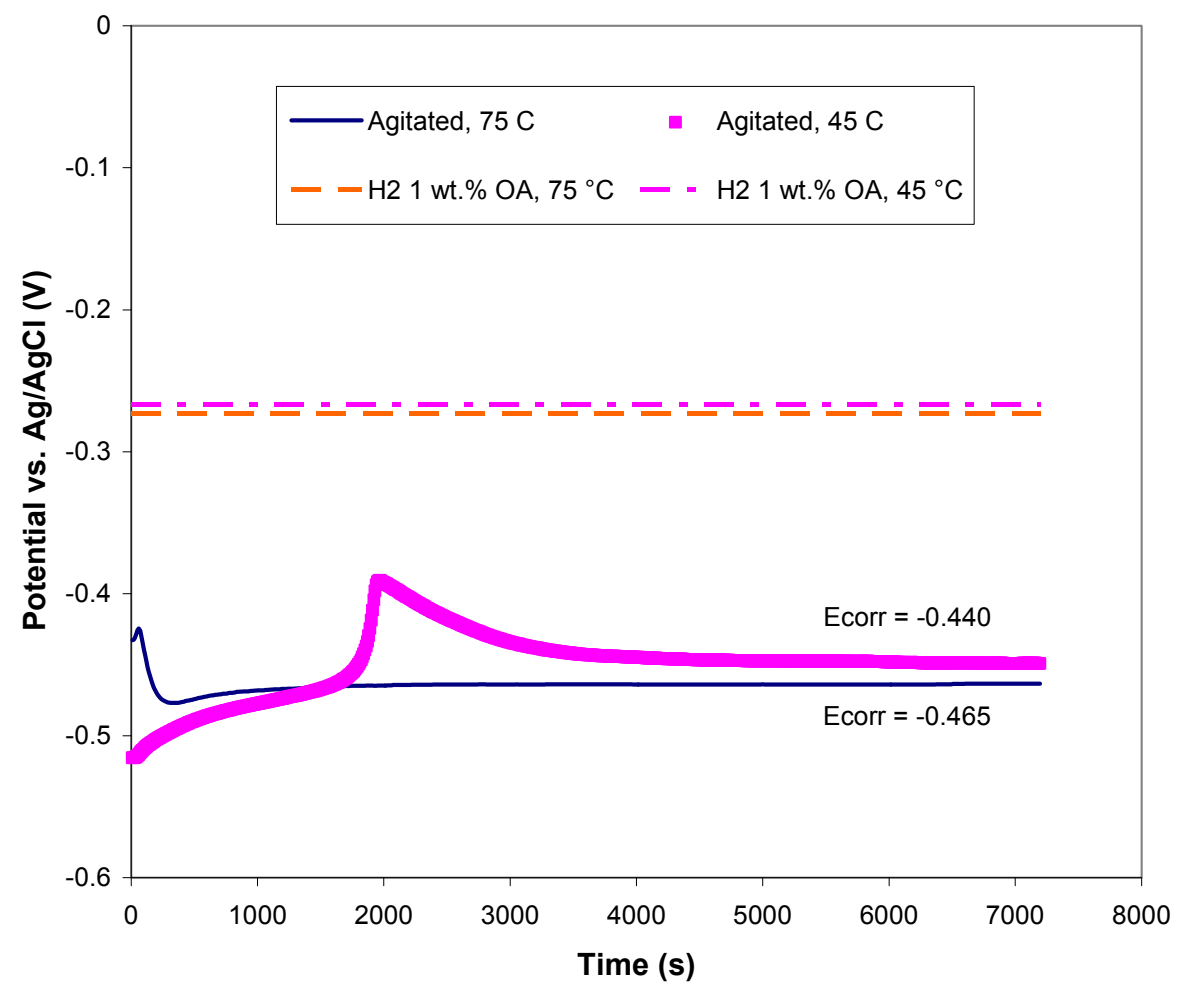

Figure 16. OCP transients for 1 wt. \% oxalic acid in an agitated solution at 45 and $75^{\circ} \mathrm{C}$.

Figure 17 shows the effect of temperature on the OCP for carbon steel in a non-agitated 1 wt.\% oxalic acid solution. It should be noted that in this case the OCP is measured over a period of days, rather than the first couple of hours. In this situation, the $\mathrm{OCP}$ at $75^{\circ} \mathrm{C}$ is noble to the potential measured at $45^{\circ} \mathrm{C}$. This observation is likely due to differences in the passive oxalate film. For the higher temperature case, the high rate of corrosion allows the ferrous ion to become supersaturated at the metal surface. Consequently a relatively non-porous oxalate film forms. This result indicates that the corrosion rate at $45^{\circ} \mathrm{C}$ would be greater than that measured at $75^{\circ} \mathrm{C}$ after approximately one day of exposure. Hydrogen evolution is still likely at both temperatures.

A comparison of Figures 16 and 17 also demonstrates the effect of agitation at each temperature. At $75^{\circ} \mathrm{C}$, the potential in the non-agitated solution is approximately 0.075 $\mathrm{V}$ greater than that in the agitated solution. This shift can be explained by the initial build-up of ferrous ions immediately adjacent to the metal surface and the resultant adherent structure of the oxalate film for the non-agitated solution at this temperature. For the $45^{\circ} \mathrm{C}$ case there was less of an effect, in fact, the potential in the agitated solution was slightly less. As suggested above, there is likely less ferrous ion being produced at the lower temperature, therefore the rate at which the ferrous oxalate film forms will be slower. The slower rate of formation will result in a more porous oxalate film. 


\section{Revision 1}

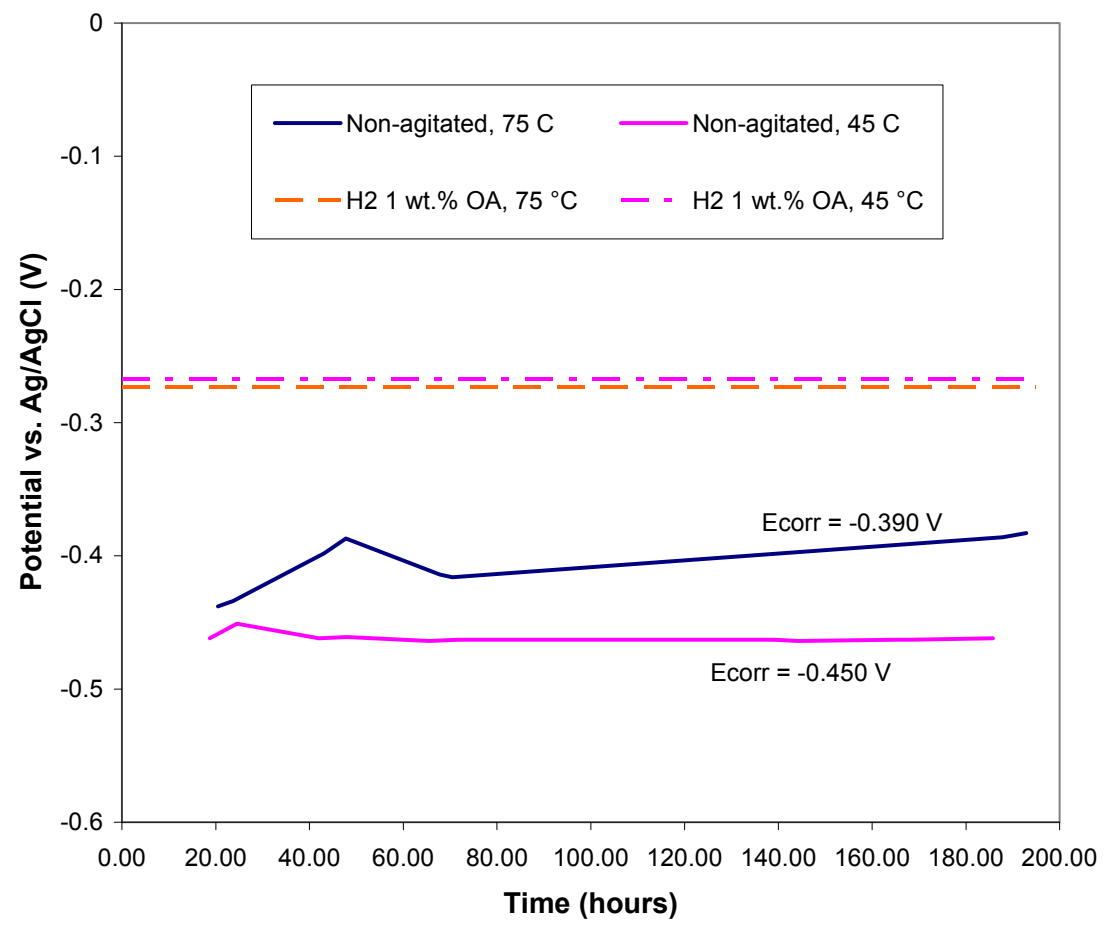

Figure 17. OCP transients for 1 wt. \% oxalic acid in a non-agitated solution at 45 and $75^{\circ} \mathrm{C}$.

Figure 18 shows the effect of temperature on the OCP for carbon steel in agitated and non-agitated $2.5 \mathrm{wt} \% \%$ oxalic acid solution. The results for both $50^{\circ} \mathrm{C}$ and $75^{\circ} \mathrm{C}$ are shown with and without agitation. At $75^{\circ} \mathrm{C}$, the OCP shifts in the noble direction for a short time before returning to a constant stable value. This shift was also observed for 1 wt. \% oxalic acid acid, and is likely associated with the formation of the ferrous oxalate film on the surface. There is not a significant difference in the time at which the shift in OCP occurs, which indicates that agitation at this temperature does not have a significant impact on the formation of the ferrous oxalate film. The lower steady state OCP for agitation once again suggests a higher corrosion rate for the agitated case versus the nonagitated at these initial times. Once the film forms, the OCP returns to a steady state value where the iron dissolution reaction, either reaction (4) or (5), is supported by the cathodic hydrogen evolution reaction. Hydrogen evolution is possible for both the agitated and non-agitated condition.

At $50{ }^{\circ} \mathrm{C}$, the shift in the OCP is not as apparent. However, it should be noted that the OCP is still gradually increasing at the end of 1 hour. The shift in the OCP may have occurred after the OCP measurements were halted. Thus at the lower temperature, the time for complete passivation simply is taking longer. The potential measured at $50{ }^{\circ} \mathrm{C}$ was slightly lower than that measured at $75^{\circ} \mathrm{C}$ after 1 hour. If the OCP shift were to take place after 1 hour, it seems likely that the steady state $\mathrm{OCP}$ for $50^{\circ} \mathrm{C}$ test, for both agitated and non-agitated, would be greater than that for the $75^{\circ} \mathrm{C}$ test. Thus the 
corrosion rate at $75^{\circ} \mathrm{C}$, at least initially, would be greater than at $50{ }^{\circ} \mathrm{C}$. As before hydrogen evolution is the likely cathodic reaction at $50^{\circ} \mathrm{C}$ as well.

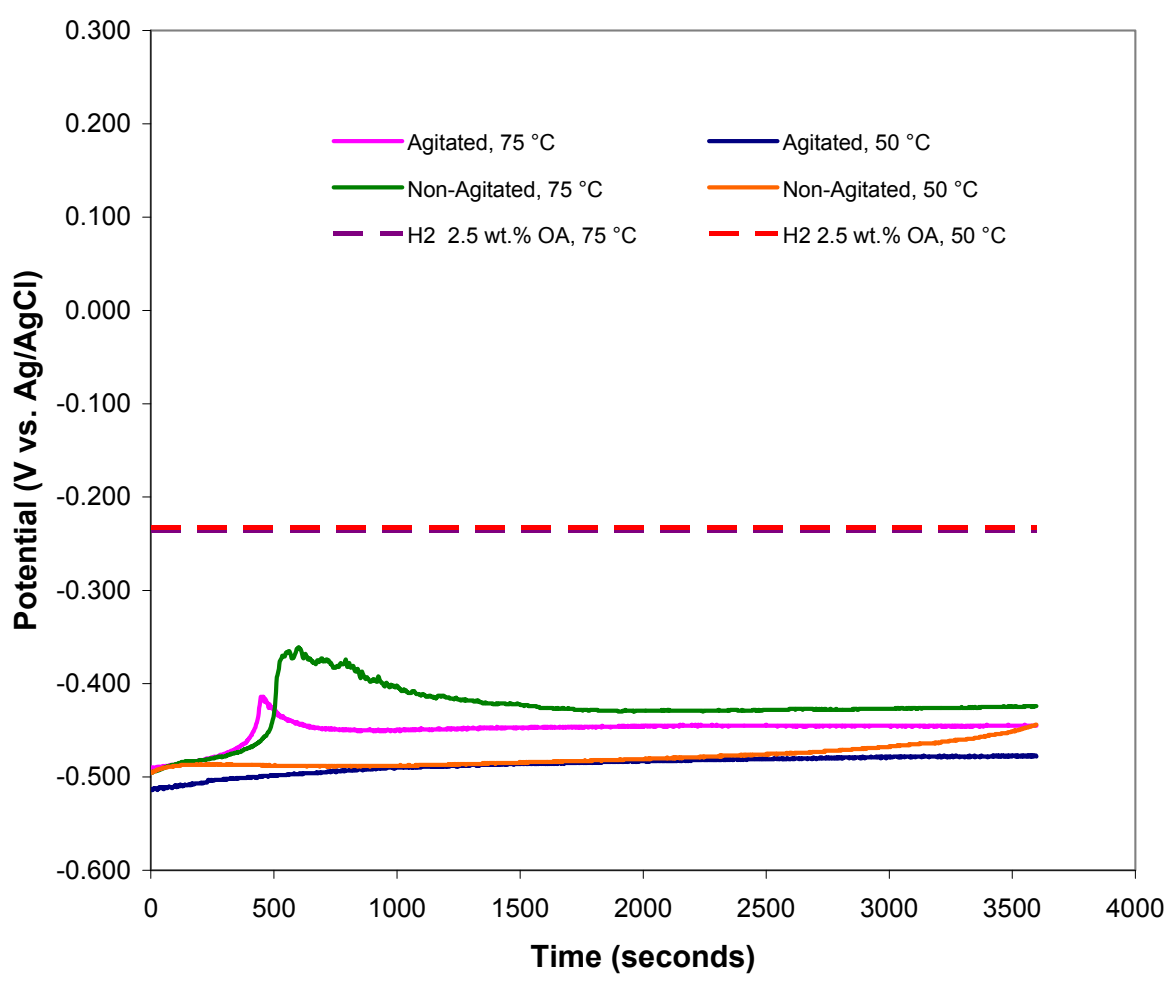

Figure 18. OCP transients for $2.5 \mathrm{wt}$ \% oxalic acid in an agitated and non-agitated solutions at 50 and $75^{\circ} \mathrm{C}$.

Figure 19 shows the effect of temperature and agitation on the OCP transient in the HM/ 1 wt.\% oxalic acid simulant mixture. In all cases the final OCP after two hours of exposure indicates that hydrogen evolution is not occurring. Initially the OCP is at a condition where hydrogen evolution is possible. In this situation the potential for the agitated solution is more positive than that for the solution that is not agitated. It is interesting to note that the initial relationships between the potentials are similar to that for the $1 \mathrm{wt} . \%$ oxalic acid. However, the OCP continuously increased in all cases, which indicates that the ferrous oxalate film is forming. Once the OCP shifts to values where hydrogen evolution is not occurring, the potential is more positive and stable in the nonagitated solution. The observation of a less stable and more negative potential is indicative that the oxalate film is less protective. Removal of the ferrous ion from the region adjacent to the metal surface due to agitation is likely responsible for this less protective oxalate. Additionally, it is observed that the potential shift occurs at an earlier time with the agitated solution. This shift may indicate that the dissolved oxidizing species or the species that is soluble with the ferrous ion is more readily available at the surface due to the agitation. Thus, these observations could be explained by all three of the mechanisms that mitigate the development of the passive oxalate layer. 
Figure 19 also shows that higher temperatures result in a more positive, stable potential for the given agitated condition. For example in the non-agitated condition, the stable potential is approximately $200 \mathrm{mV}$ greater for the test that was conducted at $75^{\circ} \mathrm{C}$ compared to that at $45^{\circ} \mathrm{C}$. The same is true for the agitated condition, although to a lesser degree. The potential shift also occurred at earlier times for the higher temperature simulant. From these results, it is clear that the higher temperatures result in a more stable oxalate film.

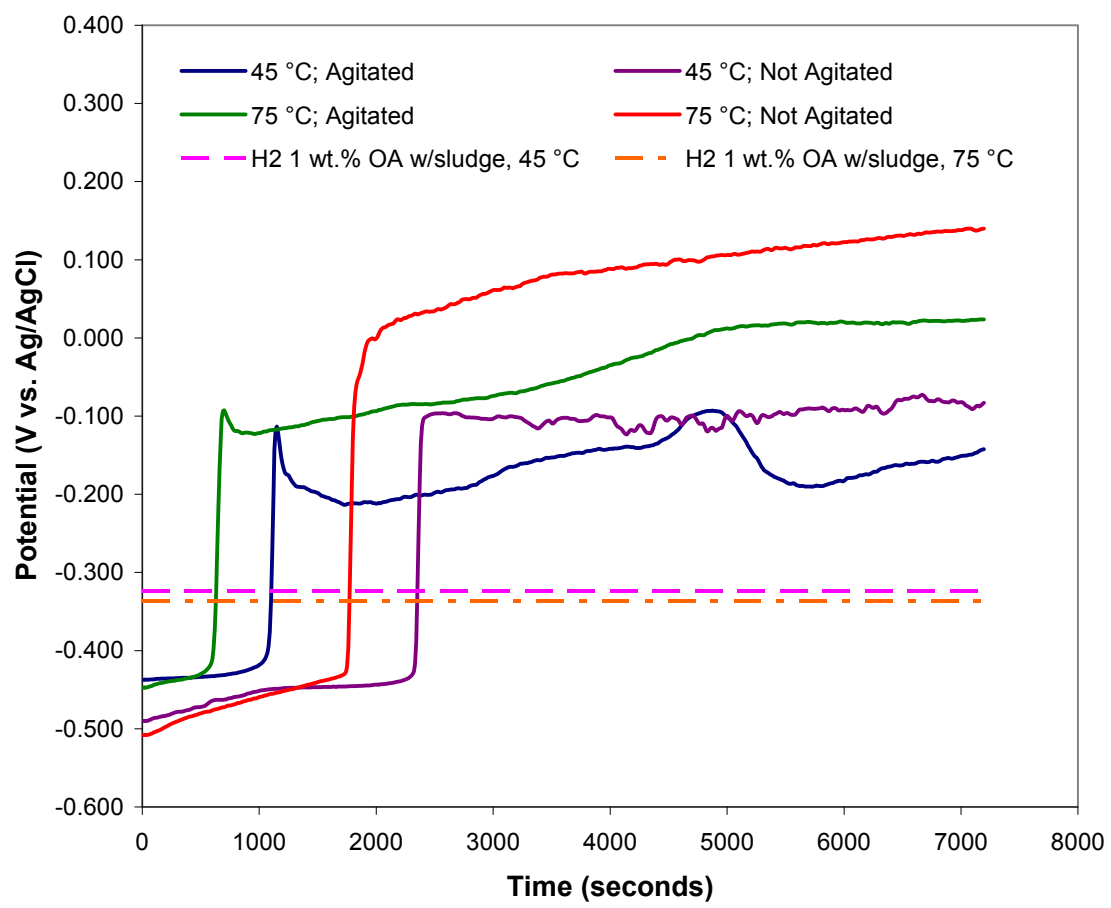

Figure 19. OCP transients for HM sludge simulant/1 wt.\% oxalic acid mixtures.

Figure 20 shows the effect of temperature and agitation on the OCP transient in the HM/ 2.5 wt. $\%$ oxalic acid simulant mixture. In all cases the final OCP indicates that hydrogen evolution is not occurring. Initially the potential is at a condition where hydrogen evolution is possible. However, polarization curves measured at this early stage of the process indicate that a transport limited cathodic reaction is occurring (see section 4.1.3). Thus, the primary cathodic reaction is again likely due to the electro-active species that are dissolving in the solution. At this stage the potential for the agitated solution is more positive than that for the solution that is not agitated. However, the potential is continuously increasing in all cases, which indicates that the ferrous oxalate film is forming. The OCP shift occurs earlier in the agitated solutions than for the non-agitated solutions. This observation again reflects the fact that the cathodic reaction is transport controlled and therefore dependent upon the concentration of the electro-active species in solution. Agitation likely promotes the dissolution of these species. 
Figure 20 also shows that the shift in the OCP occurs earlier for the higher temperature tests than the lower temperature tests. For example in the non-agitated condition, the OCP shifted for the $75^{\circ} \mathrm{C}$ test shifted approximately 2 hours before the shift was observed at $50{ }^{\circ} \mathrm{C}$. The same is true for the agitated condition, although to a lesser degree. The potential shift also occurred at earlier times for the higher temperature simulant. From these results, it is clear that the higher temperatures result in a more stable oxalate film. This observation again reflects the fact that the cathodic reaction is transport controlled and therefore dependent upon the concentration of the electro-active species in solution. Higher temperatures likely promote the dissolution of these species.

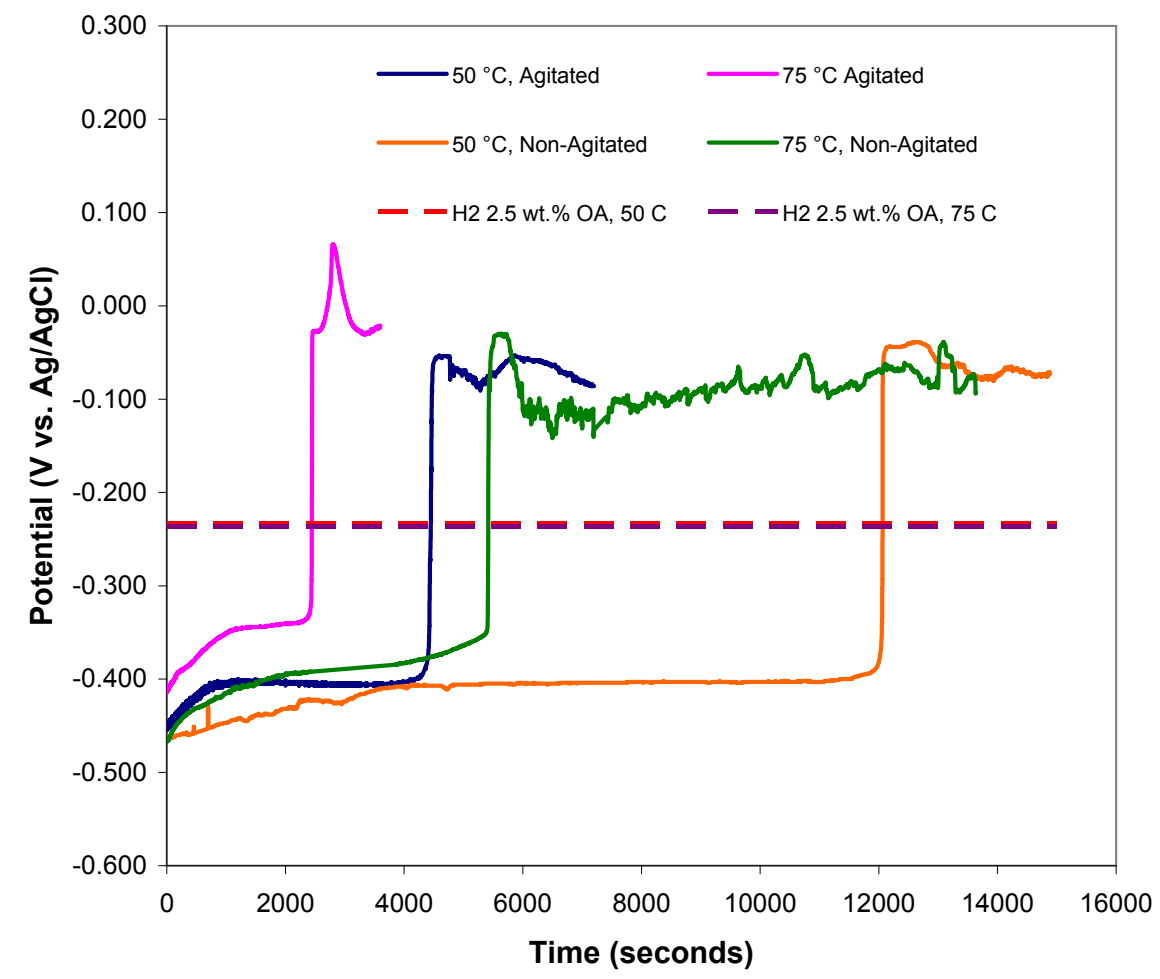

Figure 20. OCP transients for HM sludge simulant/2.5 wt. \% oxalic acid mixtures.

A comparison between Figures 19 and 20 provide an insight into the differences between utilizing $1 \mathrm{wt} . \%$ oxalic acid and $2.5 \mathrm{wt} . \%$ oxalic acid. At $50{ }^{\circ} \mathrm{C}$, the $\mathrm{OCP}$ after the shift is approximately the same indicating that there were no significant changes in the cathodic and anodic reactions. Thus, no significant difference in the observed corrosion rates for the $1 \mathrm{wt} . \%$ and the $2.5 \mathrm{wt}$ \% oxalic acid at this temperature would be expected. However, at $75{ }^{\circ} \mathrm{C}$, the potential is noticeably more active with the $2.5 \mathrm{wt} . \%$ tests than with the 1 wt. $\%$ tests. This result suggests that the rate of the cathodic reaction is significantly greater at the higher temperature. Thus, the corrosion rate at $75{ }^{\circ} \mathrm{C}$ would be expected to be greater than at $50^{\circ} \mathrm{C}$.

Figure 21 shows the effect of temperature and agitation on the OCP transient in the PUREX/1 wt.\% oxalic acid simulant mixture. In three of the four cases, the final 
potential after two hours of exposure indicates that hydrogen evolution may be occurring. The high temperature agitated condition is the only case where the OCP is clearly morenoble than the equilibrium potential for hydrogen evolution. Although the OCP for the $75^{\circ} \mathrm{C}$, agitated condition is close to this potential and appears to be rising. Based on the results of polarization scans performed, it is possible that the OCP shifts at a later time. Thus, once the ferrous oxalate forms on the surface, the same shift in the OCP may be observed. Agitation appears to result in a more noble and stable OCP at both temperatures. This may indicate that the dissolved oxidizing species, or the species that is soluble with the ferrous ion, is more readily available at the surface due to the agitation. At $45{ }^{\circ} \mathrm{C}$, the results appear to be very similar to that for the $1 \mathrm{wt} . \%$ oxalic acid. This result seems to indicate that very little of the electro-active species is dissolving in solution and reacting. At this time it appears that for this temperature hydrogen evolution could be a factor, at least initially.

Figure 21 also shows that the OCP for the $75^{\circ} \mathrm{C}$ tests is more noble than the OCP for the $45^{\circ} \mathrm{C}$. For example in the non-agitated condition, the stable potential is approximately $150 \mathrm{mV}$ greater for the test that was conducted at $75^{\circ} \mathrm{C}$ compared to that at $45^{\circ} \mathrm{C}$. The same is true for the agitated condition. The results suggest that higher corrosion rates may be expected at the lower temperature, at least initially.

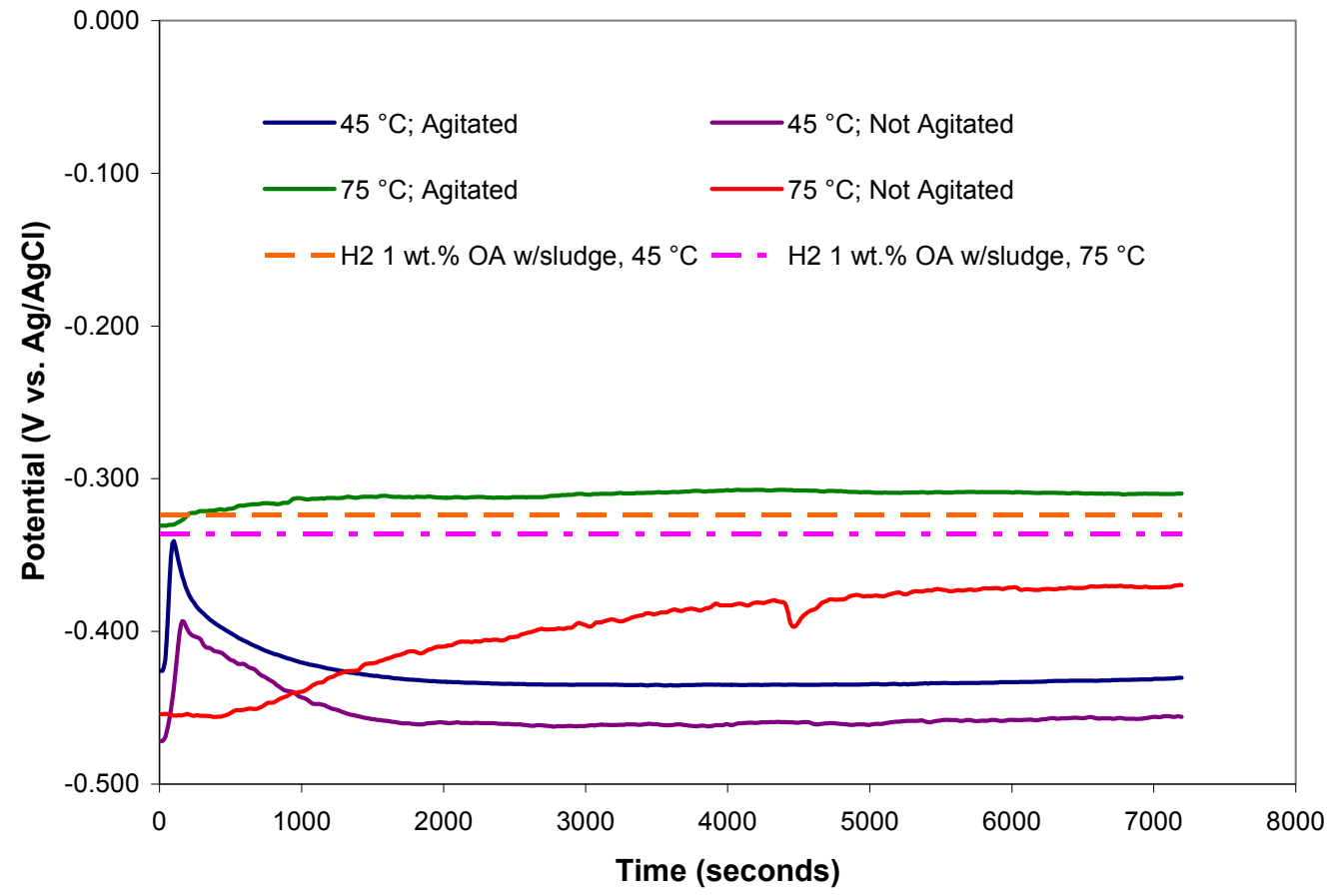

Figure 21. OCP transients for PUREX sludge simulant/1 wt.\% oxalic acid mixtures.

Figure 22 shows the effect of temperature and agitation on the OCP transients for the PUREX/2.5 wt.\% oxalic acid simulant mixture. In two of the four cases, the final OCP after two hours of exposure indicates that hydrogen evolution may be occurring. The 
OCP for the $50{ }^{\circ} \mathrm{C}$ test clearly remains more noble (i.e., greater than) to the equilibrium potential for hydrogen evolution, while the OCP for the $75^{\circ} \mathrm{C}$ test after an initial shift decays to approximately the equilibrium hydrogen potential. Although this does present the possibility of hydrogen evolution, based on the results of polarization scans performed, the primary cathodic reaction still appears to be the dissolved electro-active species. Agitation appears to result in a more active OCP at both temperatures. This result indicates that the dissolved oxidizing species or the species is more readily available at the surface due to the agitation.

Figure 22 also shows that the $75^{\circ} \mathrm{C}$ tests result in a more active (i.e., more negative) OCP than the $50{ }^{\circ} \mathrm{C}$. For example in the non-agitated condition, the OCP is approximately 150 $\mathrm{mV}$ greater for the test that was conducted at $50{ }^{\circ} \mathrm{C}$ compared to that at $75{ }^{\circ} \mathrm{C}$. The same is true for the agitated condition. The results suggest that higher corrosion rates may be expected at the higher temperature.

A comparison between Figures 21 and 22 provide an insight into the differences between utilizing 1 wt. $\%$ oxalic acid and 2.5 wt.\% oxalic acid. In all four cases the OCP shift was observed with the $2.5 \mathrm{wt} . \%$ oxalic acid, while a similar shift was not observed for the 1 wt.\% tests with PUREX. The resulting more active potentials might suggest that the corrosion rate in the $1 \mathrm{wt} . \%$ oxalic acid might be higher. However, as mentioned previously it is not known whether the potential shift in the PUREX/1 wt.\% may have occurred at a later time, and therefore was not measured. Observations from the results of the polarization scans suggest that the corrosion rates are very similar.

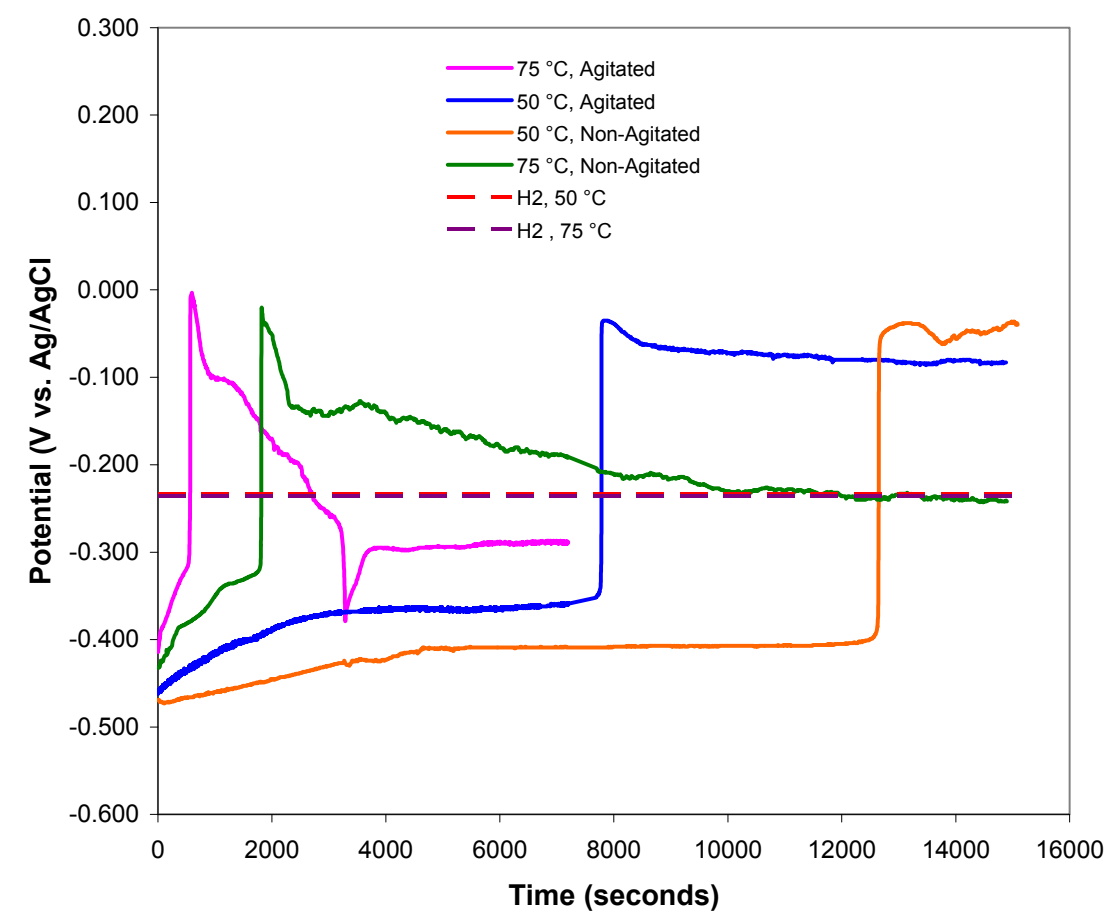

Figure 22. OCP transients for PUREX sludge simulant/2.5 wt.\% oxalic acid mixtures. 
OCP measurements in PUREX/8 wt.\% oxalic acid stimulant were made previously [1] at temperatures of $50{ }^{\circ} \mathrm{C}$ and $75^{\circ} \mathrm{C}$. The OCP shift was clearly observed in these tests as well and the final OCP was in the range of -0.1 to $0.2 \mathrm{~V}$ vs. $\mathrm{Ag} / \mathrm{AgCl}$, similar to the results for sludge simulants in the $1 \mathrm{wt} . \%$ and $2.5 \mathrm{wt} . \%$ oxalic acid. These measurements were taken over a ten day period and demonstrated that once the OCP exceeds the equilibrium hydrogen potential, it does not return below that potential at these temperatures. Longer term tests were not performed with the lower concentration oxalic acid simulants (i.e., 1 wt.\% and 2.5 wt.\%).

Figure 23 shows the effect of temperature and agitation on the OCP transient in the HMPUREX/1 wt.\% oxalic acid simulant mixture. Although no shift in the OCP was observed, in two of the four cases the final potential after two hours of exposure indicates that hydrogen evolution may be occurring. Both high temperature conditions were clearly above the potential for hydrogen evolution. At $75^{\circ} \mathrm{C}$, agitation results in a more positive potential; however, the potential has not stabilized. This result is consistent with the other simulant results indicating that agitation is disrupting the formation of the oxalate film. At $45^{\circ} \mathrm{C}$, the potential is initially more positive for the agitated condition, however, at the completion of two hours the potentials were similar. Thus, the behavior at $45{ }^{\circ} \mathrm{C}$ is similar to that in the oxalic acid, although the potentials are slightly more noble. No shift in the OCP was observed for the HM-PUREX/1 wt.\% oxalic acid. This result may also be a case where the OCP shift occurs at a later time that was not measured.

Figure 23 also shows that higher temperatures result in a more noble potential for the given agitated condition. For example, in the non-agitated condition, the stable potential is approximately $125 \mathrm{mV}$ greater for the test that was conducted at $75{ }^{\circ} \mathrm{C}$ compared to that at $45^{\circ} \mathrm{C}$. For the agitated condition, the potential is almost $200 \mathrm{mV}$ greater at the higher temperature. This suggests that the higher temperatures result in a more stable oxalate film and lower corrosion rates. However, as mentioned previously it is not known whether the potential shift in the HM-PUREX/1 wt.\% may have occurred at a later time, and therefore was not measured. 


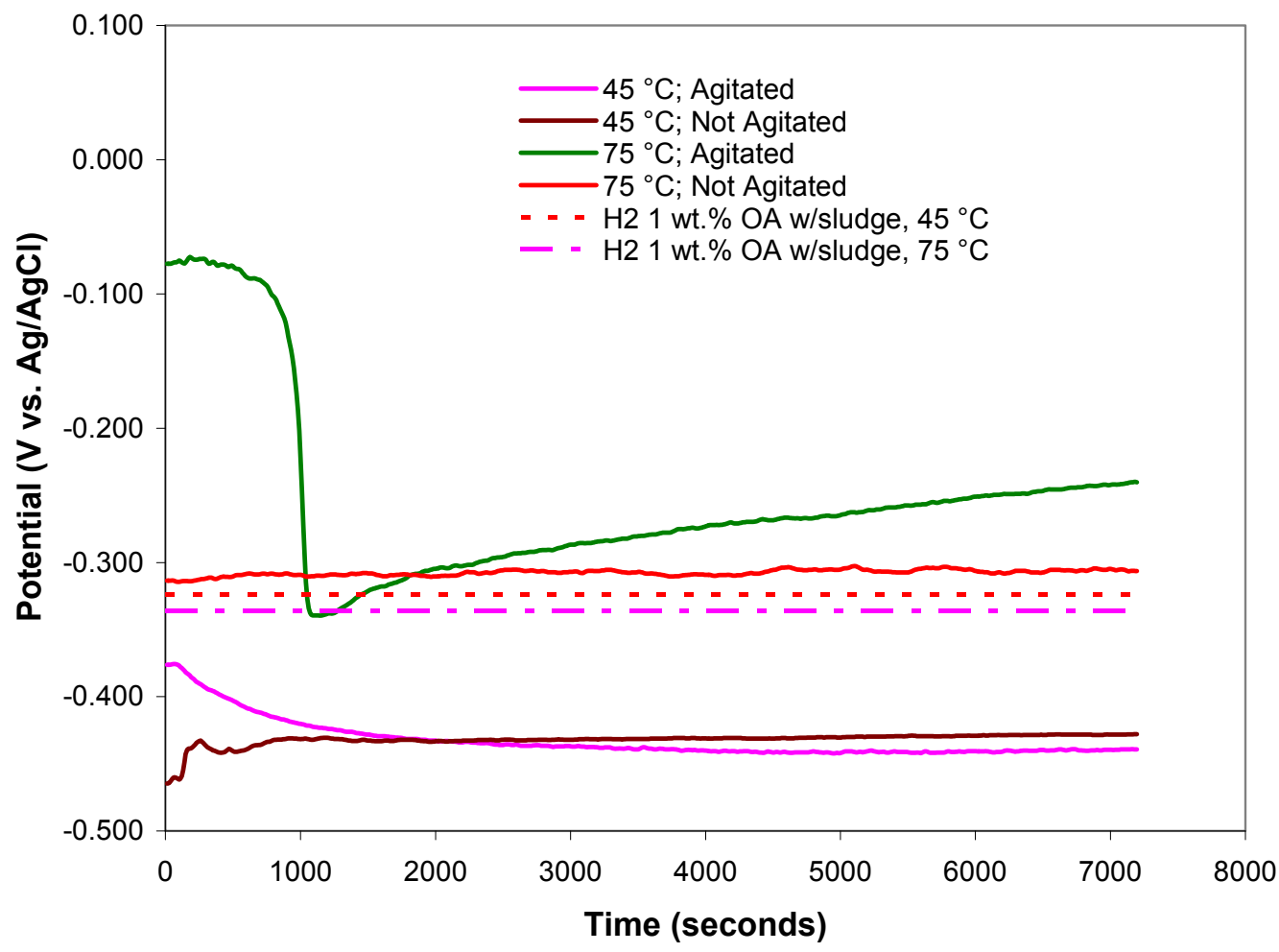

Figure 23. OCP transients for HM-PUREX sludge simulant/1 wt. \% oxalic acid mixtures.

Finally, the effect of de-aeration of the simulant on the corrosion behavior of the test materials was studied. These tests were performed to investigate a condition in the tank during chemical cleaning, where dissolved oxygen solubility becomes low. The tests at $75^{\circ} \mathrm{C}$ already simulate this condition, however, at $45^{\circ} \mathrm{C}$, some dissolved oxygen may remain in the solution. The most likely scenario for this to occur is when the cleaning solution is not agitated. To simulate the de-aerated case, nitrogen was bubbled through the solution during the test. Figures 24-26 show the comparison of the OCP behavior in an aerated and de-aerated environment for each simulant. Although there may have been some initial differences in the potential, after two hours there were essentially no differences in the measured potentials for the aerated and de-aerated conditions. Thus, a conclusion can be drawn that in all simulants oxygen may not play any significant role on the corrosion behavior of the test materials. 


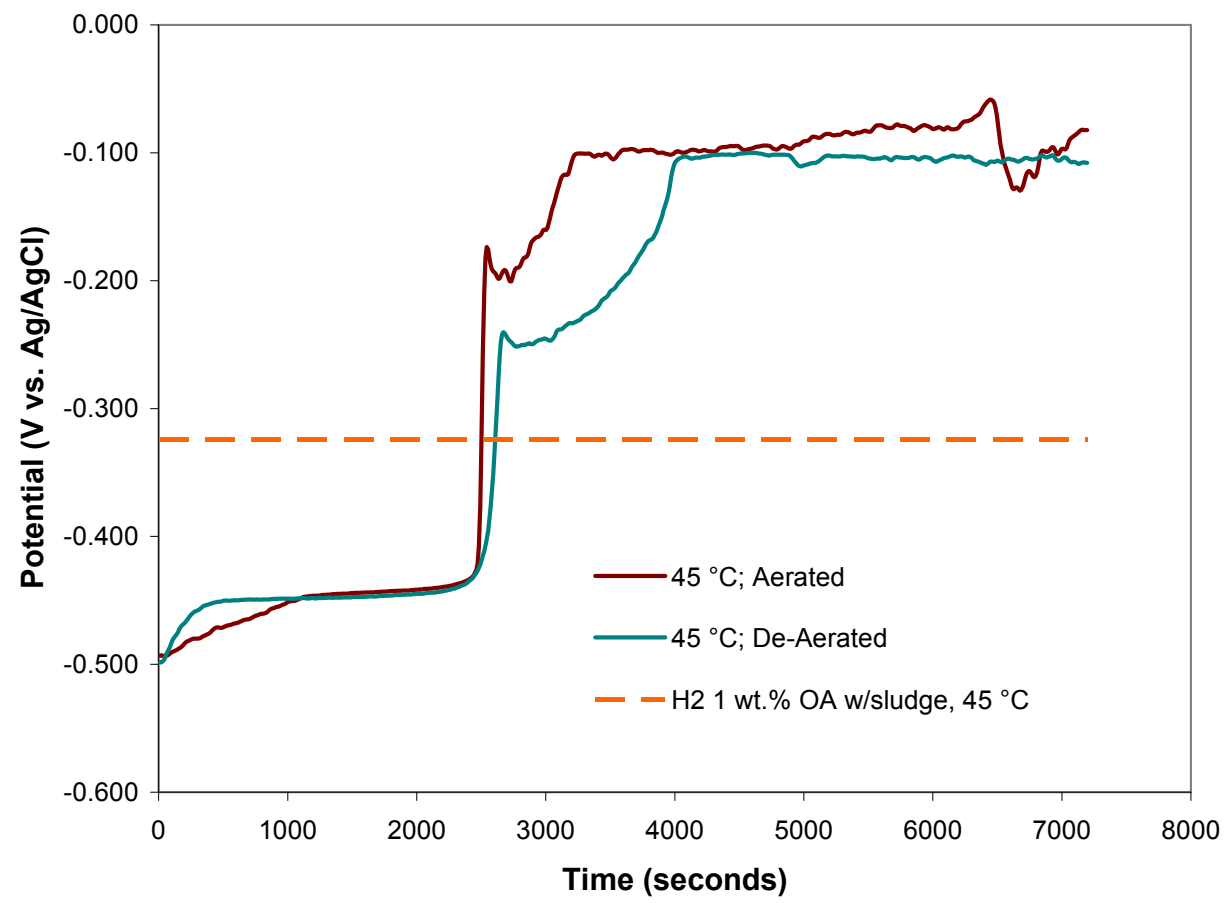

Figure 24. OCP transients for HM sludge simulant/1 wt. \% oxalic acid mixtures in aerated and de-aerated conditions.

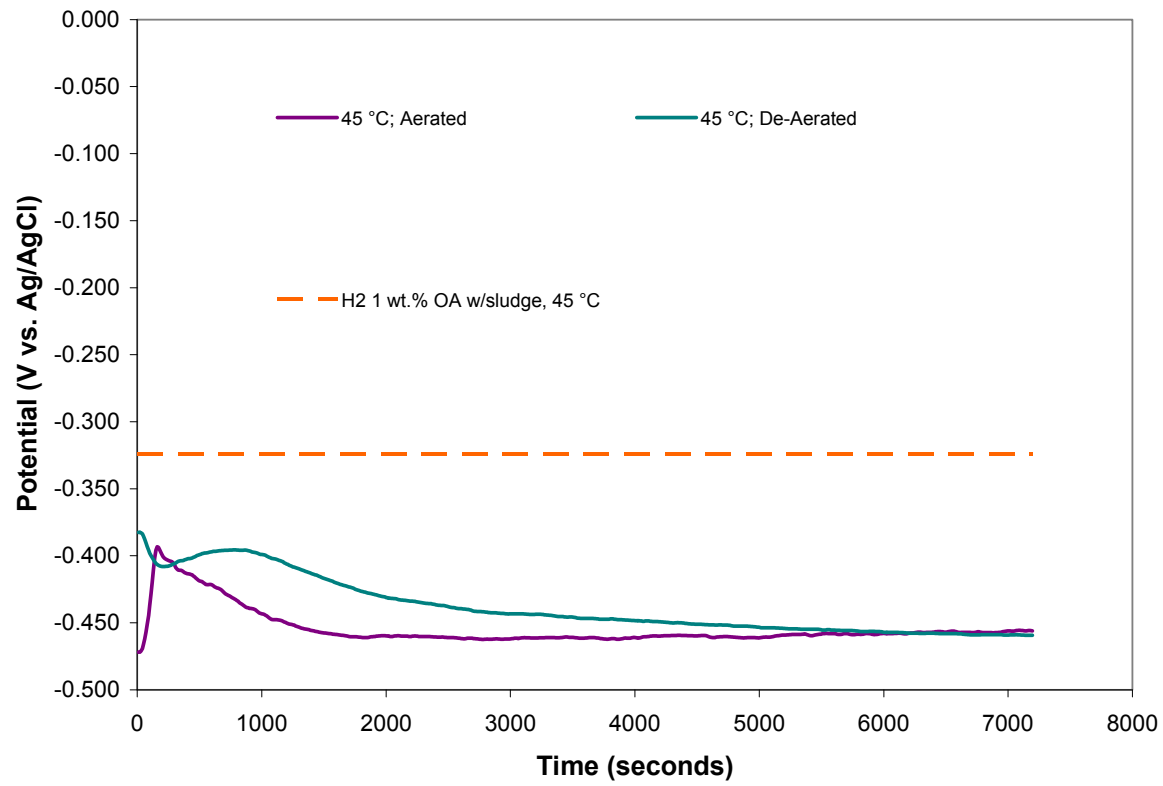

Figure 25. OCP transients for PUREX sludge simulant/1 wt.\% oxalic acid mixtures in aerated and de-aerated conditions. 


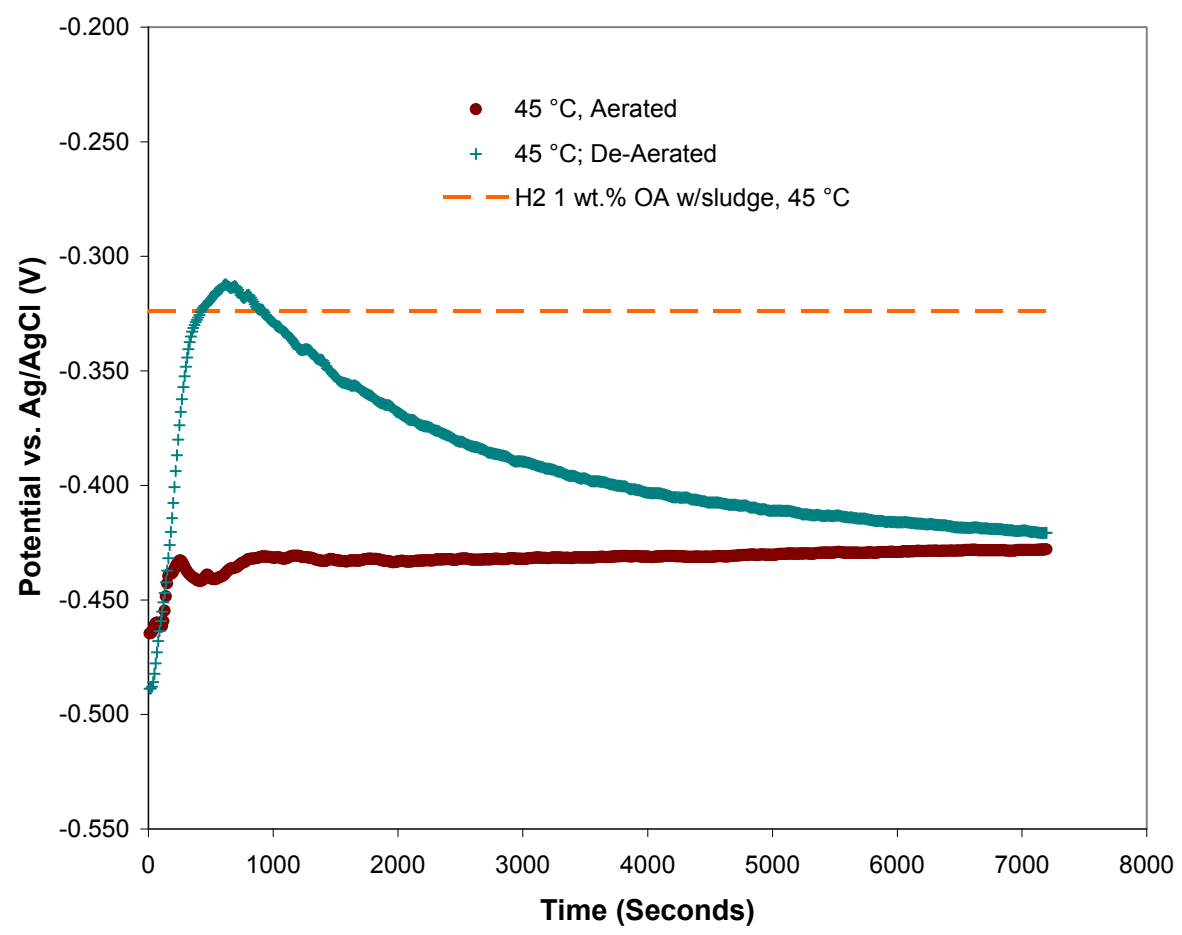

Figure 26. OCP transients for HM-PUREX sludge simulant/1 wt. \% oxalic acid mixtures in aerated and de-aerated conditions.

\subsubsection{Linear Polarization Resistance}

A significant shift in the OCP was observed when sludge simulant was present with the oxalic acid during many of the tests. Linear polarization scans were performed during these same tests before and after the OCP shift to examine the general corrosion behavior in these regions. Figure 27 shows the results of the LPR scan when the OCP was at the lower potential prior to the shift. The cathodic branch of the scan clearly shows a transport controlled reaction is taking place. As the potential approaches the zero current value, linear behavior is observed and the anodic currents that are measured are quite significant. This result indicates that while the ferrous oxalate film forms, the corrosion rates are quite high. In this case, the slope of the line suggests that the corrosion rate was on the order of $800 \mathrm{mils} / \mathrm{yr}$.

Figure 28 shows the LPR scan for the same conditions as above, but after the OCP shift. The LPR scan was more linear and the currents measured were significantly less. The corrosion rate in this case was on the order of $9 \mathrm{mils} / \mathrm{yr}$. This corrosion rate is indicative of a passivated surface and is likely more representative of the long term condition of the surface. Therefore, corrosion rates determined by LPR scans that were obtained after the OCP shift will be examined. 


\section{Revision 1}

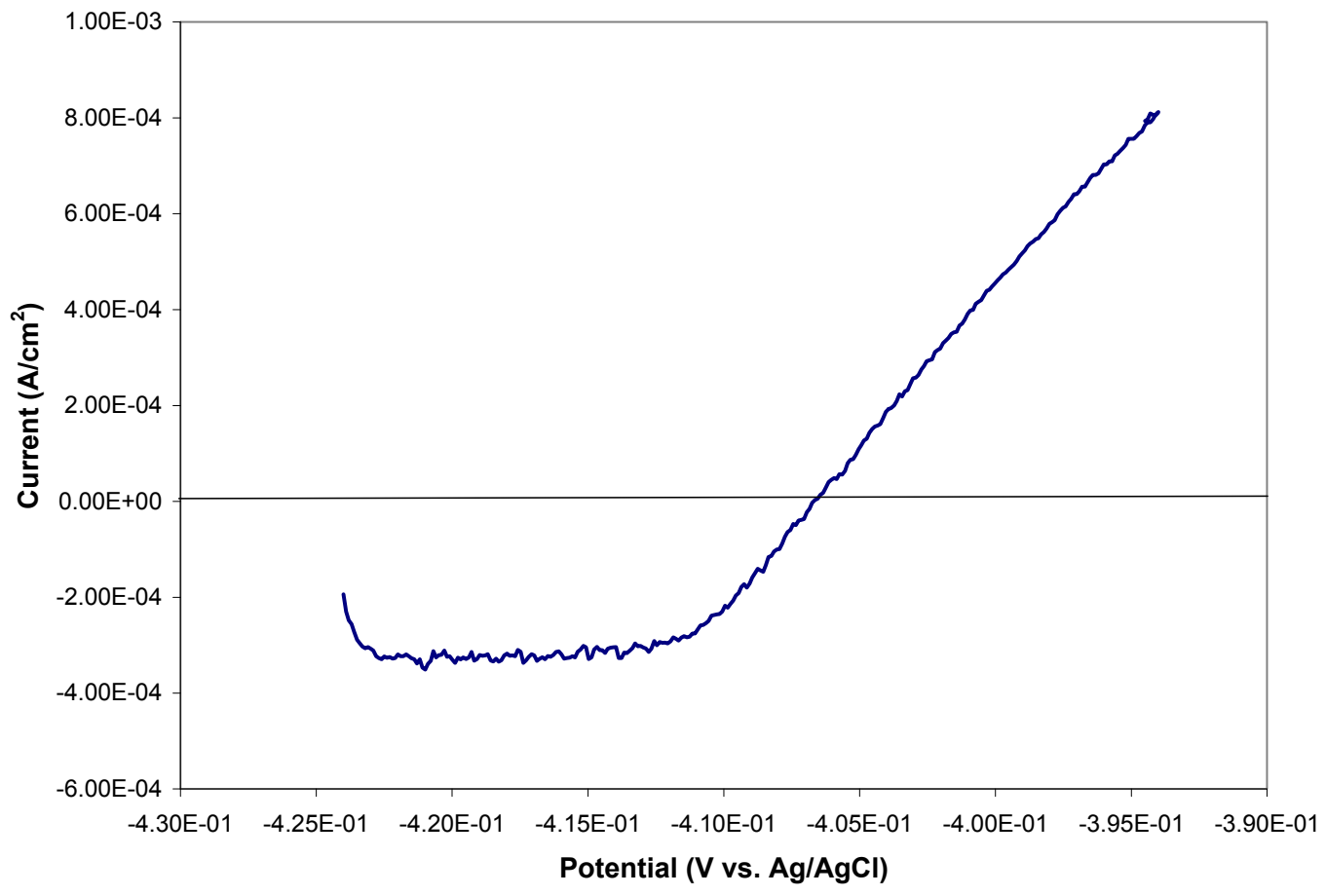

Figure 27. LPR scan for $\mathrm{HM} / 2.5$ wt. $\%$ oxalic acid at $50^{\circ} \mathrm{C}$ with the $\mathrm{OCP}$ at $-0.405 \mathrm{~V}$ vs. Ag/AgCl.

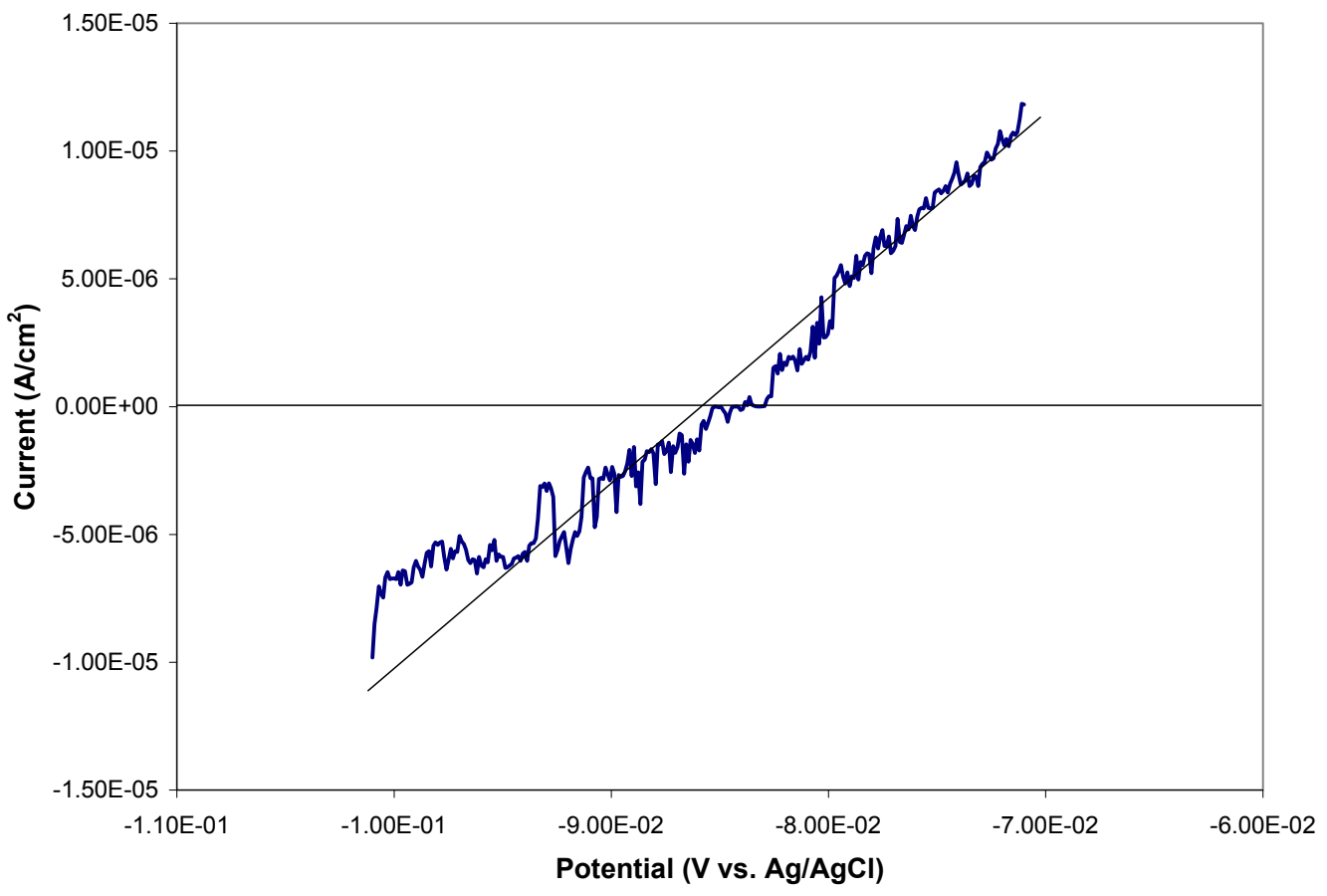

Figure 28. LPR scan for HM/2.5 wt. \% OA with OCP at -0.085 V vs. Ag/AgCl. 
Figure 29 is a summary of the corrosion rate data gathered from the linear polarization tests performed with $1 \mathrm{wt} . \%$ oxalic acid. Each symbol represents an average corrosion rate based on two or three tests. The results indicate that regardless of the environmental conditions (i.e., sludge simulant, temperature, agitation, aeration) during chemical cleaning with oxalic acid an upper bound estimate of the corrosion rate for carbon steel is 25 mpy. Figure 30 shows a similar summary of the corrosion rate data gathered from the linear polarization tests performed in $2.5 \mathrm{wt} . \%$ oxalic acid. In this case an upper bound estimate for the corrosion rate in $2.5 \mathrm{wt} . \%$ oxalic acid with the sludge simulant is $15 \mathrm{mpy}$ regardless of the environmental conditions. All of these results were obtained within the first 2 to 6 hours of exposure.

Differences due to these environmental conditions result in some variability in the corrosion rates that were observed. These differences are discussed below.

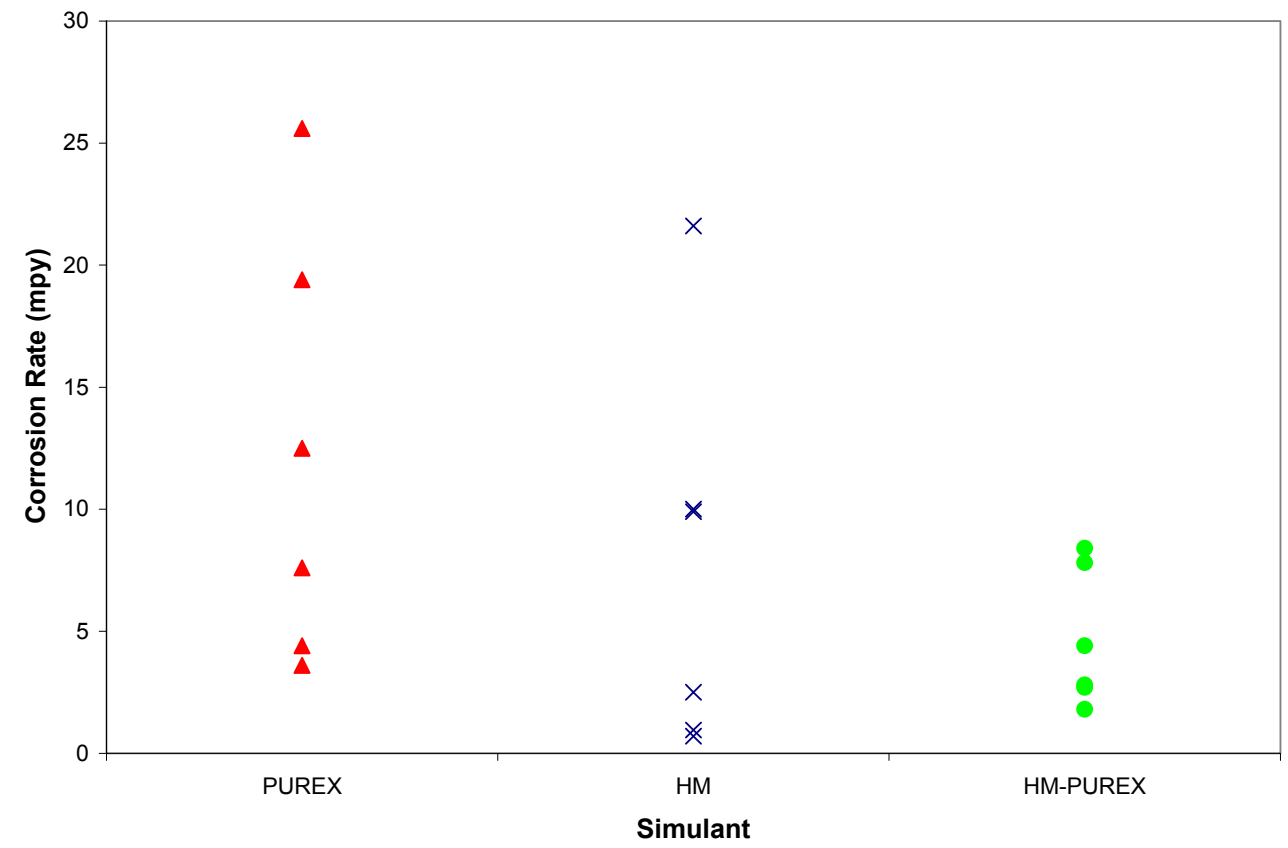

Figure 29. Corrosion rates in simulant/ 1 wt.\% oxalic acid mixtures measured by the LPR technique. 


\section{Revision 1}

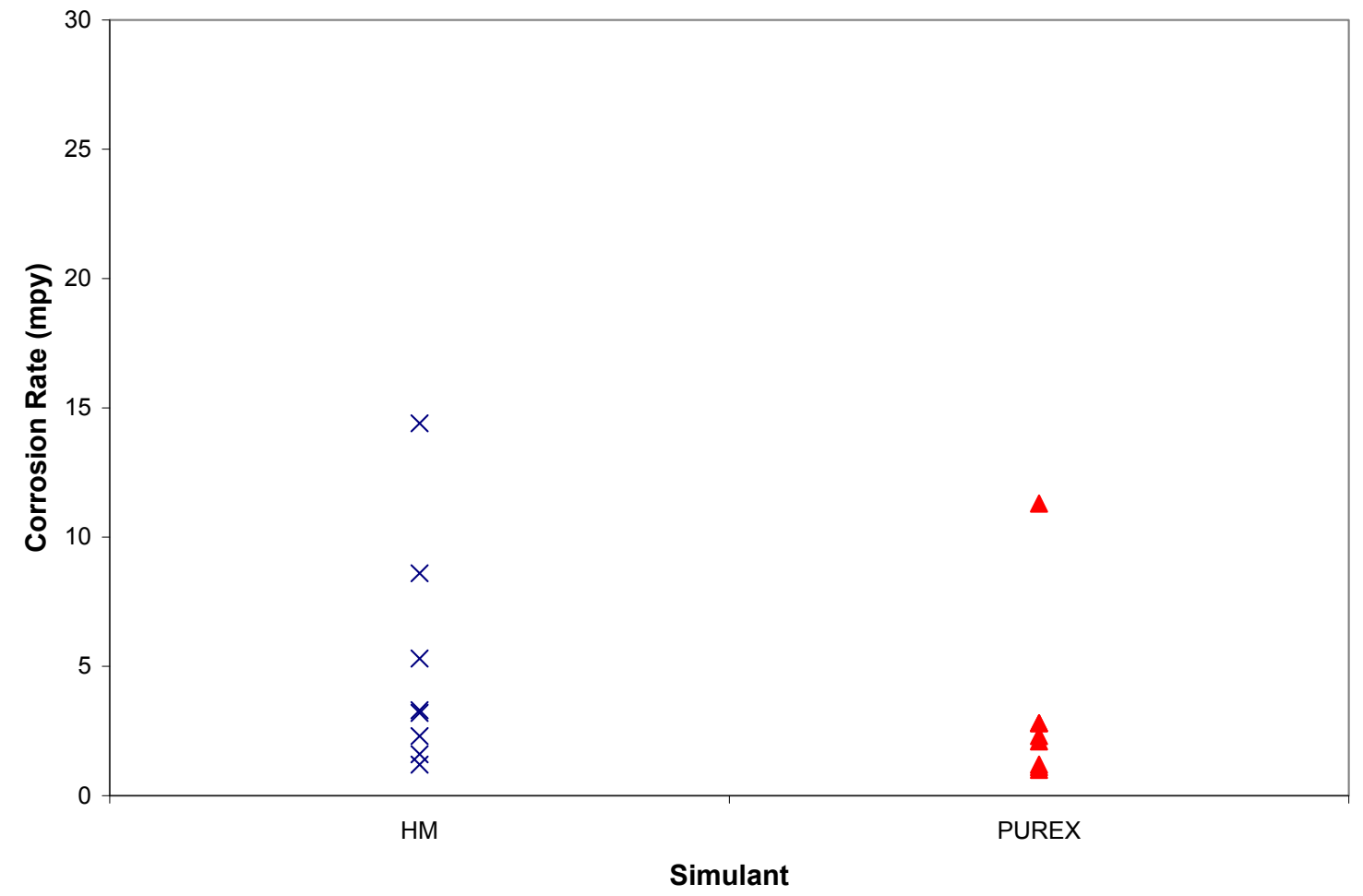

Figure 30. Corrosion rates in simulant/ 2.5 wt. \% oxalic acid mixtures measured by the LPR technique.

The first variable examined was the simulant environment. Of particular interest is the comparison between the corrosion rate in pure oxalic acid and the solutions that contain a sludge simulant as well. Figure 31 shows that the corrosion rate in the agitated pure oxalic acid is 4 to 15 times greater than those observed in the presence of sludge simulants. Note that similar behavior was observed for both $1 \mathrm{wt} . \%$ and $2.5 \mathrm{wt} . \%$ oxalic acid. In contrast, the corrosion rates in the pure oxalic acid solutions demonstrated a stronger temperature dependence than they did for the simulants. This result suggests that the nature and kinetics of the cathodic reaction have been altered by the dissolution of sludge and the development of the passive oxalate film has also been altered. The nature and the kinetics of the cathodic reactions will be investigated by performing cathodic polarization studies (see section 4.1.3), while the protective nature of the oxalate layer will be investigated with the anodic/cyclic polarization studies (see section 4.1.4). 


\section{Revision 1}

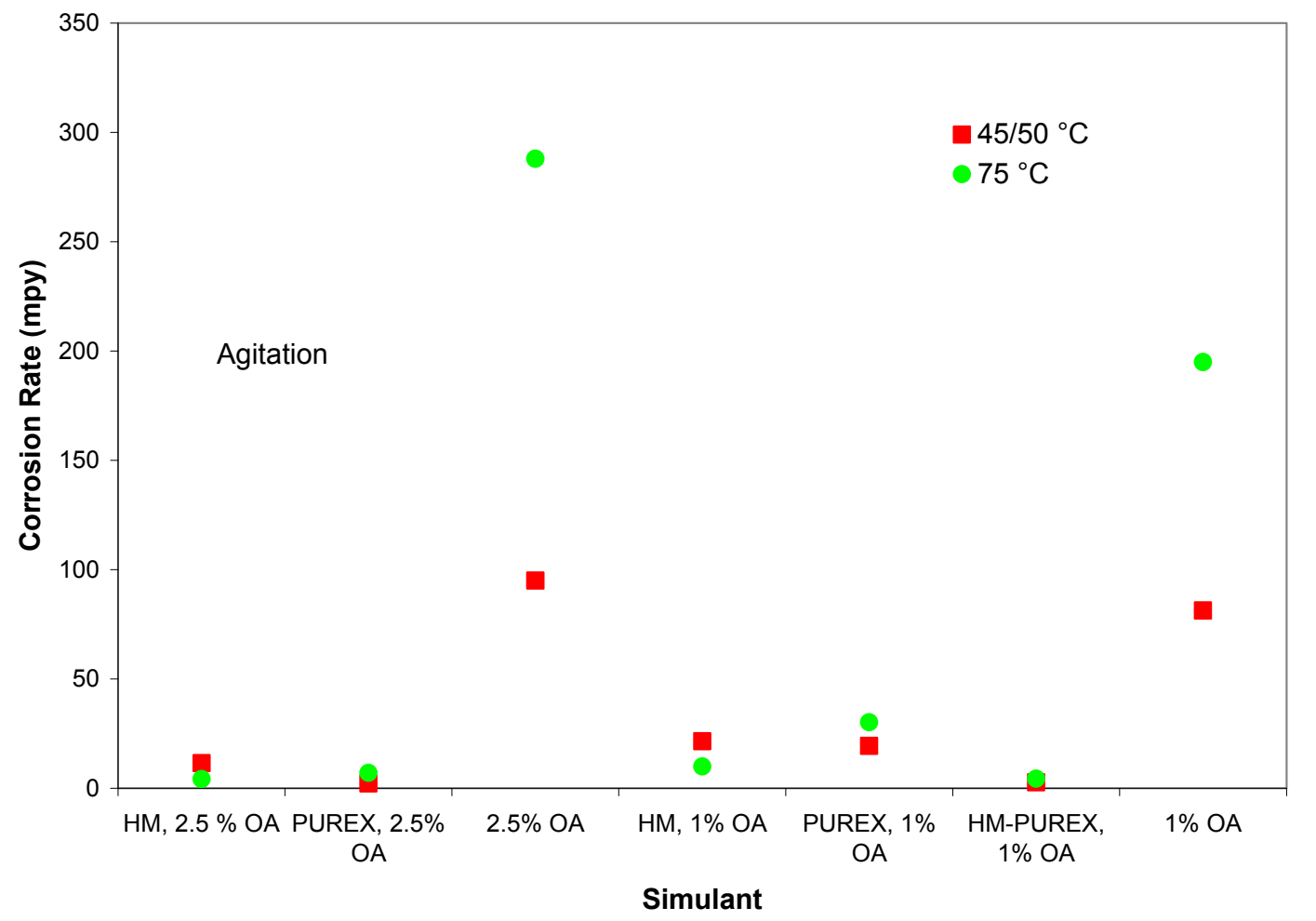

Figure 31. Corrosion rates in simulant/oxalic acid mixtures compared with pure oxalic acid in agitated solutions measured by the LPR technique. Note: 1 wt. \% oxalic acid tests were actually performed at $45{ }^{\circ} \mathrm{C}$ and $2.5 \mathrm{wt} . \%$ oxalic acid tests at $50{ }^{\circ} \mathrm{C}$.

Figure 32 shows the effect of the simulant environment on corrosion rate in non-agitated solution. Again the corrosion rate in the pure oxalic acid is 4 to 10 times greater in the oxalic acid than in the sludge simulants. The lower corrosion rates in the simulants suggest either a more tenacious oxalate film or the nature and the kinetics of the cathodic reaction have been significantly altered by the presence of dissolved species in the oxalic acid. There was a significant difference observed between the 1 wt. $\%$ oxalic acid and 2.5 wt. \% oxalic tests. For the $1 \mathrm{wt} \% \%$ oxalic acid solution, the corrosion rate was greater at $45^{\circ} \mathrm{C}$ than it was at $75^{\circ} \mathrm{C}$. These corrosion rates were measured several days after the carbon steel had been exposed to the acid. As discussed previously, this result suggests that the ferrous oxalate film that formed at higher temperatures is more tenacious and mitigates corrosion. The same situation was not observed for the $2.5 \mathrm{wt}$. $\%$ oxalic acid as the $50{ }^{\circ} \mathrm{C}$ result was lower than the corrosion rate at $75^{\circ} \mathrm{C}$. These tests were conducted within a couple of hours after exposure of the carbon steel. As will be shown by the coupon tests, the corrosion rate actually behaved similarly to the $1 \mathrm{wt} . \%$ oxalic acid solution. These results indicate that there is an incubation time for the development of the ferrous oxalate film that is temperature dependent if there is no agitation. 


\section{Revision 1}

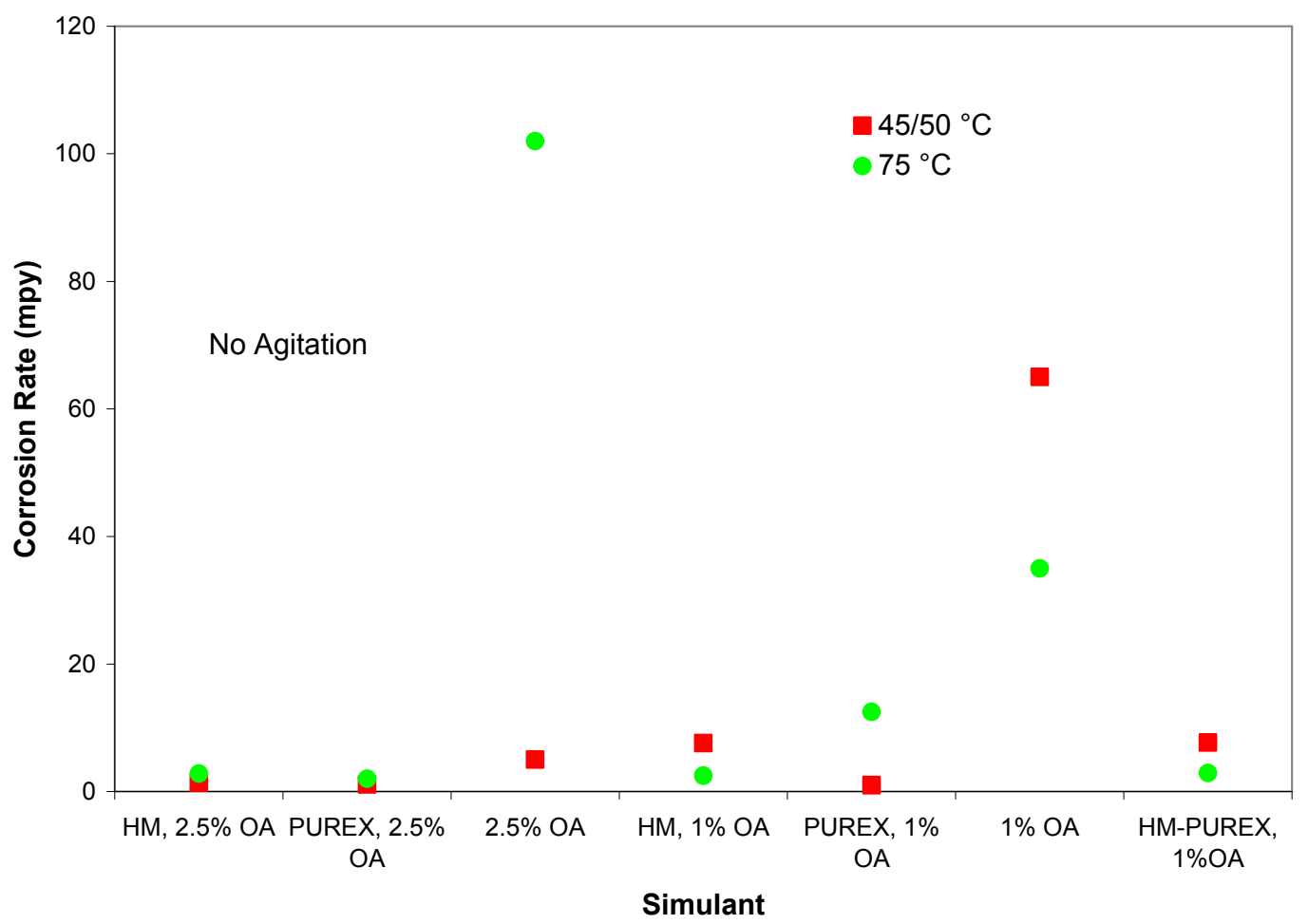

Figure 32. Corrosion rates in simulant/oxalic acid mixtures compared to pure oxalic acid in non-agitated solutions. Oxalic acid concentrations were 1 and 2 wt.\%. The 1 wt. \% and 2.5 wt. $\%$ tests were conducted at 45 and $50{ }^{\circ} \mathrm{C}$, respectively.

One difference between the simulants and the oxalic acid is the $\mathrm{pH}$. The $\mathrm{pH}$ of the pure acid is approximately 1.1, while that of the simulants with the $1 \mathrm{wt} . \%$ and $2.5 \mathrm{wt} \%$ oxalic acid was 2 and 1.3, respectively. To investigate the effects of $\mathrm{pH}$, these results were compared with LPR tests that were conducted in $8 \mathrm{wt} . \%$ oxalic acid, $\mathrm{pH} \sim 1$, that contained a small quantity of Tank $5 \mathrm{~F}$ sludge simulant [18]. These latter tests were conducted at a temperature of $50{ }^{\circ} \mathrm{C}$. Figure 33 shows that the corrosion rates for the Tank 5F sludge in $8 \mathrm{wt} . \%$ oxalic acid are very similar to those for the current tests. These rates were also less than those exhibited in $8 \mathrm{wt} . \%$ oxalic acid alone (i.e., agitated: 118 mpy and not-agitated: $40 \mathrm{mpy}$ ). This result suggests that the $\mathrm{pH}$ is not the determining factor in influencing the corrosion rate. The lower corrosion rates in the sludge simulant likely occurs due to either a reduction in the rate of the cathodic reaction or the formation of a layer that is more protective than the ferrous oxalate. 


\section{Revision 1}

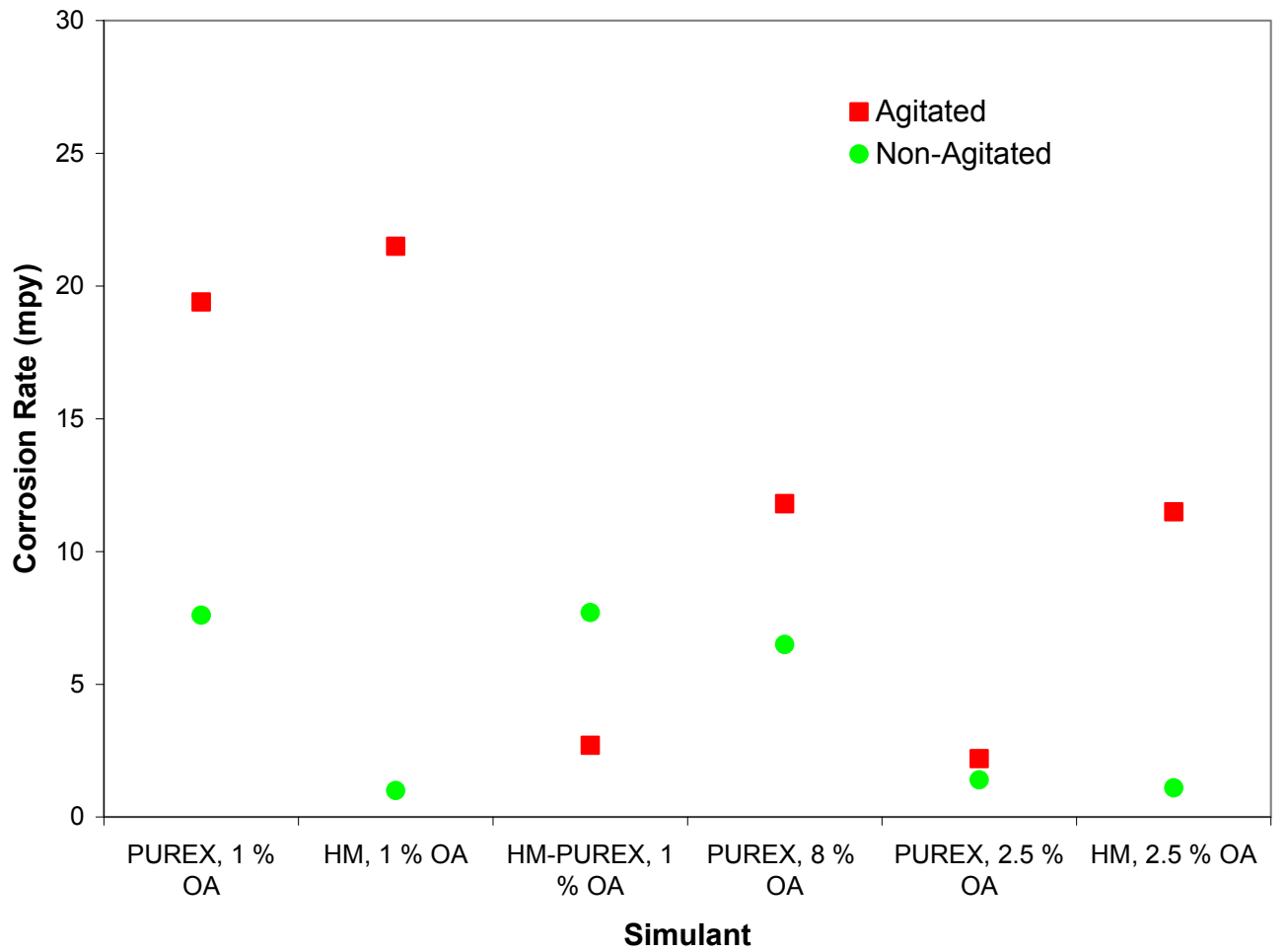

Figure 33. Corrosion rates in HM and PUREX sludge simulant/oxalic acid (1 wt.\% and 2.5 wt. \%) mixtures compared with Tank 5F sludge simulant in 8 wt.\% oxalic acid.

Figures 34 and 35 illustrate the effect of agitation on the corrosion rate with the sludge simulants for the lower and higher temperatures, respectively. In general, for both 1 wt. $\%$ and $2.5 \mathrm{wt} . \%$ agitation increased the corrosion rate by a factor of 2 to 10 . These results could be explained by the disruption of the ferrous oxalate film by the agitation or the incorporation of other oxides within the oxalate layer. The effect of agitation on the corrosion rate in the HM-PUREX blend simulant at $45^{\circ} \mathrm{C}$ is not as apparent. At this time there is no explanation for this observation. 


\section{Revision 1}

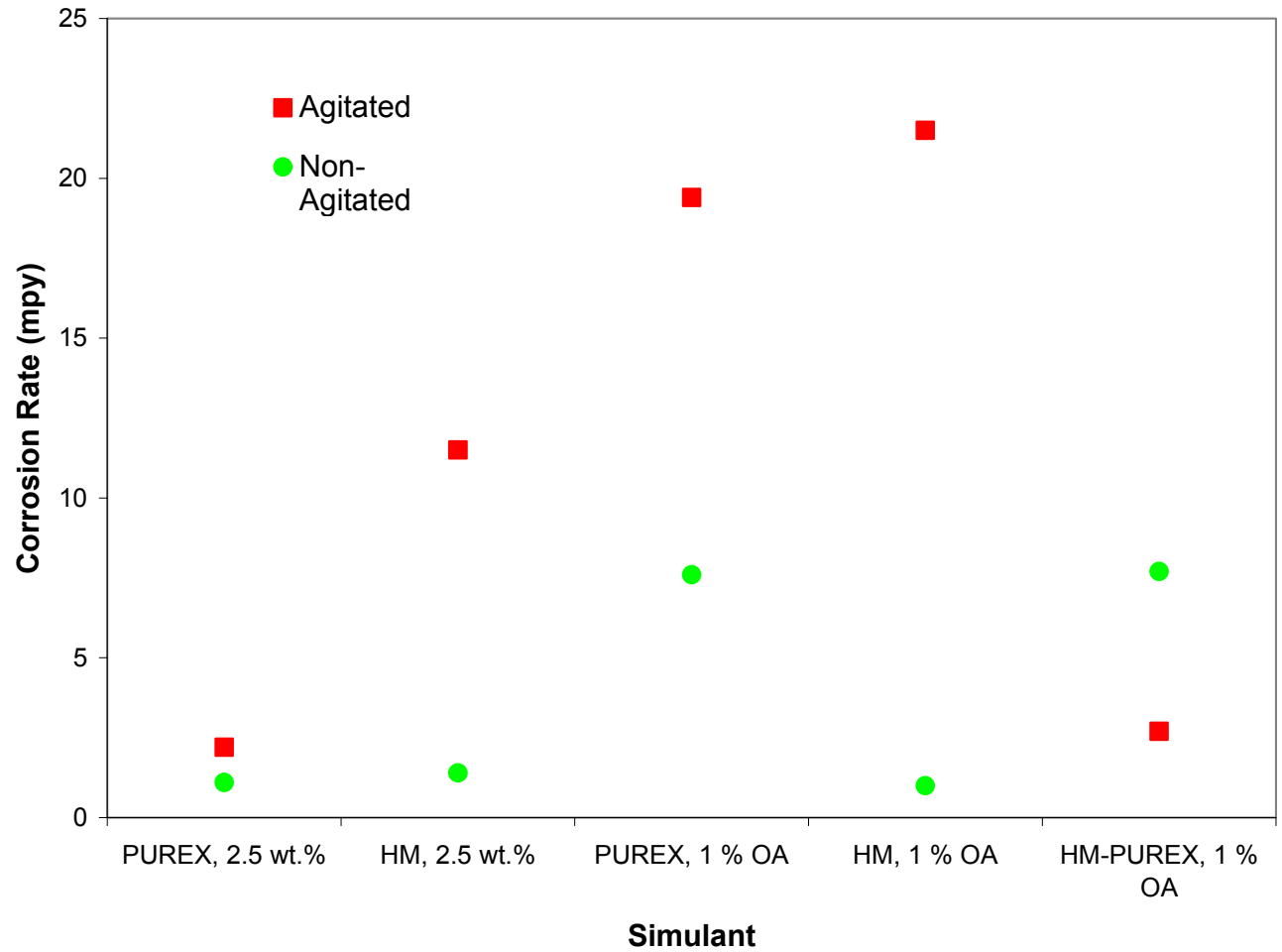

Figure 34. Corrosion rates in simulant/ oxalic acid mixtures as a function of agitation at $45^{\circ} \mathrm{C}$ or $50{ }^{\circ} \mathrm{C}$.

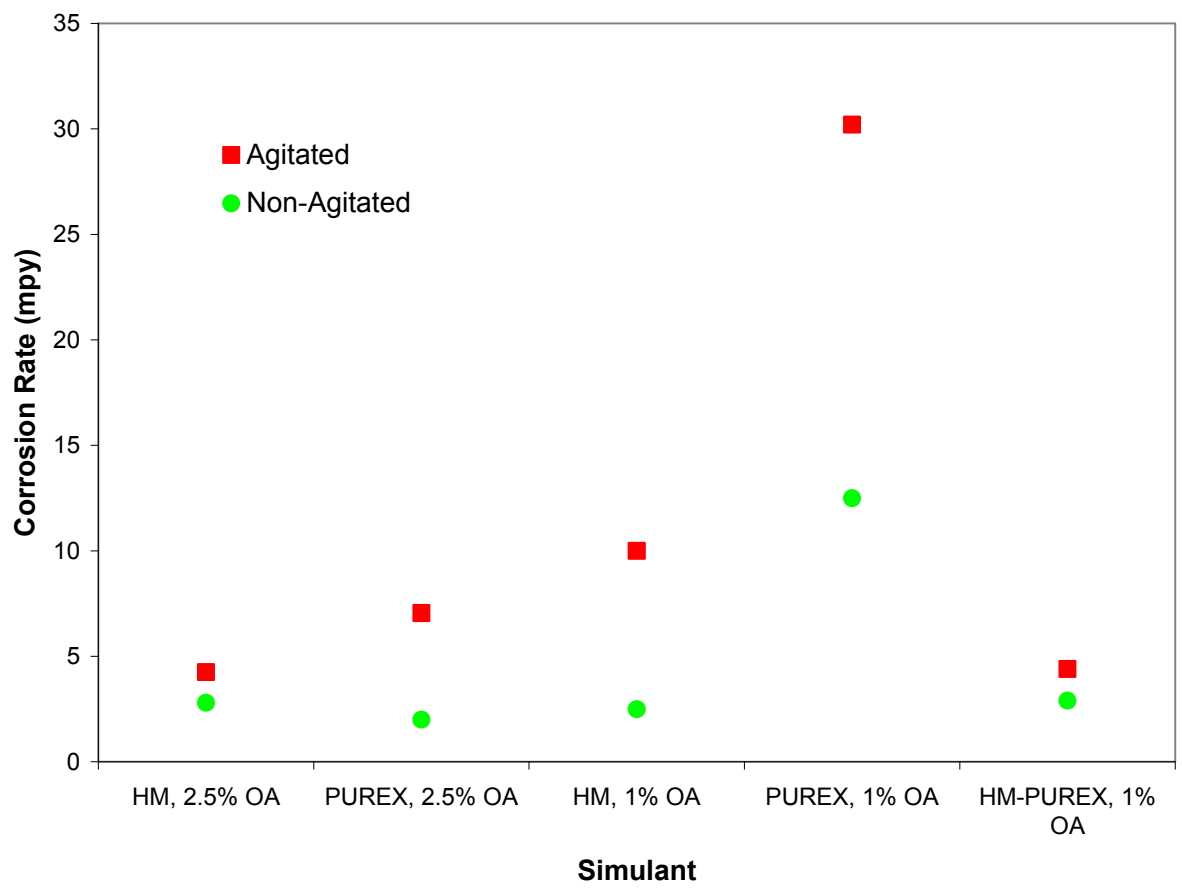

Figure 35. Corrosion rates in simulant/oxalic acid mixtures as a function of agitation at $75^{\circ} \mathrm{C}$. 


\section{Revision 1}

Figures 36 and 37 illustrate the effect of temperature on the corrosion rate in sludge simulants with and without agitation, respectively. The results showed that the corrosion rate did not have a strong dependence on temperature. In most cases the corrosion rates were likely within the error of the linear polarization measurement. Thus, the inhibiting mechanism does not appear to be temperature dependent within the range of temperatures tested, at least during the initial stages of exposure.

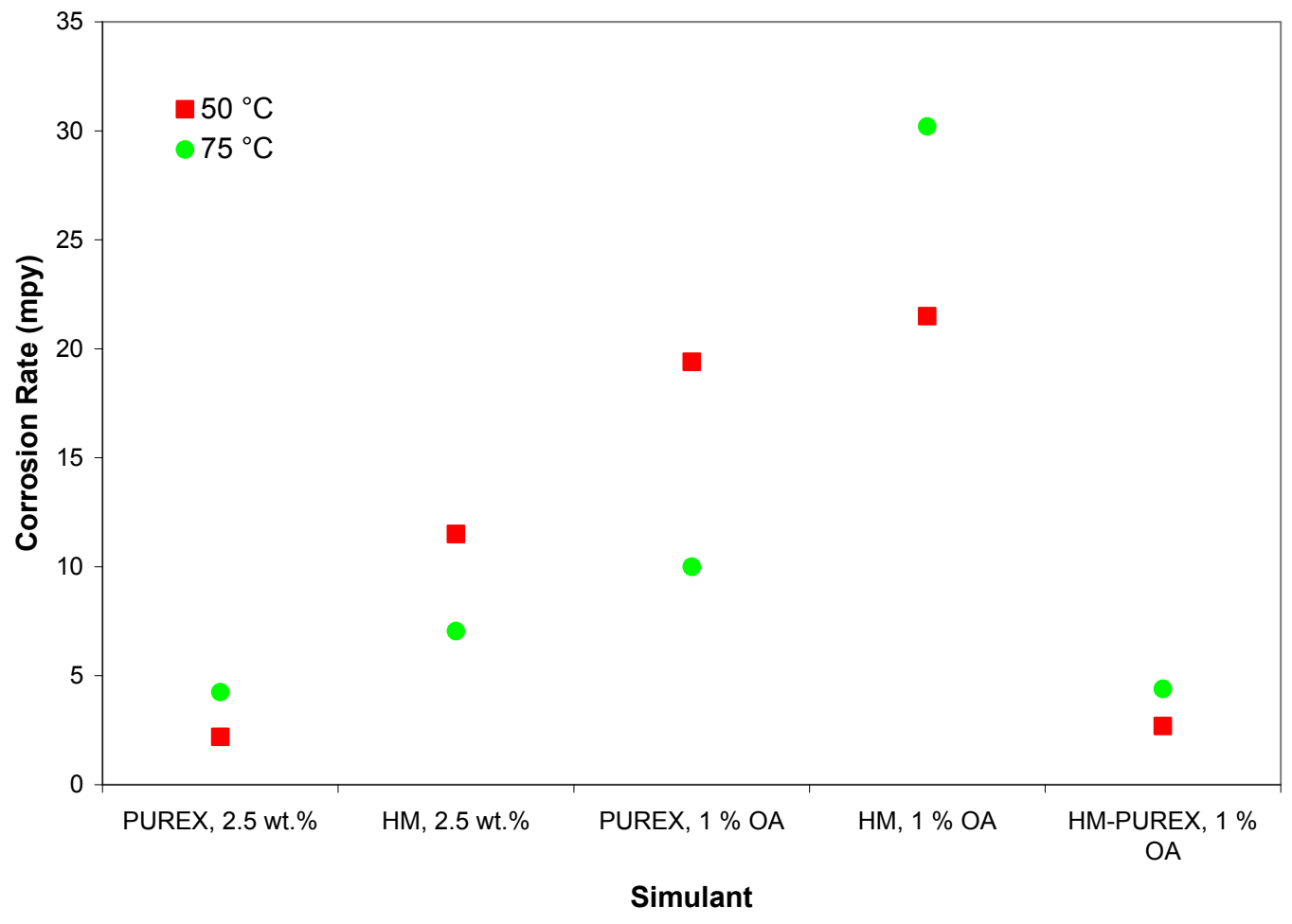

Figure 36. Corrosion rates in agitated simulant/oxalic acid mixtures as a function of temperature. 


\section{Revision 1}

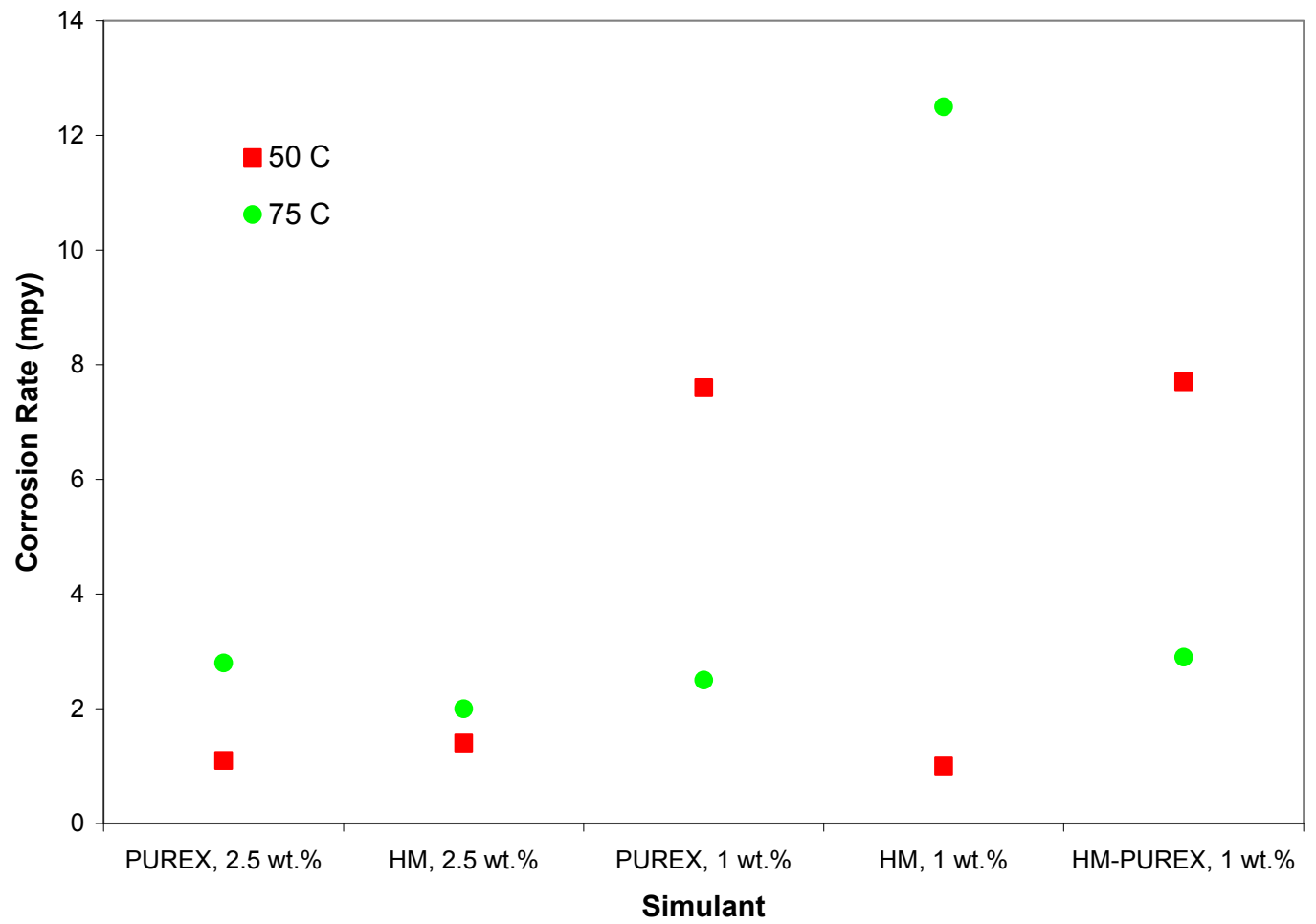

Figure 37. Corrosion rates in agitated simulant/oxalic acid mixtures as a function of temperature. Tests were performed in 1 and 2.5 wt. $\%$ oxalic acid.

Finally, the effect of aeration on the corrosion rate in the simulants was examined (see Figure 38). Although the corrosion rates in the aerated simulants are slightly higher than the de-aerated simulants, the differences are not substantial. This result suggests that oxygen plays only a minor role in the corrosion of the carbon steel in the presence of the simulant. The result may also indicate that hydrogen is not playing a significant role in the corrosion of the carbon steel as the corrosion rate remains low in the de-aerated solution. Previous tests in de-aerated, $8 \mathrm{wt} \% \%$ oxalic acid with a sludge simulant also indicate that aeration had little effect on the corrosion rate as well [18]. 


\section{Revision 1}

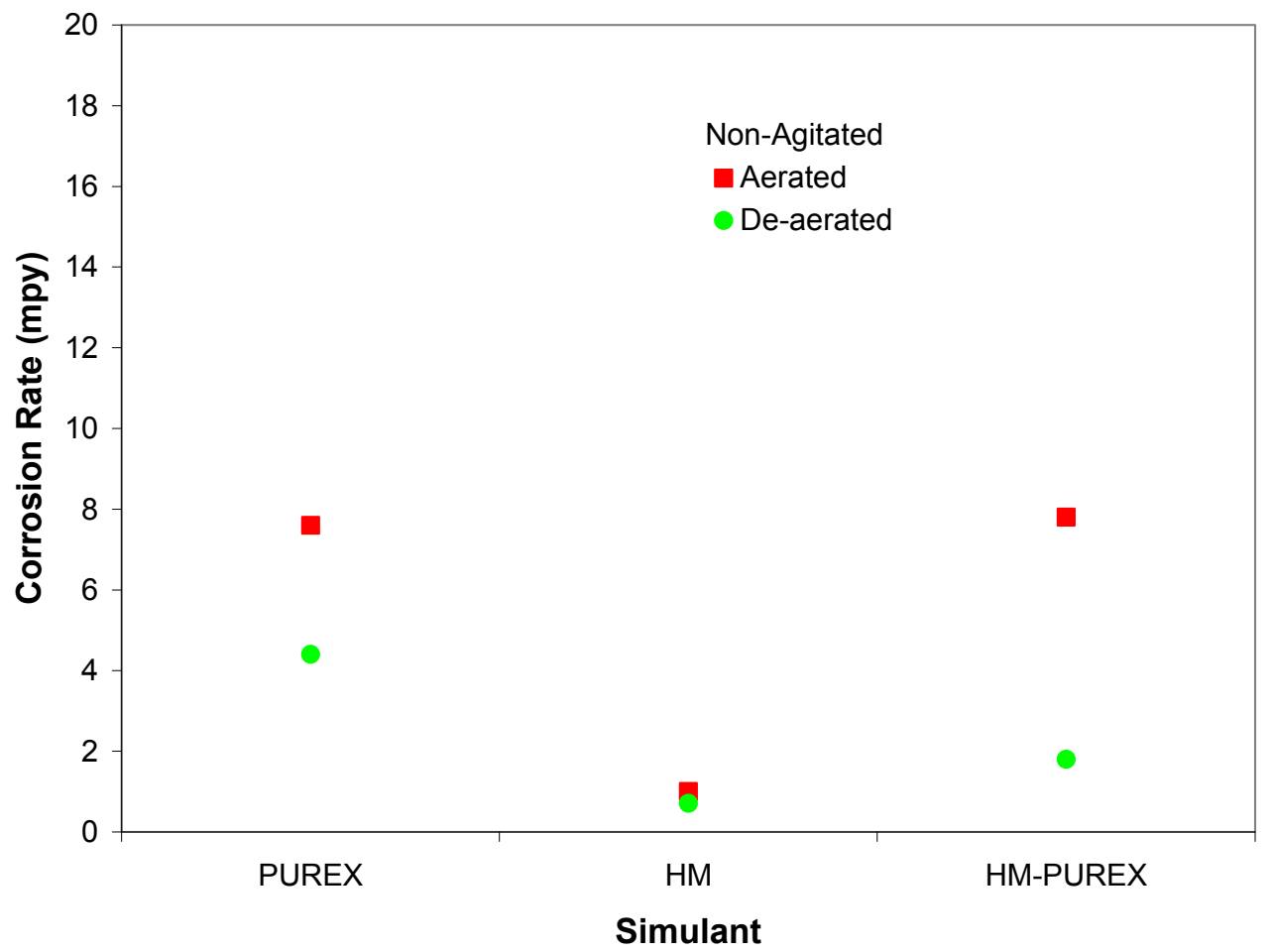

Figure 38. Corrosion rates in agitated simulant/ 1 wt. \% oxalic acid mixtures aerated and de-aerated solutions at $45^{\circ} \mathrm{C}$.

\subsubsection{Cathodic Polarization}

The values for $\alpha, \beta$ and $i_{0}$ are summarized in Table 8 . The data from tests with agitation are presented to minimize the effects of transport of the electro-active species to the metal surface and emphasize the kinetics of the reaction at the surface. From the table it is observed that for the tests performed in pure oxalic acid, $\alpha$ is between 0.4 and 0.6 , which indicates that hydrogen evolution is occurring at the steel surface. On the other hand, $\alpha$ for the solutions with a sludge simulant present is less than 0.4 , which indicates that another cathodic reaction is occurring. An example of another possible cathodic reaction include reduction of a dissolved species such as the di-oxolatoferrate ion as discussed previously [4].

The table also shows that $\mathrm{i}_{\mathrm{o}}$ is significantly lower in the sludge simulants than in pure oxalic acid. The lower exchange current densities reflect lower corrosion rates in the solutions that contain the sludge simulant. This result is in agreement with those observed for the LPR measurements discussed previously. For the $1 \mathrm{wt} \%$ oxalic acid, the $i_{0}$ was slightly higher with the PUREX simulant than the HM simulant. This results suggests that the PUREX simulant is slightly more aggressive than the HM. On the other hand, for the $2.5 \mathrm{wt} . \%$ oxalic acid the $\mathrm{i}_{\mathrm{o}}$ for the HM simulant is greater than the PUREX simulant. This result indicates that the rate at which the electroactive species dissolves into the oxalic acid is affected by the acid concentration. 
The behavior of the PUREX and HM-PUREX at $45^{\circ} \mathrm{C}$ is also of particular interest. Note that the OCP is not significantly different from that for the $1 \mathrm{wt} . \%$ oxalic acid, yet $\mathrm{i}_{\mathrm{o}}$ is significantly lower for oxalic acid with the simulants. This observation may be explained by either the anodic reaction being inhibited by the formation of a more tenacious oxalate layer or a different cathodic reaction must be operative (i.e., other than the hydrogen evolution reaction).

Table 8. Kinetic data obtained from cathodic polarization tests. All data was obtained from tests where the solutions were agitated.

\begin{tabular}{|c|c|c|c|c|c|}
\hline Simulant & $\begin{array}{c}\text { Temperature } \\
\left({ }^{\circ} \mathrm{C}\right)\end{array}$ & $\begin{array}{c}\text { OCP (V } \\
\text { vs. } \\
\text { Ag/AgCl) }\end{array}$ & $\begin{array}{c}\beta \\
\text { (V/decade) }\end{array}$ & $\alpha$ & $\mathrm{I}_{0}\left(\mu \mathrm{A} / \mathrm{cm}^{2}\right)$ \\
\hline $\begin{array}{c}1 \text { wt. } \% \text { oxalic } \\
\text { acid }\end{array}$ & 45 & -0.440 & 0.139 & 0.454 & 163 \\
\hline $\begin{array}{c}1 \text { wt. } \% \text { oxalic } \\
\text { acid }\end{array}$ & 75 & -0.465 & 0.146 & 0.473 & 543 \\
\hline $\begin{array}{c}2.5 \text { wt. } \% \\
\text { oxalic acid }\end{array}$ & 50 & -0.463 & 0.121 & 0.530 & 360 \\
\hline $\begin{array}{l}2.5 \text { wt. } \% \\
\text { oxalic acid }\end{array}$ & 75 & -0.445 & 0.115 & 0.60 & 550 \\
\hline $\begin{array}{l}\mathrm{HM} / 1 \text { wt. } \% \\
\text { oxalic acid }\end{array}$ & 45 & -0.120 & 0.256 & 0.247 & 12.3 \\
\hline $\begin{array}{l}\mathrm{HM} / 1 \mathrm{wt} \% \\
\text { oxalic acid }\end{array}$ & 75 & 0.008 & 0.243 & 0.284 & 22.3 \\
\hline $\begin{array}{l}\mathrm{HM} / 2.5 \text { wt. } \% \\
\text { oxalic acid }\end{array}$ & 50 & -0.086 & 0.17 & 0.377 & 23 \\
\hline $\begin{array}{l}\mathrm{HM} / 2.5 \text { wt. } \% \\
\text { oxalic acid }\end{array}$ & 75 & 0.007 & 0.212 & 0.326 & 15 \\
\hline $\begin{array}{c}\text { PUREX/1 } \\
\text { wt.\% oxalic } \\
\text { acid }\end{array}$ & 45 & -0.435 & NA & NA & 15 \\
\hline $\begin{array}{l}\text { PUREX/1 } \\
\text { wt.\% oxalic } \\
\text { acid } \\
\end{array}$ & 75 & -0.300 & 0.588 & 0.117 & 70 \\
\hline $\begin{array}{l}\text { PUREX/2.5 } \\
\text { wt.\% oxalic } \\
\text { acid }\end{array}$ & 50 & -0.082 & 0.261 & 0.246 & 5 \\
\hline $\begin{array}{l}\text { PUREX/2.5 } \\
\text { wt.\% oxalic } \\
\text { acid }\end{array}$ & 75 & -0.228 & 0.201 & 0.344 & 2 \\
\hline $\begin{array}{c}\text { HM- } \\
\text { PUREX/1 } \\
\text { wt.\% oxalic } \\
\text { acid }\end{array}$ & 45 & -0.431 & NA & NA & 2 \\
\hline $\begin{array}{c}\text { HM- } \\
\text { PUREX/1 } \\
\text { wt.\% oxalic } \\
\text { acid }\end{array}$ & 75 & -0.368 & NA & NA & 6 \\
\hline
\end{tabular}

NA - Not Available 
For the linear polarization tests it was assumed that the value for the Stern-Geary coefficient was $0.026 \mathrm{~V}$. This was calculated based on the assumption that the slope of the anodic and cathodic Tafel slopes was approximately $0.120 \mathrm{~V} /$ decade. For values relatively close, such as those for the oxalic acid tests, an insignificant error is introduced by this assumption. However, the Tafel slopes measured for the sludge simulants are significantly larger. To investigate this impact on the calculated corrosion rate, the HM case at $75{ }^{\circ} \mathrm{C}$ was investigated. The first step was to determine the anodic Tafel slope from the anodic polarization curve in much the same manner as the cathodic Tafel slope was determined. The anodic Tafel slope was estimated to be approximately 0.160 $\mathrm{V} /$ decade, which results in a Stern-Geary coefficient of $0.042 \mathrm{~V}$. This gives a corrosion rate of 5.7 mpy compared to $3.5 \mathrm{mpy}$ if the corrosion rate was calculated from the previous assumption. Thus the corrosion rate would have been under predicted by approximately $40 \%$. This error is typical for corrosion rate measurements gathered by linear polarization measurements.

The effect of the addition of the sludge simulant on the cathodic polarization curve is shown visually in Figures 39 (i.e 1 wt.\% oxalic acid) and 40 (2.5 wt.\% oxalic acid). These tests were performed at $75{ }^{\circ} \mathrm{C}$ with agitation. These figures clearly show that the cathodic reaction kinetics were significantly slower in solutions that contain sludge simulants than that in the oxalic acid alone. This conclusion is indicated by the lower exchange current densities. Thus, lower corrosion rates would be anticipated in the presence of sludge. Although the differences are small, it appears that for the 1wt.\% oxalic acid with sludge simulant, the current density for the PUREX is slightly greater than that of the HM. Thus, the oxalic acid with the PUREX simulant is slightly more aggressive than the HM. For the $2.5 \mathrm{wt}$.\% oxalic acid with sludge simulant the opposite was observed; that is the HM appeared to be slightly more aggressive.

Additionally, for the $1 \mathrm{wt} . \%$ oxalic acid solution with sludge simulant the current density is approaching a limiting value after $0.2 \mathrm{~V}$ of cathodic polarization. Thus, even with agitation, the rate of the cathodic reaction is limited by the concentration of the dissolved electro-active species in solution. On the other hand, for the $2.5 \mathrm{wt} \% \%$ oxalic acid solution with sludge simulant the current density continues to increase gradually throughout the whole scan. This result indicates that the concentration of the electroactive species is greater in the $2.5 \mathrm{wt} . \%$ oxalic acid than it is in the $1 \mathrm{wt} . \%$ oxalic acid solution. 


\section{Revision 1}

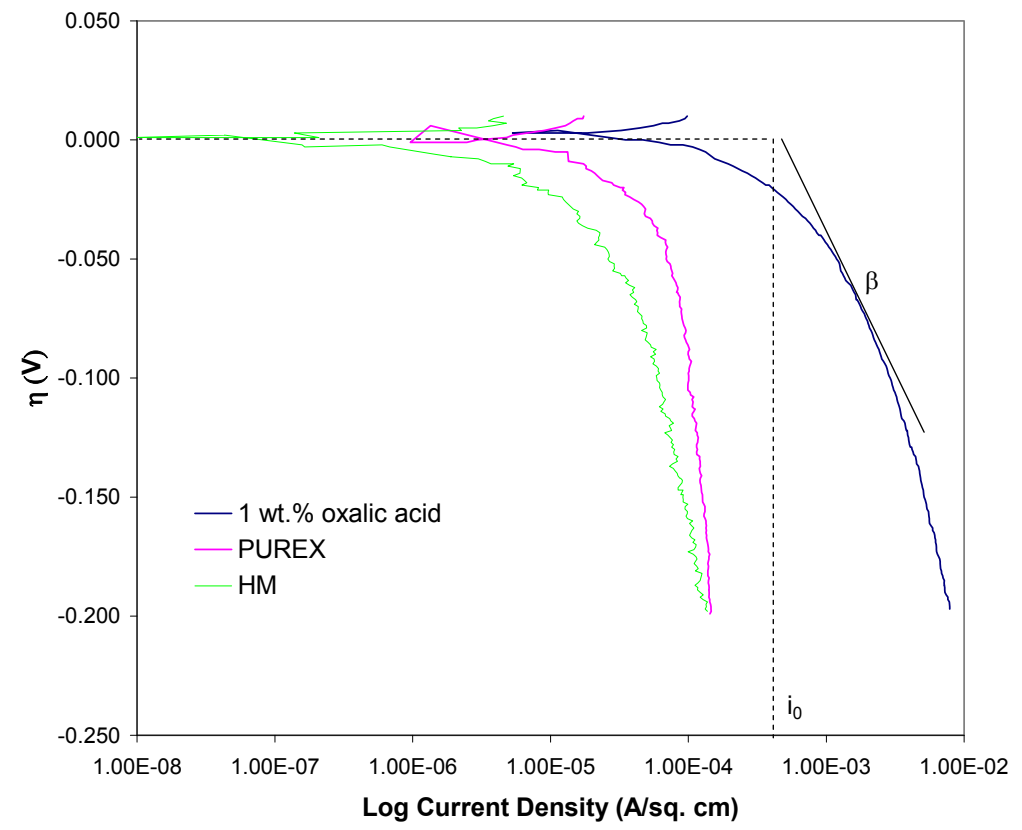

Figure 39. Cathodic polarization curves for the simulants with 1 wt. $\%$ oxalic acid at $75^{\circ} \mathrm{C}$ with agitation.

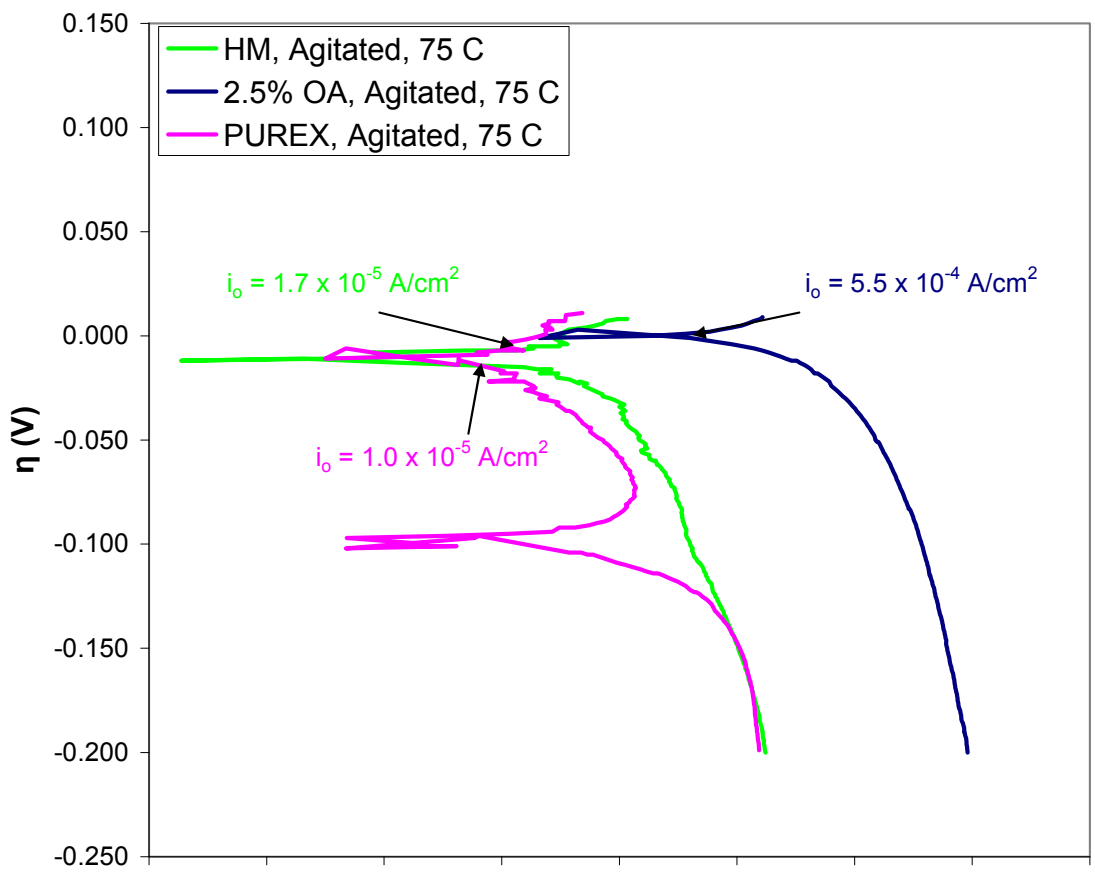

1.00E-09 1.00E-08 1.00E-07 1.00E-06 1.00E-05 1.00E-04 1.00E-03 1.00E-02 1.00E-01

\section{Log Current Density $\left(\mathrm{A} / \mathrm{cm}^{2}\right)$}

Figure 40. Cathodic polarization curves for the simulants with 2.5 wt. \% oxalic acid at $75^{\circ} \mathrm{C}$ with agitation. 


\section{Revision 1}

The effect of agitation is illustrated in Figure 41. These tests were performed with $\mathrm{HM} / 2.5 \mathrm{wt} . \%$ oxalic acid at $50{ }^{\circ} \mathrm{C}$. The exchange current density is approximately an order of magnitude greater for the agitated solution than the non-agitated, indicating that agitation increases the aggressiveness of the solution. The shape of both curves illustrates that at this temperature the cathodic reaction is transport controlled after $0.2 \mathrm{~V}$ of polarization. The limiting current density is also nearly an order of magnitude greater for the agitated solution than for the non-agitated. This result suggests that agitation increases the concentration of the aggressive species in solution.

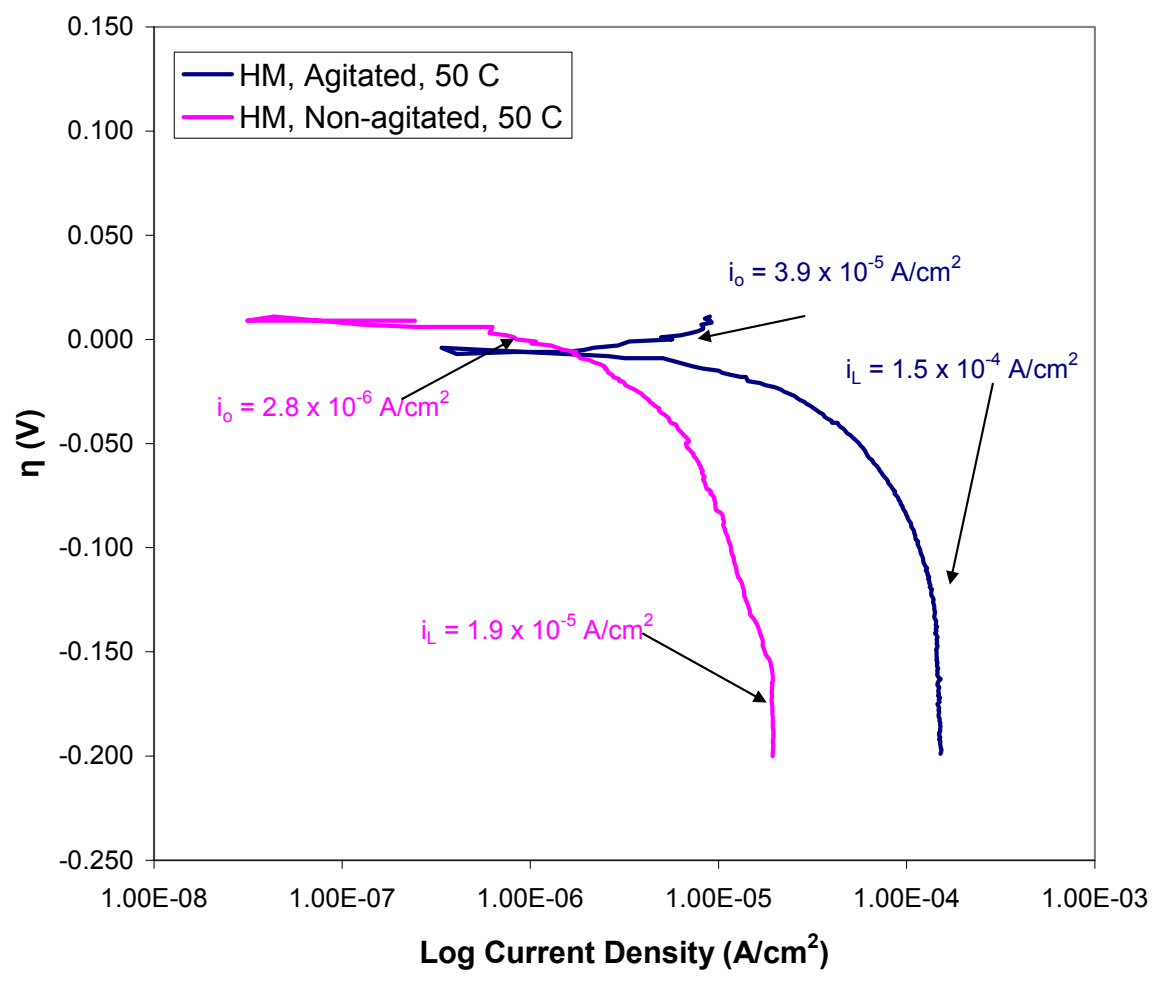

Figure 41. Cathodic polarization curves for $\mathrm{HM} / 2.5$ wt. $\%$ oxalic acid at $50{ }^{\circ} \mathrm{C}$ with and without agitation.

The effect of temperature is illustrated in Figure 42. These tests were performed with $\mathrm{HM} / 2.5 \mathrm{wt} . \%$ oxalic acid at $50{ }^{\circ} \mathrm{C}$ and $75{ }^{\circ} \mathrm{C}$ with no agitation. The exchange current density is approximately a factor of 2 greater for the higher temperature solution, indicating that the solutions are more aggressive at the higher temperature. However, the effect of temperature within the range of these tests is not as great as the effect of agitation. The shape of both curves illustrates that at this temperature the cathodic reaction is transport controlled after $0.2 \mathrm{~V}$ of polarization. The limiting current density is also approximately a factor of 2 greater for the agitated solution than for the non-agitated. This result suggests that temperature increases the concentration of the aggressive species in solution. 


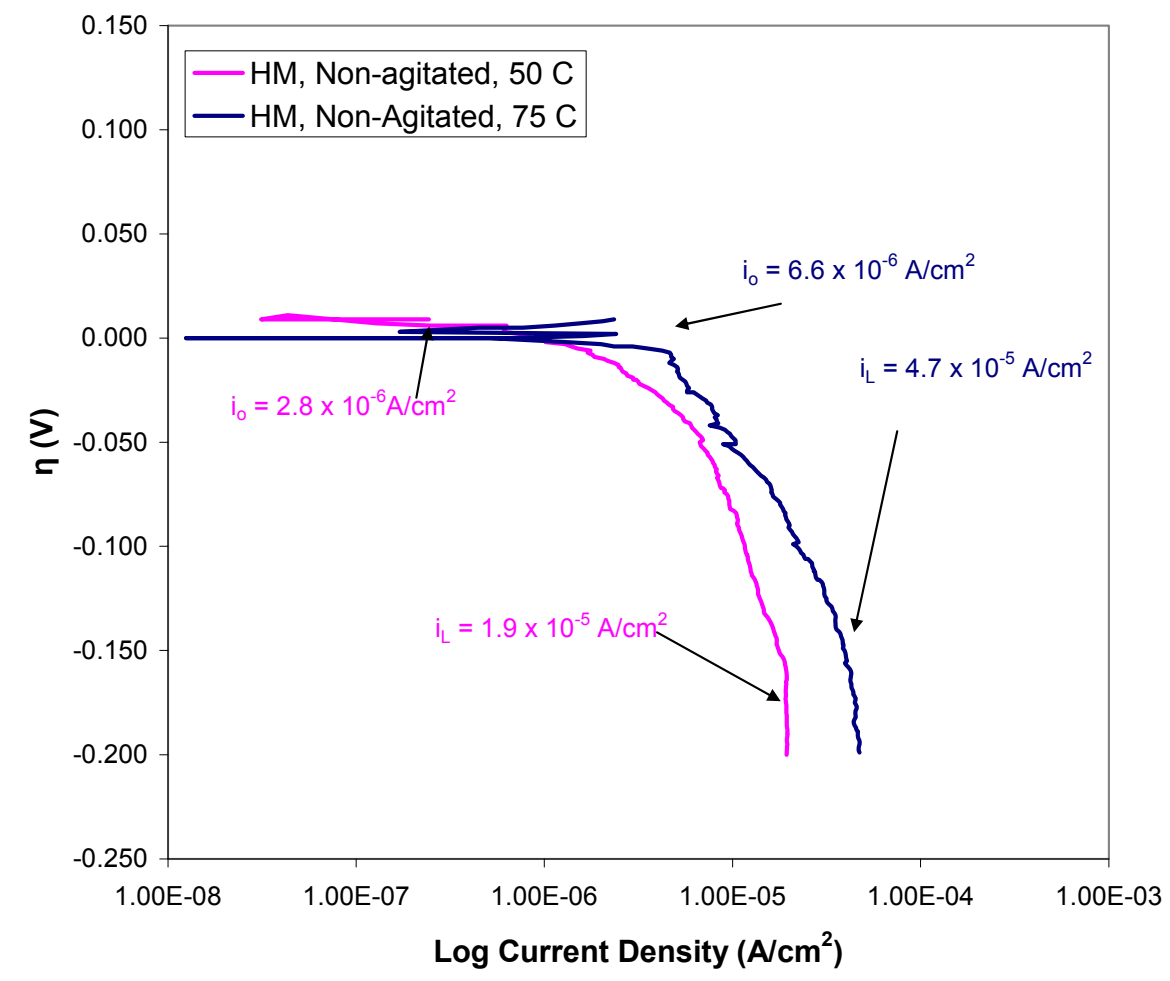

Figure 42. Cathodic polarization curves for $\mathrm{HM} / 2.5 \mathrm{wt} . \%$ oxalic acid at $50{ }^{\circ} \mathrm{C}$ and $75{ }^{\circ} \mathrm{C}$ without agitation.

\subsubsection{Anodic and Cyclic Potentiodynamic Polarization}

Figures 43 and 44 show the results of CPP testing in environments containing $1 \mathrm{wt} . \%$ and 2.5 wt. $\%$ oxalic acid. The tests were performed at $75^{\circ} \mathrm{C}$ with agitation. In both cases negative hysteresis was observed indicating no susceptibility to localized attack. Observation of the samples after testing showed evidence of an oxide or oxalate film on the surface. No evidence of localized attack such as pitting was observed. Therefore, general corrosion of carbon steel with the formation of a passive ferrous oxalate film occurs in both cases. 
Revision 1

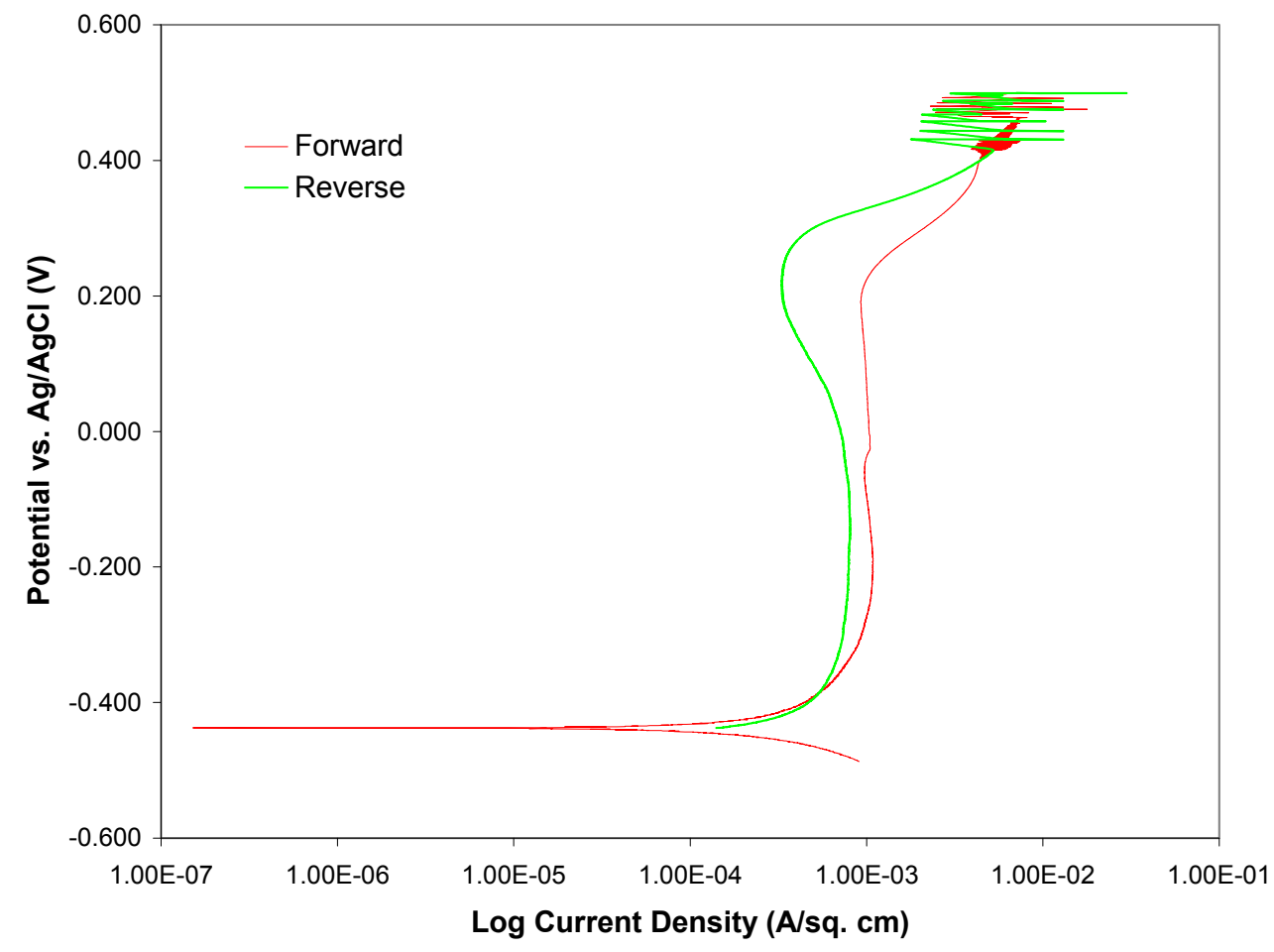

Figure 43. CPP scan in agitated, 1 wt. $\%$ oxalic acid at $75{ }^{\circ} \mathrm{C}$.

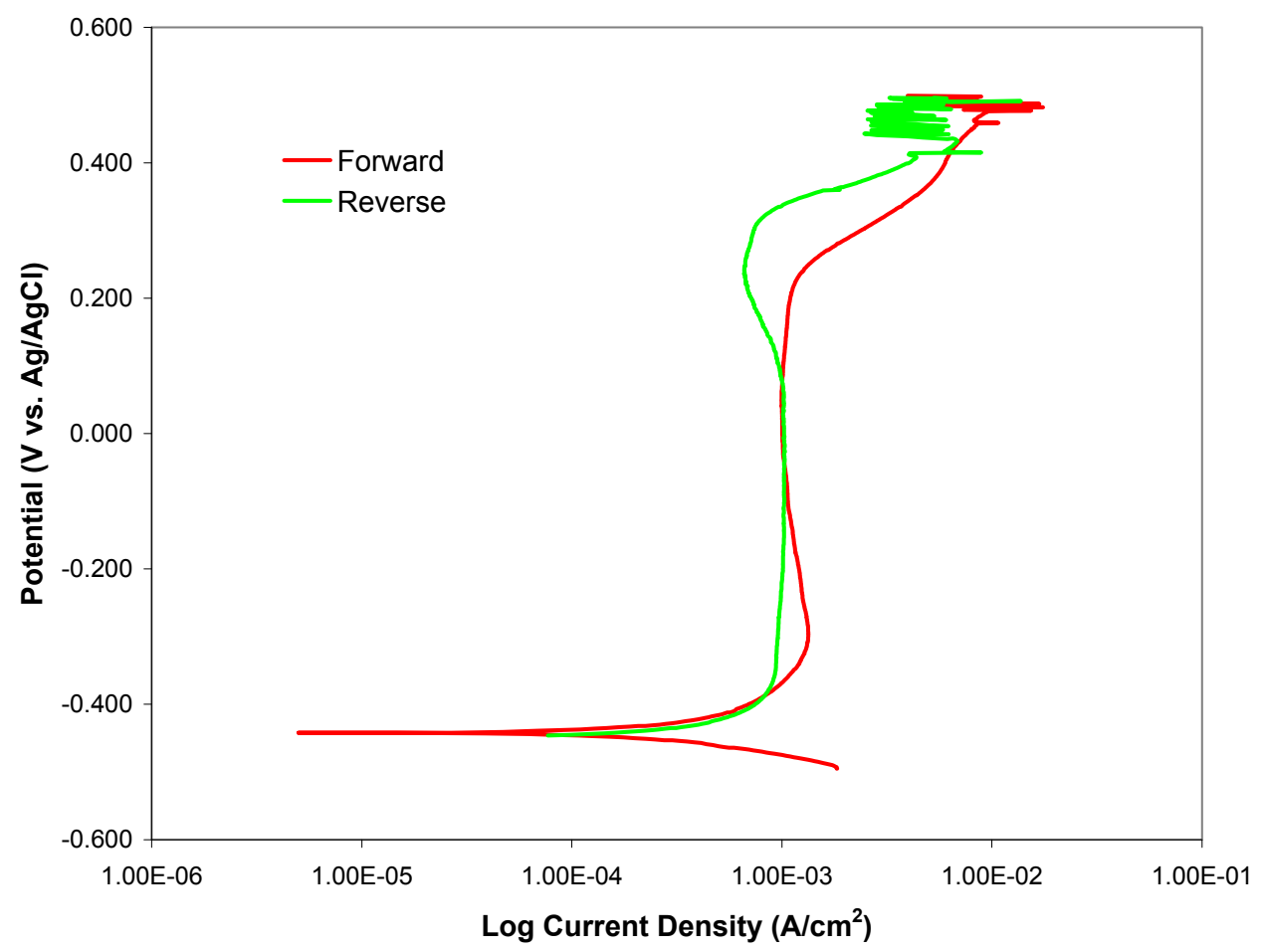

Figure 44. CPP scan in agitated, 2.5 wt. $\%$ oxalic acid at $75{ }^{\circ} \mathrm{C}$. 
Figures 45 and 46 show the results of CPP testing in environments containing $1 \mathrm{wt} \% \%$ and 2.5 wt. $\%$ oxalic acid and the PUREX sludge simulant. The tests were performed at $75{ }^{\circ} \mathrm{C}$ with agitation. Negative hysteresis was observed in the case of the 1 wt.\% oxalic acid test indicating no susceptibility to localized attack. The results from the $2.5 \mathrm{wt} . \%$ test are a little less clear as cross-over occurred on the reverse scan (i.e., the current density of the reverse scan was greater than the forward scan). This result could be an indication that the ferrous oxalate is less protective in this environment. Figure 47 shows the results of CPP testing in environments containing $2.5 \mathrm{wt} . \%$ oxalic acid and the PUREX sludge simulant at $50{ }^{\circ} \mathrm{C}$ with agitation. This case also gave a somewhat unclear result as negative hysteresis, although small, was observed initially followed by cross-over. This further substantiates the notion that the simulant with the $2.5 \mathrm{wt} . \%$ solution is more aggressive. The forward portion of the scan is quite different for the two oxalic acid concentrations. This difference will be discussed further when the anodic polarization scans are discussed.

Observation of the samples after testing showed evidence of an oxide or oxalate film with no evidence of localized attack such as pitting. Therefore, general corrosion of carbon steel with the formation of a passive ferrous oxalate film would be expected in both cases.

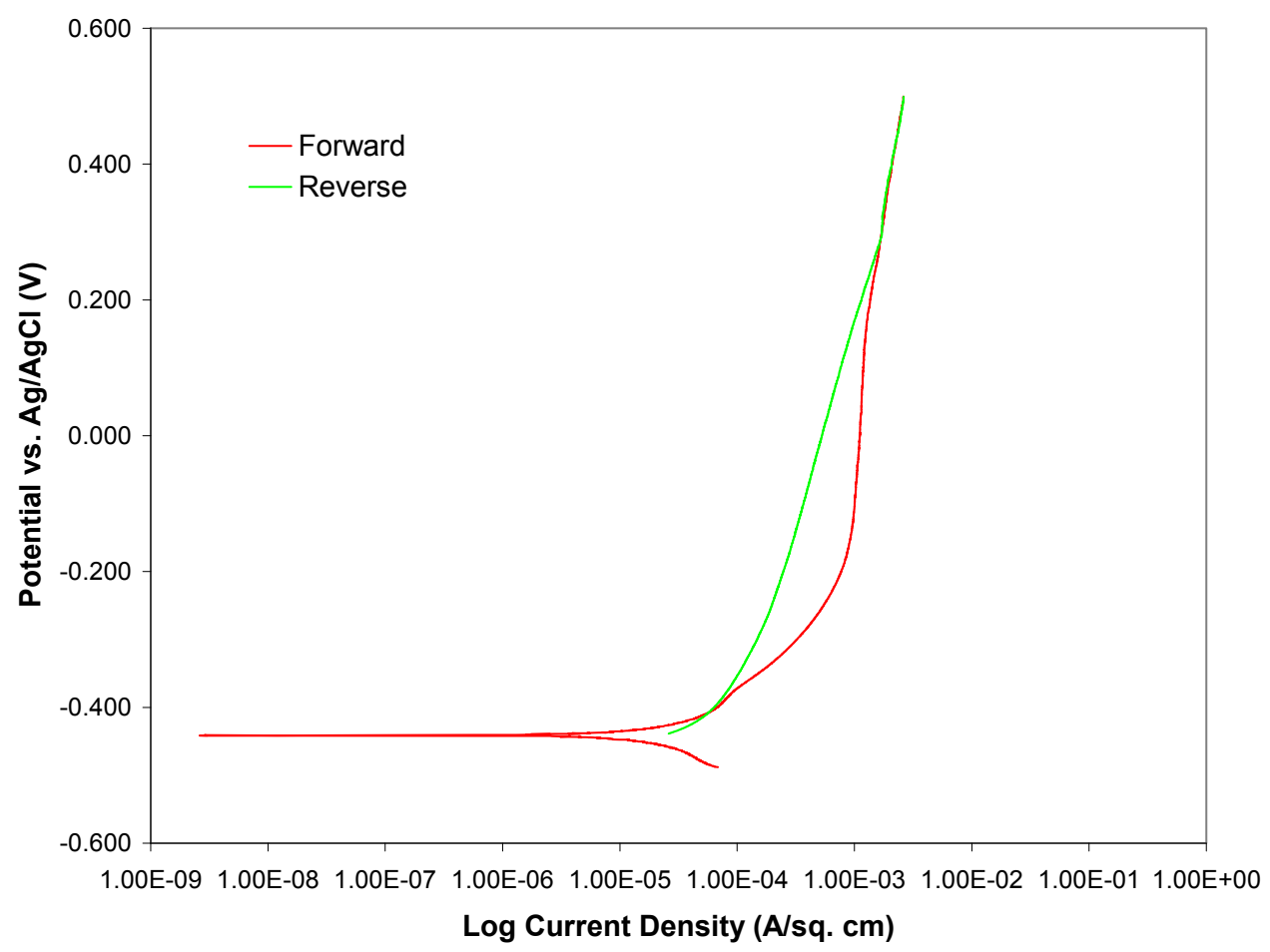

Figure 45. CPP scan in agitated, PUREX/1 wt. \% oxalic acid mixture at $75{ }^{\circ} \mathrm{C}$. 


\section{Revision 1}

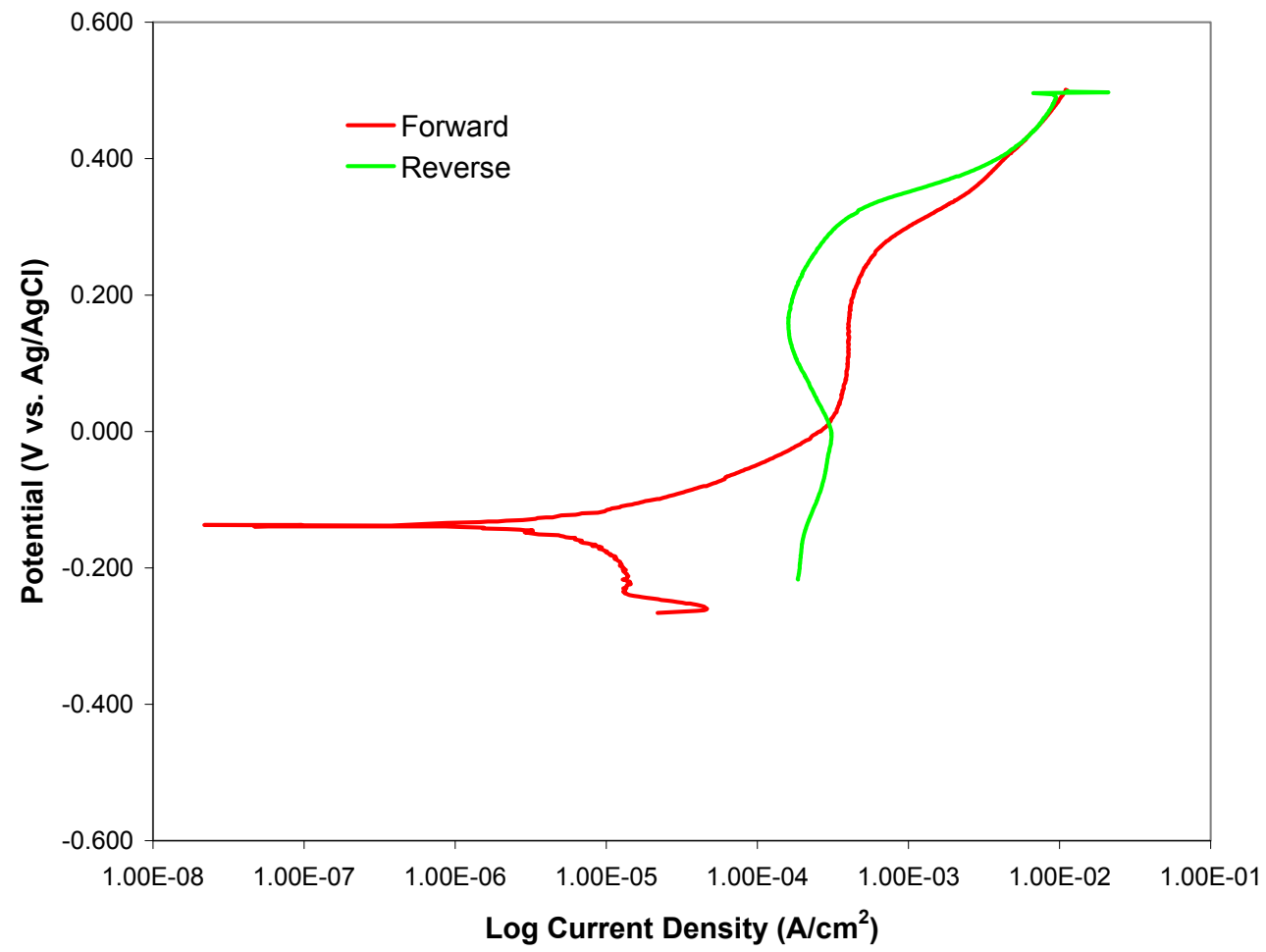

Figure 46. CPP scan in agitated, PUREX/2.5 wt. \% oxalic acid mixture at $75{ }^{\circ} \mathrm{C}$.

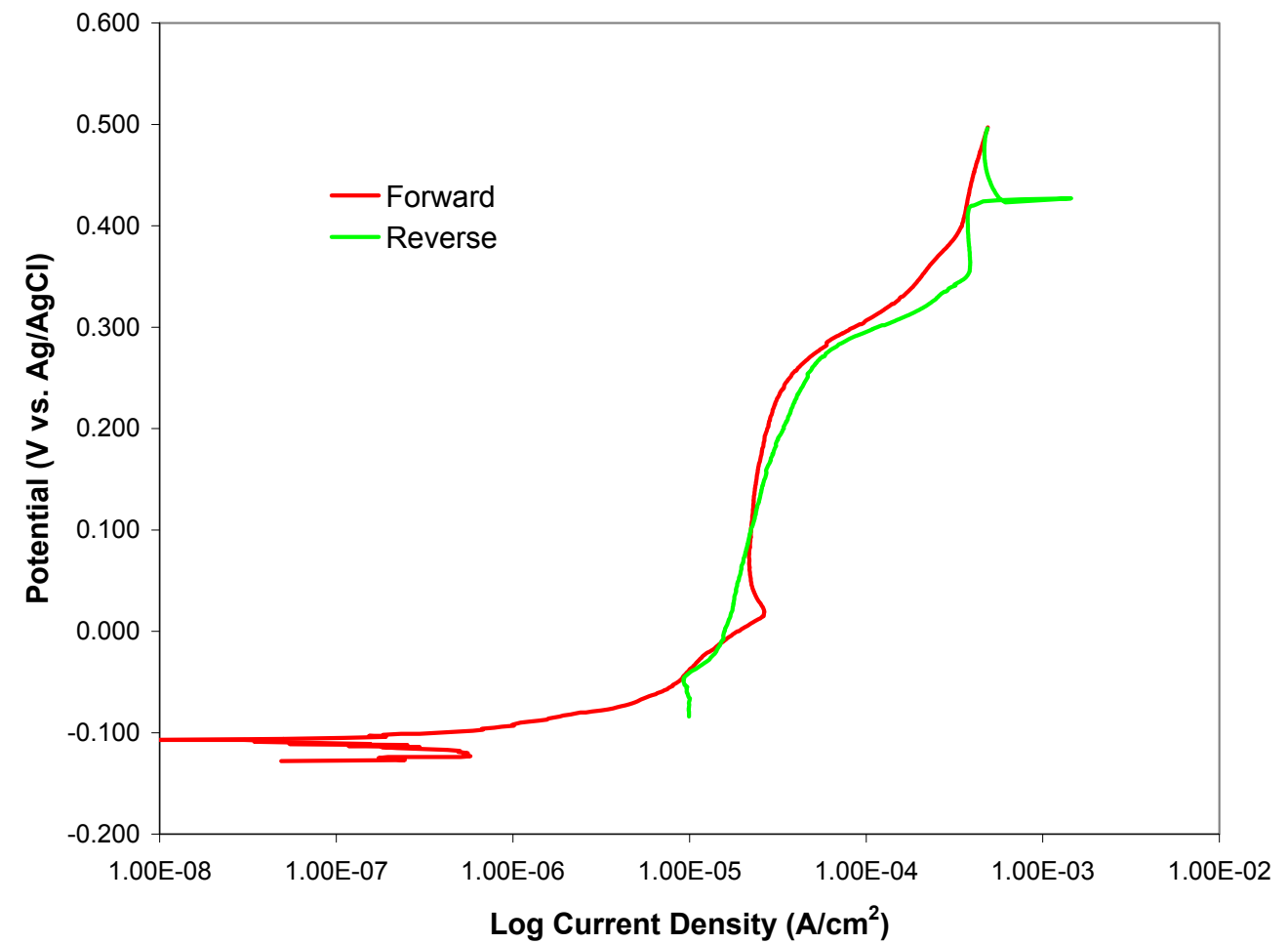

Figure 47. CPP scan in agitated, PUREX/2.5 wt. \% oxalic acid mixture at $50{ }^{\circ} \mathrm{C}$. 


\section{Revision 1}

Figures 48 and 49 show the results of CPP testing in environments containing $1 \mathrm{wt} . \%$ and $2.5 \mathrm{wt} . \%$ oxalic acid and the HM sludge simulant. The tests were performed at $75{ }^{\circ} \mathrm{C}$ with agitation. Negative hysteresis was observed initially in both cases, however, crossover was also observed on the reverse scan. This result is unclear and indicates that the HM simulant may result in localized attack at either oxalic acid concentration. Figure 50 shows the the results of CPP testing in environments containing $2.5 \mathrm{wt} \% \%$ oxalic acid and the $\mathrm{HM}$ sludge simulant at $75^{\circ} \mathrm{C}$ without agitation. This case also gave a somewhat unclear result as negative hysteresis, although small, was observed initially followed by cross-over. All these results indicate that carbon steel may be more susceptible to localized attack in the HM simulant than with the PUREX. The forward scans in all three cases were very similar, however, they are unlike that for the PUREX simulant. These differences will be explored later when the anodic polarization scans are discussed.

Observation of the samples after testing showed evidence of an oxide or oxalate film with no evidence of localized attack such as pitting (see Figure 51). Therefore, general corrosion of carbon steel, with the formation of a passive ferrous oxalate film, would be expected in both cases.

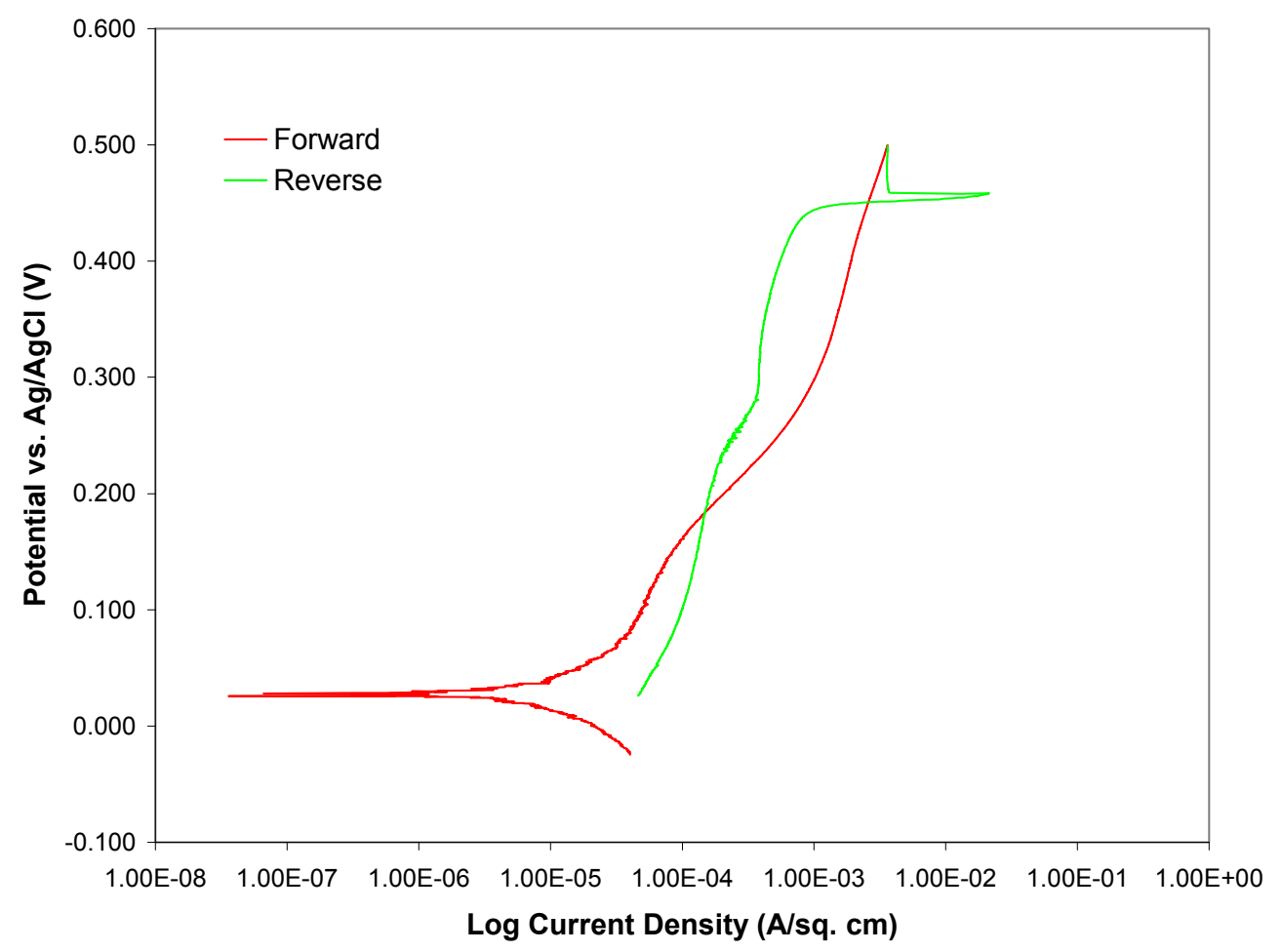

Figure 48. CPP scan in agitated, HM/1 wt.\% oxalic acid mixture at $75{ }^{\circ} \mathrm{C}$. 
Revision 1

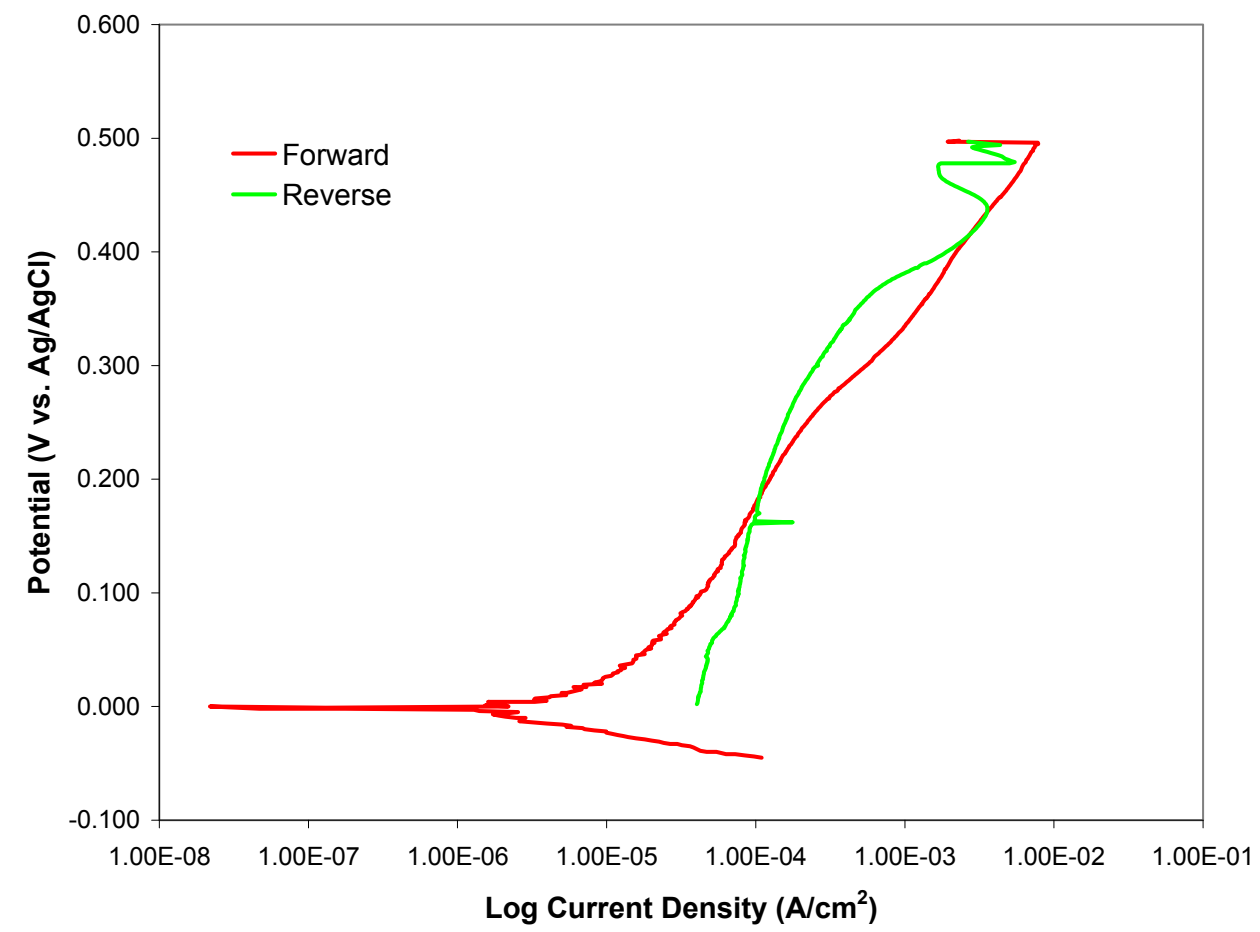

Figure 49. CPP scan in agitated, HM/2.5 wt. \% oxalic acid mixture at $75^{\circ} \mathrm{C}$.

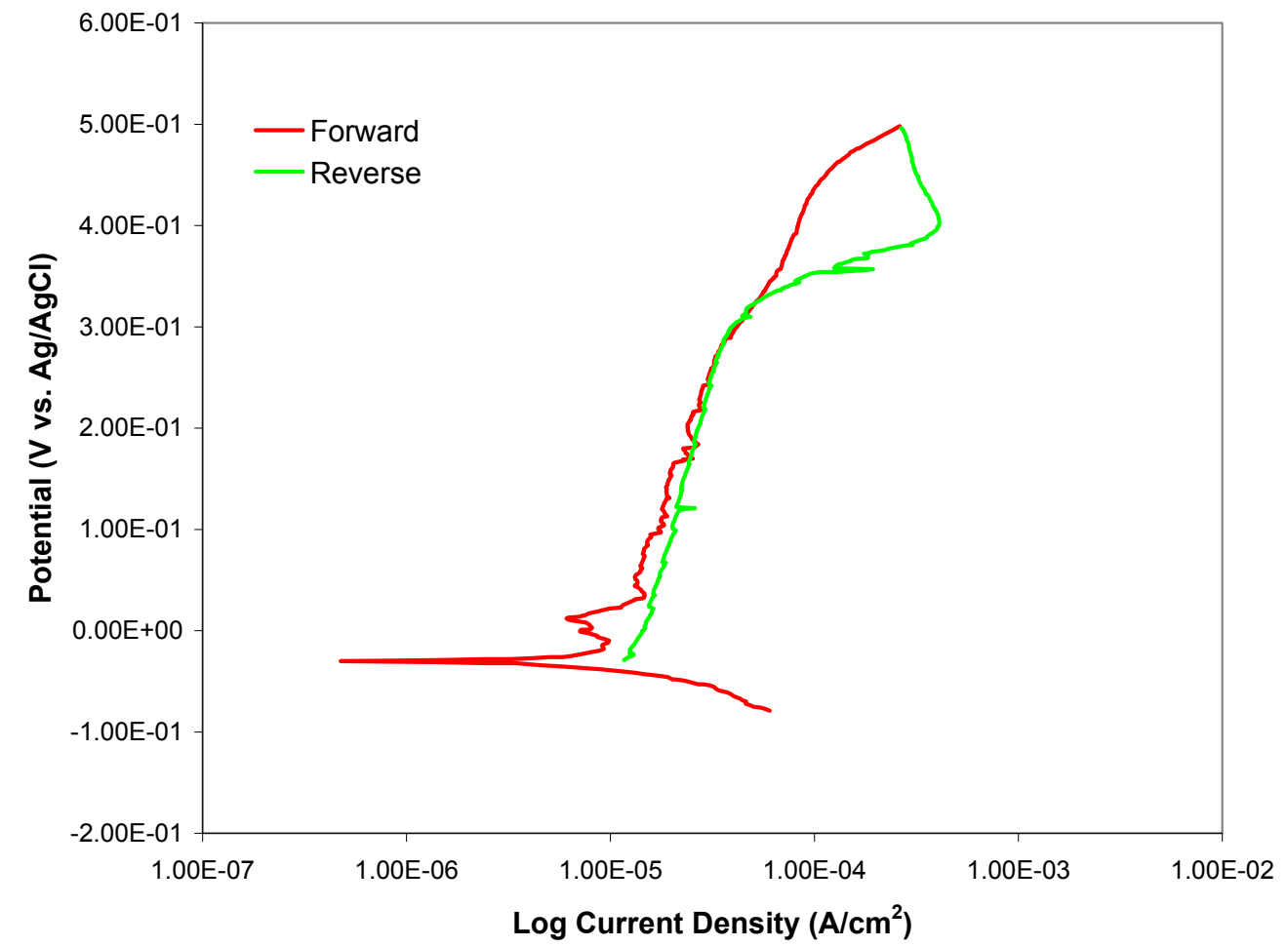

Figure 50. CPP scan in non-agitated, HM/2.5 wt.\% oxalic acid mixture at $75{ }^{\circ} \mathrm{C}$. 


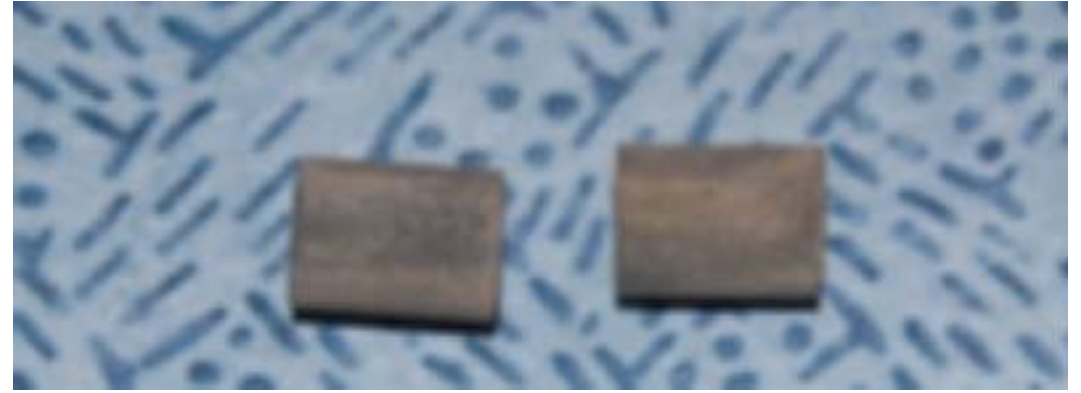

Figure 51. Photograph of electrochemical samples after testing in agitated, $\mathrm{HM} / 1$ wt. \% oxalic acid mixture at $75^{\circ} \mathrm{C}$.

Figure 52 shows the results of CPP testing in environments containing 1 wt. $\%$ with the HM-PUREX sludge simulant. The tests were performed at $75^{\circ} \mathrm{C}$ with agitation.

Negative hysteresis was observed initially, however, cross-over was also observed late in the reverse scan. This result is also unclear and indicates that the HM-PUREX simulant may result in localized attack at either oxalic acid concentration. The shape of the scan appears to be more similar to that of the PUREX. The late cross-over, may reflect the presence of the HM sludge simulant. Thus, the environment is more aggressive than that with the PUREX simulant, but not as aggressive as that with the HM simulant.

Observation of the sample after testing showed evidence of an oxide or oxalate film with no evidence of localized attack such as pitting. Therefore, general corrosion of carbon steel with the formation of a passive ferrous oxalate film would be expected. 


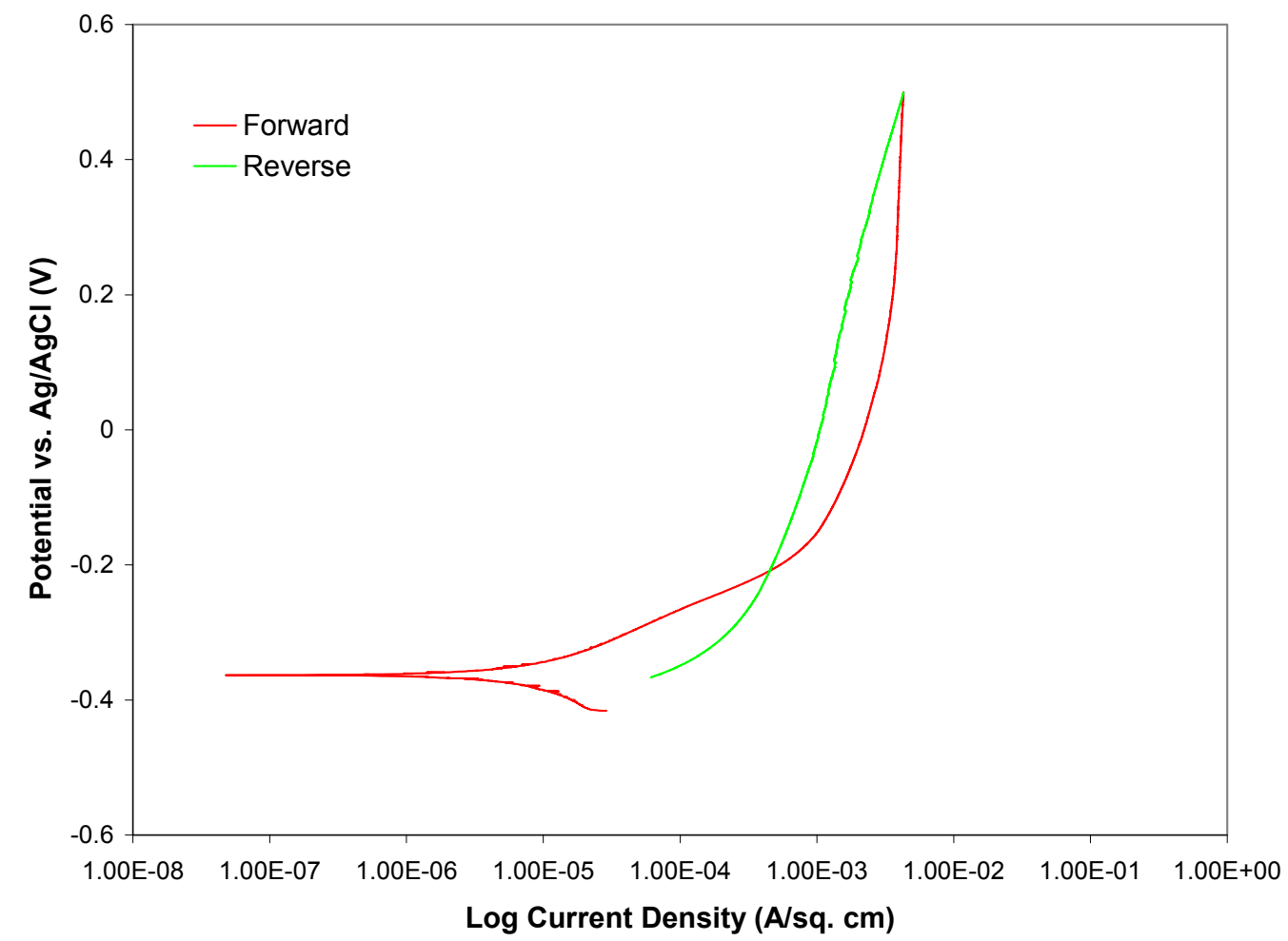

Figure 52. CPP scan in agitated, HM-PUREX/1 wt.\% oxalic acid mixture at $75{ }^{\circ} \mathrm{C}$.

Close examination of the CPP curves however, indicates that there are differences in the corrosion behavior of the test material for the simulants that are illustrated by analyzing the forward, or anodic, scan. Therefore, the remaining analyses have been focused on the development of mechanistic information from anodic polarization scans (i.e., the forward portion of the CPP scan).

Figure 53 shows superimposed anodic polarization diagrams in environments containing $1 \mathrm{wt} . \%$ oxalic acid and the 3 simulants with agitation at $75^{\circ} \mathrm{C}$. The oxalic acid, PUREX, and HM-PUREX blend solutions had similar behavior. All diagrams showed very similar OCP, however, $\mathrm{I}_{\mathrm{p}}$ for the oxalic acid was slightly lower than the other two simulants indicating a more protective oxalate film is present. A breakdown potential at approximately $0.200 \mathrm{~V}$ was observed for the $1 \mathrm{wt} . \%$ oxalic acid solution. This breakdown potential has been identified as being due to destruction of the ferrous oxalate film. A similar breakdown potential was observed for the PUREX simulant, however, it occurred at a lower potential $(\sim 0.05 \mathrm{~V})$. The smaller difference between $\mathrm{E}_{\text {corr }}$ and $\mathrm{E}_{\mathrm{b}}$ and the higher $\mathrm{I}_{\mathrm{p}}$, for the PUREX simulant compared to the oxalic acid solution indicates that the oxalate film was not as protective in this solution. A similar breakdown was not observed for the HM-PUREX blend simulant. However, the OCP was shifted toward more positive potentials. This result is likely due to the influence of the HM simulant present in the sludge. Given that the oxalate film is not as protective in the PUREX and HM-PUREX simulants, it is likely that the reduction in the corrosion rate is due to a change in the cathodic kinetics. Even though the OCP is below the potential where 
hydrogen evolution is thermodynamically possible, another anodic reaction is responsible for the depression of the corrosion rate. A likely candidate for the cathodic reaction is the reduction of the di-oxaltoferrate ion.

The most dramatic difference in the anodic polarization scan was observed in the presence of HM simulant. The OCP was significantly noble and as a result the magnitudes of $i_{0}$ and $I_{p}$ were much lower. These observations suggest that the ferrous oxalate film is more protective at the OCP than in the other simulants and oxalic acid and that a different cathodic reaction may occur. However, the breakdown potential was observed at approximately $0.200 \mathrm{~V}$. This potential is similar to the breakdown potential for the ferrous oxalate species in the $1 \mathrm{wt} . \%$ oxalic acid solution. The proximity of the breakdown potential to $\mathrm{E}_{\text {corr }}$ indicates that the ferrous oxalate film will not be very stable in these solutions should there be a relatively small change in the potential from OCP, and thus could be more susceptible to breaking down leading to higher general corrosion rates. This observation agrees with the results for the OCP, which based on the potential fluctuations, indicated an unstable film had formed on the surface in the HM solutions.

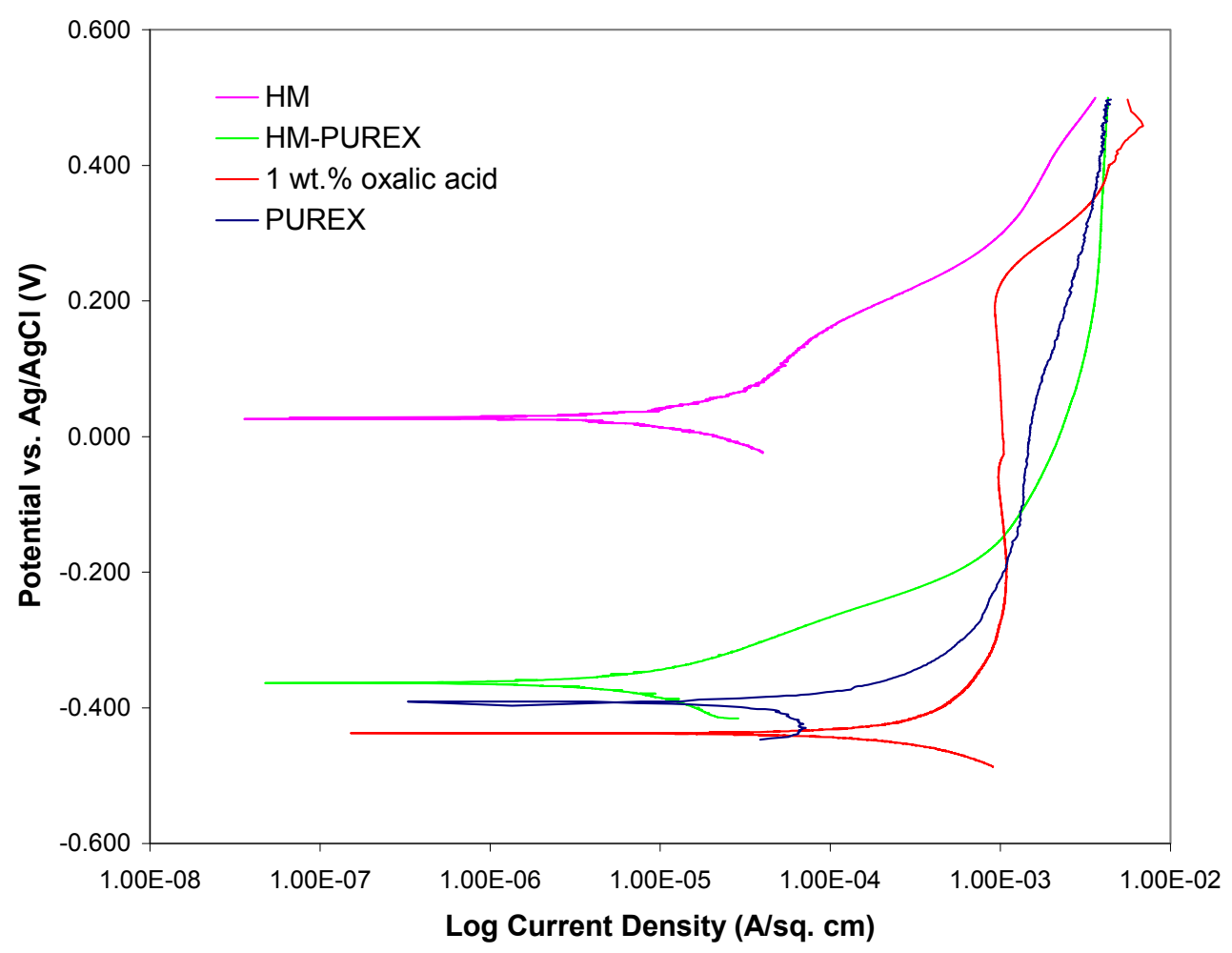

Figure 53. Anodic polarization scans for the different simulants with 1 wt.\% oxalic acid at $75{ }^{\circ} \mathrm{C}$ with agitation.

Figure 54 shows superimposed anodic polarization diagrams in environments containing 2.5 wt. $\%$ oxalic acid and the HM and PUREX simulants under agitation at $75^{\circ} \mathrm{C}$. The behavior of the $2.5 \mathrm{wt} . \%$ oxalic acid is very similar to the $1 \mathrm{wt} . \%$ oxalic acid. The scan for the PUREX simulant exhibited a passive region, although the current density is at 
lower value than for the pure oxalic acid. The scan for the HM simulant exhibited even less of a passive regime than the PUREX. A breakdown potential at approximately 0.200 $\mathrm{V}$ for both the PUREX and HM were observed. This breakdown potential is associated with the destruction of the ferrous oxalate film. Given that the value of $\mathrm{E}_{\text {corr }}$ for the HM simulant is closer to this breakdown potential than that for the PUREX simulant, this suggests that carbon steel in the HM simulant would be more susceptible to localized attack due to loss of the ferrous oxalate film. The results of these scans also suggest that both PUREX and HM are more susceptible to localized attack in the $2.5 \mathrm{wt} . \%$ oxalic acid than the $1 \mathrm{wt} . \%$ oxalic acid.

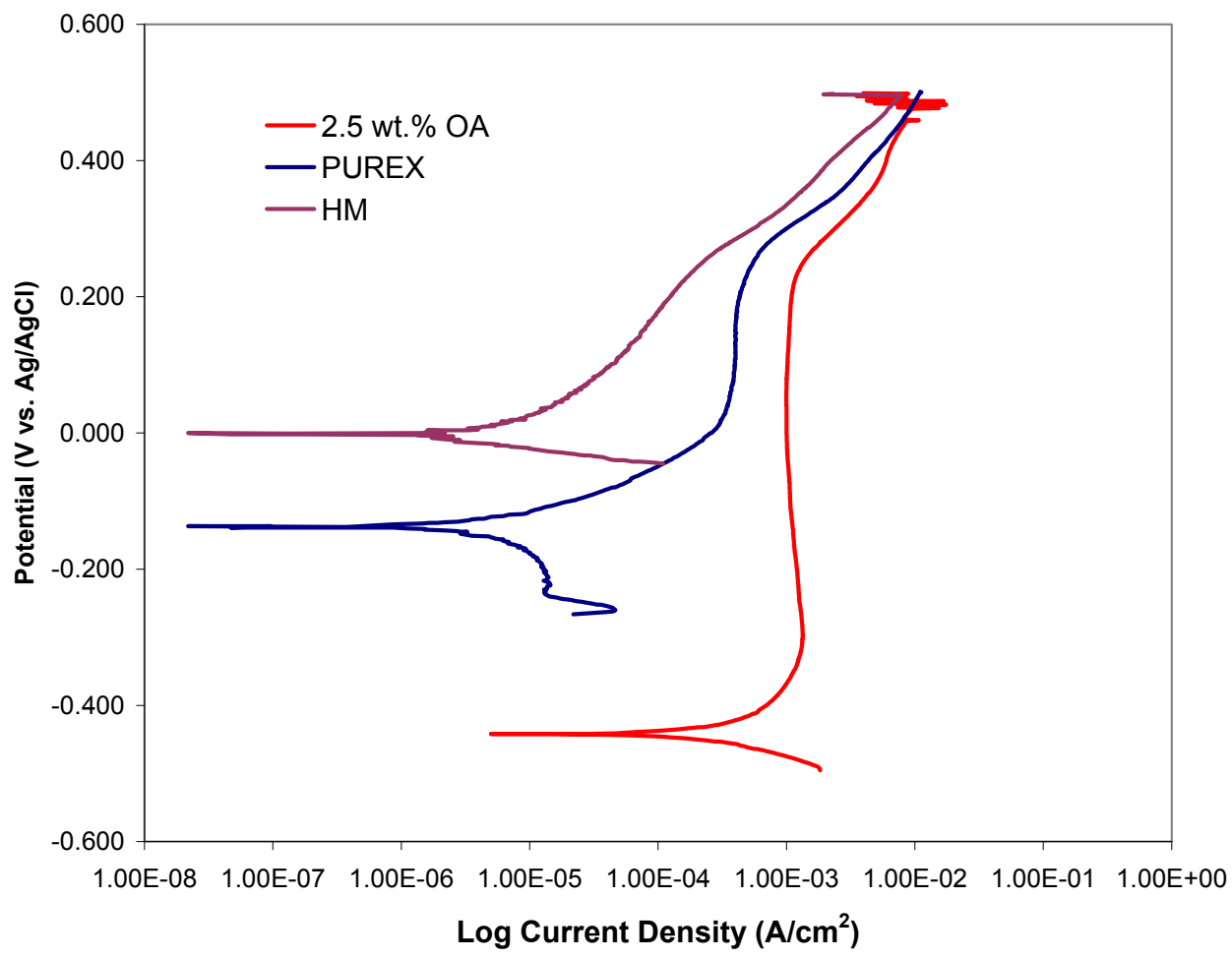

Figure 54. Anodic polarization scans for the different simulants with 2.5 wt.\% oxalic acid at $75^{\circ} \mathrm{C}$ with agitation.

The effect of agitation and temperature on the development of the ferrous oxalate film was investigated for each simulant. Figure 55 shows the effects for the PUREX/1 wt.\% oxalic acid simulant. In this simulant, agitation resulted in higher anodic current densities than those observed in the non-agitated condition at both temperatures. The higher passive current densities are indicative of a higher corrosion rate and a passive film that is not as protective. Removal of the ferrous ion from the surface by the agitation or substitution of solids species into the oxalate film, as opposed to the formation of the ferrous oxalate could reduce the effectiveness of the oxalate film.

Figure 55 also shows that the current density increased with temperature. A less protective oxalate film would allow for the metal dissolution reaction to occur more 


\section{Revision 1}

easily. Thus, an increase in the corrosion rate with increasing temperature would be expected.

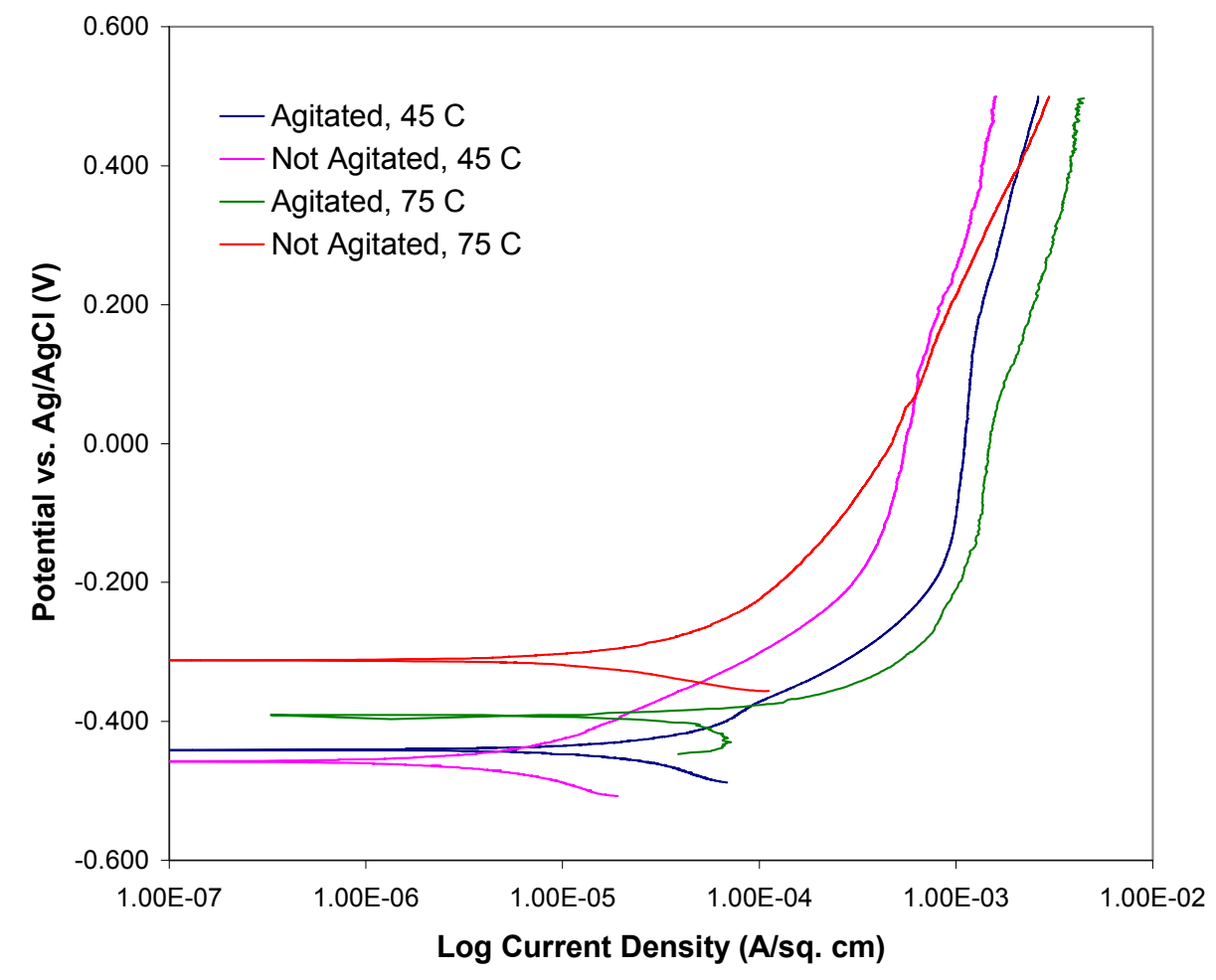

Figure 55. Anodic polarization scans for the PUREX/1wt.\% oxalic acid mixture.

Figure 56 is the x-ray diffraction (XRD) result for the sample after the CPP scan in the agitated PUREX/1 wt.\% oxalic acid solution at $75^{\circ} \mathrm{C}$. Only the ferric oxide akageneite was present on the surface. There were no ferrous species, including ferrous oxalate, observed on the sample, which indicates that the ferrous oxalate species had been altered during the scan. In Figure 56 an increase in the current density is observed at approximately $0.15 \mathrm{~V}$. This increase is similar to that observed for oxalic acid at approximately $0.2 \mathrm{~V}$. The observation that the current increase occurs at a lower potential in the simulant than the oxalic acid, indicates that the oxalate layer is not as protective. 


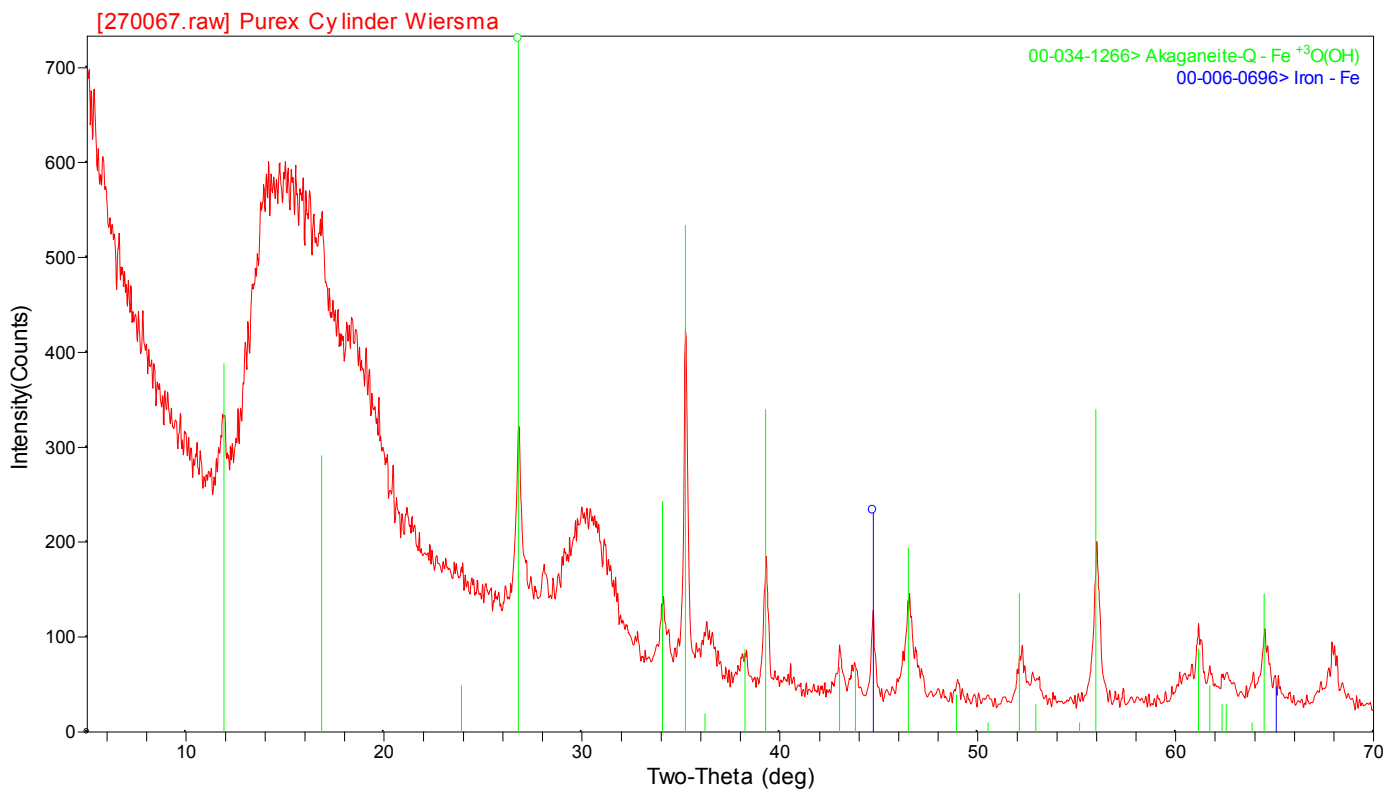

Figure 56. XRD results for electrochemical sample exposed to the PUREX/1 wt.\% oxalic acid mixture.

Figure 57 shows the environmental effects for the PUREX/2.5 wt.\% oxalic acid simulant. All four environments exhibited a certain degree of passivation followed by breakdown of the ferrous oxalate at approximately $0.2 \mathrm{~V}$ vs. $\mathrm{Ag} / \mathrm{AgCl}$. In this simulant, agitation resulted in higher anodic current densities than those observed in the non-agitated condition at both temperatures. The higher passive current densities are indicative of a higher corrosion rate and less protective film that is not as protective. Removal of the ferrous ion from the surface by the agitation or substitution of solids species into the oxalate film, as opposed to the formation of the ferrous oxalate, could reduce the effectiveness of the oxalate film.

Figure 57 also shows that the current density increased with temperature. The scans performed at the lower temperature exhibited an anodic peak at approximately $0.05 \mathrm{~V}$ vs $\mathrm{Ag} / \mathrm{AgCl}$. This likely reflects the formation of the ferrous oxalate film. Given that the difference between $\mathrm{E}_{\text {corr }}$ and the breakdown potential is less for the lower temperature, it appears that the metal may be more susceptible to localized corrosion at the lower temperatures. However, the current densities for the $50^{\circ} \mathrm{C}$ tests are very low and therefore any attack that initiated may be relatively minor. On the other hand, the current densities for the $75^{\circ} \mathrm{C}$ are nearly two orders of magnitude greater than those at $50{ }^{\circ} \mathrm{C}$. Thus, if localized corrosion were to initiate, the degree of corrosion would likely be much more severe at the higher temperature. 


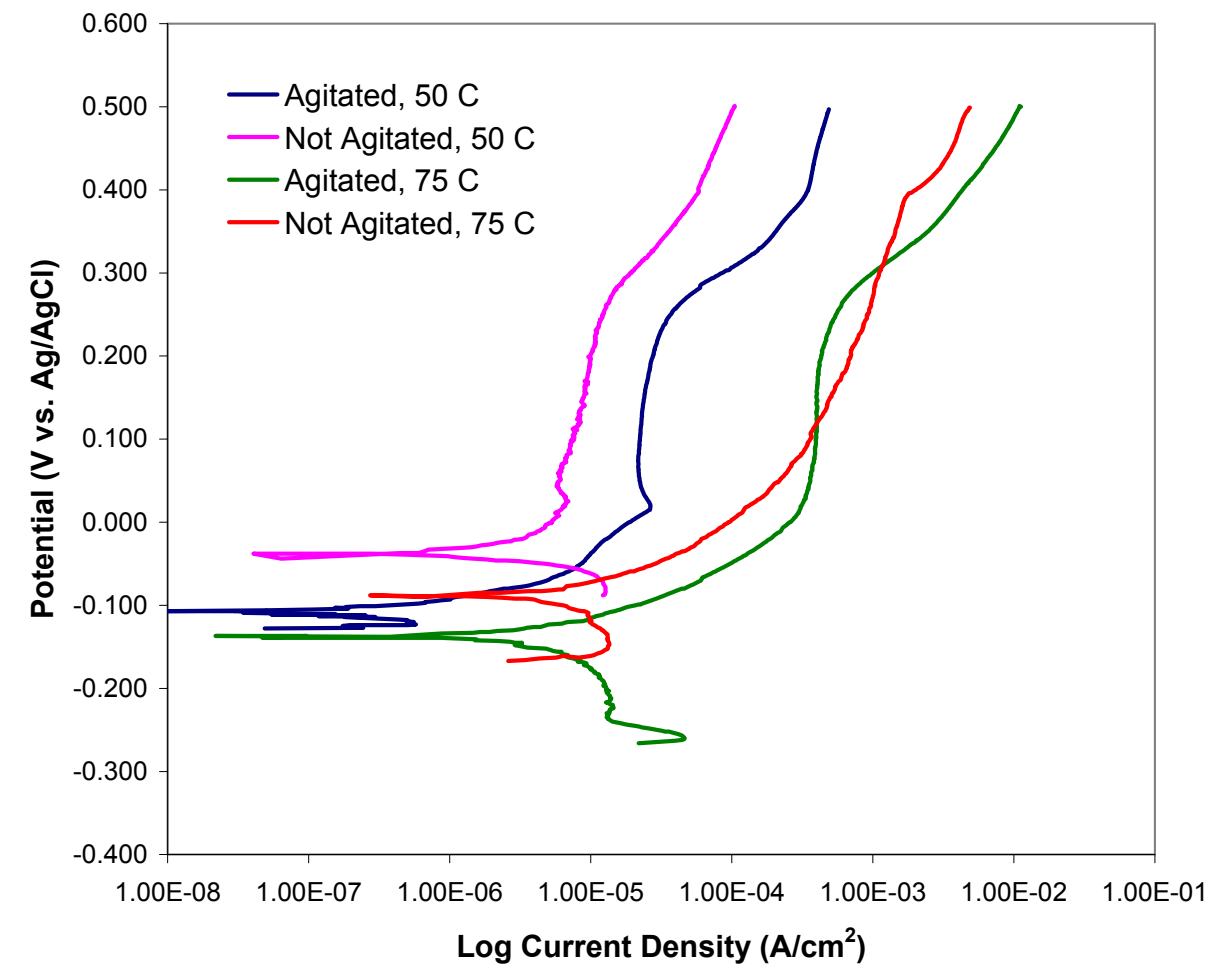

Figure 57. Anodic polarization scans for the PUREX/2.5 wt.\% oxalic acid mixture.

Figure 58 shows that the effects of agitation and temperature for the HM/1 wt $\%$ oxalic acid simulant are more dramatic than those observed for the PUREX/1 wt.\% oxalic acid simulant (see Figure 55). In this simulant, agitation also results in higher anodic current densities than those observed in the non-agitated condition at both temperatures. The higher anodic current densities are indicative of a ferrous oxalate film that is not as protective. Removal of the ferrous ion from the surface by the agitation or substitution of solids species into the oxalate film in preference to the formation of the ferrous oxalate could reduce the effectiveness of the oxalate film. One interesting aspect of the $45^{\circ} \mathrm{C}$ test is that the breakdown of the oxalate film in the agitated solution occurs at a much lower potential than the non-agitated condition. Thus mixing has a strong effect on the stability of the ferrous oxalate film that forms in the HM simulant. The slower anodic kinetics (i.e., ferrous ion production) coupled with the removal of the ferrous ions from the surface of the metal would result in a thinner protective oxalate film.

This figure also shows that the current density increases with temperature. A less protective oxalate film would allow for the metal dissolution reaction to occur more easily. Thus, an increase in the corrosion with temperature would be expected. 


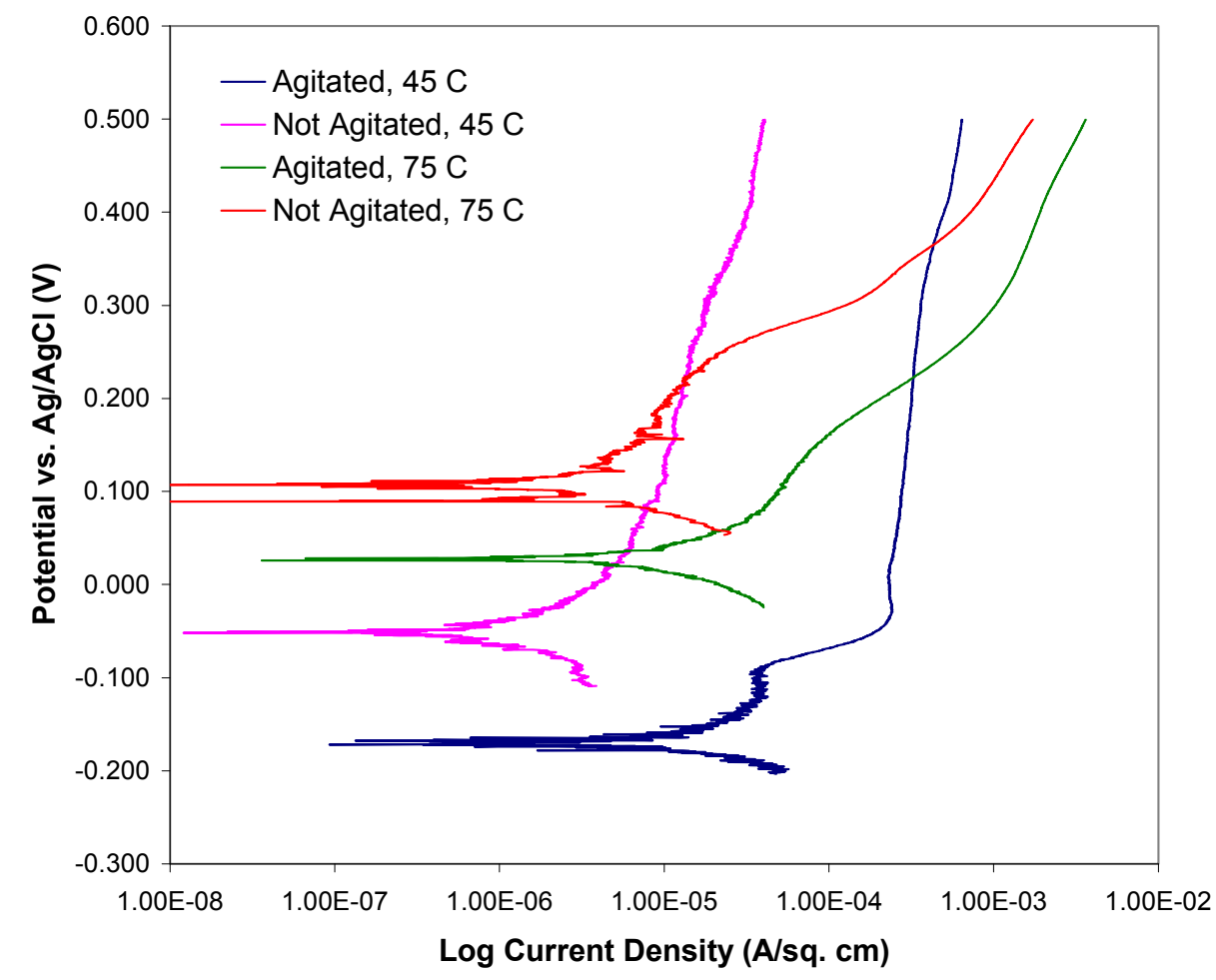

Figure 58. Anodic polarization scans for the HM/1wt.\% oxalic acid mixture.

Figure 59 shows that the effects of agitation and temperature for the HM/2.5 wt $\%$ oxalic acid simulant. In this simulant, both scans performed at $50{ }^{\circ} \mathrm{C}$ exhibited some degree of passivation followed by breakdown of ferrous oxalate at approximately $0.2 \mathrm{~V}$ vs.

$\mathrm{Ag} / \mathrm{AgCl}$. Agitation did result in a higher current density, which is again indicative of a ferrous oxalate film that is not as protective. Removal of the ferrous ion from the surface by the agitation or substitution of solids species into the oxalate film in preference to the formation of the ferrous oxalate could reduce the effectiveness of the oxalate film. The tests at $75^{\circ} \mathrm{C}$ resulted in unique results. In the case of both the agitated and non-agitated no passive region was observed. Thus, either spontaneous active corrosion or localized corrosion may exist. Given the difference in current density, one might expect that spontaneous localized corrosion would occur without agitation, while higher general corrosion rates might be exhibited with agitation.

Figure 59 also shows that the current density increases with temperature. The unique result in this case was that the difference in the current density for the $50{ }^{\circ} \mathrm{C}$ and $75{ }^{\circ} \mathrm{C}$ with no agitation was not significant. A possible explanation for this observation is that the OCP is at a value where ferrous oxalate does not form. This explanation is further substantiated due to the lack of an active peak at $0.05 \mathrm{~V}$ vs. $\mathrm{Ag} / \mathrm{AgCl}$. If localized attack were to occur, the most severe case would be at $75^{\circ} \mathrm{C}$. 


\section{Revision 1}

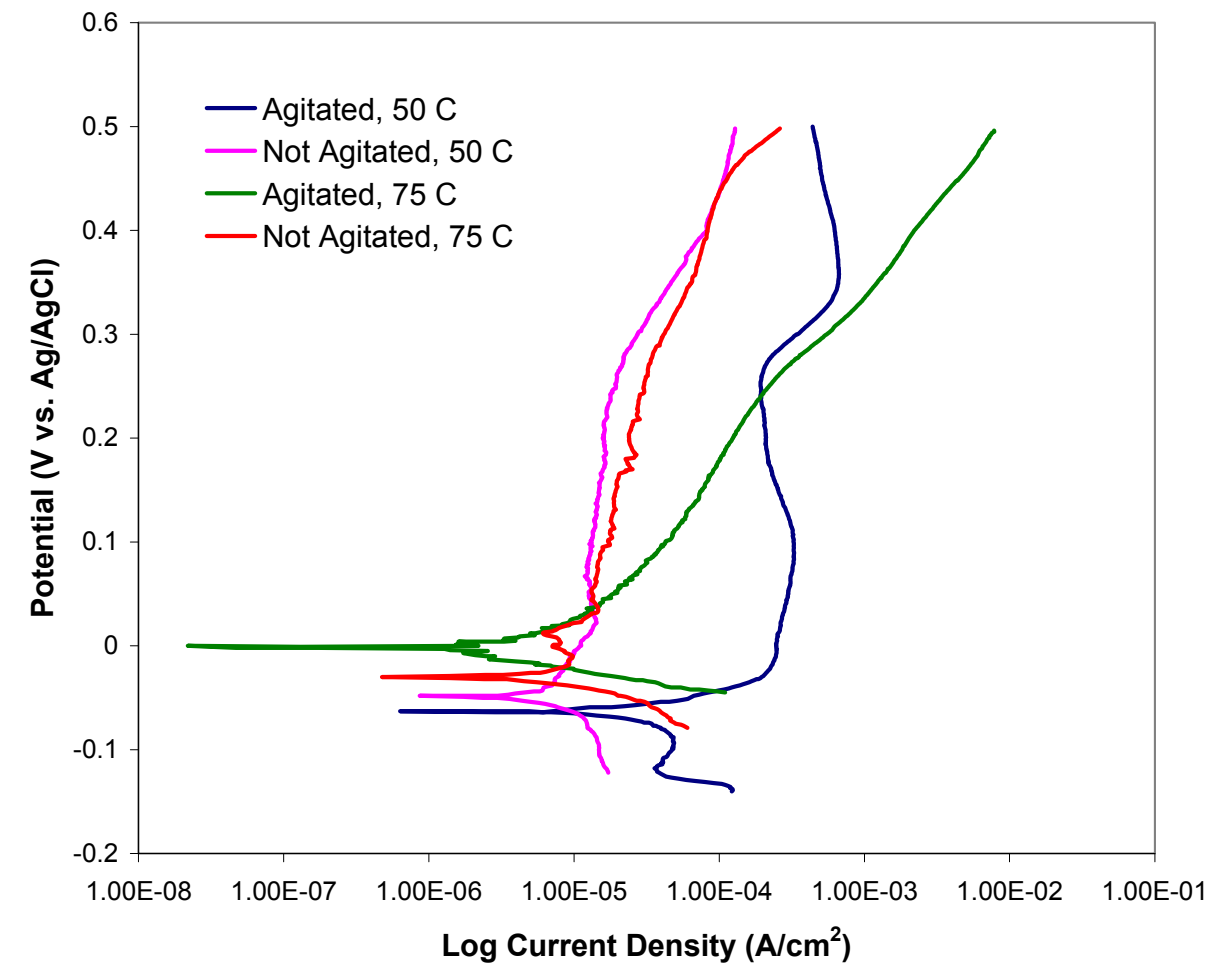

Figure 59. Anodic polarization scans for the HM/2.5wt. \% oxalic acid mixture.

Figure 60 shows that the effects of agitation and temperature for the HM-PUREX/1 wt.\% oxalic acid simulant are rather insignificant. The shape of the curves is very similar to that of the PUREX/1 wt.\% oxalic acid simulant. However, the current densities are greater in this simulant than those observed for the PUREX simulant. Thus the ferrous oxalate film that forms is not as protective. However, the corrosion rates measured in this environment by LPR were lower than that observed for PUREX and are of the same magnitude as the HM simulant. This indicates that the slower cathodic reaction rates are responsible for the low corrosion rates that are observed near the open circuit potential. 


\section{Revision 1}

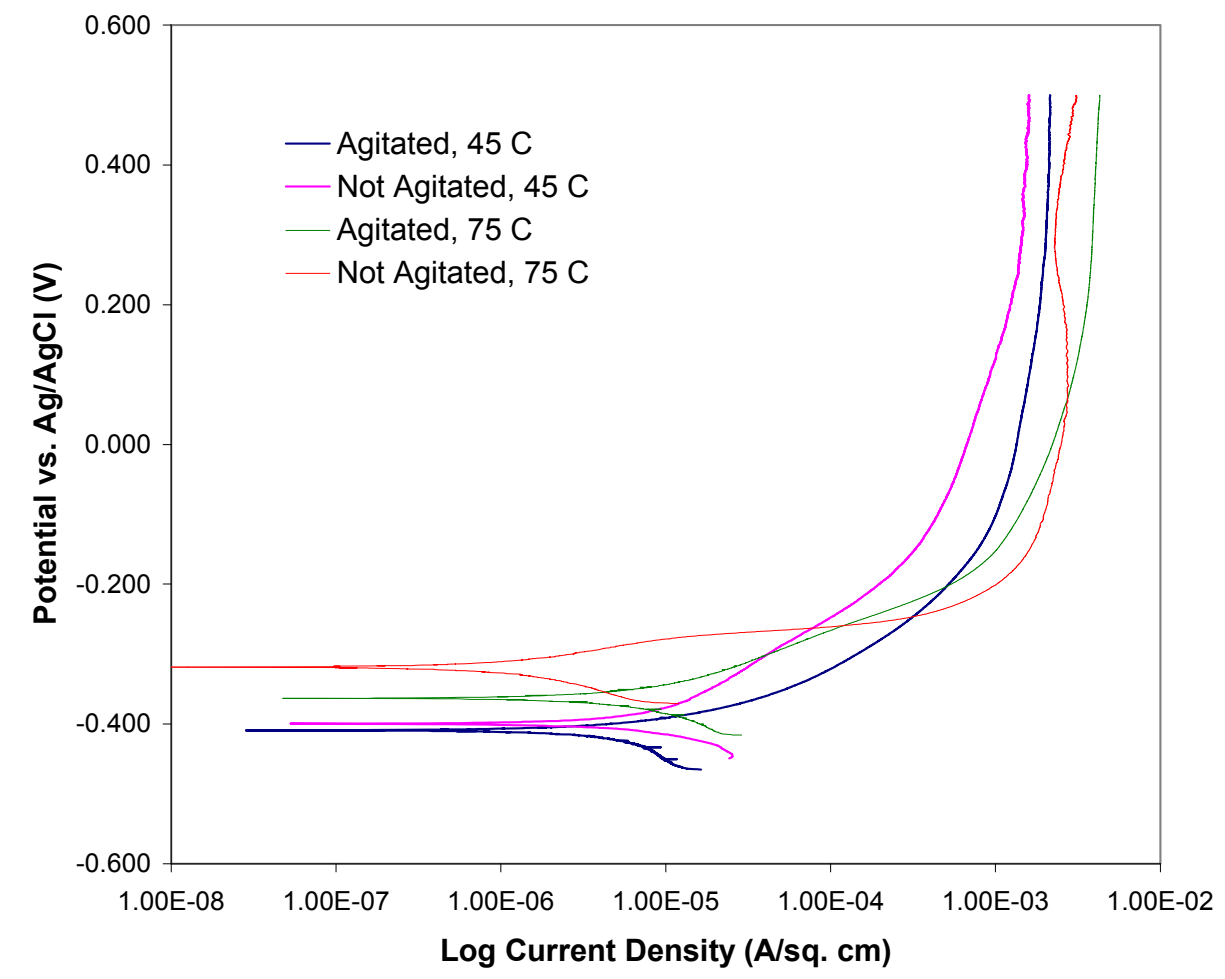

Figure 60. Anodic polarization scans for the HM-PUREX/1wt.\% oxalic acid mixture.

Figure 61 shows that the effects of de-aeration for the PUREX simulant are also insignificant. Thus, oxygen has little effect on the development of the protective film or the kinetics of the cathodic reaction. Similar results were obtained for anodic scans in the presence of HM and HM-PUREX simulants. 


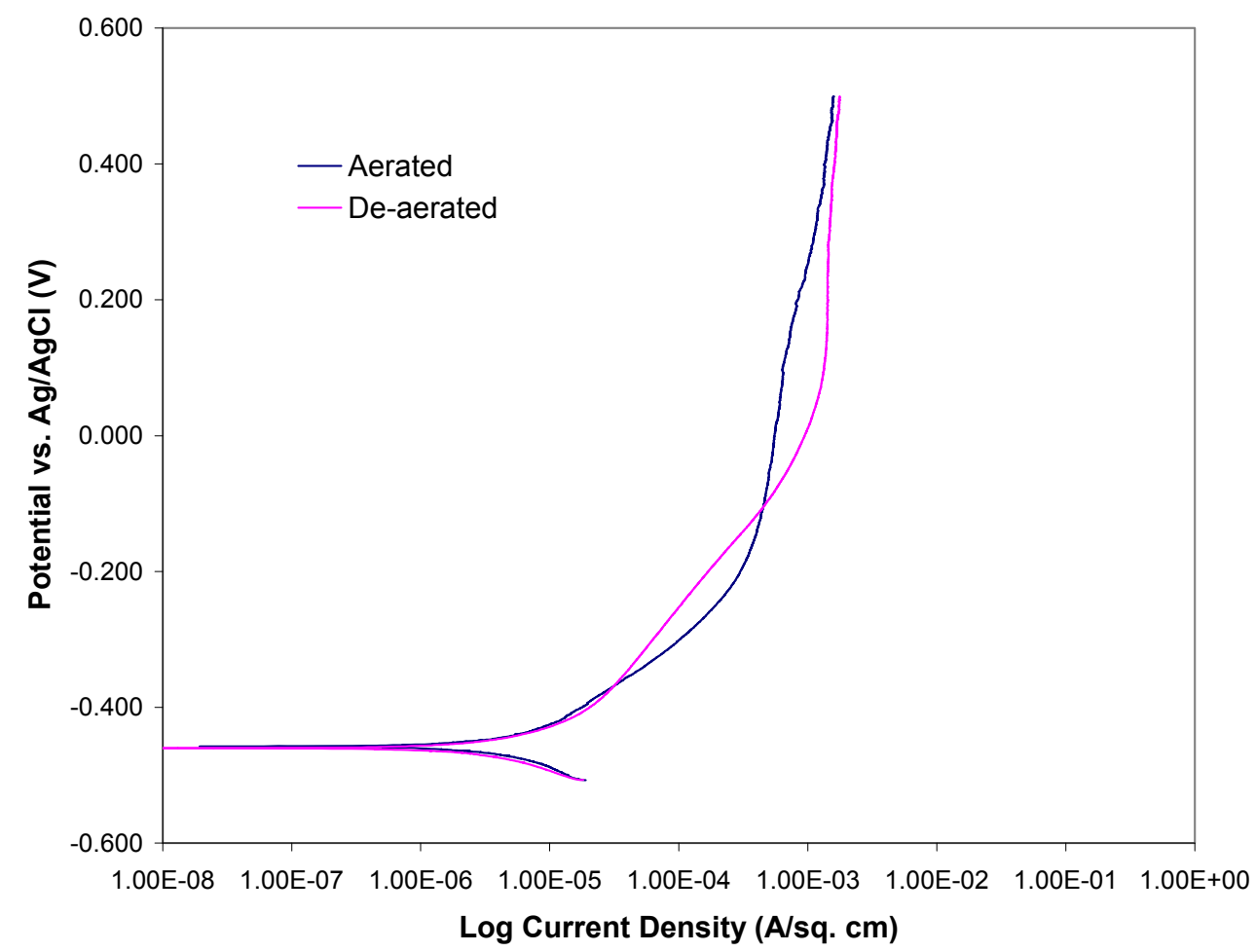

Figure 61. Anodic polarization scans for the PUREX/1wt.\% oxalic acid mixture under aerated and de-aerated conditions.

\subsection{Coupon Immersion Tests}

\subsubsection{Solution Analyses}

The solutions for the $1 \mathrm{wt} . \%$ and $2.5 \mathrm{wt} . \%$ oxalic acid coupon tests conducted with the sludge simulants were very different in appearance at the completion of the test. Figure 62 shows the that for the PUREX/1 wt.\% oxalic acid test the solution was reddish-brown or the color of the original sludge simulant. The reddish-brown color is indicative of solid iron oxides still suspended in the solution. Little if any dissolution appears to have occurred in the solution. Similar observations were made for the HM and HM-PUREX simulants as well.

On the other hand, the PUREX/2.5 wt.\% turned a yellowish-green color (see Figure 62). This color was indicative of dissolved ferric oxalates present in solution. Yellow suspended solids are also present in the solution which is likely ferrous oxalate solids that have precipitated and spalled from the surface of the steel coupon. The color change occurred approximately 1 day after the initiation of the $75^{\circ} \mathrm{C}$ coupon test and approximately 6 days after the initiation of the test at $50{ }^{\circ} \mathrm{C}$. These solution changes were observed for the HM simulant as well. Of particular interest were the solution colors that formed during the $75^{\circ} \mathrm{C}$ test with the HM simulant. The non-agitated test solution evolved into a reddish-brown color during the test, while the agitated solution became a pale yellow color toward the end of the test. 


\section{Revision 1}

The presence of the yellow suspended solids occurred even in the tests at $75^{\circ} \mathrm{C}$. This result is in contrast to test with $2.5 \mathrm{wt} . \%$ oxalic acid alone at $75^{\circ} \mathrm{C}$ where the solution was clear. A possible explanation is that for the test with oxalic acid alone, the ferrous oxalate is formed by a rapid anodic reaction such as that shown in Equation (7). The film is very adherent and therefore no ferrous oxalate solids spall off into solution. On the other hand, when sludge is present the ferrous oxalate may be formed by an electrochemical step such as the cathodic reaction shown in Equation (10). This reaction is controlled by the concentration of the sludge that is dissolved in the solution. This reaction is also relatively slow and thus the ferrous oxalate is not as adherent to the surface. The fact that no ferrous oxalate species were observed in the case of the $1 \mathrm{wt} . \%$ oxalic acid would seem to indicate that the concentration of the dissolved species was not sufficient to produce the ferrous oxalate in that case.

The sludge dissolution reactions result in a consumption of hydrogen anions and hence an increase in $\mathrm{pH}$, particularly at lower acid concentrations [31]. In order to maintain the $\mathrm{pH}$ at approximately 2 during the coupon tests, $1 \mathrm{wt} . \%$ oxalic acid was added periodically. Figures 63-68 show the $\mathrm{pH}$ as a function of the exposure time during the tests for the inner and the outer vessel. As can be seen from these figures, the $\mathrm{pH}$ continued to gradually increase during the tests. Large jumps in $\mathrm{pH}$ typically occurred over the weekends, when acid adjustments could not be made. In general, the $\mathrm{pH}$ was a little more difficult to control in the agitated solution, which likely reflects the higher rate of dissolution. At one stage of the HM and PUREX coupon test ( day 13) too much acid was added to the vessels. Additional supernate was added to ensure that the $\mathrm{pH}$ was controlled at 2 .
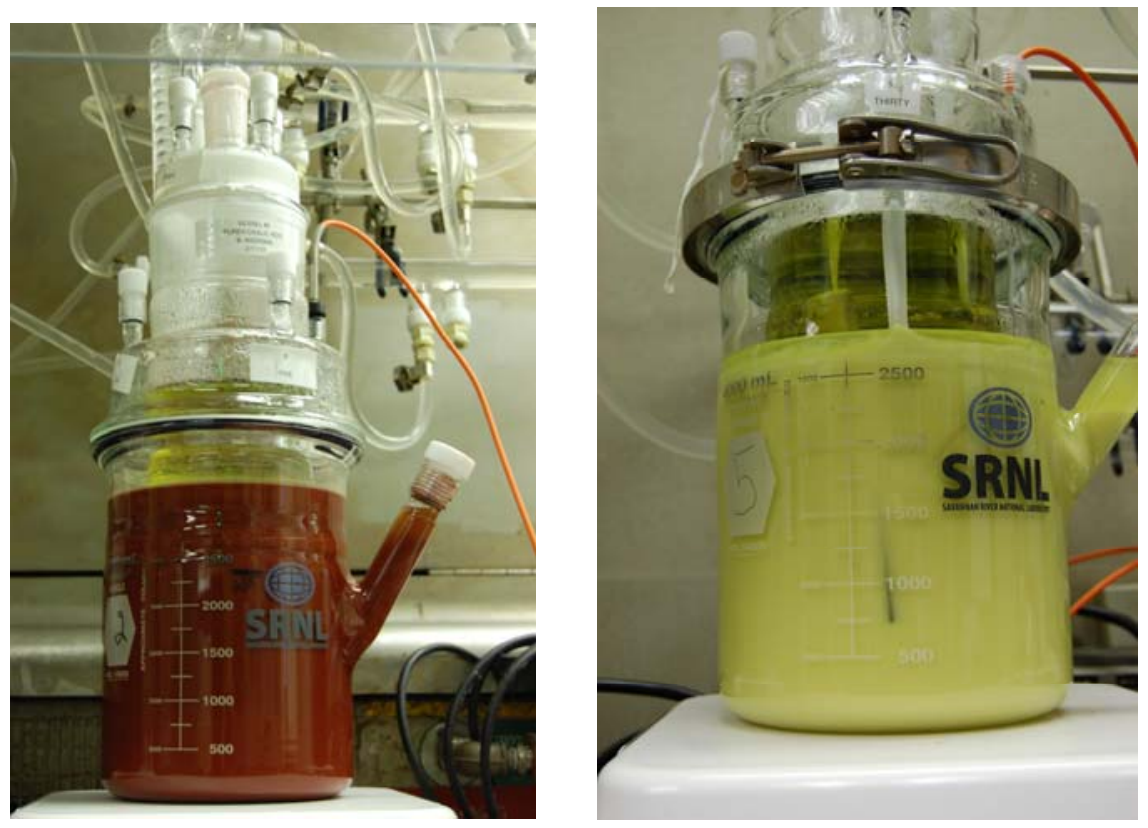

Figure 62. Solution Color for (a) PUREX/1 wt. $\%$ oxalic acid at $45{ }^{\circ} \mathrm{C}$ and (b) PUREX/2.5 wt. \% oxalic acid at $50{ }^{\circ} \mathrm{C}$. 


\section{Revision 1}

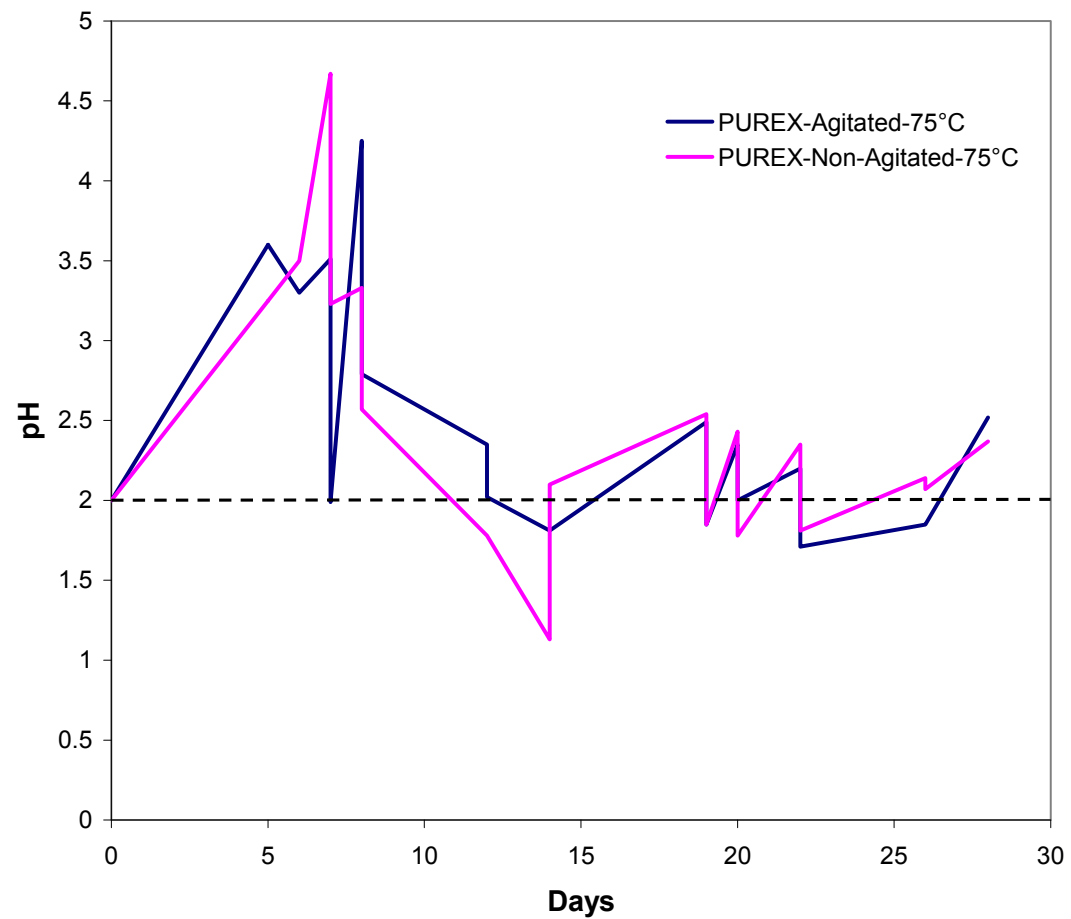

Figure 63. $\mathrm{pH}$ transient during Coupon Tests in the PUREX/1 wt.\% oxalic acid mixture at $75{ }^{\circ} \mathrm{C}$.

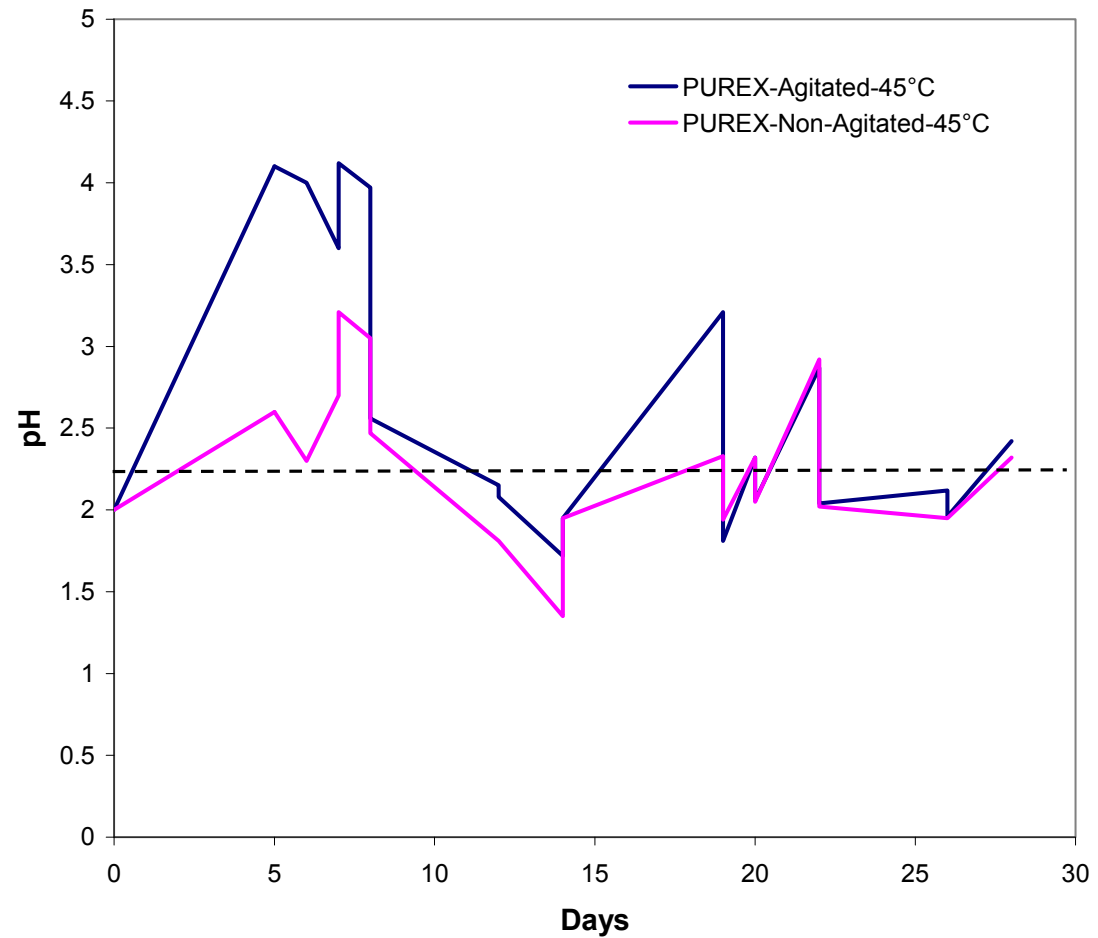

Figure 64. pH transient during Coupon Tests in the PUREX/1 wt.\% oxalic acid mixture at $45^{\circ} \mathrm{C}$. 


\section{Revision 1}

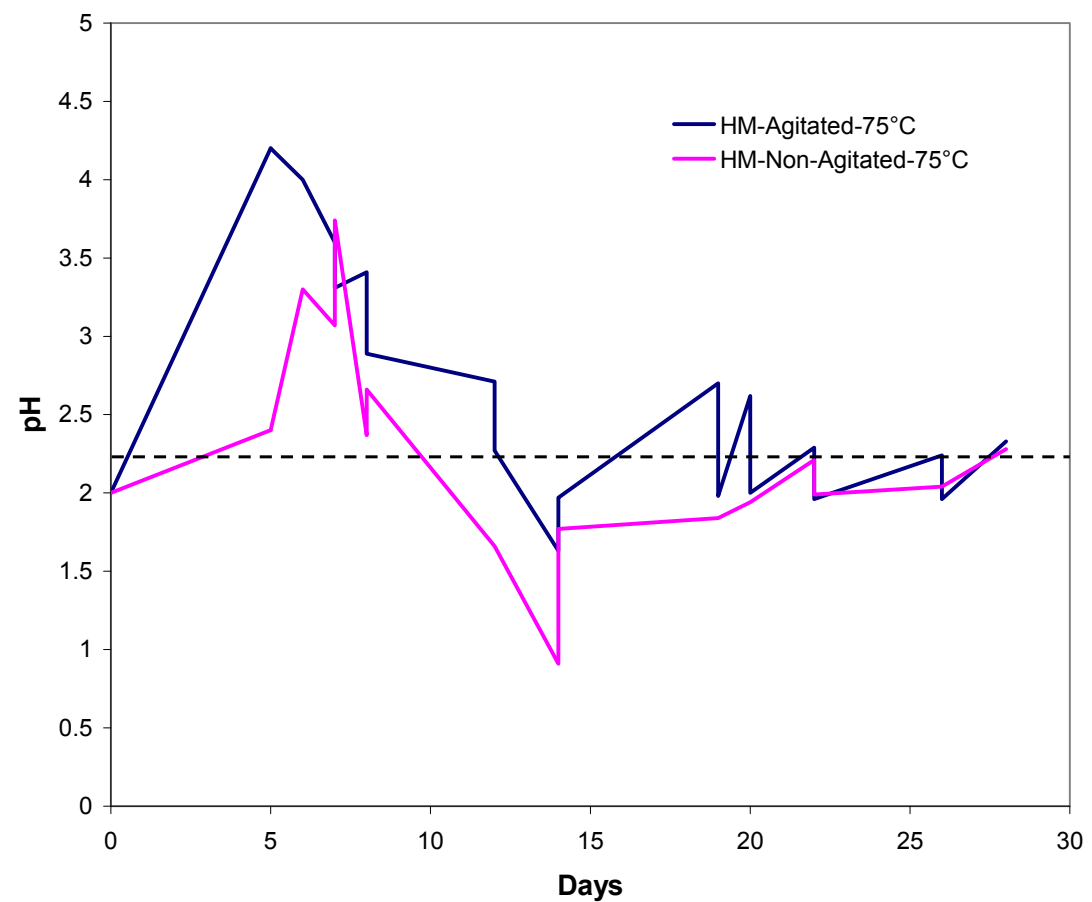

Figure 65. pH transient during Coupon Tests in the HM/1 wt.\% oxalic acid mixture at $75{ }^{\circ} \mathrm{C}$.

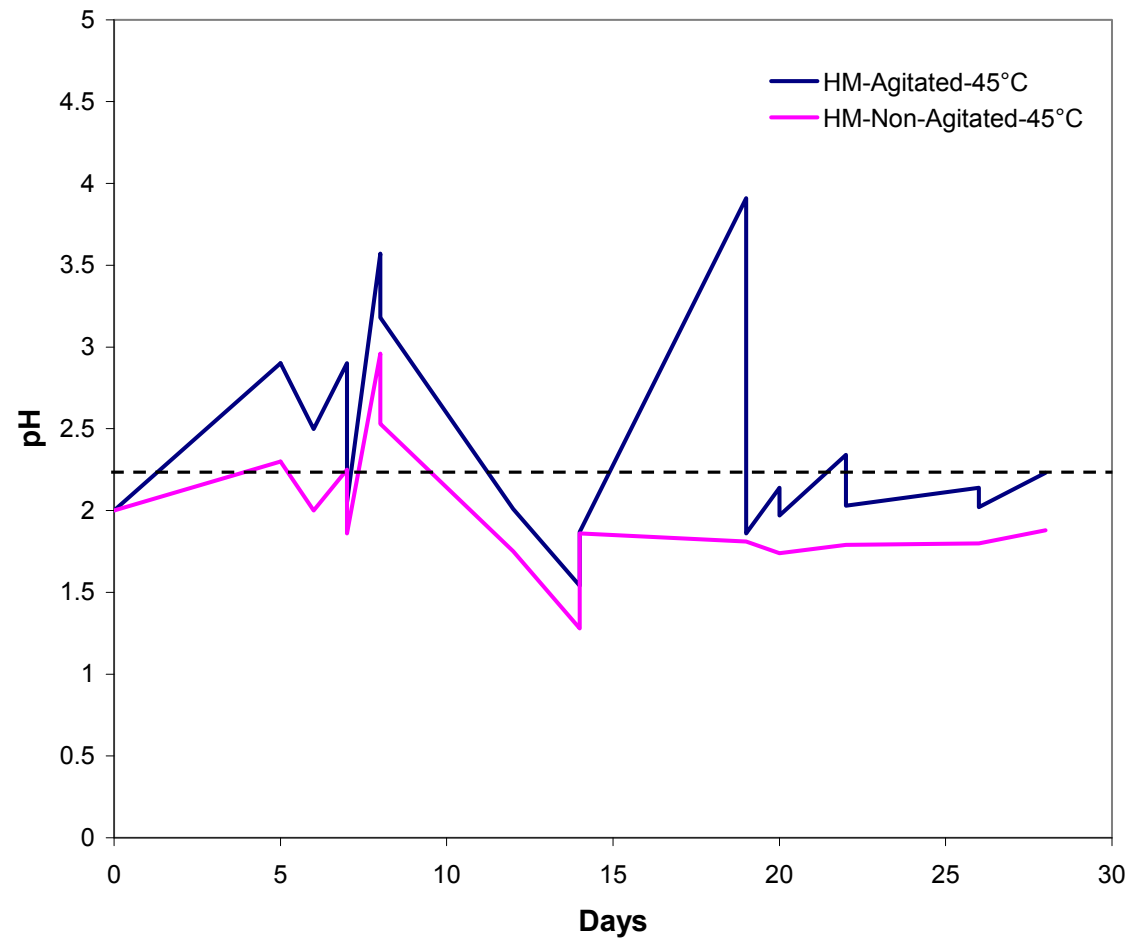

Figure 66. pH transient during Coupon Tests in the HM/1 wt.\% oxalic acid mixture at $45{ }^{\circ} \mathrm{C}$. 


\section{Revision 1}

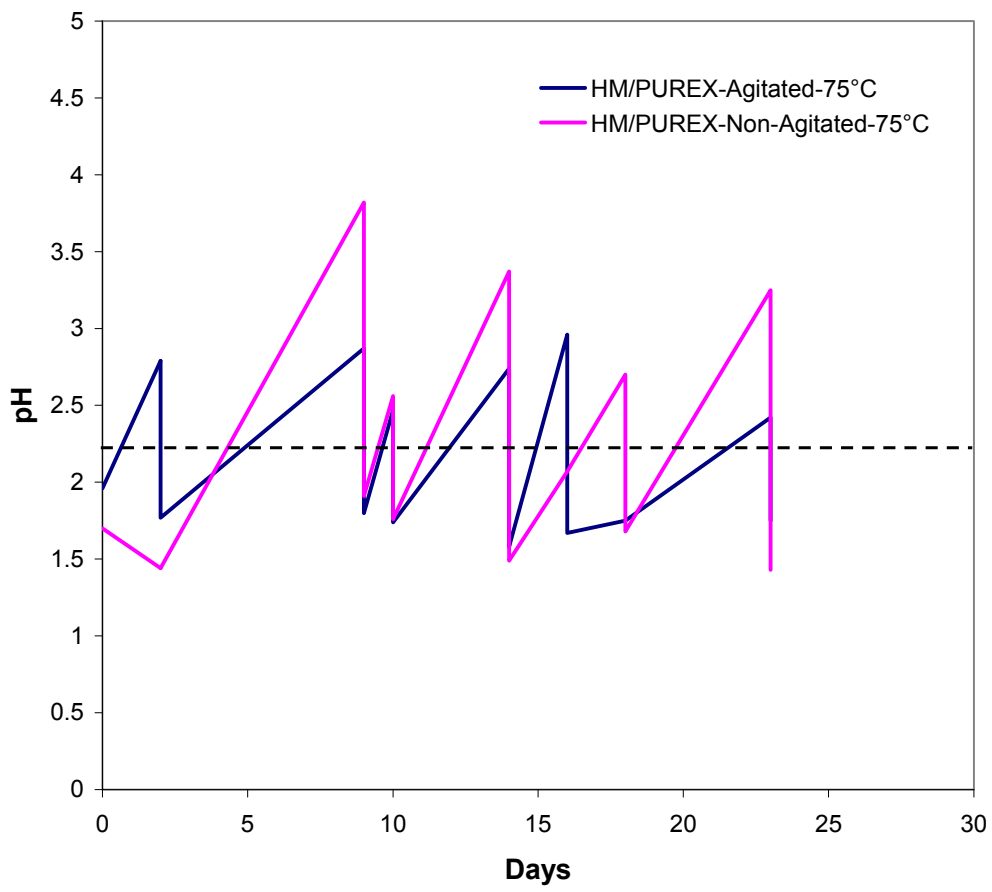

Figure 67. $\mathrm{pH}$ transient during Coupon Tests in the HM-PUREX/1 wt.\% oxalic acid mixture at $75^{\circ} \mathrm{C}$.

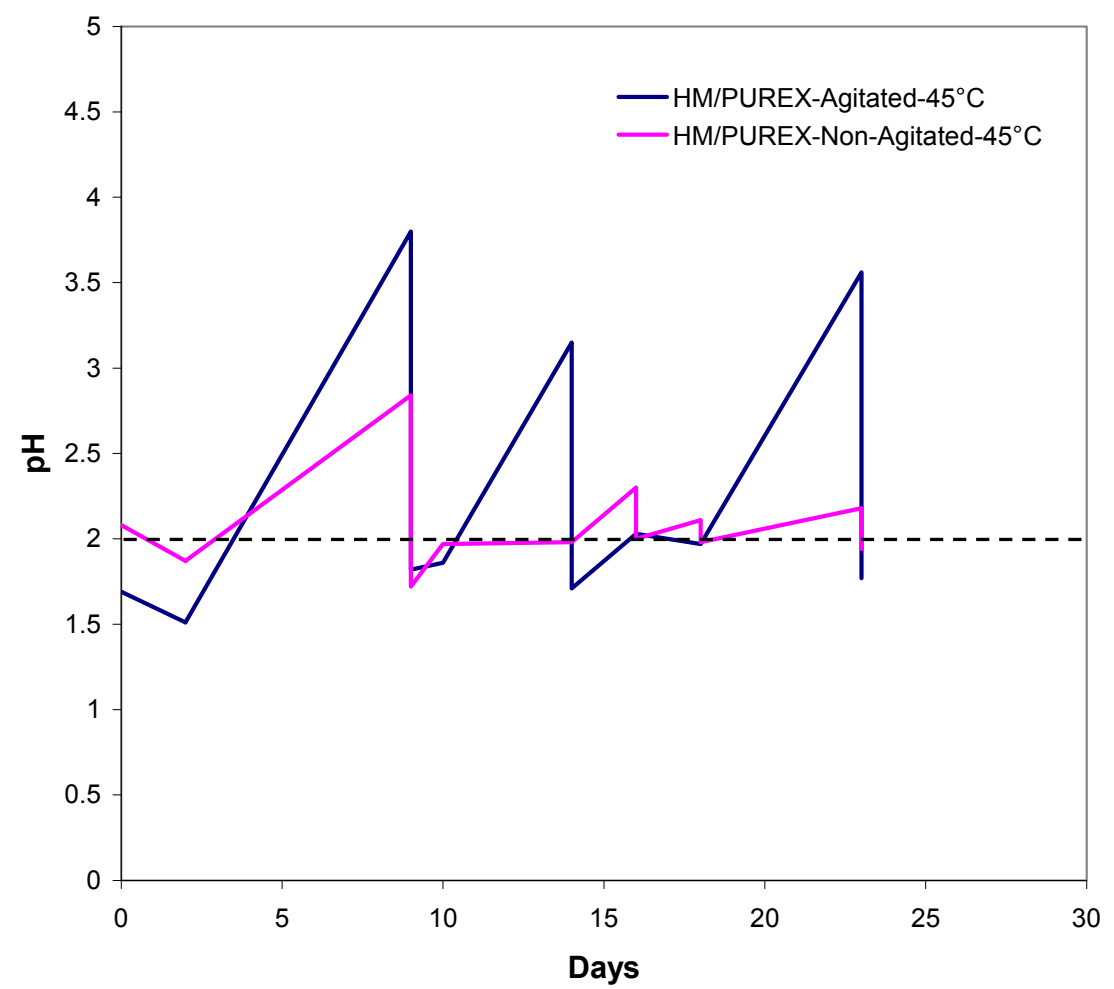

Figure 68. pH transient during Coupon Tests in the HM-PUREX/1 wt.\% oxalic acid mixture at $45^{\circ} \mathrm{C}$. 


\section{Revision 1}

Figures 69-71 show the amount of oxalic acid that was added to the vessel during the tests. The volume added for the PUREX and the HM tests were adjusted for the addition of the supernate. With this adjustment, an addition rate of approximately $12 \mathrm{ml} /$ day was required to maintain the $\mathrm{pH}$ at 2 . Although not ideal, it likely represents $\mathrm{pH}$ changes that will occur in the treatment tank when $1 \mathrm{wt} . \%$ oxalic acid is utilized for chemical cleaning.

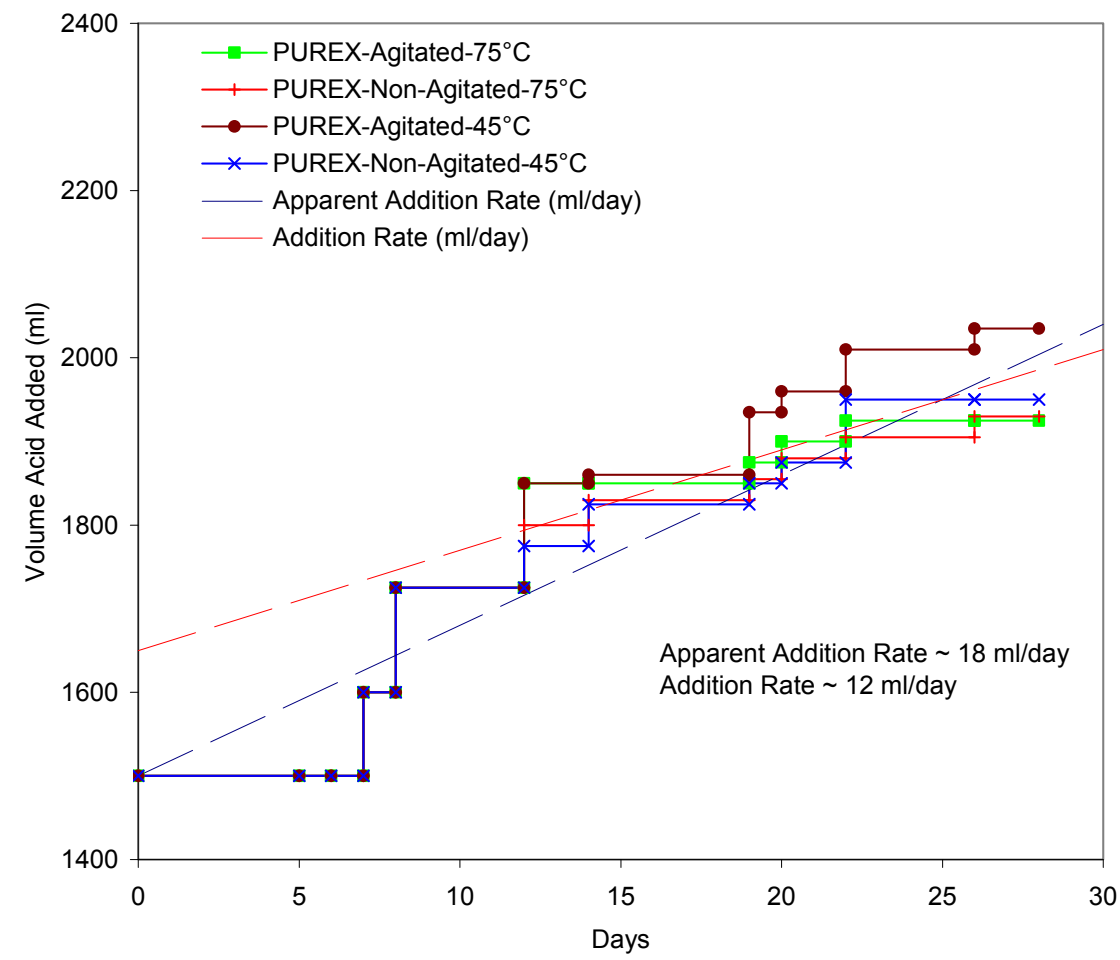

Figure 69. Volume of acid added during coupon tests in the PUREX/1 wt.\% oxalic acid mixture. 


\section{Revision 1}

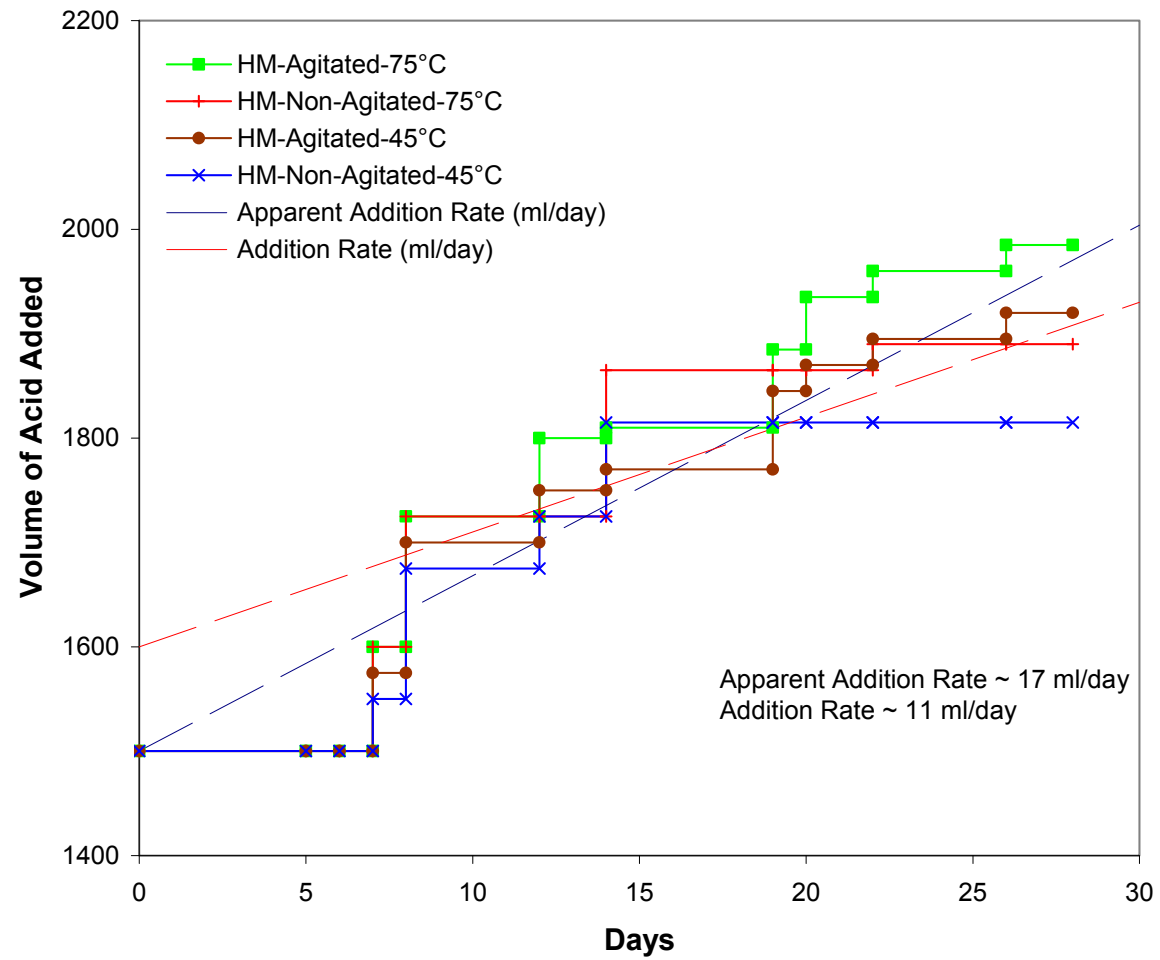

Figure 70. Volume of acid added during coupon tests in the HM/1 wt.\% oxalic acid mixture.

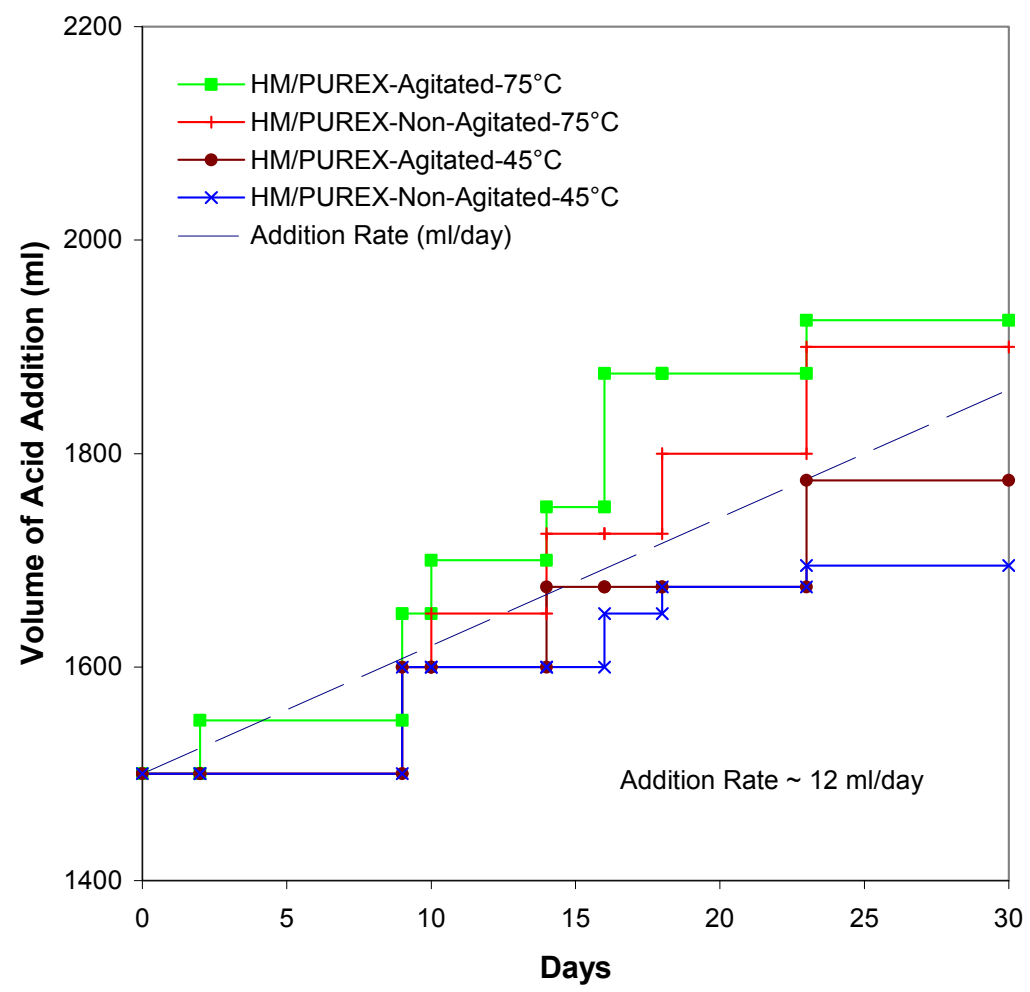

Figure 71. Volume of acid added during coupon tests in the HM-PUREX/1 wt.\% oxalic acid mixture. 
In contrast, for the most part the $\mathrm{pH}$ of the test solutions with $2.5 \mathrm{wt} . \%$ oxalic acid remained steady at approximately 1.3 for the duration of the tests. The lone exception occurred for the test solution with HM sludge simulant at $75^{\circ} \mathrm{C}$. During the first 25 days the $\mathrm{pH}$ remained at 1.3. During the final 5 days, the $\mathrm{pH}$ gradually increased to approximately 4 . The $\mathrm{pH}$ did not exceed 2 until the final day of the testing. The cause of this $\mathrm{pH}$ increase is not known at this time.

Analyses of the solutions following coupon testing were performed to determine the changes that occurred during the test. The results obtained in the PUREX and HM solutions are shown in Tables 9 through 12. Significant increases in the concentrations of iron, aluminum, manganese and calcium were observed as the concentration of oxalic acid was increased. In most cases, for the $2.5 \mathrm{wt} . \%$ oxalic acid tests the concentration of iron and aluminum that dissolved in solution increased when the solution was not agitated. In contrast, for the $1 \mathrm{wt} . \%$ oxalic acid tests agitation in general seemed to increase the amount of iron and aluminum that went into solution, although the differences were frequently small. At this time there is not an explanation for the results for the $2.5 \mathrm{wt} . \%$ oxalic acid tests.

Significant decreases in the concentrations of nitrate, nitrite, oxalate and sodium were also observed. The reduction in oxalate likely was due to the precipitation of the ferrous oxalate on the coupon. The analyses suggest that more of the oxalate stayed in solution with the HM sludge simulant than the PUREX sludge simulant at both oxalic acid concentrations. The decrease in the other anions was likely the result of dilution of the supernate. The reduction in the nitrite concentration also occurred due to decomposition once the $\mathrm{pH}$ is below 6 [32].

One of the mechanisms that inhibit the formation of the oxalate film is the presence of anions that form soluble salts with the ferrous ion. Chloride and sulfate are examples of such anions. Recent tests with PUREX simulant dissolved in $1 \mathrm{wt} \%$ oxalic acid with $0.05 \mathrm{M}$ sulfate showed that the stability of the ferrous oxalate film could be compromised in this manner. Pitting corrosion was observed at temperatures of 45 and $75^{\circ} \mathrm{C}$ [33]. From these tables it is apparent that the chloride and sulfate concentrations were higher in the PUREX solution than in the HM solution. Thus higher corrosion rates may be expected to occur in the PUREX solutions compared to the HM.

Another mechanism that inhibits the formation of the oxalate film is the presence of an oxidizing species that converts the ferrous ion to ferric ion. The agitated PUREX and $\mathrm{HM}$ solutions that were tested at $75^{\circ} \mathrm{C}$ were analyzed for mercury, a strong oxidizing agent. The concentration of $\mathrm{Hg}$ in the PUREX/1 wt.\% oxalic acid simulant was $25 \mathrm{mg} / \mathrm{l}$, while the $\mathrm{Hg}$ concentration in the $\mathrm{HM} / 1 \mathrm{wt} . \%$ oxalic acid simulant was $15 \mathrm{mg} / \mathrm{l}$. The final levels of $\mathrm{Hg}$ in the $2.5 \mathrm{wt} . \%$ oxalic acid were much lower than that observed for the $1 \mathrm{wt} . \%$, typically less than $5 \mathrm{mg} / \mathrm{l}$. This result may indicate that the mercuric $\left(\mathrm{Hg}^{2+}\right)$ or mercurous anion $\left(\mathrm{Hg}_{2}{ }^{2+}\right)$ has been more efficiently depleted in the $2.5 \mathrm{wt} . \%$ solutions. The reduction of mercuric or mercurous on the surface (i.e., a localized secondary 
Revision 1

cathodic reaction) could increase the corrosion rate and susceptibility the material in a local area.

Table 9. Final solution analyses for the coupon tests in the PUREX/1 wt.\% oxalic acid mixture.

\begin{tabular}{|c|c|c|c|c|c|c|}
\hline & \multicolumn{6}{|c|}{ Concentration $(\mathrm{mg} / \mathrm{l})$} \\
\hline Analyte & Initial Supernate & 1 wt.\% Oxalic Acid & PUREX, $75^{\circ} \mathrm{C}$, Agitation & PUREX, $75^{\circ} \mathrm{C}$, No Agitatic & CPUREX, $45^{\circ} \mathrm{C}$, Agitation & PUREX, $45^{\circ} \mathrm{C}$, No Agitation \\
\hline Chloride & 1760 & $\begin{array}{c}0 \\
\end{array}$ & 108 & 92 & 43 & 70 \\
\hline Nitrite & 11000 & 0 & $<10$ & $<10$ & $<10$ & $<10$ \\
\hline Nitrate & 3270 & 0 & 578 & 708 & 560 & 817 \\
\hline Sulfate & 1600 & 0 & 39 & 62 & 38 & 70 \\
\hline Oxalate & $<10$ & 14000 & 8720 & 9030 & 10100 & 9970 \\
\hline Aluminum & 158 & 0 & 272 & 104 & 316 & 88.4 \\
\hline Calcium & $<1$ & 0 & 174 & 171 & 182 & 227 \\
\hline Iron & $<1$ & 0 & 1100 & 1210 & 1160 & 1670 \\
\hline Manganese & $<1$ & 0 & 320 & 252 & 252 & 267 \\
\hline Potassium & 155 & 0 & 35 & 27 & 12 & 13 \\
\hline \begin{tabular}{|l|} 
Sodium \\
\end{tabular} & 13700 & 0 & 705 & 899 & 611 & 914 \\
\hline \begin{tabular}{|l|} 
Sulfur \\
\end{tabular} & 558 & 0 & 17 & 25 & 17 & 29 \\
\hline Silicon & $<10$ & 0 & 36 & 28 & 36 & 31 \\
\hline
\end{tabular}

Table 10. Final solution analyses for the coupon tests in the PUREX/2.5 wt.\% oxalic acid mixture.

\begin{tabular}{|l|c|c|c|c|c|c|}
\cline { 2 - 7 } \multicolumn{1}{l|}{} & \multicolumn{7}{c|}{ Concentration (mg/l) } \\
\hline Analyte & $\begin{array}{l}\text { Initial } \\
\text { Supernate }\end{array}$ & $\begin{array}{l}2.5 \mathrm{wt} . \% \text { Oxalic } \\
\text { Acid }\end{array}$ & $\begin{array}{l}\text { PUREX } 75{ }^{\circ} \mathrm{C}, \\
\text { Agitation }\end{array}$ & $\begin{array}{l}\text { PUREX 75 }{ }^{\circ} \mathrm{C}, \\
\text { No Agitation }\end{array}$ & $\begin{array}{l}\text { PUREX 50 }{ }^{\circ} \mathrm{C}, \\
\text { Agitation }\end{array}$ & $\begin{array}{l}\text { PUREX 50 }{ }^{\circ} \mathrm{C}, \\
\text { No Agitation }\end{array}$ \\
\hline Chloride & 1760 & 0 & 32 & 19 & 29 & 13 \\
\hline Nitrite & 11000 & 0 & $<10$ & $<10$ & $<10$ & $<10$ \\
\hline Nitrate & 3270 & 0 & 256 & 86 & 53 & 96 \\
\hline Sulfate & 1600 & 0 & $<100$ & $<100$ & $<100$ & $<100$ \\
\hline Oxalate & $<10$ & 25000 & 22400 & 19200 & 16500 & 19000 \\
\hline Aluminum & 158 & 0 & 724 & 844 & 785 & 785 \\
\hline Calcium & $<1$ & 0 & 120 & 403 & 58 & 273 \\
\hline Iron & $<1$ & 0 & 2370 & 5400 & 551 & 3780 \\
\hline Manganese & $<1$ & 0 & 162 & 314 & 83 & 143 \\
\hline Mercury & $\mathrm{NA}$ & 0 & 2.2 & 13.4 & 15.9 & 2.4 \\
\hline Potassium & 155 & 0 & 6 & $<5$ & $<5$ & $<5$ \\
\hline Sodium & 13700 & 0 & 356 & 342 & 355 & 354 \\
\hline Sulfur & 558 & 0 & 18 & 23 & 18 & 23 \\
\hline Silicon & $<10$ & 0 & 25 & 14 & 15 & 9.5 \\
\hline
\end{tabular}

Table 11. Final solution analyses for the coupon tests in the HM/1 wt. \% oxalic acid mixture.

\begin{tabular}{|c|c|c|c|c|c|c|}
\hline & \multicolumn{6}{|c|}{ Concentration (mg/l) } \\
\hline Analyte & Initial Supernate & 1 wt.\% Oxalic Acid & $\mathrm{HM}, 75^{\circ} \mathrm{C}$, Agitation & $\mathrm{HM}, 75^{\circ} \mathrm{C}$, No Agitation & $\mathrm{HM}, 45^{\circ} \mathrm{C}$, Agitation & HM, $45^{\circ} \mathrm{C}$, No Agitation \\
\hline Chloride & 54 & 0 & 16 & 14 & $<10$ & $<10$ \\
\hline Nitrite & 913 & 0 & $<10$ & $<10$ & $<10$ & $<10$ \\
\hline Nitrate & 5100 & 0 & 207 & 517 & 223 & 458 \\
\hline Sulfate & 200 & 0 & $<10$ & 23 & $<10$ & 17 \\
\hline Oxalate & 30 & 14000 & 14000 & 8390 & 11100 & 12000 \\
\hline Aluminum & 143 & 0 & 401 & 311 & 345 & 315 \\
\hline Calcium & $<1$ & 0 & 124 & 11 & 72 & 13 \\
\hline Iron & $<1$ & 0 & 1340 & 448 & 721 & 390 \\
\hline Manganese & $<1$ & 0 & 682 & 269 & 316 & 287 \\
\hline Potassium & 206 & 0 & 26 & 35 & 18 & 24 \\
\hline Sodium & 8410 & 0 & 492 & 989 & 527 & 836 \\
\hline \begin{tabular}{|l|} 
Sulfur \\
\end{tabular} & 88 & 0 & 6 & 9 & 4 & 7 \\
\hline Silicon & 1 & 0 & 48 & 26 & 35 & 27 \\
\hline
\end{tabular}


Table 12. Final solution analyses for the coupon tests in the $H M / 2.5$ wt. $\%$ oxalic acid mixture.

\begin{tabular}{|c|c|c|c|c|c|c|}
\hline & \multicolumn{6}{|c|}{ Concentration (mg/l) } \\
\hline Analyte & $\begin{array}{l}\text { Initial } \\
\text { Supernate }\end{array}$ & $\begin{array}{l}2.5 \text { wt. } \% \text { Oxalic } \\
\text { Acid }\end{array}$ & $\begin{array}{l}\mathrm{HM} 75^{\circ} \mathrm{C}, \\
\text { Agitation }\end{array}$ & $\begin{array}{l}\mathrm{HM} 75^{\circ} \mathrm{C} \text {, No } \\
\text { Agitation }\end{array}$ & $\begin{array}{l}\mathrm{HM} 50^{\circ} \mathrm{C}, \\
\text { Agitation }\end{array}$ & $\begin{array}{l}\mathrm{HM} 50^{\circ} \mathrm{C} \text {, No } \\
\text { Agitation }\end{array}$ \\
\hline Chloride & 54 & 0 & $<100$ & $<100$ & $<100$ & $<100$ \\
\hline Nitrite & 913 & 0 & $<100$ & $<100$ & $<100$ & $<100$ \\
\hline Nitrate & 5100 & 0 & $<100$ & 122 & 236 & 260 \\
\hline Sulfate & 200 & 0 & $<100$ & $<100$ & $<100$ & $<100$ \\
\hline Oxalate & 30 & 25000 & 20200 & 27200 & 19900 & 21800 \\
\hline Aluminum & 143 & 0 & 2600 & 3700 & 838 & 3260 \\
\hline Calcium & $<1$ & 0 & 104 & 113 & 68 & 124 \\
\hline Iron & $<1$ & 0 & 635 & 1060 & 1020 & 697 \\
\hline Manganese & $<1$ & 0 & 268 & 414 & 159 & 324 \\
\hline Mercury & NA & 0 & 3.1 & 0.7 & 2.7 & 0.3 \\
\hline Potassium & 206 & 0 & 14 & 13 & 17 & 17 \\
\hline Sodium & 8410 & 0 & 484 & 444 & 581 & 593 \\
\hline Sulfur & 88 & 0 & 8 & 6 & 8 & 7 \\
\hline Silicon & 1 & 0 & 35 & 22 & 23 & 24 \\
\hline
\end{tabular}

Table 13 shows the final solution analysis for the coupon tests that were performed in 2.5 wt.\% oxalic acid. The solution chemistry is a strong function of temperature. At $50{ }^{\circ} \mathrm{C}$, there was a significant depletion in the oxalate concentration. Much of the oxalate has precipitated as ferrous oxalate. The greater extent of depletion in the non-agitated solution correlated with the higher corrosion rate observed at this condition. In contrast, at very little ferrous oxalate precipitated during the $75^{\circ} \mathrm{C}$ test as evidenced by the clear solution. Most of the oxalate remained in solution. A higher concentration of the corroded iron was dissolved into solution as well at the higher temperature.

Table 13. Final solution analyses for the coupon tests in the $2.5 \mathrm{wt}$. $\%$ oxalic acid.

\begin{tabular}{|c|c|c|c|c|c|}
\hline & \multicolumn{5}{|c|}{ Concentration (mg/l) } \\
\hline Analyte & $\begin{array}{l}2.5 \text { wt. } \% \text { Oxalic } \\
\text { Acid }\end{array}$ & $\begin{array}{l}\mathrm{OA} 75^{\circ} \mathrm{C} \\
\text { Agitation }\end{array}$ & $\begin{array}{l}\mathrm{OA} 75^{\circ} \mathrm{C}, \text { No } \\
\text { Agitation }\end{array}$ & $\begin{array}{l}\mathrm{OA} 50^{\circ} \mathrm{C}, \\
\text { Agitation }\end{array}$ & $\begin{array}{l}\text { OA } 50^{\circ} \mathrm{C} \text {, No } \\
\text { Agitation }\end{array}$ \\
\hline Chloride & $\begin{array}{c}0 \\
\end{array}$ & $<100$ & $<100$ & $<100$ & $<100$ \\
\hline Nitrite & 0 & $<100$ & $<100$ & $<100$ & $<100$ \\
\hline Nitrate & 0 & $<100$ & $<100$ & $<100$ & $<100$ \\
\hline Sulfate & 0 & $<100$ & $<100$ & $<100$ & $<100$ \\
\hline Oxalate & 25000 & 21100 & 25200 & 14400 & 9340 \\
\hline Aluminum & 0 & 1 & 0.6 & 2 & 3 \\
\hline Calcium & 0 & 0 & 0 & 0 & 0 \\
\hline Iron & 0 & 1500 & 1470 & 825 & 364 \\
\hline Manganese & 0 & 7 & 14 & 9 & 7 \\
\hline Mercury & 0 & 0 & 0 & 0 & 0 \\
\hline Potassium & 0 & 0 & 0 & 0 & 0 \\
\hline Sodium & 0 & 0 & 0 & 0 & 0 \\
\hline Sulfur & 0 & 1 & 1.1 & 1 & 1.2 \\
\hline Silicon & 0 & 12 & 6.3 & 12 & 21 \\
\hline
\end{tabular}




\subsubsection{Surface Analyses}

Photographs of the post-test coupons are shown in Figures 72 through 75. These posttest coupons reveal all the corrosion products that formed during the coupon tests. For the tests that were performed with 1 wt.\% oxalic acid (see Figures 72 and 74), all coupons were covered with ferrous oxalate and what appeared to be particles from the sludge. In general, higher temperatures and agitation appeared to increase the thickness of the oxalate film and the density of the sludge particles on the coupons that were exposed to the PUREX and HM simulants. The opposite appeared to be true for the coupons exposed to the HM-PUREX solution. The solid layer that formed on the coupons that had been exposed to oxalic acid at $45{ }^{\circ} \mathrm{C}$ was thicker and looser than that that formed on the coupon at $75{ }^{\circ} \mathrm{C}$. This observation is consistent with the mechanism described in section 2.2.

For the tests performed with sludge simulants in $2.5 \mathrm{wt} \%$ oxalic acid (see Figures 73 and $75)$, only ferrous oxalate, at varying degrees of coverage, was typically observed. The lone exception was the coupon test in HM sludge simulant at $75^{\circ} \mathrm{C}$ with no agitation. In this case, reddish-brown deposits were observed along with the ferrous oxalate. The deposits were in vertically oriented streaks on the coupon. Although the coupons tested at the same condition with agitation did not exhibit the same deposits (i.e., only ferrous oxalate was observed) it was clear that the corrosion was much more severe on these coupons than the others.

The coupons were analyzed for the solids present on the surface. For a baseline, the XRD result for the ferrous oxalate layer that formed in $1 \mathrm{wt} . \%$ and $2.5 \mathrm{wt} . \%$ oxalic acid are shown in Figures 76 and 77. Figure 78 is the XRD result for a coupon exposed to the $\mathrm{HM} / 1$ wt. $\%$ oxalic acid simulant at $75^{\circ} \mathrm{C}$ with agitation. Hematite and corundum, which are iron and aluminum oxides respectively, were blended into the ferrous oxalate (i.e., humboldtine) matrix. Hematite is a silver gray to reddish brown color, while corundum in the pure form is transparent. Both hematite and corundum were added directly to the solids during the preparation of the sludge simulant. Thus, both oxides may have simply blended in with the re-crystallized ferrous oxalate. However, at potentials greater than approximately $-0.200 \mathrm{~V}$ vs. $\mathrm{Ag} / \mathrm{AgCl}$ the following anodic reaction may occur that produces hematite [4]:

$2 \mathrm{Fe}+3 \mathrm{H}_{2} \mathrm{O} \longrightarrow \gamma \mathrm{Fe}_{2} \mathrm{O}_{3}+6 \mathrm{H}^{+}+6 \mathrm{e}^{-}$

During OCP measurements in the HM/1 wt.\% oxalic acid simulants the potentials were observed to shift to values greater than $-0.200 \mathrm{~V}$ vs. $\mathrm{Ag} / \mathrm{AgCl}$. Thus, in the HM simulants an initial layer of ferrous oxalate may have formed prior to the OCP shift, followed by the electrochemical deposition of hematite. In this latter reaction, the iron is converted to a ferric compound and the potential is well above the value where hydrogen evolution would be thermodynamically possible. 
Figures 79 and 80 show the XRD results for HM/2.5 wt.\% oxalic acid simulants. For the case where the solution was agitated (see Figure 79) only ferrous oxalate was observed. However, for non-agitated condition goethite, an iron oxide, was observed in addition to the ferrous oxalate. The goethite was associated with the reddish-brown deposits that were on the coupons. Goethite has a yellowish to reddish brown color. Goethite forms when ferric nitrate reacts with hydroxide [34]. The recipe for preparation of the sludge was reviewed and it is likely that the goethite formed during this time [22]. Thus, hematite, which again was added to the sludge solids, and goethite were likely present in the initial sludge solids. However, the Pourbaix diagram indicates that goethite and hematite are unstable at $\mathrm{pH} 1.2$ in a reducing environment and tend to dissolve [6]. The only means by which this could occur would be if the ferrous ion was oxidized to the ferric species. This reaction would need to be polarized by a strong oxidizing agent for this to occur.

Figure 81 shows the XRD result for a coupon exposed to the HM-PUREX/1 wt.\% oxalic acid simulant at $75{ }^{\circ} \mathrm{C}$. Hematite and goethite were identified along with the ferrous oxalate. As mentioned previously goethite likely formed during the preparation of the sludge [22]. Thus, hematite, which again was added to the sludge solids, and goethite were likely present in the initial sludge solids. However, the electrochemical reaction that forms hematite is less likely to have occurred given the OCP values for the HMPUREX/1 wt.\% oxalic acid simulant.

Figure 82 shows the XRD result for a coupon exposed to the PUREX/1 wt.\% oxalic acid simulant at $75^{\circ} \mathrm{C}$ with agitation. Hematite, goethite and akageneite, an iron oxide as well, were identified along with the ferrous oxalate. Akageneite has a golden or yellowish brown color. Akaganeite forms in a high chloride environment at a $\mathrm{pH}$ less than 5 and at temperatures greater than $40{ }^{\circ} \mathrm{C}$. The result is a ferric oxy-hydroxide compound that contains between 1 and $7 \mathrm{wt} \%$ chloride. The preparation of the PUREX simulant was reviewed to determine when the akaganeite may have formed [22]. Sodium chloride was not added to the simulant until after thermal aging of the washed sludge was completed and the $\mathrm{pH}$ of the simulant was above 10. Therefore, it is likely that the akaganeite formed after the addition of the oxalic acid and during the coupon test when the temperature was raised above $40{ }^{\circ} \mathrm{C}$. Hematite and goethite were present in the initial sludge solids.

Figure 83 shows the XRD result for a coupon exposed to the PUREX/2.5 wt.\% oxalic acid simulant at $75{ }^{\circ} \mathrm{C}$ with agitation. Ferrous oxalate alone was observed on the metal surface in this case as well as for the other tests that were performed with the PUREX/2.5 wt.\% simulant. This result is consistent with a reaction that produces ferrous oxalate, such as that shown in Equation 10. 


\section{Revision 1}

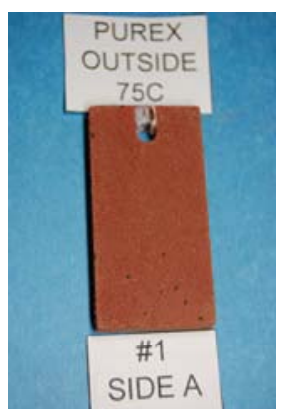

Agitation

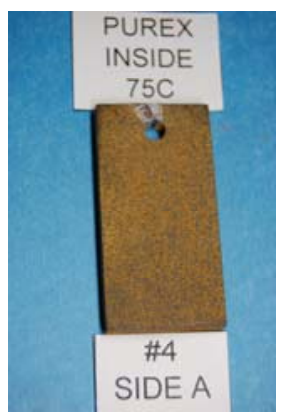

No Agitation

(a)

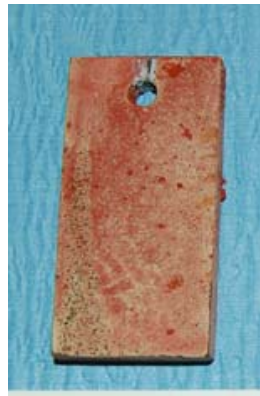

17

SEVENTEEN

Agitation

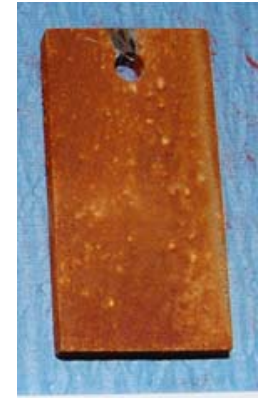

20
No Agitation

(c)

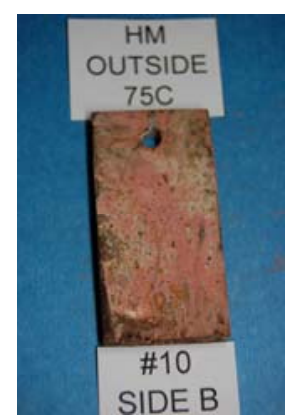

Agitation

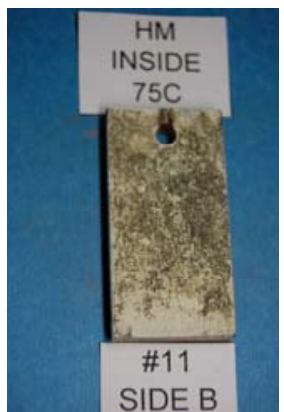

No Agitation

(b)

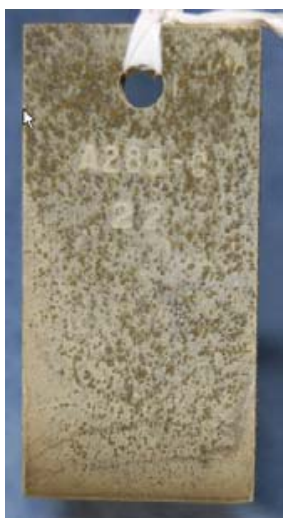

No Agitation

(d)

Figure 72. Photographs from coupons tested in a) PUREX/1 wt. $\%$ oxalic acid, b) HM/1 wt .\% oxalic acid, c) HM-PUREX/1 wt. \% oxalic acid, and d) 1 wt. \% oxalic acid at $75^{\circ} \mathrm{C}$. 
Revision 1

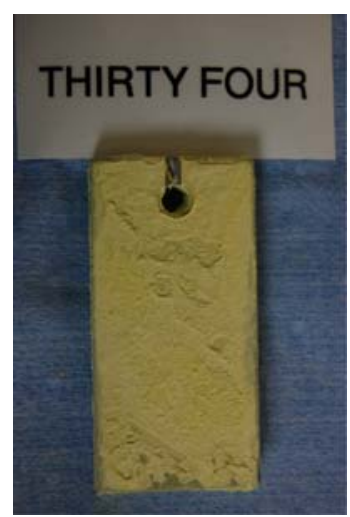

Agitation

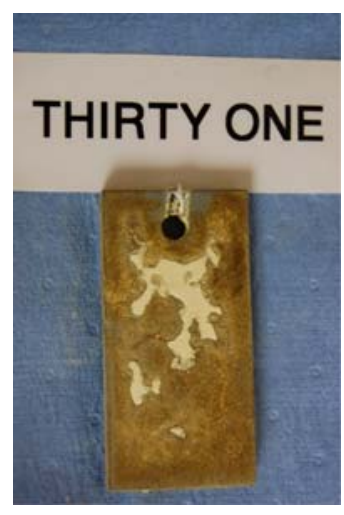

No Agitation

(a)

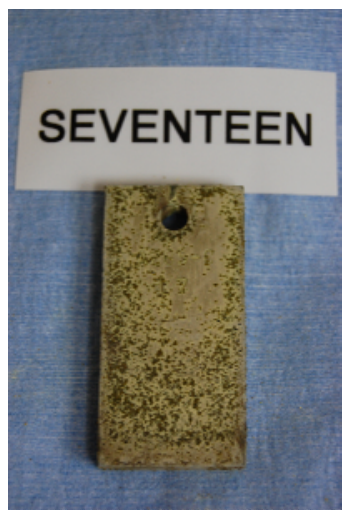

Agitation

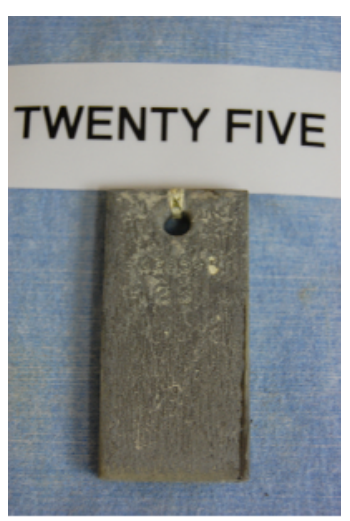

Agitation

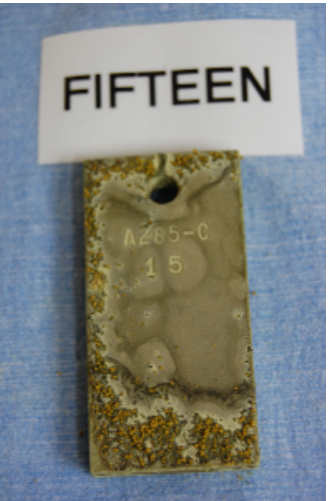

No Agitation

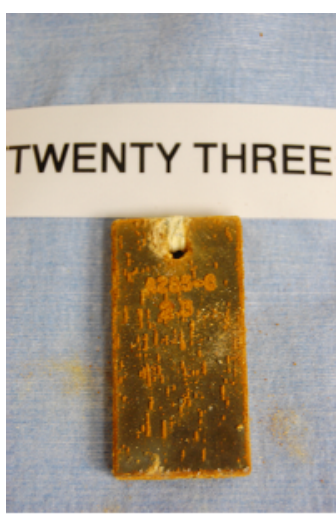

No Agitation

(b)

(c)

Figure 73. Photographs from coupons tested in a) PUREX/2.5 wt.\% oxalic acid, b) HM/2.5 wt. \% oxalic acid, and c) $2.5 \mathrm{wt} . \%$ oxalic acid at $75^{\circ} \mathrm{C}$. 


\section{Revision 1}

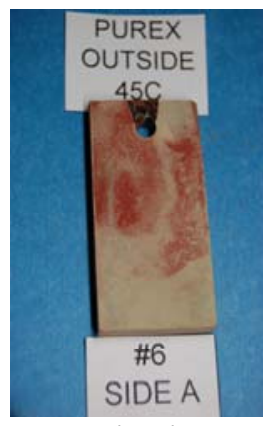

Agitation

(a)

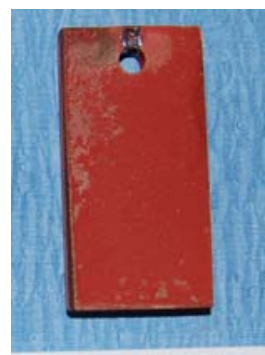

22

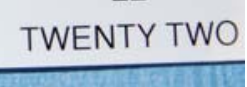

Agitation

(a)

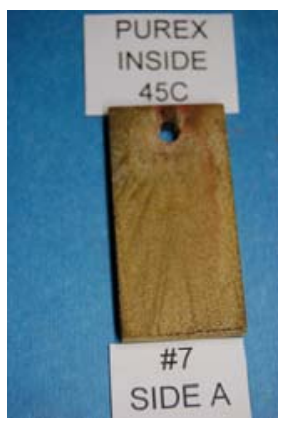

No Agitation

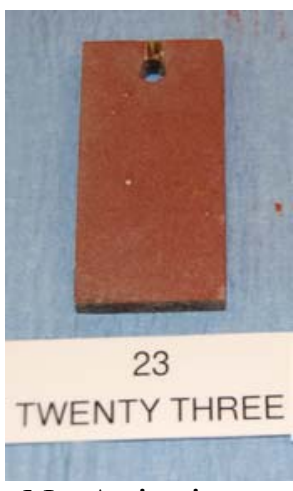

(c)

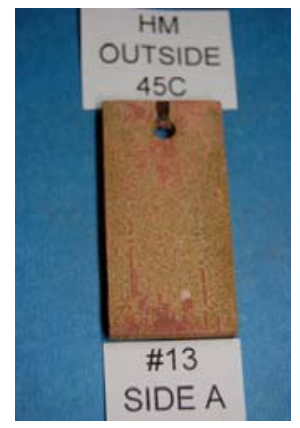

Agitation

(b)

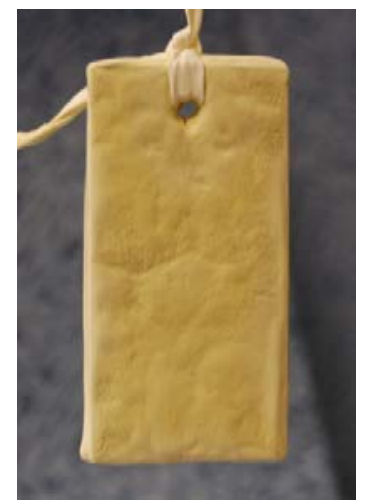

No Agitation

(d)

Figure 74. Photographs from coupons tested in a) PUREX/1 wt.\% oxalic acid, b) HM/1 wt. \% oxalic acid, c) HM-PUREX/1 wt.\% oxalic acid, and d) 1 wt.\% oxalic acid at $45{ }^{\circ} \mathrm{C}$. 
SRNL-STI-2010-00535

Revision 1
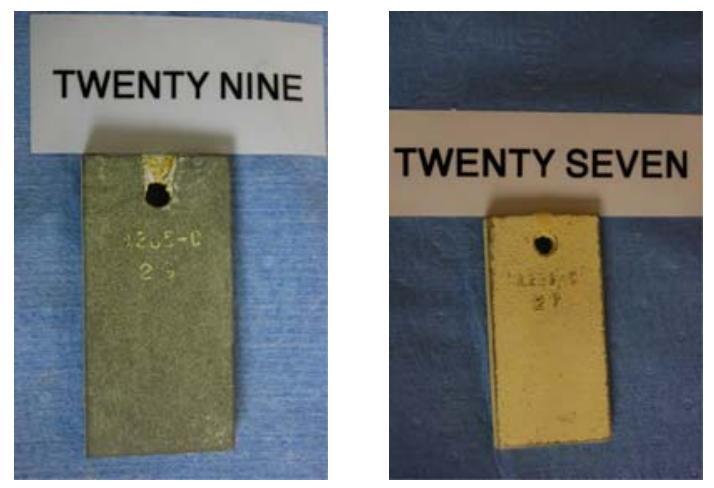

Agitation

(a)

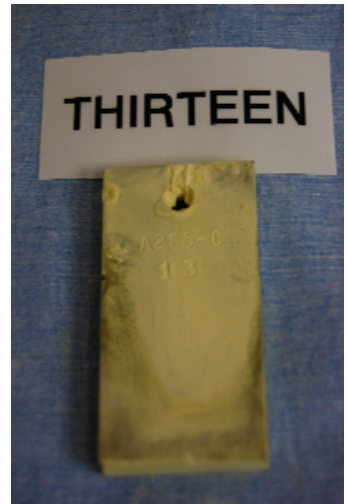

Agitation
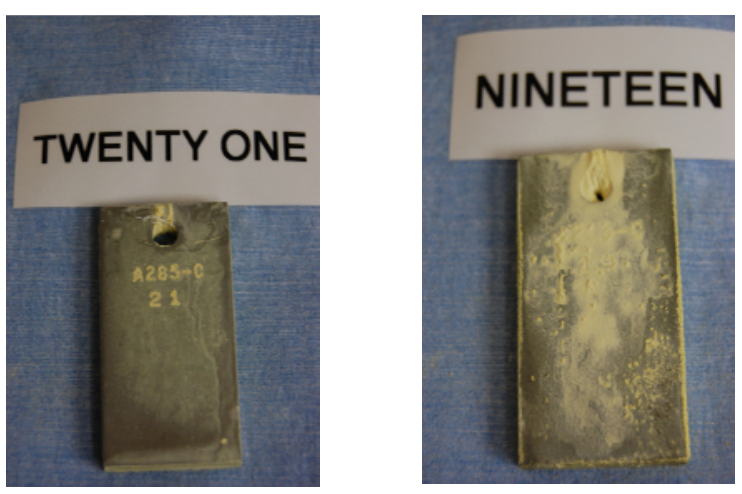

Agitation

(b)

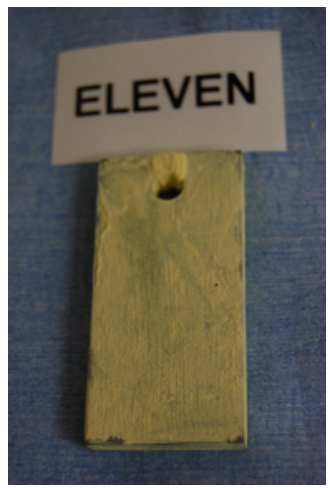

No Agitation

(c)

Figure 75. Photographs from coupons tested in a) PUREX/2.5 wt.\% oxalic acid, b) HM/2.5 wt. \% oxalic acid, c) 2.5 wt. \% oxalic acid at $50{ }^{\circ} \mathrm{C}$. 


\section{Revision 1}

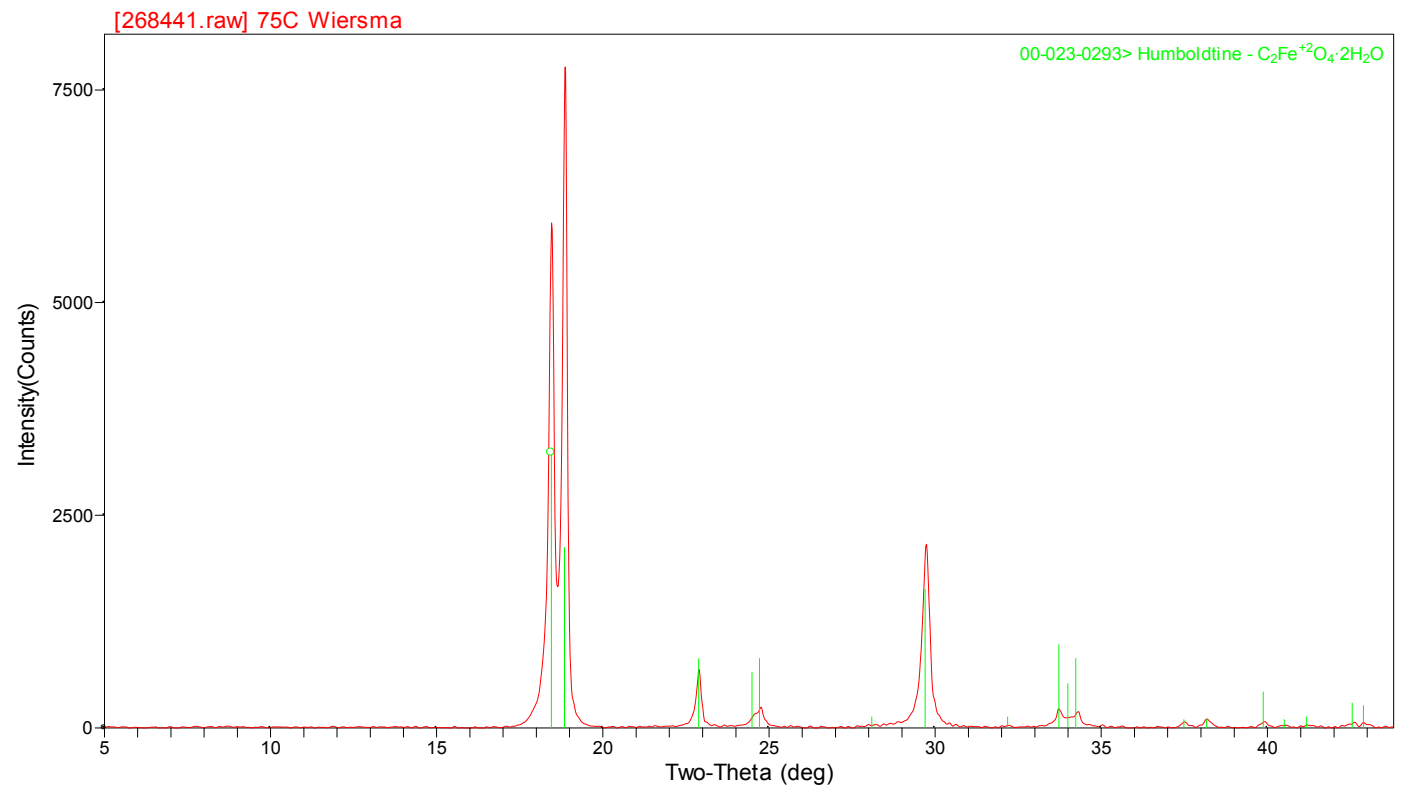

Figure 76. XRD analysis of coupon exposed to $1 \mathrm{wt} \% \%$ oxalic acid at $75^{\circ} \mathrm{C}$ under stagnant conditions.

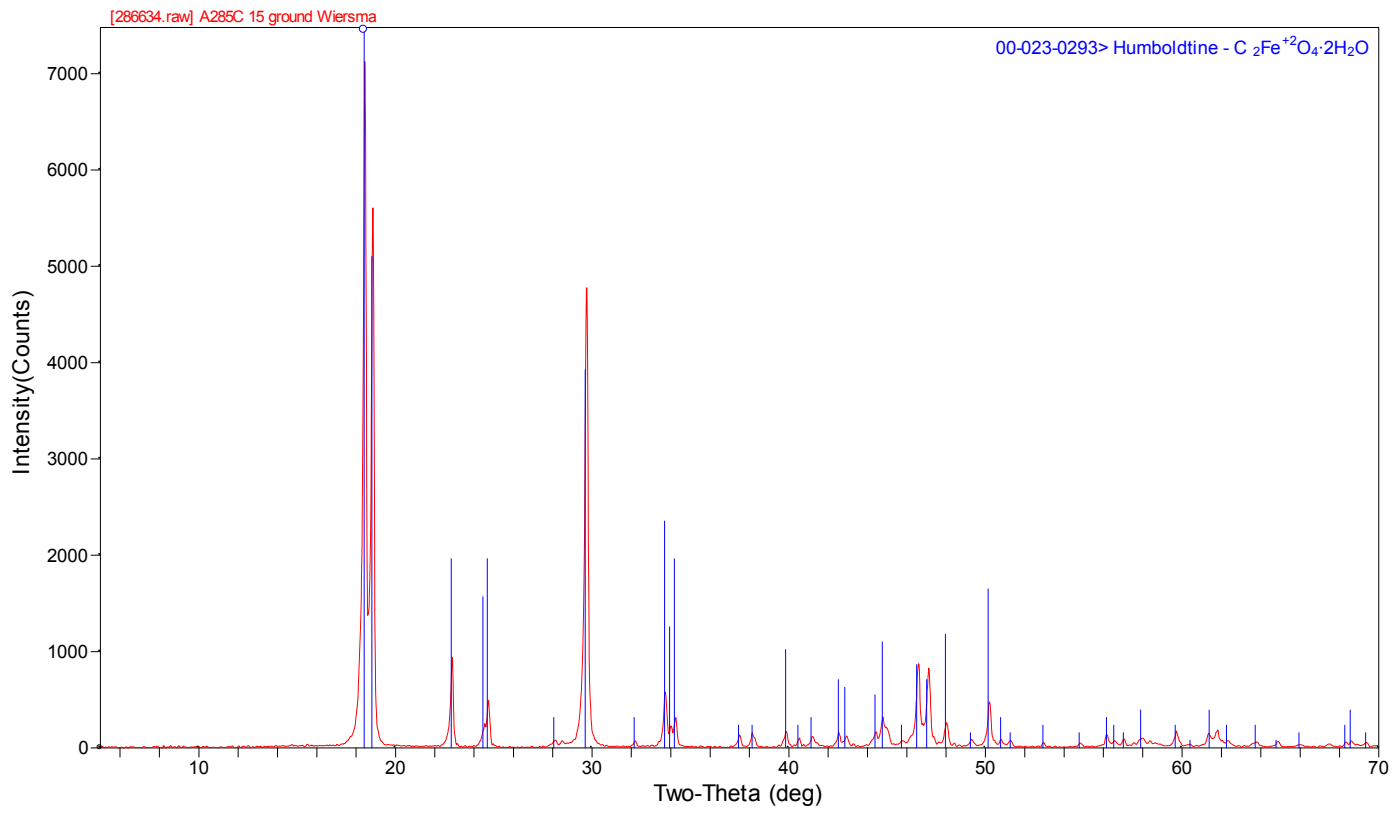

Figure 77. XRD analysis of coupon exposed to 2.5 wt. \% oxalic acid at $75{ }^{\circ} \mathrm{C}$ under stagnant conditions. 


\section{Revision 1}

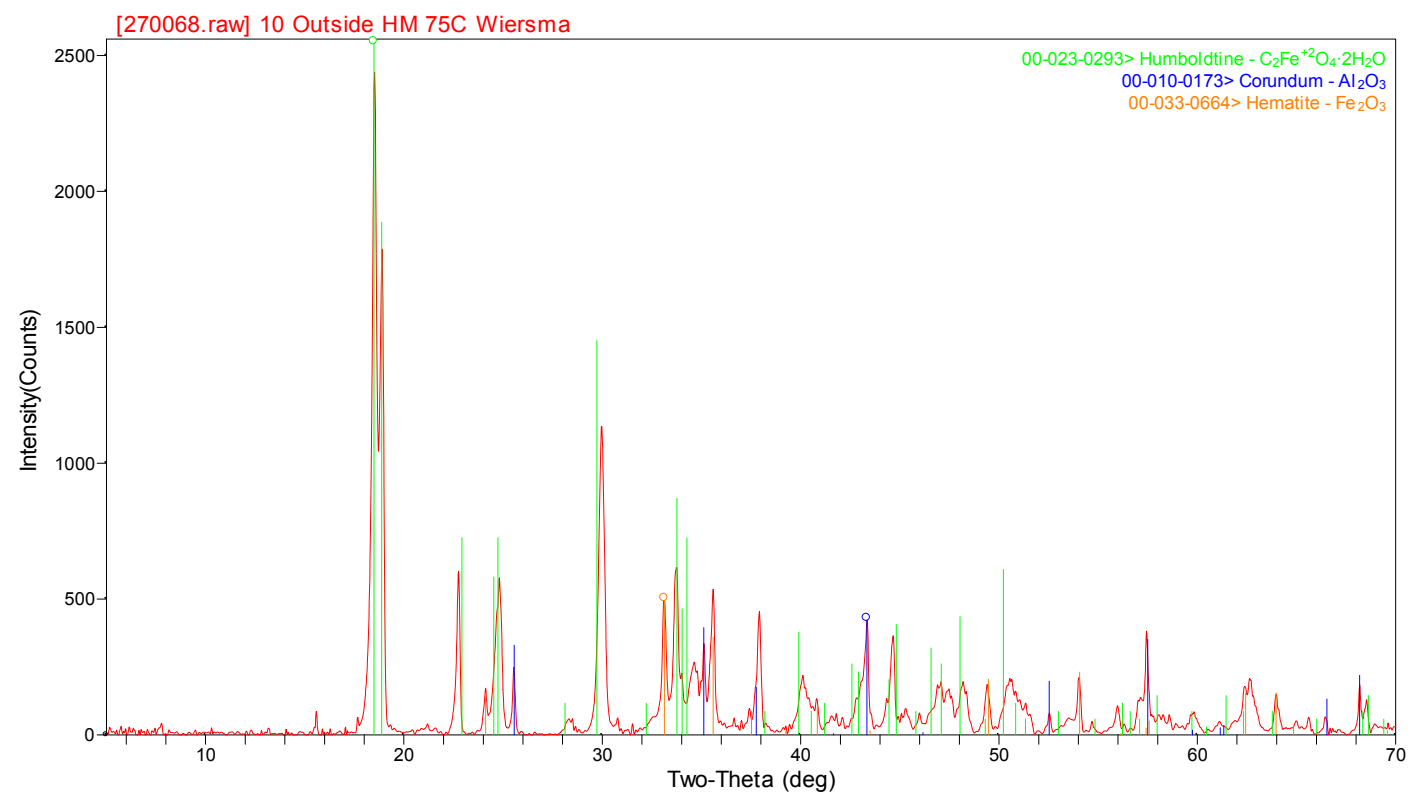

Figure 78. XRD analysis of coupon exposed to the HM/1 wt.\% oxalic acid mixture at $75^{\circ}$ under agitated conditions.

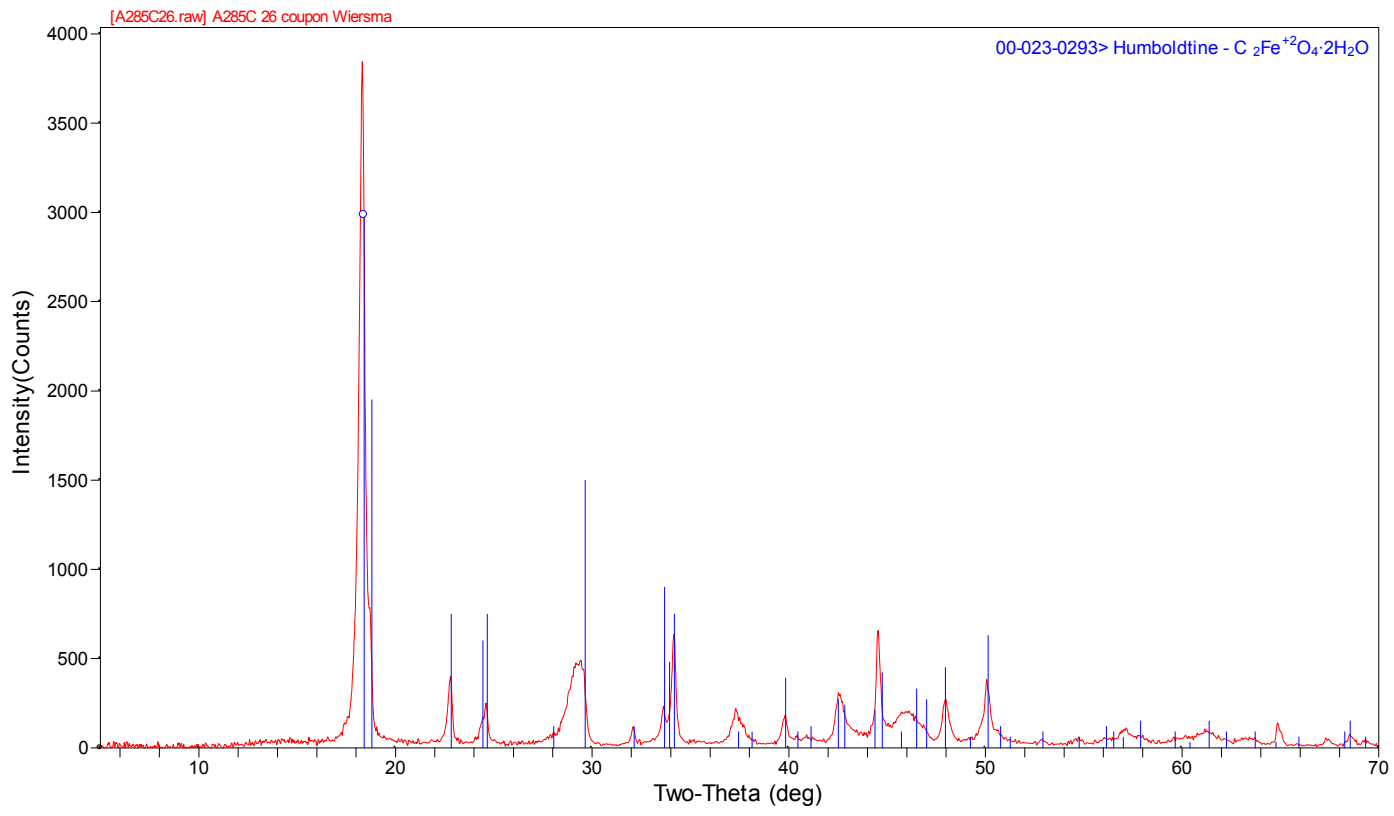

Figure 79. XRD analysis of coupon exposed to the HM/2.5 wt. \% oxalic acid mixture at $75^{\circ}$ under agitated conditions. 


\section{Revision 1}

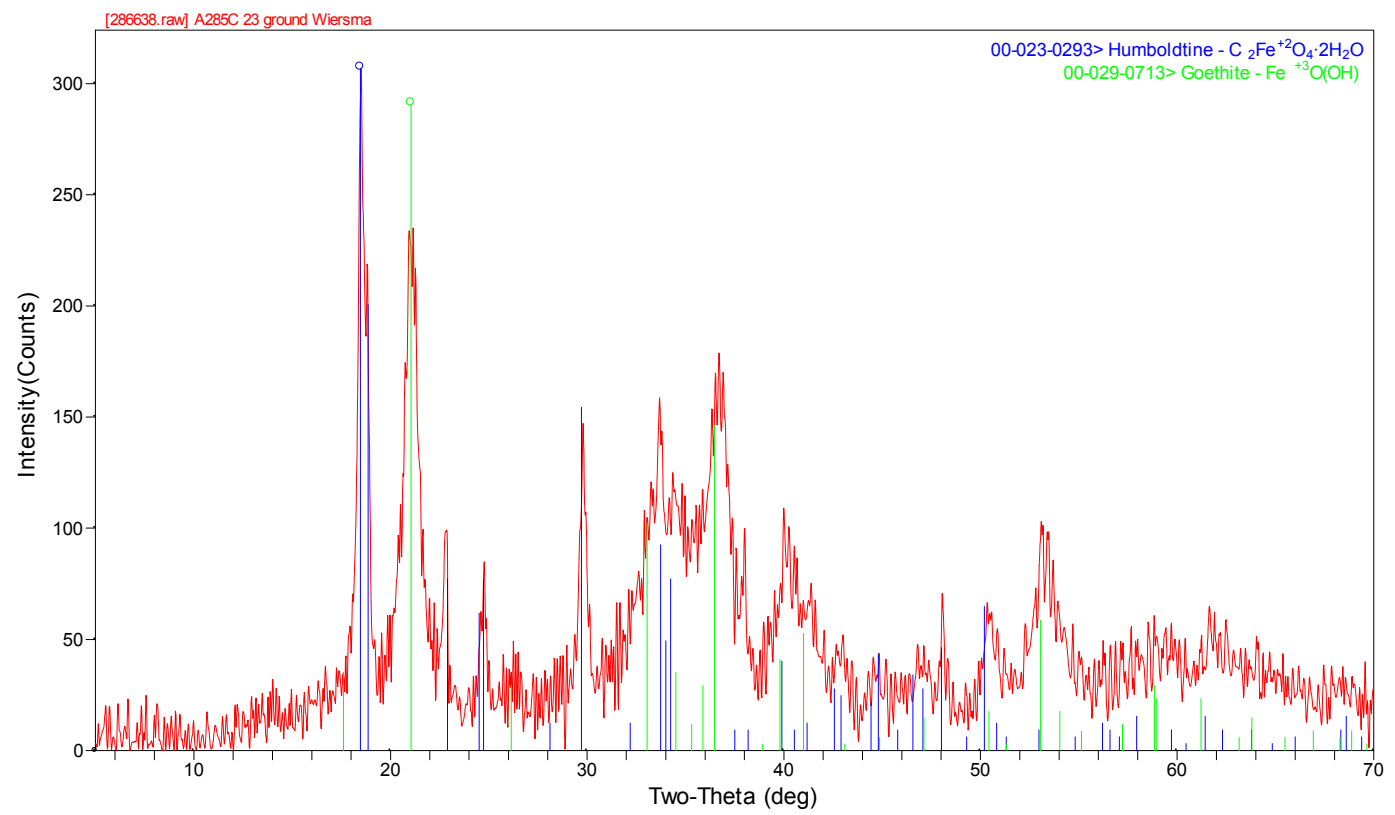

Figure 80. XRD analysis of coupon exposed to the HM/2.5 wt. \% oxalic acid mixture at $75^{\circ}$ under stagnant conditions.

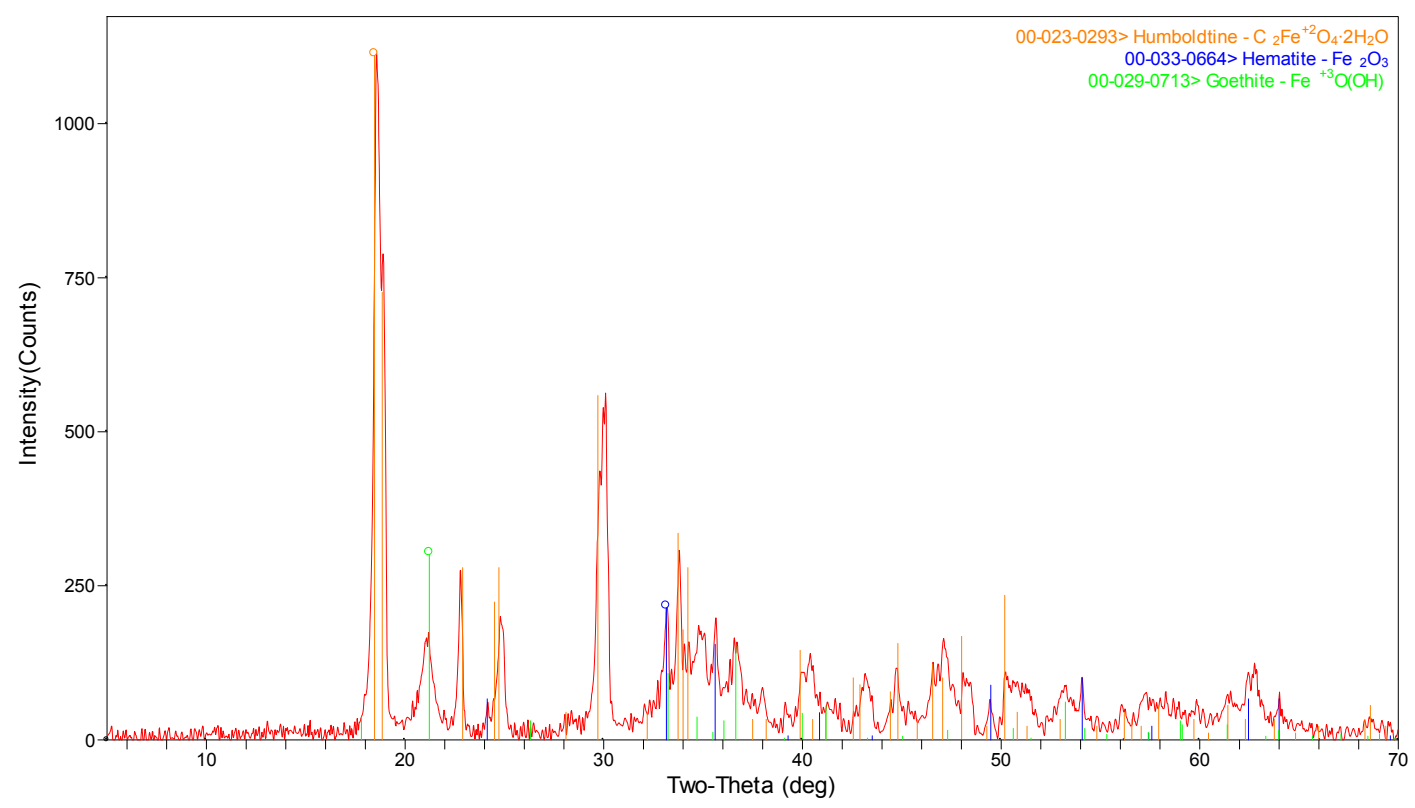

Figure 81. XRD analysis of coupon exposed to the HM-PUREX/1 wt.\% oxalic acid mixture at $75^{\circ} \mathrm{C}$ under agitated conditions. 


\section{Revision 1}

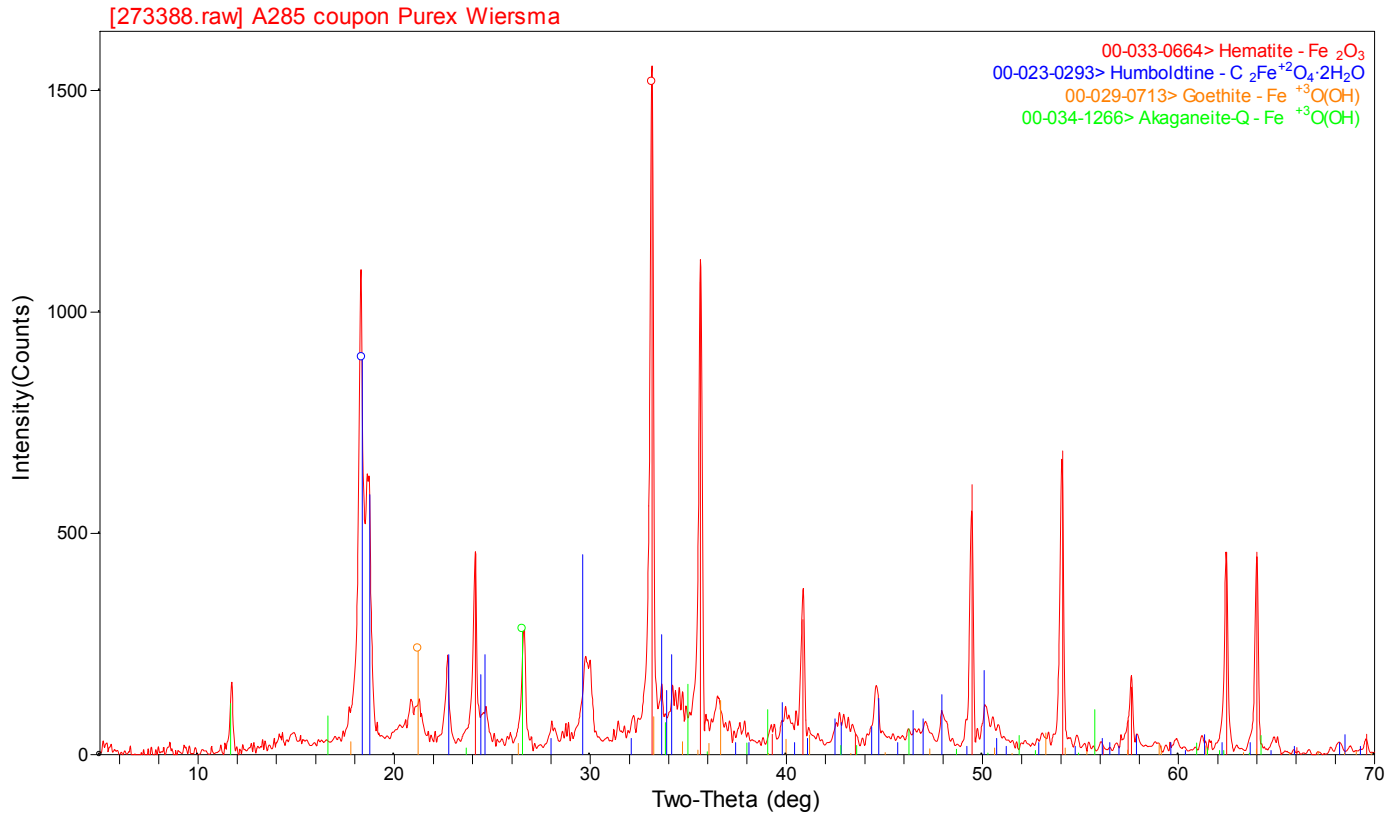

Figure 82. XRD analysis of coupon exposed to the PUREX/1 wt.\% oxalic acid mixture at $75^{\circ} \mathrm{C}$ under agitated conditions.

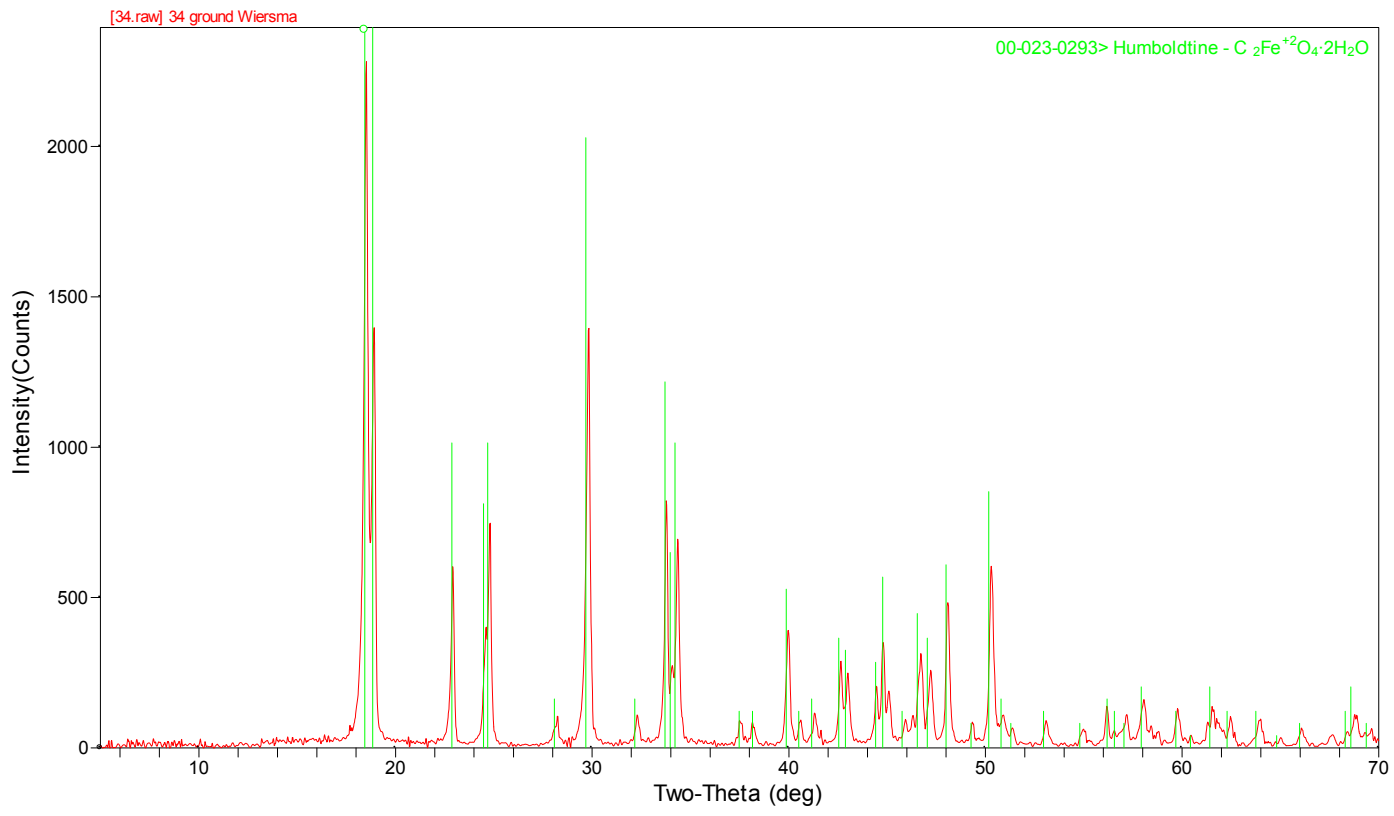

Figure 83. XRD analysis of coupon exposed to the PUREX/2.5 wt.\% oxalic acid mixture at $75{ }^{\circ} \mathrm{C}$ under agitated conditions. 
Figure 84 shows the photographs of coupons after cleaning with Clarke's solution and prior to weighing. The surface of the coupon exposed to $1 \mathrm{wt} . \%$ oxalic acid was generally corroded showing no evidence of pitting, although the surface had a roughened appearance. The identification numbers and original grinding marks were removed due to corrosion. The coupon exposed to the HM-PUREX/1 wt.\% oxalic acid simulant was also generally corroded with no evidence of pitting. The identification numbers could still be read, however the original grinding marks were removed due to corrosion. The HM-PUREX coupon is representative of the other coupons that had been exposed to either the PUREX or the HM simulant that was dissolved in $1 \mathrm{wt} \%$ oxalic acid.

In most cases, similar results were observed for the $2.5 \mathrm{wt} . \%$ oxalic acid solution. The 2.5 wt. \% oxalic acid was very similar as only general corrosion was observed. Likewise, coupons exposed to the PUREX/2.5 wt.\% oxalic acid simulants at both temperatures and the $\mathrm{HM} / 2.5 \mathrm{wt} . \%$ oxalic acid simulant at $50{ }^{\circ} \mathrm{C}$ exhibited general corrosion to a lesser degree than the coupons in oxalic acid alone. The exception occurred for the coupons in the $\mathrm{HM} / 2.5$ wt. $\%$ oxalic acid at $75^{\circ} \mathrm{C}$, where pitting was observed in the stagnant solution, and pitting with general corrosion occurred in the agitated solution (see Figure 85). The pits in the non-agitated solution had a hemi-spherical morphology. Over time some of the pits coalesced and gave the pit a narrow, oblong appearance. The shape of these pits differs considerably from pits observed in other waste storage applications [35]. Those pits tend to be broader and shallower in depth and a rougher appearance. As can be seen by looking at the edge of the coupon (see Figure $85 \mathrm{a}$ ), the bottom of the pits has a smooth almost polished appearance. The coupons in the agitated solutions not only exhibited hemi-spherical pits, but considerable general attack had also occurred.

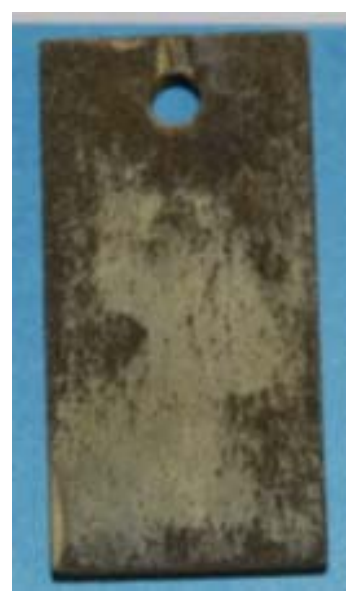

(a)

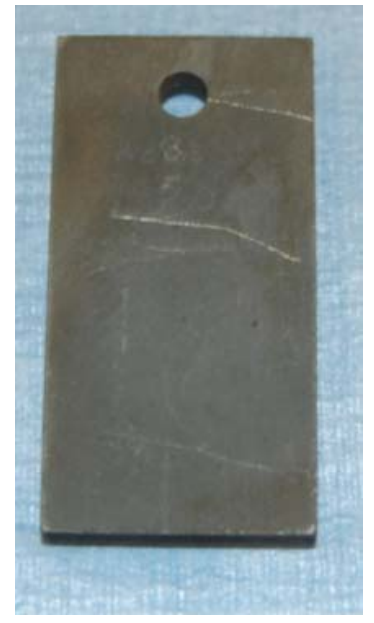

(b)

Figure 84. Cleaned Coupon showing general corrosion (a) 1 wt. \% oxalic acid, (b) HM-PUREX/1 wt.\% oxalic acid 

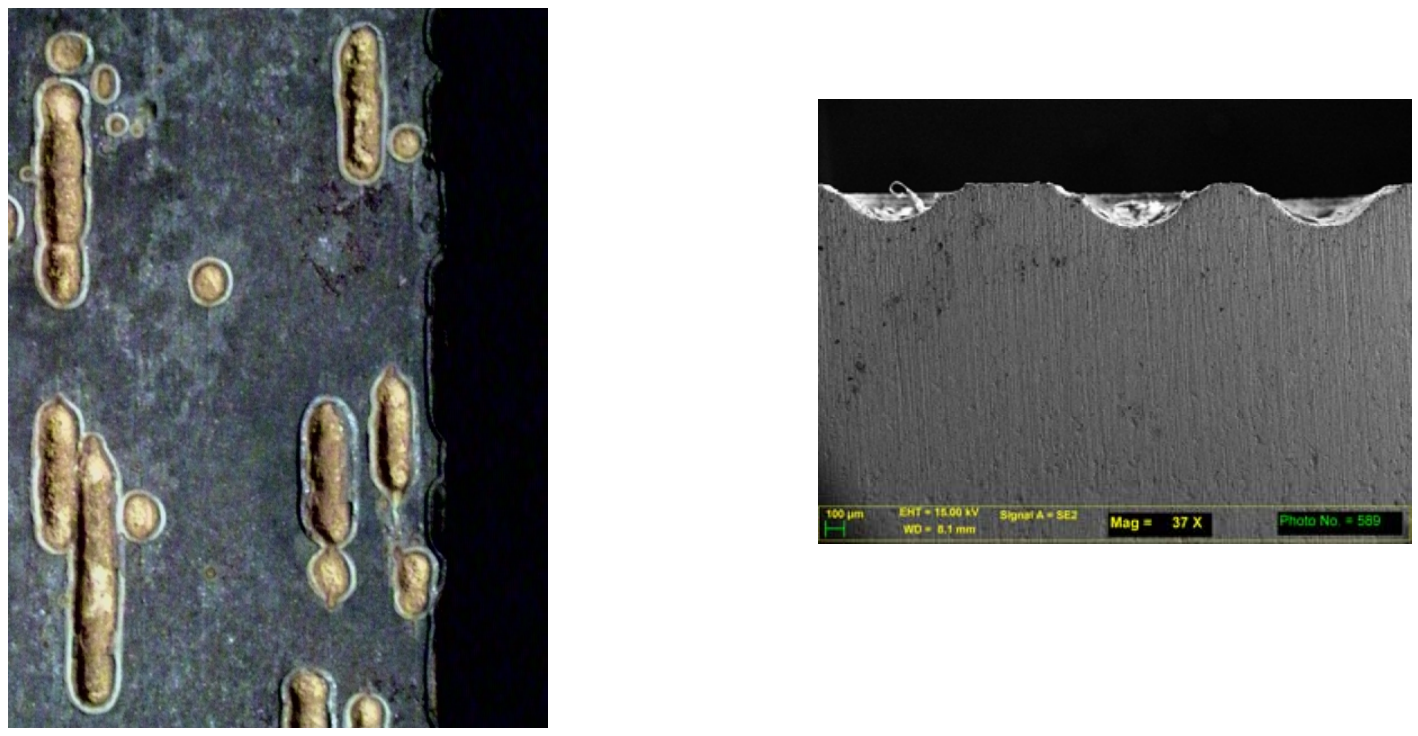

(a)

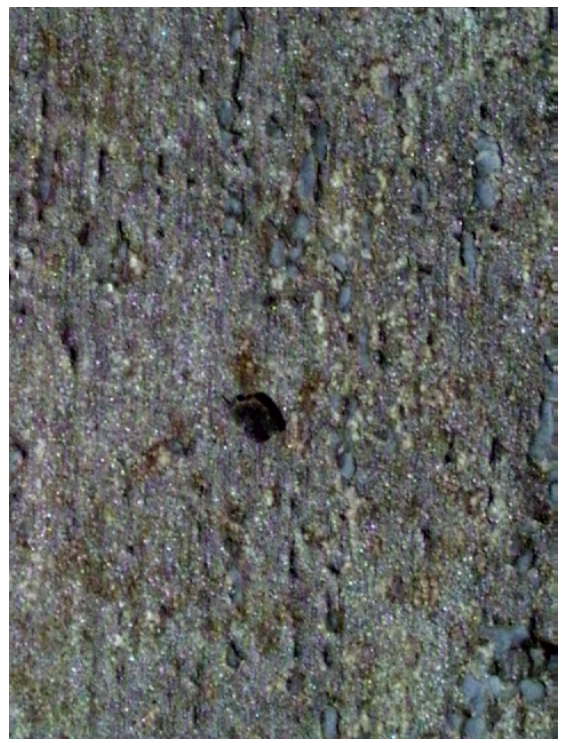

(b)

Figure 85. Cleaned Coupon showing pitting corrosion in (a) HM/2.5 wt. \%oxalic acid at $75{ }^{\circ} \mathrm{C}$ with no agitation, (b) HM-PUREX/2.5 wt. $\%$ oxalic acid at $75{ }^{\circ} \mathrm{C}$ with agitation. 
The corrosion morphology for the coupons exposed to HM/2.5 wt.\% oxalic acid with no agitation was examined further with the scanning electron microscope (SEM). Energy Dispersive Spectroscopy (EDS) was utilized in tandem with the SEM to identify any species present in and around the pits. Figure 86 is an SEM micrograph of the hemispherical pits that were present on the coupon. Some of the corrosion product remained behind in the occluded cell. The coalescence of the spherical pits into an oblong "streak" is also shown. EDS results for the region adjacent to the pits indicated that the primary constituents were iron, carbon and oxygen, which is consistent with the iron oxalate film and also the presence of iron oxide (i.e., goethite). The lighter color is likely the ferrous oxalate and the goethite is likely the darker color. Within the pit, in addition to these constituents, significant quantities of aluminum were also present. Aluminum is one of the primary constituents of the HM sludge simulant and may have become entrapped in the corrosion products in the pits. The EDS results also indicate an oxygen peak that has a higher relative intensity than that observed on the exterior of the pit. This suggests that there is a larger fraction of iron and or aluminum oxide present in the pit. A higher magnification micrograph of the corrosion products in the pits is shown in Figure 87. Particles on the order of 3 microns or less were observed evenly dispersed on the surface of the corrosion product. EDS identified that these particles contained mercury. This result suggests that mercury was involved in the development of the pits.

The corrosion morphology for the coupons exposed to HM/2.5 wt.\% oxalic acid with agitation was also examined further with SEM and EDS. Figure 88 is an SEM micrograph of the surface showing a characteristic "striped" pattern. The dark stripes are areas where preferential attack of the surface has occurred. Iron, carbon, oxygen, aluminum, and silicon were identified in the lighter regions around the stripes. These elements are either consistent with the ferrous oxalate corrosion product or were present in the initial sludge. The dark striped areas were predominantly iron and oxygen, indicating the presence of iron oxide alone. No ferrous oxalate seems to be in this area. A closer examination of the surface (see Figure 89) indicated the presence of small less than 3 micron particles. These particles were identified as either mercury or silver. A strong sulfur peak was also identified with the mercury particles. Thus, again mercury has been identified with accelerated local attack of the surface. 


\section{Revision 1}

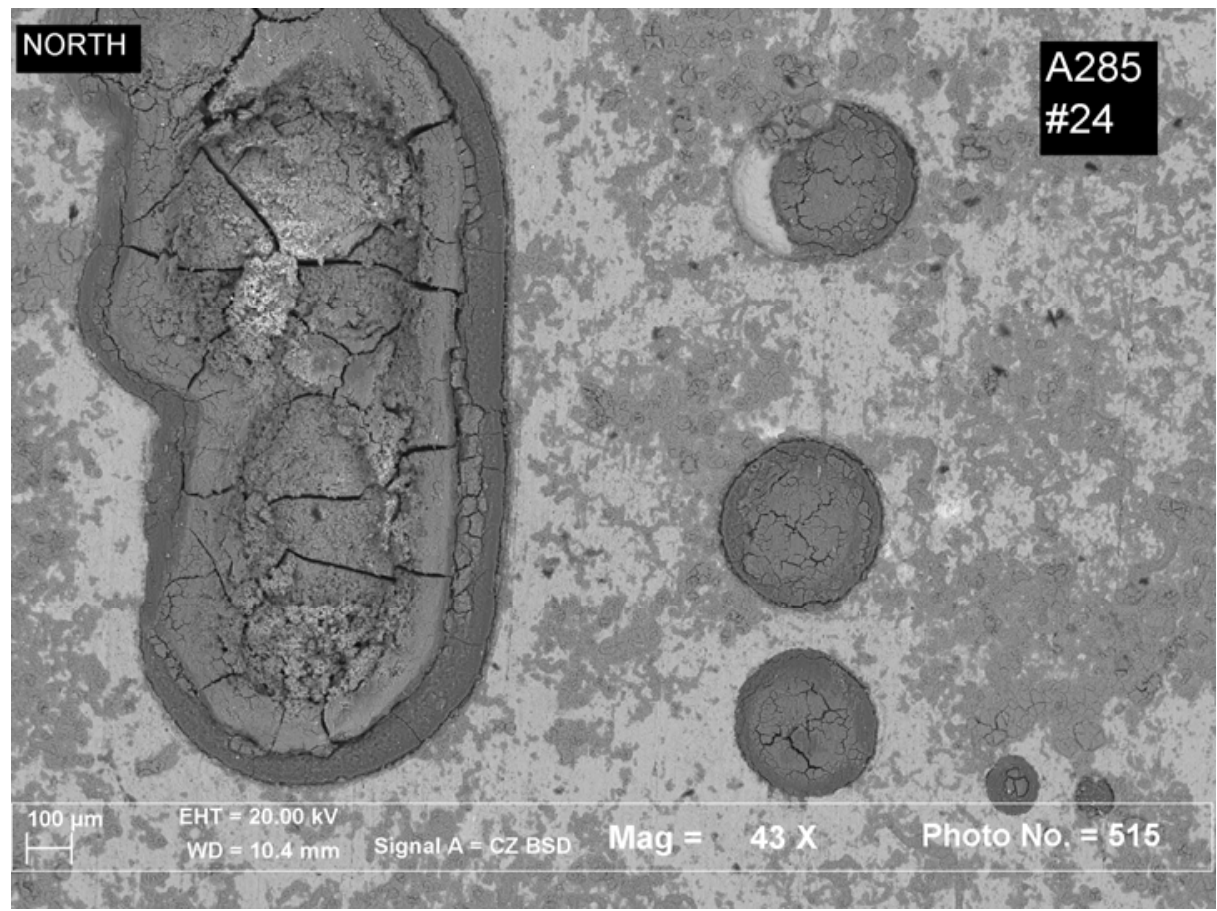

Figure 86. SEM micrograph showing the hemi-spherical and oblong shaped pits. This coupon was tested in $\mathrm{HM} / 2.5 \mathrm{wt}$.\% oxalic acid at $75{ }^{\circ} \mathrm{C}$ with no agitation.

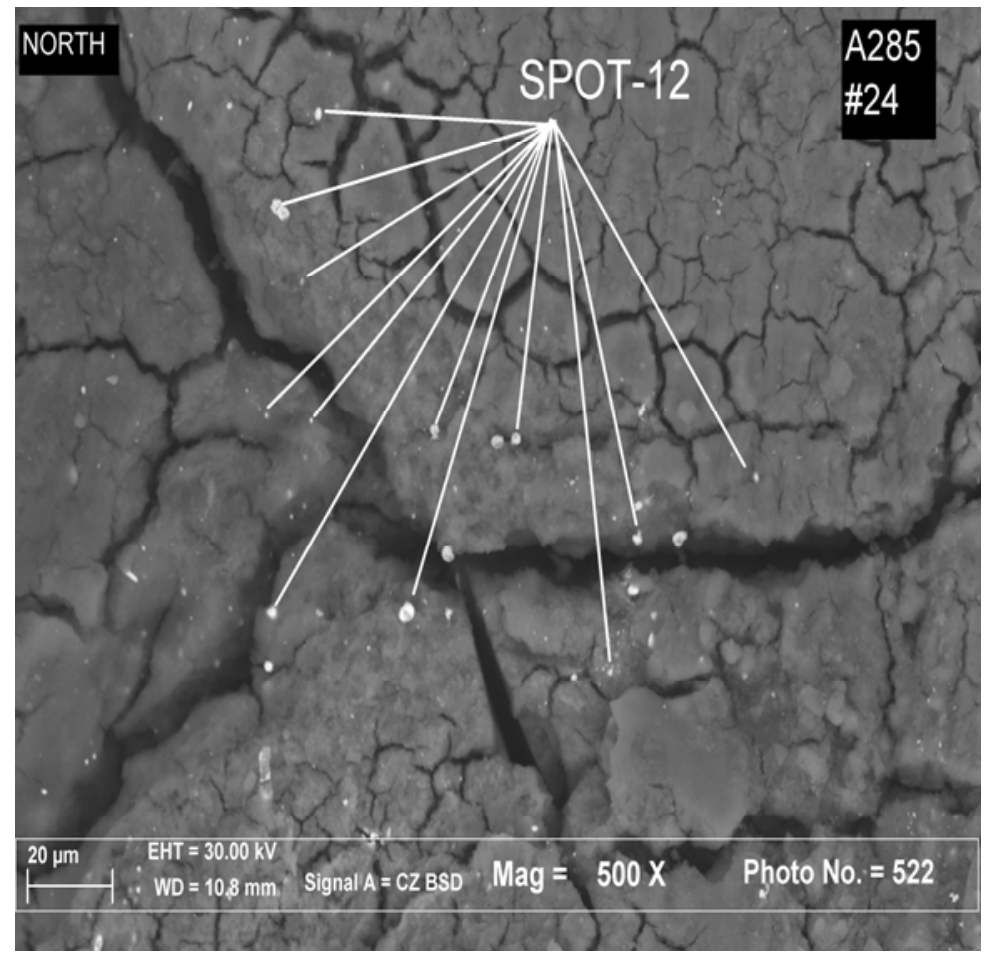

Figure 87. SEM micrograph showing the mercury particles dispersed with in the corrosion product in side a pit. This coupon was tested in HM/2.5 wt. \% oxalic acid at $75{ }^{\circ} \mathrm{C}$ with no agitation. 
Revision 1

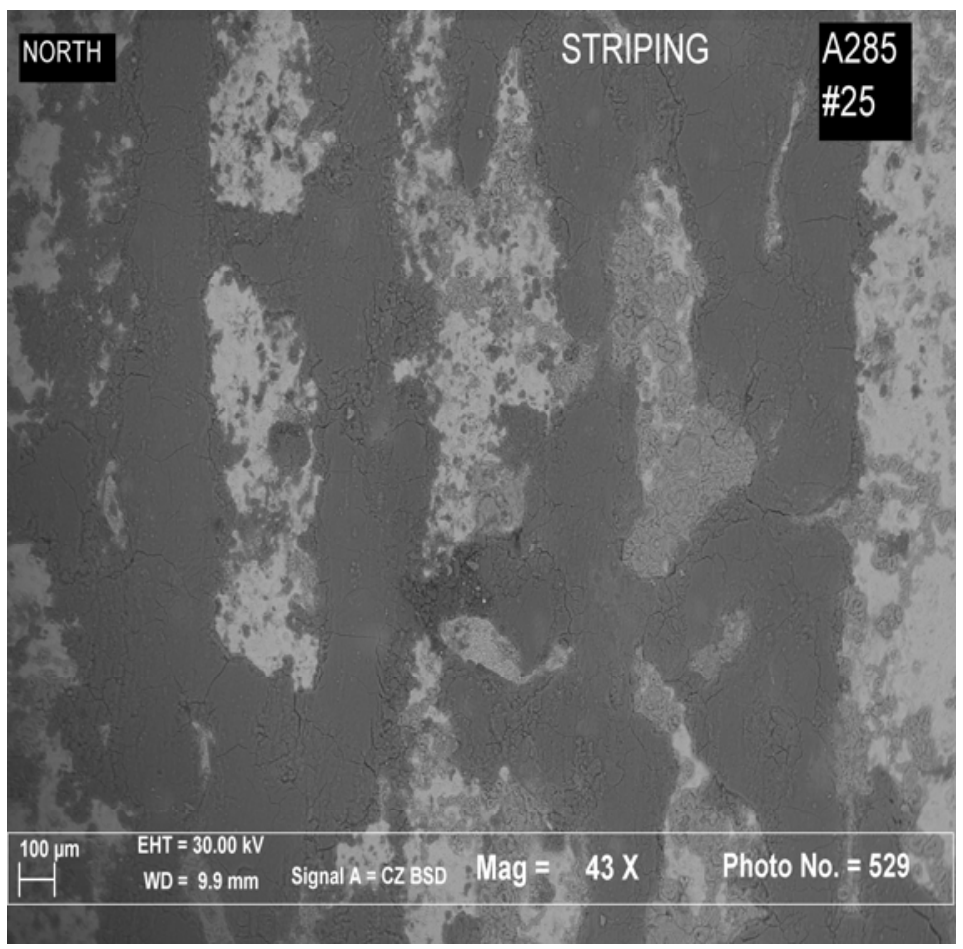

Figure 88. SEM micrograph showing "striped" pattern on the surface. This coupon was tested in $\mathrm{HM} / 2.5 \mathrm{wt}$. \% oxalic acid at $75^{\circ} \mathrm{C}$ with agitation.

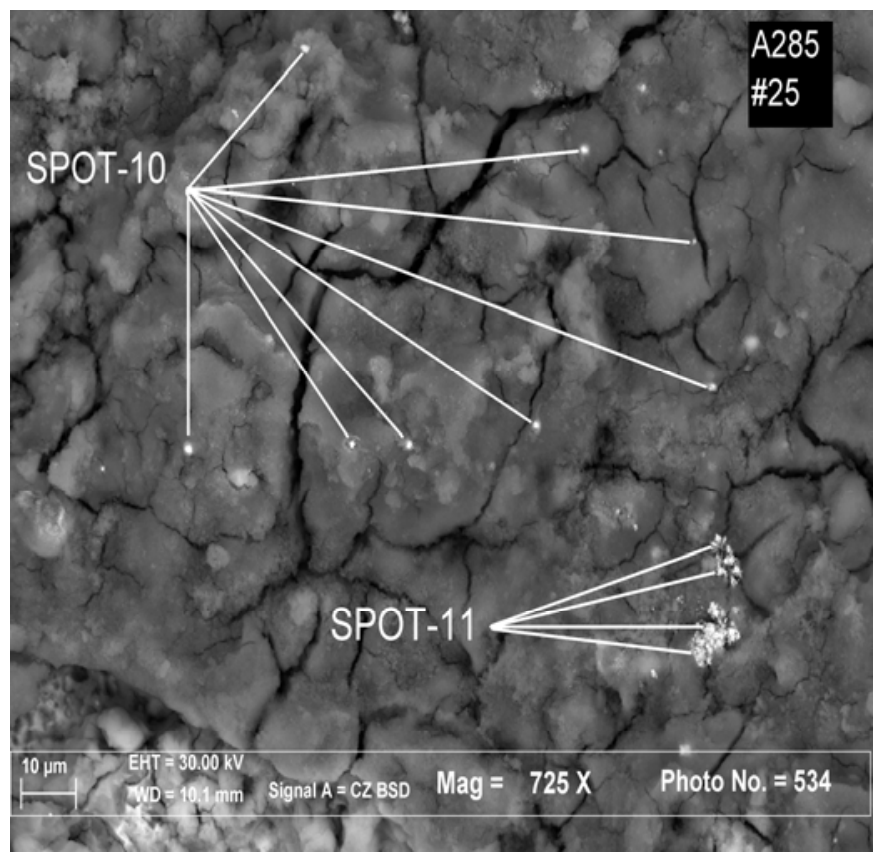

Figure 89. SEM micrograph showing mercury (Spot 10) and silver (Spot 11) particles dispersed within the dark striped areas. This coupon was tested in HM/2.5 wt. \% oxalic acid at $75^{\circ} \mathrm{C}$ with agitation. 
Mercuric or mercurous ion provides the strong oxidizing agent necessary to produce the goethite. A possible mechanism to explain the formation of goethite is as follows. Iron and aluminum oxides are initially entrapped on the surface of the coupon with the iron oxalate. The mercuric species is adsorbed from the solution by the aluminum oxides [36]. If the temperature is high enough, the aluminum oxide begins to dissolve leaving either a mercuric or mercurous species present on the surface. The presence of the mercury species polarizes the surface at a local site. For example, the mercurous species may be involved in reactions at local sites according to the following reactions.

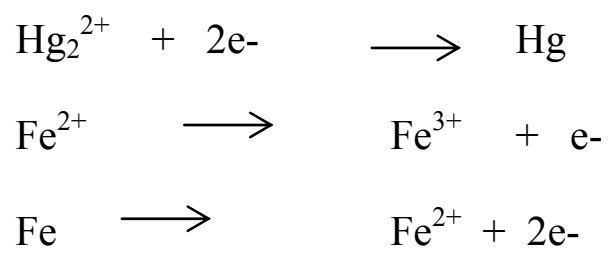

Note that the ferric ions produced by reaction (18) accelerate the rate of reaction (19) at oxidizing potentials [15]. The ferric ion would reacts with water to form the goethite. The equilibrium potentials for the mercurous and mercuric species are approximately $+0.4 \mathrm{~V}$ and $+0.7 \mathrm{~V}$ vs. $\mathrm{Ag} / \mathrm{AgCl}$, respectively [6]. These potentials are noble to the equilibrium OCP values that were measured during the tests, and the breakdown potential for ferrous oxalate. Therefore, wherever this reaction occurs on the metal surface, the ferrous oxalate will not form to slow the reaction. Interestingly, the cyclic and anodic polarization scans were only carried out to $+0.5 \mathrm{~V}$ vs. $\mathrm{Ag} / \mathrm{AgCl}$. No pitting was observed during the short-term electrochemical tests. Given that the equilibrium potential for the mercurous species is within this range, this suggests that the mercuric species is possibly being reduced to mercury. This explanation may also be the reason for the absence of localized attack during these tests. Time could also be a factor as the adsorption rate of the mercuric ion may limit the build-up of a sufficient concentration of species to polarize the local site.

The PUREX simulant also contained approximately the same amount of mercuric nitrate as the HM. Therefore, a similar result might be expected. However, the aluminum oxide concentration is much lower in the PUREX simulant. Therefore, there is much less mercuric ion adsorbed near the metal surface. The low concentration of mercurous or mercuric ion on the surface would limit the additional corrosion that could occur.

\subsubsection{Corrosion Rate Determination}

The corrosion rate (CR, in units of mpy) is related to the weight loss of the coupon by the following equation:

$$
\mathrm{CR}=\frac{3.45 \times 10^{6}}{\operatorname{AxTx} \rho} \mathrm{w}
$$




\section{Revision 1}

where $\mathrm{w}$ is the weight loss in grams, $\mathrm{A}$ is the area in $\mathrm{cm}^{2}, \mathrm{~T}$ is the exposure time in hours, and $\rho$ is the density in $\mathrm{g} / \mathrm{cm}^{3}$.

Figure 90 presents the corrosion rate data generated from the coupon tests performed with the sludge simulants dissolved in 1 wt.\% oxalic acid. Each symbol represents the results from a single test. The results indicate that regardless of the environmental conditions (i.e., sludge simulant, temperature, agitation, aeration) during chemical cleaning with $1 \mathrm{wt} . \%$ oxalic acid an upper bound estimate of the corrosion rate for carbon steel is 25 mpy.

These results compared well with the corrosion rates predicted by the linear polarization technique. This comparison is illustrated in Figure 91. In this figure the coupon test results are the average corrosion rate of two duplicate coupons and the LPR tests results are the average corrosion rate of two or three coupons. The corrosion rates estimated by the LPR technique were in excellent agreement with the coupon results for the PUREX and HM environments in the $1 \mathrm{wt} \%$ oxalic acid. On the other hand, the corrosion rates estimated by the LPR technique under-predicted the coupon corrosion rates in the HMPUREX environment. The under-prediction occurred primarily in the high temperature and agitated solution conditions.

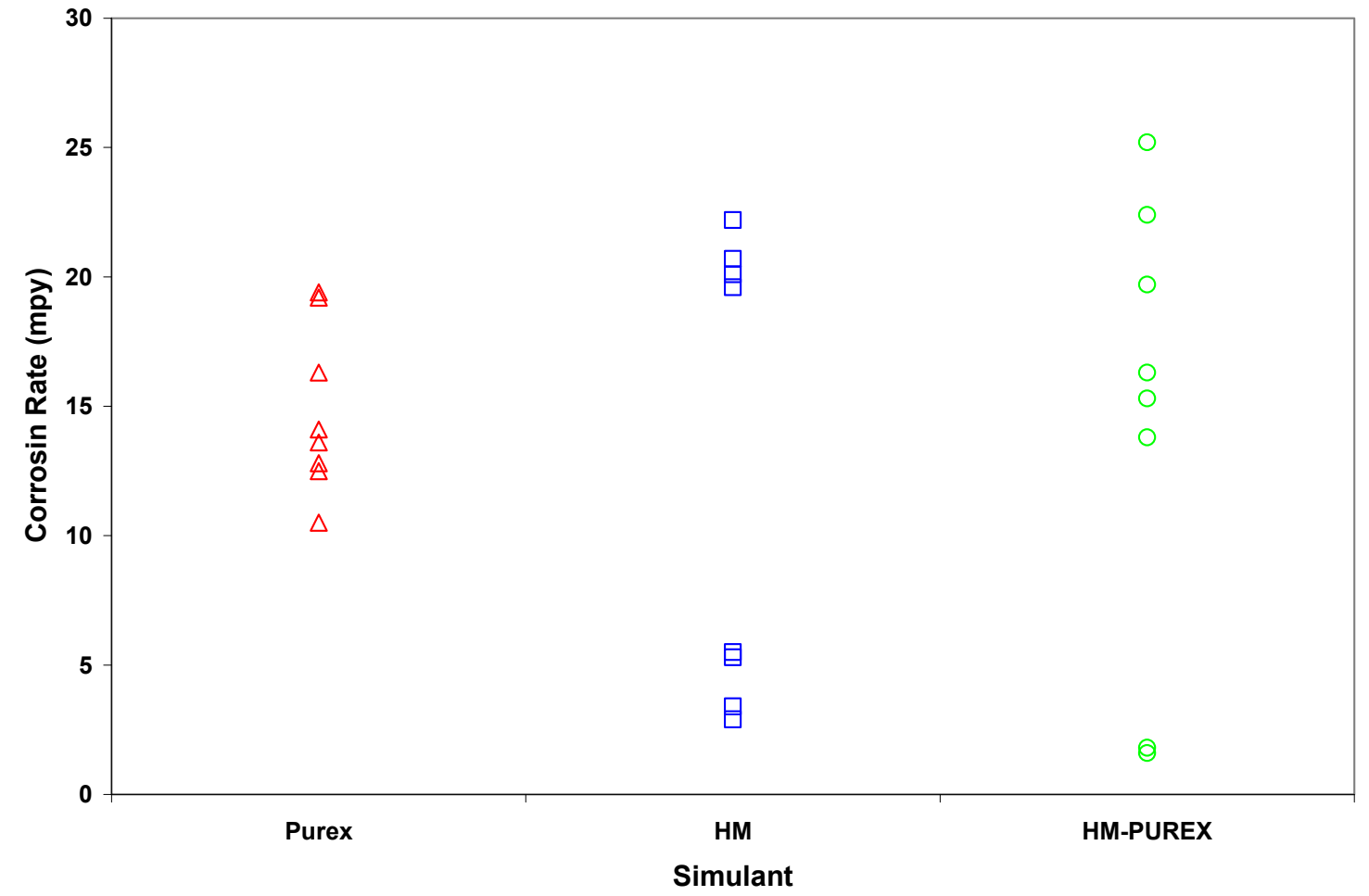

Figure 90. Corrosion rates determined from coupon tests in the sludge simulants with 1 wt. \% oxalic acid. 


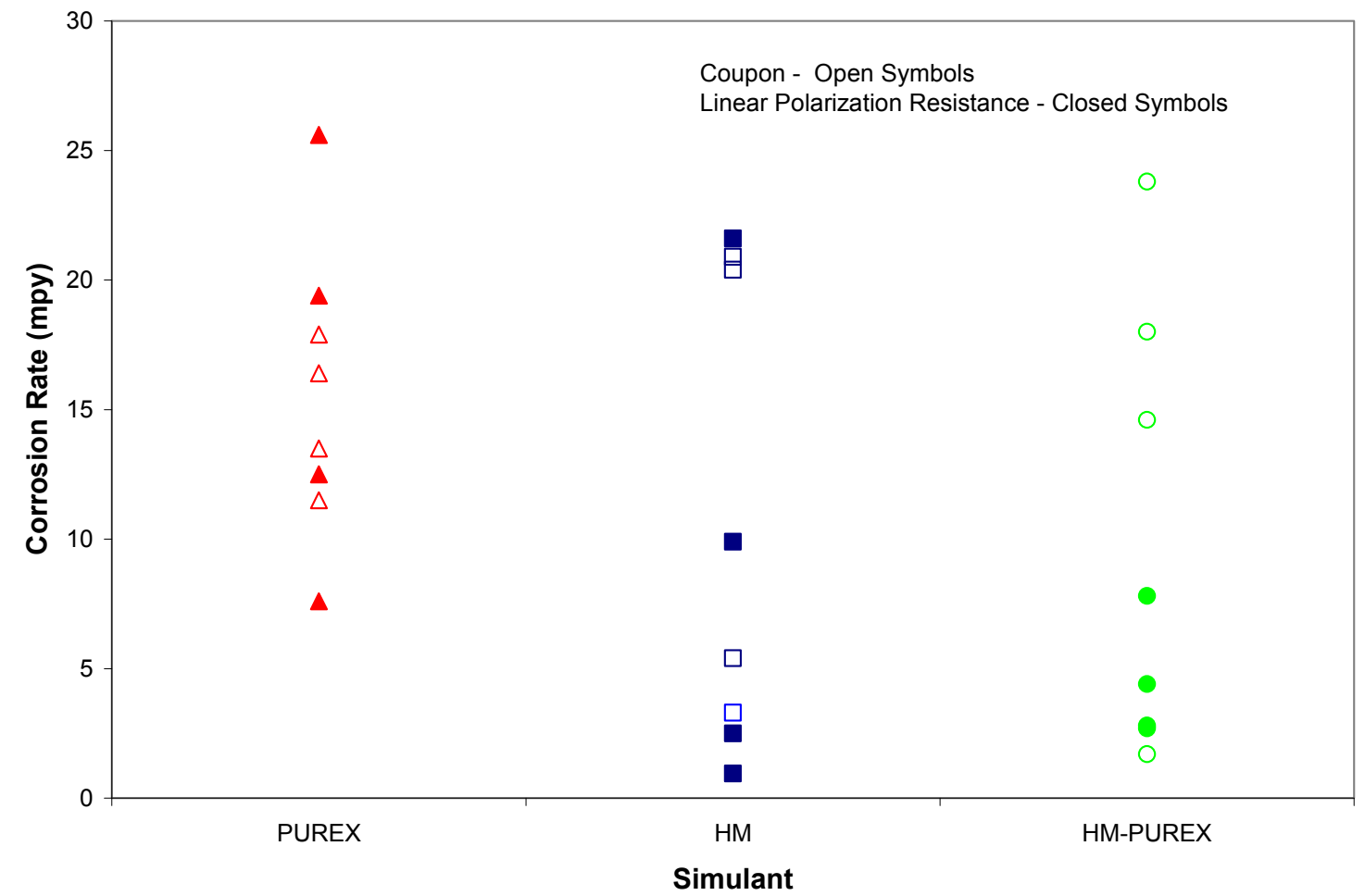

Figure 91. Comparison between LPR and coupon test corrosion rate estimates for the sludge simulants in 1 wt.\% oxalic acid.

Figure 92 presents the corrosion rate data generated from the coupon tests performed with the sludge simulants dissolved in $2.5 \mathrm{wt} . \%$ oxalic acid. Each symbol represents the results from a single test. The corrosion rates in the these tests were more variable than those performed in $1 \mathrm{wt} . \%$ oxalic acid with corrosion rates ranging between 15 to 88 mils/yr. Five of the 16 coupons tested in sludge simulant with $2.5 \mathrm{wt} . \%$ oxalic acid had corrosion rates greater than $30 \mathrm{mils} / \mathrm{yr}$.

There also appeared to be a significant difference between the corrosion rates predicted by the linear polarization technique and the coupon tests. This comparison is illustrated in Figure 93. In this figure the coupon test results are the average corrosion rate of two duplicate coupons and the LPR tests results are the average corrosion rate of two or three coupons. In general, the LPR technique under-predicted the corrosion rates observed during the longer term coupon tests. This type of result can occur if the environment is changing during the test such that the final environment is more aggressive than the initial. Thus, while the LPR technique provides an accelerated, instantaneous assessment of the corrosion rate, the effectiveness as a long term predictor of the corrosion rate is limited to environment where the corrosion rate is relatively constant. 


\section{Revision 1}

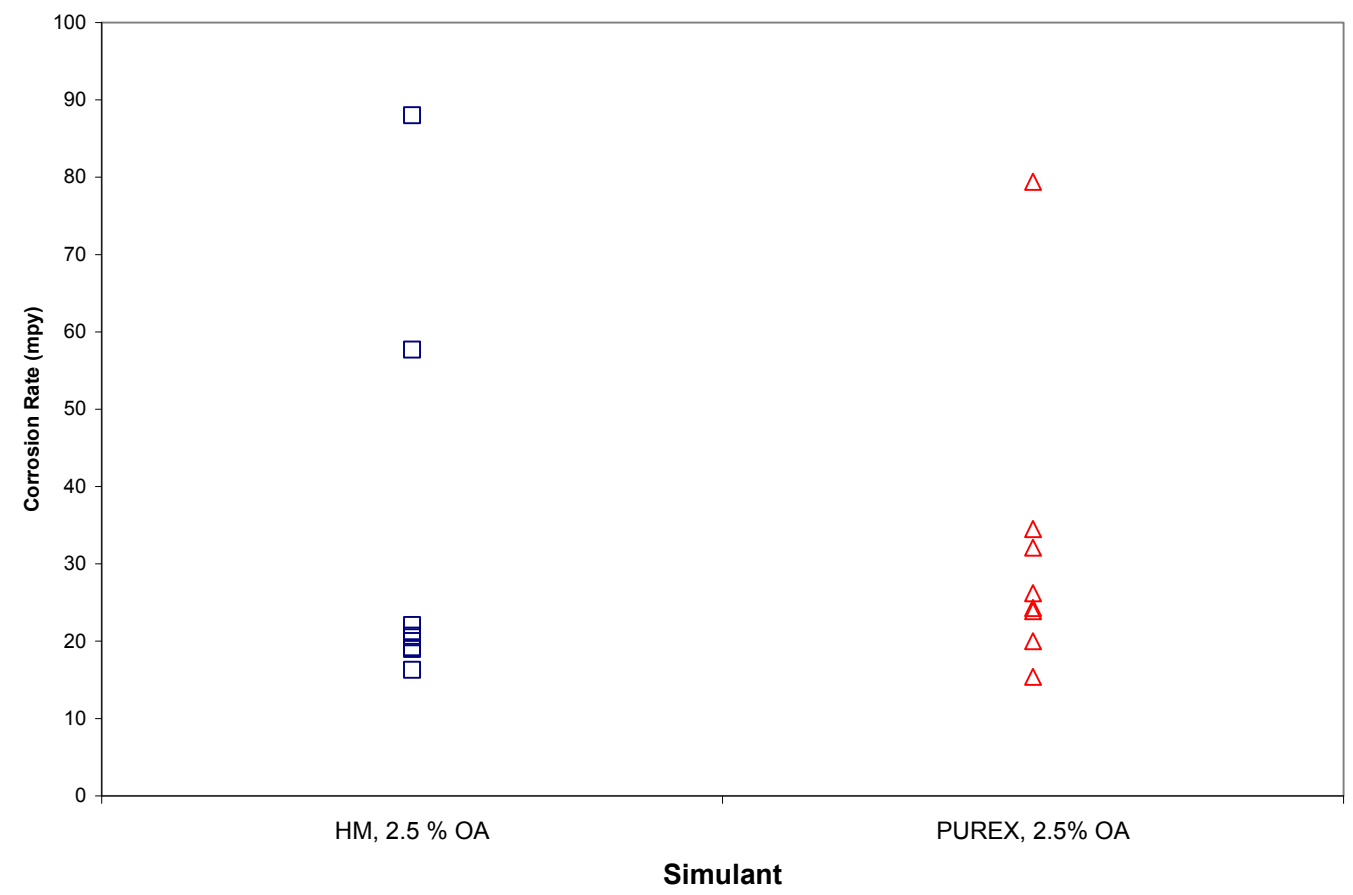

Figure 92. Corrosion rates determined from coupon tests in the sludge simulants with 2.5 wt. \% oxalic acid.

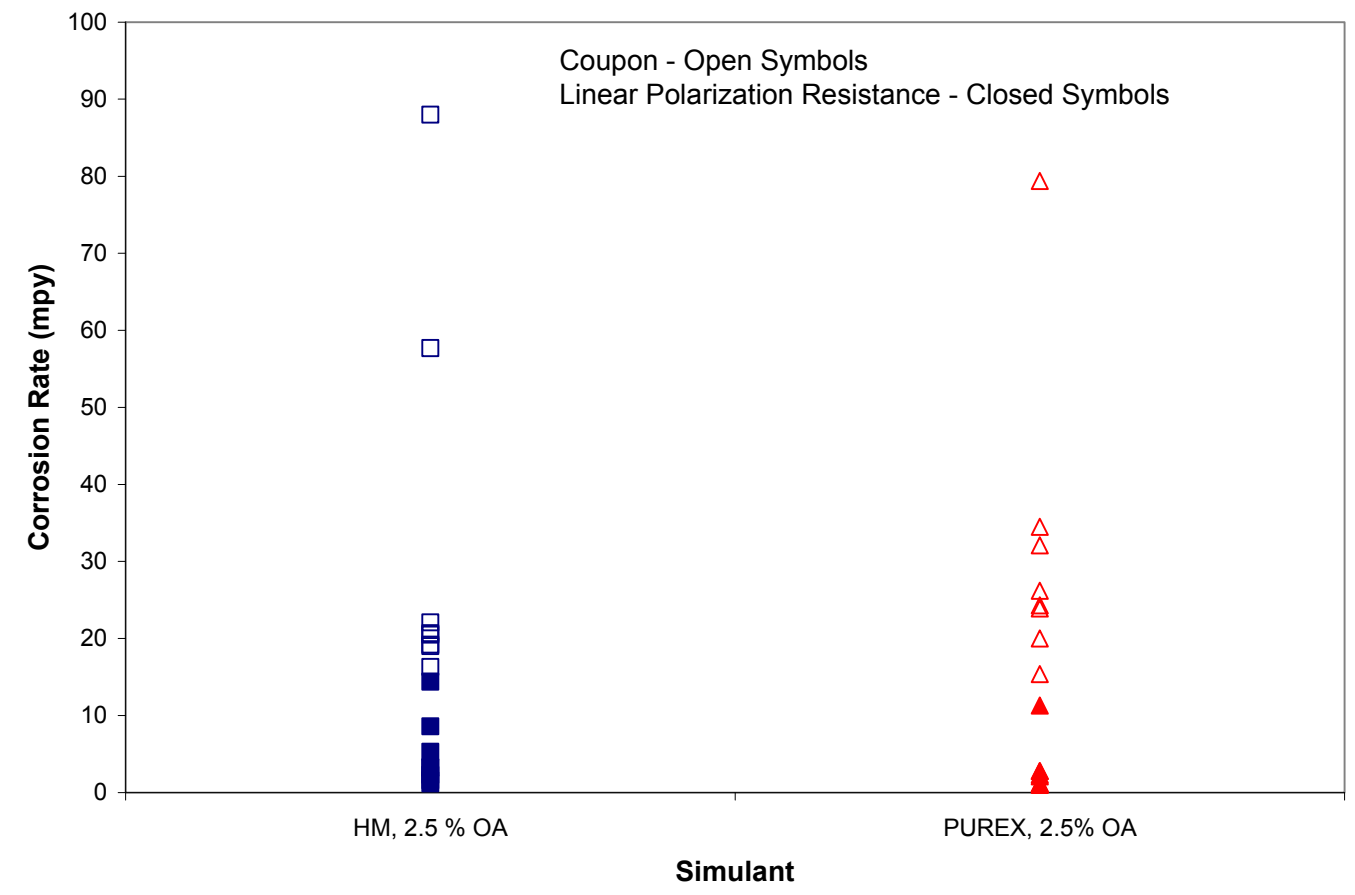

Figure 93. Comparison between LPR and coupon test corrosion rate estimates for the sludge simulants in 2.5 wt.\% oxalic acid. 
Differences in environmental conditions resulted in the variability in the corrosion rates observed during the coupon tests. These differences were also examined in light of the mechanistic information gathered from the LPR tests. The first variable examined was the sludge simulant environment. Of particular interest is the comparison between the corrosion rate in $1 \mathrm{wt} . \%$ oxalic acid solution and the solutions with the simulants. Figure 94 shows that the corrosion rate in the non-agitated $1 \mathrm{wt} . \%$ oxalic acid at $45^{\circ} \mathrm{C}$ was approximately 5 times greater than that observed in the solutions containing sludge simulants at the same temperature. It also appears that the corrosion rate has a stronger dependence on temperature with the oxalic acid than the simulant environments. For the non-agitated condition the corrosion rate in the oxalic acid solution is greater at $45^{\circ} \mathrm{C}$ than that at $75^{\circ} \mathrm{C}$. As discussed previously, these results suggest that for the ferrous oxalate film formed at higher temperatures was more tenacious and suppressed corrosion. The lower corrosion rates in the presence of a sludge simulant suggest either a more tenacious oxalate film or the nature and the kinetics of the cathodic reaction have been significantly altered by the presence of dissolved species in the oxalic acid. The results of the cyclic polarization tests indicated that the oxalate film is slightly more protective than the oxalic acid. However, the oxalate layer that forms in the PUREX and the HMPUREX is less protective. Based on the observations of the cathodic reactions, it seems likely that the presence of dissolved species such as the di-oxolatoferrate ion can inhibit the corrosion rate.

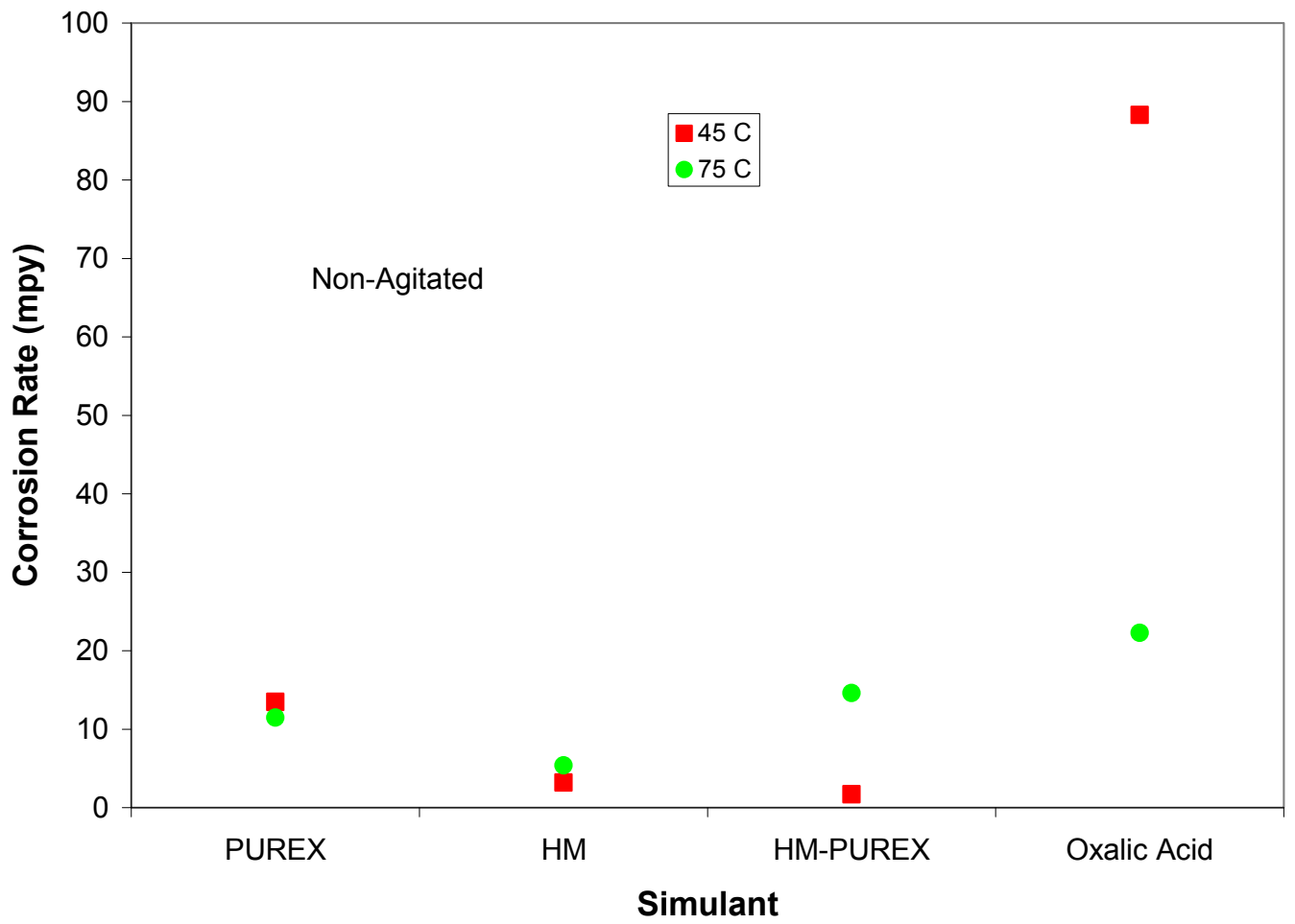

Figure 94. Corrosion rates in sludge simulants compared with 1 wt.\% oxalic acid.

Figure 95 shows that the corrosion rate in the non-agitated $2.5 \mathrm{wt} . \%$ oxalic acid at $50{ }^{\circ} \mathrm{C}$ was approximately 6 to 7 times greater than that observed in the solutions containing 
sludge simulants at the same temperature. It also appears that the corrosion rate has a stronger dependence on temperature with the oxalic acid than the simulant environments. For the non-agitated condition the corrosion rate in the oxalic acid solution is 6 to 7 times greater at $50{ }^{\circ} \mathrm{C}$ than that at $75^{\circ} \mathrm{C}$. As discussed previously, these results suggest that for the ferrous oxalate film formed at higher temperatures was more tenacious and suppressed corrosion. The lower corrosion rates in the presence of a sludge simulant suggest either a more tenacious oxalate film or the nature and the kinetics of the cathodic reaction have been significantly altered by the presence of dissolved species in the oxalic acid. Based on the observations of the cathodic reactions, it seems likely that the presence of dissolved species such as the di-oxolatoferrate ion can inhibit the corrosion rate. However, the results of the CPP scans suggest that the metal may be susceptible to localized corrosion.

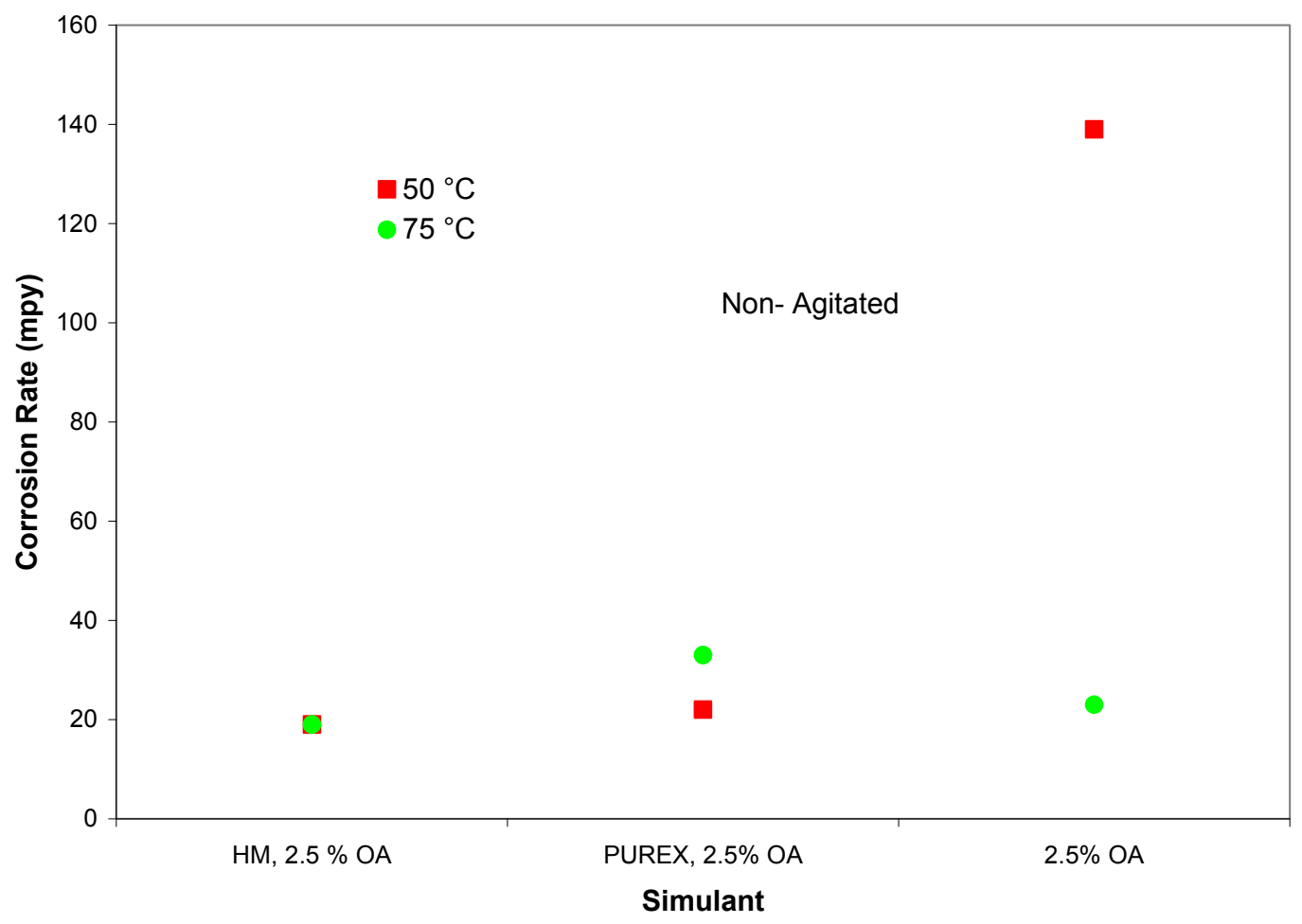

Figure 95. Corrosion rates in sludge simulants compared with 2.5 wt. \% oxalic acid in non-agitated solutions.

Figure 96 shows that the corrosion rates in the agitated sludge simulants exposed to 2.5 wt. $\%$ oxalic acid were variable. For the $\mathrm{HM} / 2.5 \mathrm{wt} . \%$ oxalic acid simulant at $75{ }^{\circ} \mathrm{C}$, the average corrosion rate was 73 mils/yr, just slightly less than the 89 mils/yr measured for oxalic acid. The variability was also observed at $50{ }^{\circ} \mathrm{C}$ for the coupons tested in the PUREX $/ 2.5 \mathrm{wt} . \%$ oxalic acid simulant. The general corrosion rate was approximately 50 mils/yr at this condition. These results likely reflect how agitation disrupts the development of the ferrous oxalated film and the result is a less protective film. These results also may reflect the effect of agitation on the dissolution of key aggressive species, such as mercury anions. 


\section{Revision 1}

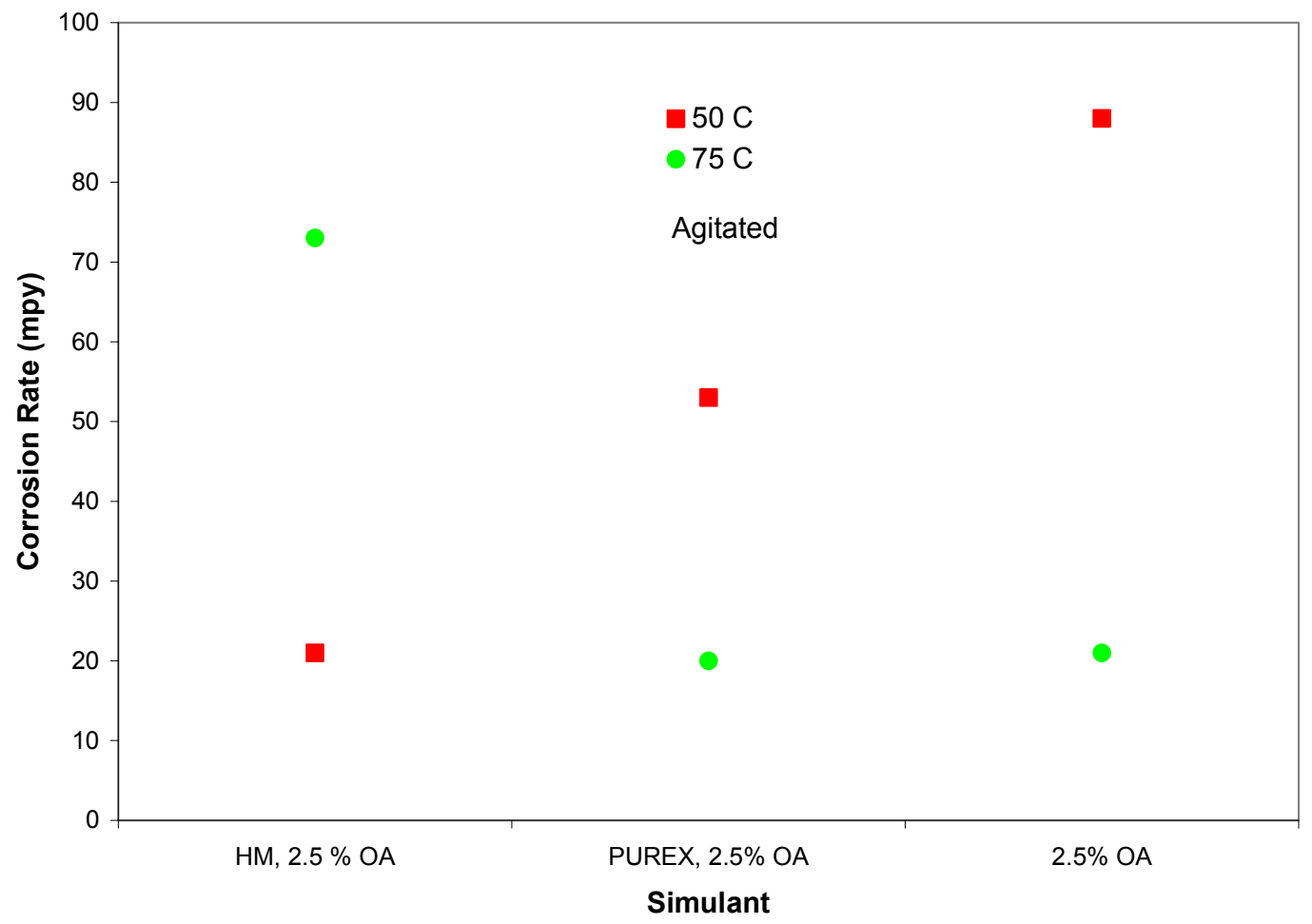

Figure 96. Corrosion rates in sludge simulants compared with 2.5 wt. $\%$ oxalic acid in agitated solutions.

The results from the present coupon tests were compared with the results of coupon tests conducted with Tank 5F sludge (PUREX) simulant in $8 \mathrm{wt} . \%$ oxalic acid [1]. These Tank $5 \mathrm{~F}$ tests were conducted at a temperature of 50 and $75^{\circ} \mathrm{C}$ and the solutions were not agitated. Figure 97 shows that the corrosion rates for the Tank 5F sludge in $8 \mathrm{wt} . \%$ oxalic acid are very similar to those for the more dilute oxalic acid concentrations at 75 ${ }^{\circ} \mathrm{C}$ and slightly higher at $50{ }^{\circ} \mathrm{C}$. These results were similar to that observed for the LPR tests and result suggests that the $\mathrm{pH}$ is not the determining factor in reducing the corrosion rate. No longer term coupon tests were performed for the Tank 5F simulant in 8 wt.\% oxalic acid with agitation. 


\section{Revision 1}

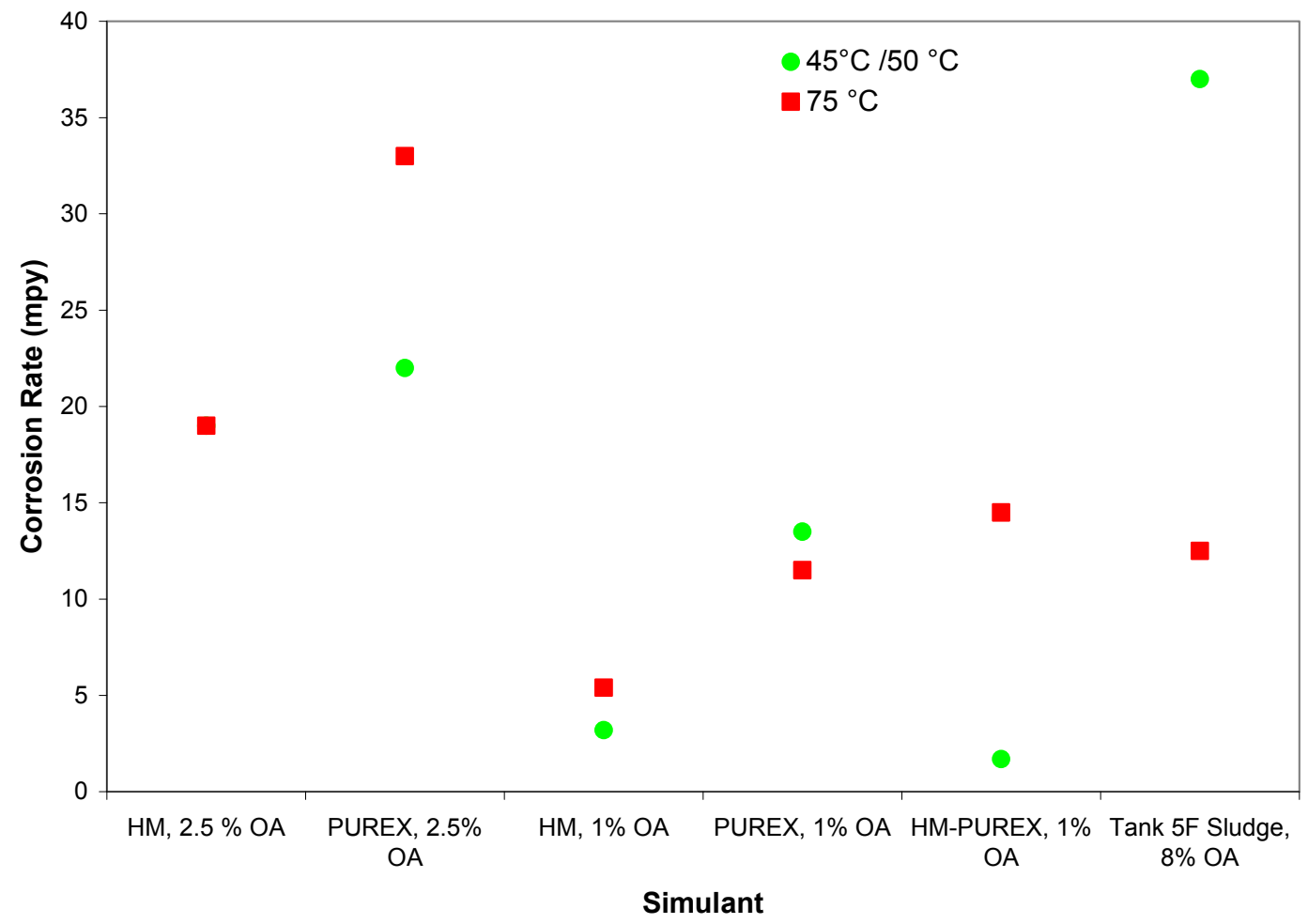

Figure 97. Corrosion rates in sludge simulants compared with 8 wt. \% OA with sludge simulant at $50{ }^{\circ} \mathrm{C}$ (Note recent tests in 1 wt. \% oxalic acid were at $45^{\circ} \mathrm{C}$ ). The solutions were non-agitated.

Figures 98 and 99 show the effect of agitation on the corrosion rate in the presence of sludge simulants in $1 \mathrm{wt} . \%$ oxalic acid. Agitation increased the corrosion rates in all simulants at both testing temperatures. These results could be explained by the disruption of the ferrous oxalate film by the agitation or the incorporation of other oxides within the oxalate layer. These results are in agreement with those measured by the LPR technique. 


\section{Revision 1}

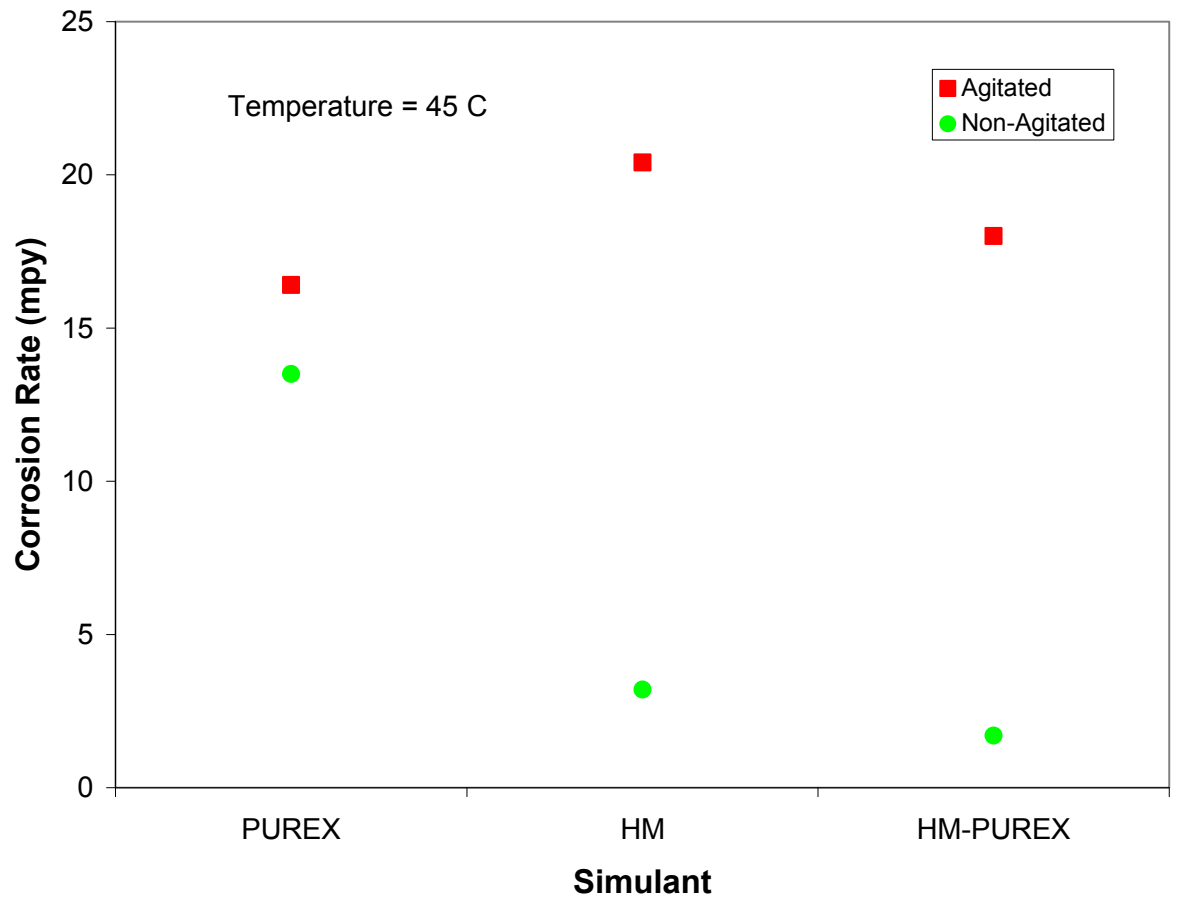

Figure 98. The effect of agitation on the corrosion rates in the sludge simulants with 1 wt. $\%$ oxalic acid at $45{ }^{\circ} \mathrm{C}$.

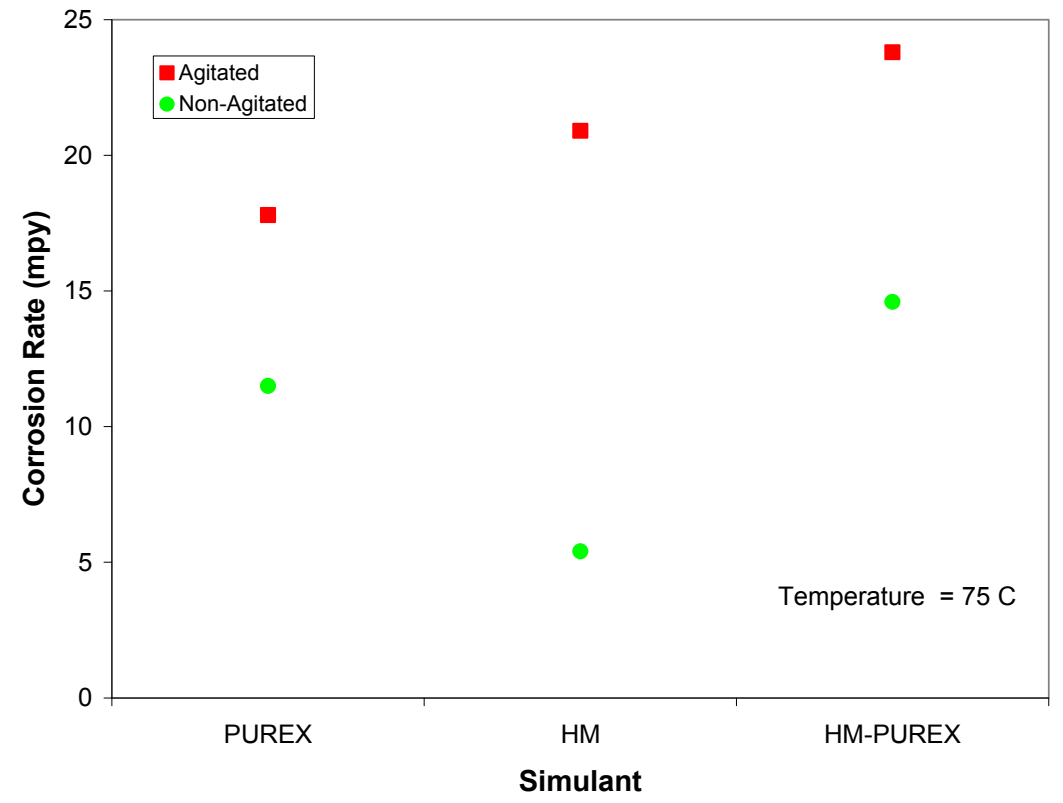

Figure 99. The effect of agitation on the corrosion rates in the sludge simulants with 1 wt. \% oxalic acid at $75{ }^{\circ} \mathrm{C}$. 


\section{Revision 1}

Figures 100 and 101 show the effect of agitation on the corrosion rate in the presence of sludge simulants in $2.5 \mathrm{wt} . \%$ oxalic acid. At $50{ }^{\circ} \mathrm{C}$, agitation did not seem to have a significant effect on the corrosion rate in the HM/2.5 wt.\% oxalic acid simulant, however, a significant increase with agitation was observed for the PUREX/2.5 wt.\% simulant. This $53 \mathrm{mil} / \mathrm{yr}$ corrosion rate represents an average of two coupons. The corrosion rate of the first coupon was $26 \mathrm{mil} / \mathrm{yr}$, approximately the same as the HM/2.5 wt.\% oxalic acid simulant, while the corrosion rate for the second coupon was $79 \mathrm{mils} / \mathrm{yr}$. Only general corrosion, no localized attack, was observed on the samples exposed to the PUREX/2.5 wt.\% oxalic acid simulant. The cause of the difference in the corrosion rates is uncertain. Perhaps a difference in the flow pattern around the coupon with the higher corrosion rate resulted in disruption of the ferrous oxalate film. The result is consistent however, with the electrochemical results, which suggest that agitation may result in a more aggressive environment.

At $75^{\circ} \mathrm{C}$, agitation did not seem to have a significant effect on the corrosion rate in the PUREX/2.5 wt.\% oxalic acid simulant, however, a significant increase with agitation was observed for the $\mathrm{HM} / 2.5 \mathrm{wt} \%$ simulant. This results was opposite of that observed in the tests at $50{ }^{\circ} \mathrm{C}$. In the case of the $\mathrm{HM} / 2.5 \mathrm{wt} . \%$ oxalic acid agitated simulant both coupons exhibited high general corrosion rates with extensive pitting corrosion. Although the non-agitated coupon tests in this simulant resulted in a low general corrosion rate, extensive pitting corrosion was observed on both coupons. The presence of an oxidizing species such as a mercury cation dissolved in the HM simulant may have resulted in a more aggressive environment. The result is consistent however, with the electrochemical results, which suggests that agitation may result in a more aggressive environment.

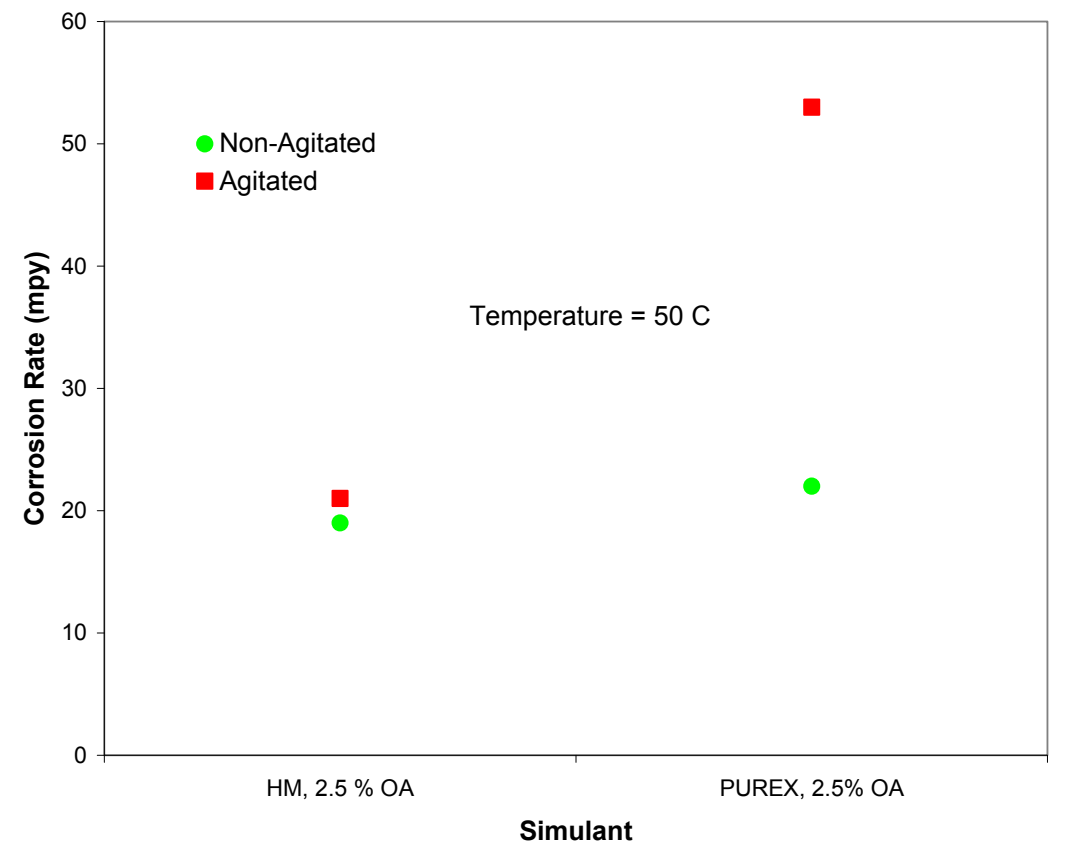

Figure 100. The effect of agitation on the corrosion rates in the sludge simulants with 2.5 wt. \% oxalic acid at $50{ }^{\circ} \mathrm{C}$. 


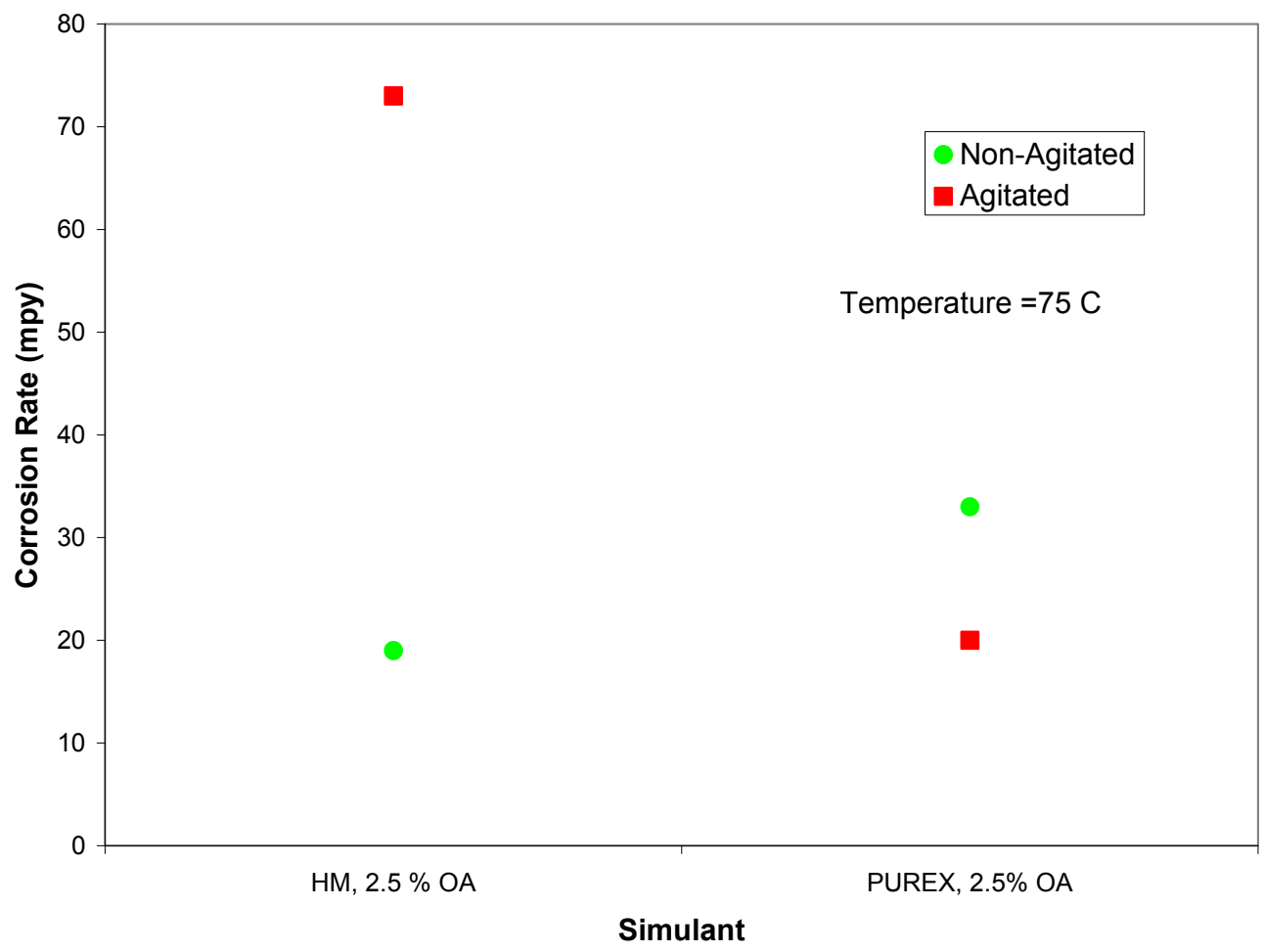

Figure 101. The effect of agitation on the corrosion rates in the sludge simulants with 2.5 wt. $\%$ oxalic acid at $75^{\circ} \mathrm{C}$.

Figures 102 and 103 illustrate the effect of temperature on the corrosion rate in sludge simulants with $1 \mathrm{wt} . \%$ oxalic acid. The results showed that the temperature did not significantly influence the corrosion rate for either the agitated or non-agitated condition. These results are in agreement with the corrosion rates measured by the LPR technique. Thus, the inhibiting mechanism does not appear to be temperature dependent within the tested temperature range. 


\section{Revision 1}

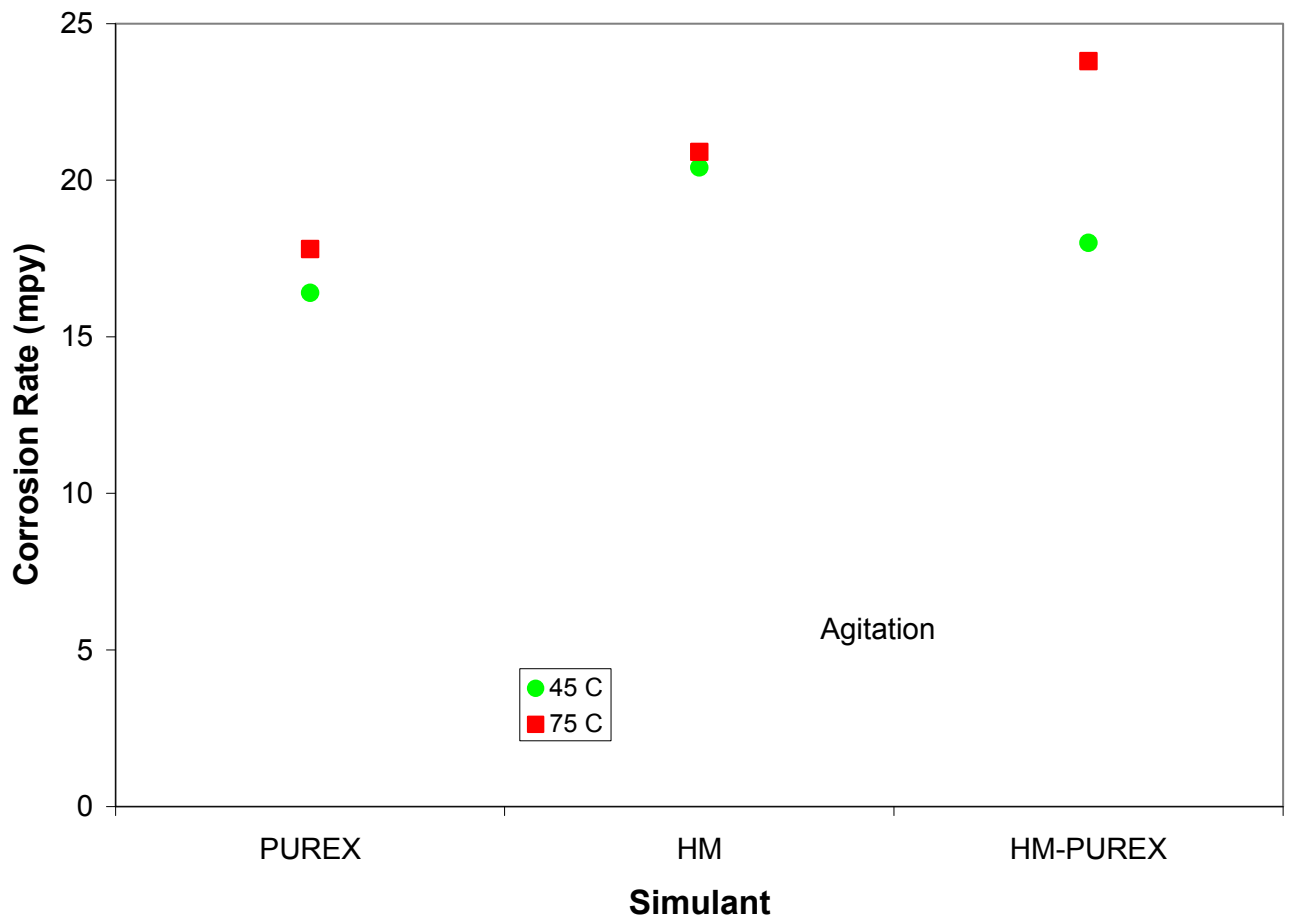

Figure 102. The effect of temperature on the corrosion rates in the sludge simulants with 1 wt. \% oxalic acid with agitation.

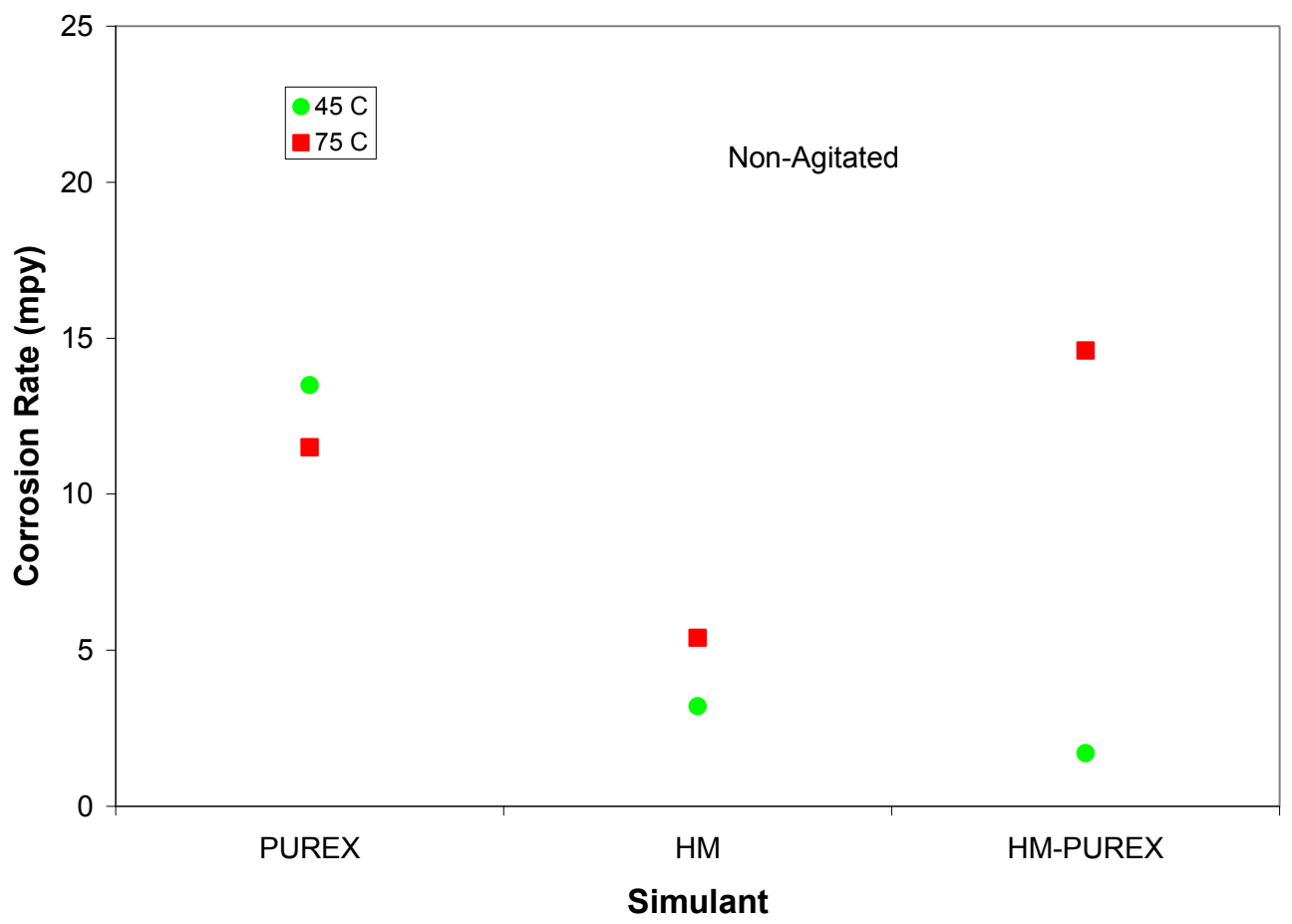

Figure 103. The effect of temperature on the corrosion rates in the sludge simulant with 1 wt. \% oxalic acid with no agitation. 


\section{Revision 1}

Figures 104 and 105 illustrate the effect of temperature on the corrosion rate in sludge simulants with $2.5 \mathrm{wt} . \%$ oxalic acid. The results showed that the temperature did not significantly influence the corrosion rate for the non-agitated condition. However, there was significant variability with temperature for the agitated solutions. These differences are more likely a reflection of the variability in the development of the ferrous oxalate film due to the agitation of the solution.

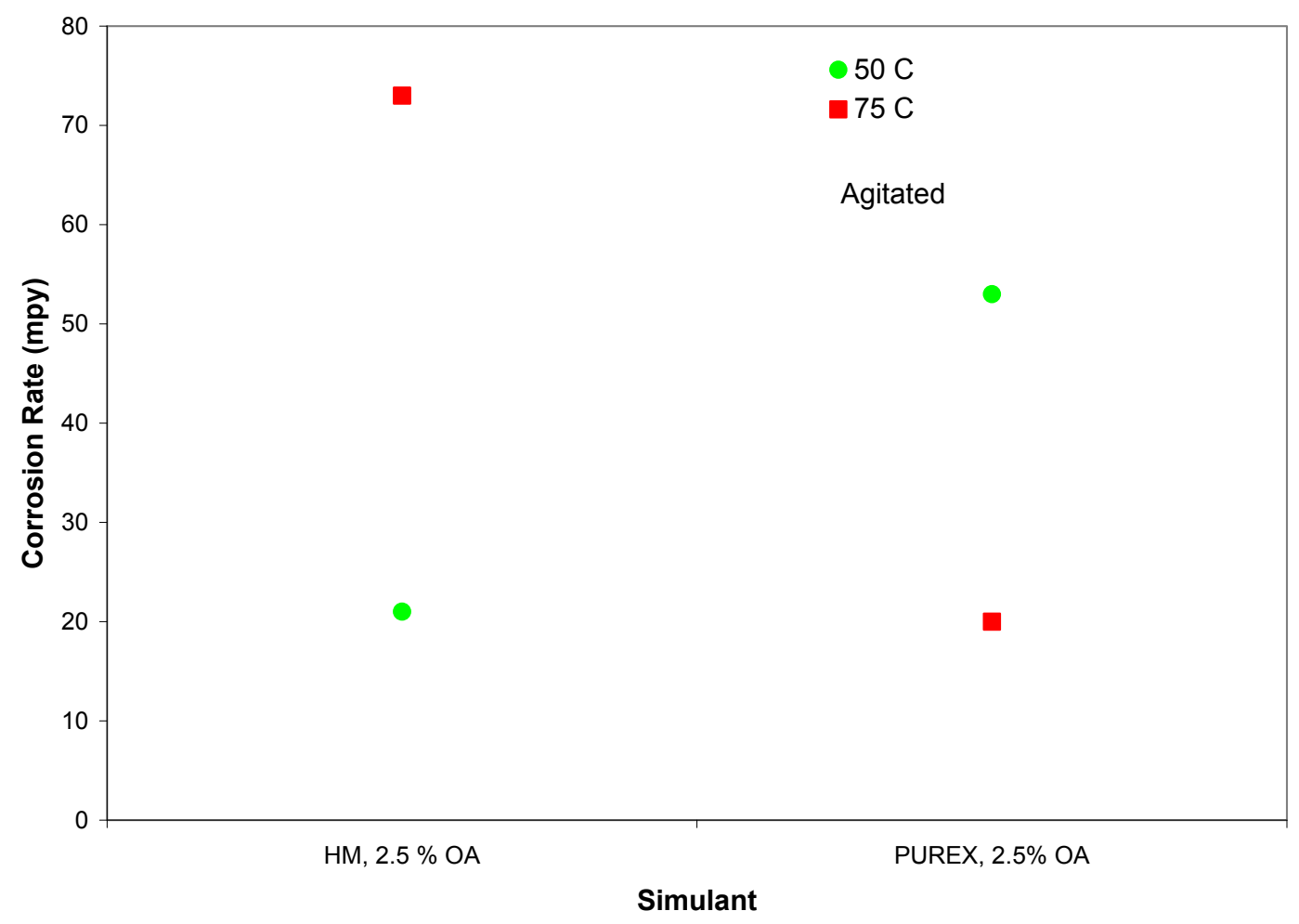

Figure 104. The effect of temperature on the corrosion rates in the sludge simulants with 2.5 wt. \% oxalic acid with agitation. 


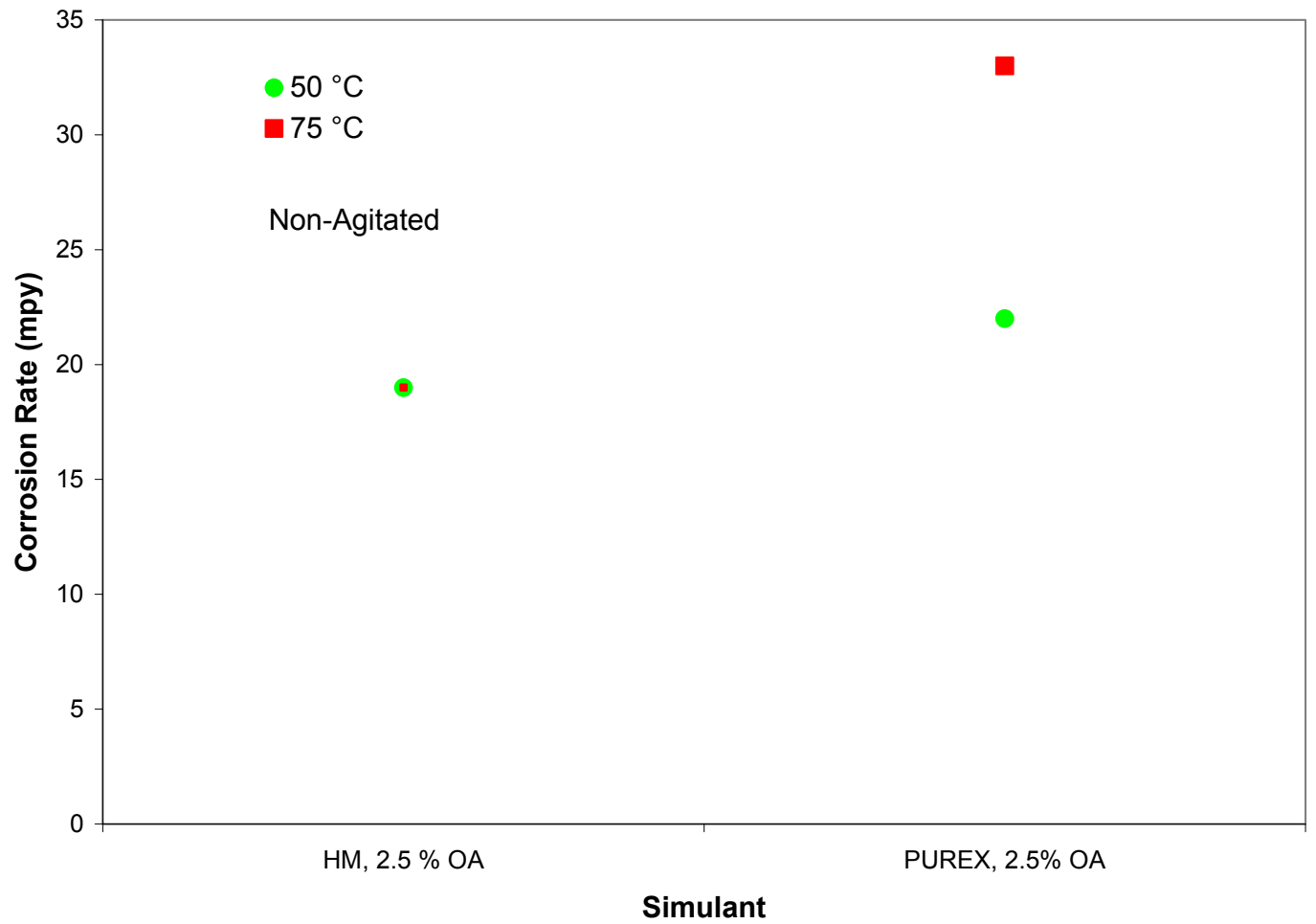

Figure 105. The effect of temperature on the corrosion rates in the sludge simulant with 2.5 wt. \% oxalic acid with no agitation.

Pitting corrosion was observed on coupons immersed in HM/2.5 wt.\% oxalic acid solutions at $75{ }^{\circ} \mathrm{C}$ for both the non-agitated and agitated condition. Ten to fifteen pit depths were measured on each coupon to obtain an estimate of the severity of the pitting. The pit depths on the coupons exposed to the non-agitated simulants ranged between 11 to 33 mils in depth, with an average pit depth of 20 mils. Given that the tests were for approximately 30 days, the maximum pitting rate was approximately $365 \mathrm{mils} / \mathrm{yr}$. The pit depths on the coupons exposed to the agitated solutions ranged between 24 to 50 mils in depth, with an average pit depth of 37 mils. The maximum pitting rate in this case was approximately $600 \mathrm{mpy}$. The evidence of localized corrosion in these cases is not totally unexpected as the results of the polarization scans suggested that the steel may be susceptible to localized attack in the HM/2.5 wt.\% oxalic acid environment. No localized corrosion was observed in tests with the Tank $5 \mathrm{~F} / 8 \mathrm{wt}$. $\%$ oxalic acid, similar to the PUREX/oxalic acid simulant. However, it is unknown if the HM/8 wt.\% oxalic acid environment would result in pitting since not testing was performed at this condition.

\subsection{Summary and Conclusions}

Corrosion rate data for carbon steel exposed to the ECC treatment tank environment was obtained to evaluate the degree of corrosion that occurs. These tests were also designed to determine the effect of various environmental variables such as temperature, agitation and sludge slurry type on the corrosion behavior of carbon steel. Coupon tests were performed to estimate the corrosion rate during the ECC process, as well as determine 
any susceptibility to localized corrosion. Electrochemical studies were performed to develop a better understanding of the corrosion mechanism. The tests were performed in 1 wt.\% and 2.5 wt.\% oxalic acid with HM and PUREX sludge simulants.

The following results and conclusions were made based on this testing:

1. In 1 wt.\% oxalic acid with a sludge simulant, carbon steel corroded at a rate of less than 25 mpy within the temperature and agitation levels of the test. No susceptibility to localized corrosion was observed.

2. In 2.5 wt. $\%$ oxalic acid with a sludge simulant, the carbon steel corrosion rates ranged between 15 and 88 mpy. The most severe corrosion was observed at 75 ${ }^{\circ} \mathrm{C}$ in the $\mathrm{HM} / 2.5$ wt.\% oxalic acid simulant. Pitting and general corrosion increased with the agitation level at this condition. No pitting and lower general corrosion rates were observed with the PUREX/2.5 wt.\% oxalic acid simulant. The electrochemical and coupon tests both indicated that carbon steel is more susceptible to localized corrosion in the HM/oxalic acid environment than in the PUREX/oxalic acid environment.

3. The corrosion rates for PUREX/8 wt.\% oxalic acid were greater than or equal to those observed for the PUREX/2.5 wt.\% oxalic acid. No localized corrosion was observed in the tests with the $8 \mathrm{wt} . \%$ oxalic acid. Testing with HM/8 wt.\% oxalic acid simulant was not performed. Thus, a comparison with the results with 2.5 wt.\% oxalic acid, where the corrosion rate was 88 mpy and localized corrosion was observed at $75^{\circ} \mathrm{C}$, cannot be made.

4. The corrosion rates in 1 and $2.5 \mathrm{wt} . \%$ oxalic acid solutions were temperature dependent:

a. At $50{ }^{\circ} \mathrm{C}$, the corrosion rates ranged between 90 to 140 mpy over the 30 day test period. The corrosion rates were higher under stagnant conditions.

b. At $75^{\circ} \mathrm{C}$, the initial corrosion rates were as high as $300 \mathrm{mpy}$ during the first day of exposure. The corrosion rates increased with agitation. However, once the passive ferrous oxalate film formed, the corrosion rate decreased dramatically to less than 20 mpy over the 30 day test period. This rate was independent of agitation.

5. Electrochemical testing indicated that for oxalic acid/sludge simulant mixtures the cathodic reaction has transport controlled reaction kinetics. The literature suggests that the dissolution of the sludge produces a di-oxalatoferrate ion that is reduced at the cathodic sites. The cathodic reaction does not appear to involve hydrogen evolution. On the other hand, electrochemical tests demonstrated that the cathodic reaction for corrosion of carbon steel in pure oxalic acid involves hydrogen evolution.

6. Agitation of the oxalic acid/sludge simulant mixtures typically resulted in a higher corrosion rates for both acid concentrations. The transport of the ferrous ion away from the metal surface results in a less protective ferrous oxalate film.

7. A mercury containing species along with aluminum, silicon and iron oxides was observed on the interior of the pits formed in the HM/2.5 wt.\% oxalic acid simulant at $75{ }^{\circ} \mathrm{C}$. The pitting rates in the agitated and non-agitated solution were $2 \mathrm{mils} /$ day and $1 \mathrm{mil} /$ day, respectively. A mechanism by which the mercury 
interacts with the aluminum and silicon oxides in this simulant to accelerate corrosion was proposed.

\subsection{Records and Quality Assurance}

The treatment tank corrosion rate data was required to support safety class operations and therefore must meet certain qualifications. The corrosion rate data collected from coupon tests was selected, rather than the electrochemical data, because it includes the critical element of time that may not be captured with the short term linear polarization resistance test. The result is that the correlation between the coupon data and the linear polarization resistance data is inconsistent and not always in agreement.

The original technical task request (TTR) and technical task and quality assurance plan (TTQAP) were written in FY10 and covered the treatment tank corrosion testing in 1 wt.\% oxalic acid $[37,38]$. No requirements to support safety class operations were included in either document. Mid-way through the testing, the TTR was revised to require the data to support safety class operations. Procedural controls and requirements that were utilized during the FY10 were identified and documented (e.g., mill certification of steel coupons, M\&TE requirements for balances and temperature control equipment, etc.), which demonstrated that the coupon corrosion rate data was of sufficient quality to support safety class operations. These items were documented in laboratory notebook SRNL-NB-2009-00151.

The revised TTR and TTQAP for the treatment tank corrosion testing in FY11 included the use of 2.5 wt.\% oxalic acid [3, 39]. Requirements to support safety class operations were included in this case. The procedural controls and requirements for the for the corrosion rate data determined in FY11 and FY10 were identical. Therefore, because "equivalent controls" were utilized [40] and these controls are sufficient to support safety class operations, both sets of data are qualified. The controls and requirements for the FY11 tests were also documented in laboratory notebooks SRNL-NB-2011-00026 and SRNL-NB-2011-00064.

\subsection{Acknowledgements}

The assistance of K. R. Hicks and K. J. Kalbaugh in the performance of the tests is gratefully acknowledged. Conversations with J. I. Mickalonis, K. J. Imrich, C. J. Martino and W.D. King were extremely useful in understanding and interpreting the results. 


\subsection{References}

1. D. T. Herman, et. al., "Investigating Hydrogen Generation and Corrosion in the Treatment Tank and the Potential Formation of a Floating Layer in the Neutralization Tank During Waste Tank Heel Chemical Cleaning", WSRC-STI2007-00209, April 30, 2007.

2. B. J. Wiersma, "Corrosion Mechanisms and Rates for Carbon Steel and Stainless Steel Materials Exposed to Oxalic Acid Solutions," WSRC-TR-2004-00109, March 2004.

3. J. I. Mickalonis et. al, "Task Technical and Quality Assurance Plan for Simulant Development, Production, and Corrosion Testing for Enhanced Chemical Cleaning", SRNL-RP-2009-01038, Rev. 2, February 2011.

4. S. O. Lee, "Dissolution of Iron Oxides by Oxalic Acid", Ph.D. Thesis, The University of New South Wales, September, 2005.

5. M. E. Stallings, D. T. Hobbs, and B. J. Wiersma, "Dissolutionof Simulated and Radioactive Savannah River Site High Level Waste Sludges with Oxalic Acid and Citric Acid Solutions", WSRC-TR-2004-00043, March 26, 2004.

6. Atlas of Electrochemical Equilibria in Aqueous Solutions, Ed. by M. Pourbaix, NACE International, Houston TX, p. 317, 1974.

7. Corrosion: Understanding the Basics, Ed. by J. R. Davis, ASM International, Metals Park, OH, p. 63, 2000.

8. Information from the website http://www/wou.edu/las/physci/ch412/pourbaix.htm.

9. S. N. Saltykov, et. al, "Anodic Behavior of White Iron Phases in Oxalic Media", Protection of Metals, Vol. 40, No. 1, pp. 56-61, 2004.

10. S. N. Saltykov, "A Mechanism of the Anodic Dissolution of Armco Iron and High Strength Ferritic Cast Iron in an Oxalate Medium”, Protection of Metals, Vol. 37, No. 2, pp. 186-191, 2001.

11. L. A. Sokolova, et. al., "The Passivation of Iron in Oxalate Solutions", Protection of Metals, Vol. 12, No.2, pp. 145-153, 1976.

12. L. D. Perrigo, "Anodic Protection of Carbon Steel in Oxalic Acid", Materials Protection, pp. 73-76, March, 1966.

13. I. Sekine and C. Okano, "Corrosion Behavior of Mild Steel and Ferritic Stainless Steels in Oxalic Acid Solution”, Corrosion, Vol. 45, No. 11, pp. 924-932, 1989.

14. V. K. Gouda, et. al., "The Corrosion Behavior in Organic Acid Solutions - II. A Steel Electrode", Corrosion Science, Vol. 20, pp. 1091-1099, 1980.

15. M. A. Streicher, "Synergistic Inhibition of Ferric Ion Corrosion During Chemical Cleaning of Metal Surfaces", Corrosion, Vol. 28, No. 4, p. 143, April, 1972.

16. M. S. Abdel Aal, et. al., "Influence of $\mathrm{Fe}^{2+}$ ion on the Corrosion of Carbon Steel", Materials Chemistry and Physics, Vol 39, pp. 290-297, 1995.

17. M. S. Abdel Aal, et. al., "Anodic Behavior of Mild Steel in Deaerated Carboxylic Acid Solutions Containing $\mathrm{NO}_{2}{ }^{-}, \mathrm{Cl}^{-}$, and $\mathrm{NO}_{3}{ }^{-}$Ions", Br. Corr. J., Vol. 16, No. 4, 1981.

18. B. J. Wiersma, "Electrochemical Studies on the Corrosion of Carbon Steel in Oxalic Acid Cleaning Solutions”, WSRC-STI-2007-00210, April, 2007. 


\section{Revision 1}

19. B. J. Wiersma, "Hydrogen Generation During the Corrosion of Carbon Steel in Oxalic Acid", WSRC-TR-2004-00441, August, 2004.

20. V. Lopez and M. J. Pena, "Electrochemical Kinetic Study of the Fe(III)-Fe(II) System in Oxalate Medium”, Electrochimica Acta, Vol. 26, No. 7, pp. 857-863, 1981.

21. D. Panias, et. al., "Mechanisms of Dissolution of Iron Oxides in Aqueous Oxalic Acid Solutions", Hydrometallurgy, Vol. 42, pp. 257-265, 1996.

22. M. Abdallah and H.E. Megahed, "Cyclic Voltammograms of Iron and C-Steels in Oxalic Acid Solutions and Investigation of the effect of Phenyl Phtalimide as Corrosion Inhibitors", Monatshefte fur Chemie, Vol. 126, pp. 519-527, 1995.

23. R. E. Eibling, "Development of Hazardous Sludge Simulants for Enhanced Chemical Cleaning Tests", SRNL-STI-2010-00170, April 2010.

24. "Standard Test Method for Conducting Potentiodynamic Polarization Resistance Measurements," ASTM G59-97, Reapproved in 2003.

25. M. Stern and A. L. Geary, J. Electrochemical Society, Vol. 104, No. 1, pp. 56-63, 1957.

26. J. R. Scully, "Polarization Resistance Method for Determination of Instantaneous Corrosion Rates", Corrosion, Vol. 56, No. 2, pp. 199-217, February 2000.

27. G. Kear and F. C. Walsh, "The Characteristics of a True Tafel Slope", Corrosion and Materials, Vol. 30, No. 6, December, 2005.

28. H. H. Uhlig, Corrosion and Corrosion Control, $2^{\text {nd }}$ Edition, John Wiley and Sons, NY, NY, 1971.

29. B. J. Wiersma, J. I. Mickalonis, "Determination of Corrosion Inhibitor Criteria for Type III/IIIA Tanks During Salt Dissolution Operations (U)", WSRC-STI-200600029, September, 2007.

30. "Standard Practice for Preparing, Cleaning, and Evaluating Corrosion Test Specimens", ASTM G 1- 03, 2003.

31. W. D. King and M. S. Hay, "Alternative Enhanced Chemical Cleaning: Basic Studies Results FY09”, SRNL-STI-2009-00791, Rev. 0, February, 2010.

32. T. P. Hoar, "Nitrite Inhibition of Corrosion: Some Practical Cases", Corrosion, May 1957, pp. 63-64.

33. W. D. King, M. S. Hay and B. J. Wiersma, "Alternative Enhanced Chemical Cleaning: Corrosion Studies Results FY2010”, SRNL-STI-2010-00555, Rev. 0, September, 2010.

34. U. Schwertmann and R.M. Cornell, Iron Oxides in the Laboratory: Preparation and Characterization, VCH Publishing, New York, 1991.

35. R. L. Sindelar et. al., "SRS High Level Waste Tank and Piping SystemsStructural Integrity Program and Topical Report", WSRC-TR-95-0076, June 1995.

36. S. Rio and A. Delebarre, "Removal of Mercury in Aqueous Solution be Fluidized Bed Plant Fly Ash”, Fuel, Vol. 82, pp. 153-159, 2003.

37. E. T. Ketusky, "Enhanced Chemical Cleaning (ecc) Hazardous Simulant Development and Treatment Tank Corrosion Testing", HLE-TTR-2009-116, Rev. 0, August 2009. 


\section{Revision 1}

38. C. J. Martino et. al., "Task Technical and Quality Assurance Plan for Simulant Development, Production, and Corrosion Testing for Enhanced Chemical Cleaning", SRNL-RP-2009-01038, Rev. 1, December 2009.

39. A. Hansen, "Enhanced Chemical Cleaning (ecc) Hazardous Simulant Development and Treatment Tank Corrosion Testing", HLE-TTR-2009-116, Rev. 2, December 2010.

40. Conduct of Engineering and Technical Support, Procedural Manual E7, Procedure 3.70, Rev. 4, "Qualification of Existing Data”, June 2004. 